Universidade de São Paulo

Instituto de Física de São Carlos

Gustavo Garcia Rondina

Novas ideias para o Método de Basin-Hopping Monte Carlo aplicado à otimização global de Clusters e Nanopartículas 

Gustavo Garcia Rondina

\section{Novas ideias para o Método de Basin-Hopping Monte Carlo aplicado à otimização global de Clusters e Nanopartículas}

Dissertação apresentada ao Programa de PósGraduação em Física do Instituto de Física de São Carlos da Universidade de São Paulo, para obtenção do título de Mestre em Ciências.

Área de Concentração: Física Aplicada Opção: Física Computacional

Orientador: Prof. Dr. Juarez Lopes Ferreira da Silva

Versão Corrigida

(versão original disponível na Unidade que aloja o Programa)

São Carlos 


\section{AUTORIZO A REPRODUÇÃO E DIVULGAÇÃO TOTAL OU PARCIAL DESTE TRABALHO, POR QUALQUER MEIO CONVENCIONAL OU ELETRÔNICO PARA FINS DE ESTUDO E PESQUISA, DESDE QUE CITADA A FONTE.}

Ficha catalográfica elaborada pelo Serviço de Biblioteca e Informação do IFSC, com os dados fornecidos pelo(a) autor(a)

\section{Rondina, Gustavo Garcia}

Novas ideias para o Método de Basin-Hopping Monte Carlo aplicado à otimização global de Clusters e Nanopartículas / Gustavo Garcia Rondina; orientador Juarez Lopes Ferreira da Silva - versão corrigida -São Carlos, 2013. $163 \mathrm{p}$.

Dissertação (Mestrado - Programa de Pós-Graduação em Física Aplicada Computacional) -- Instituto de Física de São Carlos, Universidade de São Paulo, 2013.

1. Otimização global. 2. Clusters. 3.

Nanopartículas. 4. Teoria do funcional da densidade. I. da Silva, Juarez Lopes Ferreira, orient. II. Título. 


\section{AGRADECIMENTOS}

Agradeço aos meu pais, Mara e Hamilton, que sempre incentivaram meus estudos e apoiaram minhas aspirações acadêmicas. Também aos meus irmãos, Ronaldo e Nathália, e à minha avó, Maria Criseide.

Sou muito grato ao meu orientador, Dr. Juarez Lopes Ferreira da Silva, que ao longo desses anos mostrou paciência, compreensão e disponibilidade. Agradeço pelos conselhos e pelas inúmeras discussões enriquecedoras que tivemos. O sucesso deste trabalho deve-se em grande parte à orientação dedicada que ele me proporcionou.

Agradeço aos membros do grupo de Teoria Quântica de Nanomateriais do IQSC, atuas e antigos, pelas discussões e companheirismo. Em especial, agradeço aos colegas Maurício Jeomar Piotrowski e Anderson Silva Chaves pelas discussões sobre clusters e nanopartículas. Sou grato também ao colega Henrique Musseli Cezar pela colaboração no desenvolvimento do código de otimização global.

Sou grato às agências CAPES e FAPESP pelas bolsas concedidas, e também ao IFSC pelo apoio financeiro nas ocasiões em que o requisitei. Sou grato pelo tempo computacional obtido no supercomputador Blue Gene/P graças à colaboração firmada entre o Laboratório de Computação Científica Avançada da Universidade de São Paulo e o Research Computing Support Group da Universidade de Rice. Agradeço ao Centro de Informática de São Carlos por hospedar o cluster de computadores do nosso grupo.

Agradeço também funcionários do IFSC, Sílvio, Ricardo, Patrícia e Maria Cristina, sempre prestativos e dispostos a ajudar 

"What would the properties of materials be if we could really arrange the atoms the way we want them? They would be very interesting to investigate theoretically. I can't see exactly what would happen, but I can hardly doubt that when we have some control of the arrangement of things on a small scale we will get an enormously greater range of possible properties that substances can have, and of different things that we can do."

Richard P. Feynman em uma palestra ministrada durante a reunião anual da American Physical Society, em 29 de dezembro de 1959. 



\section{RESUMO}

RONDINA, G. G. Novas ideias para o Método de Basin-Hopping Monte Carlo aplicado à otimização global de clusters e Nanopartículas. 2013. 163 p. Dissertação (Mestrado em Ciências) - Instituto de Física de São Carlos, Universidade de São Paulo, São Carlos, 2013.

Neste trabalho é introduzido e avaliado um conjunto de novas ideias para aumentar a eficiência do método Basin-Hopping Monte Carlo (BHMC) aplicado à otimização global de clusters e nanopartículas, que resultou no método BHMC revisado. Dentro deste método, tomou-se o cuidado de manter as características fundamentais do método BHMC padrão, que consistem na transformação da superfície de energia potencial em um conjunto de basins de atração, e no emprego de amostragem de Monte Carlo utilizando o critério de Metropolis. As ideias por trás do método BHMC revisado incluem um grande conjunto de operadores locais e não-locais construídos especificamente para clusters e nanopartículas e que permitem maior mobilidade sobre a superfície de energia potencial durante a busca pelo mínimo global, duas estratégias de seleção de operadores, e um operador de filtro estrutural para remover soluções não-físicas. A eficiência do método apresentado foi avaliada através da sua aplicação a um grande número de clusters e nanopartículas de tamanhos variados, compreendendo sistemas descritos tanto por potenciais empíricos, quanto por primeiros princípios dentro do formalismo da teoria do funcional da densidade (DFT). Os sistemas investigados foram clusters de Lennard-Jones e Sutton-Chen contendo até 148 átomos, um conjunto de nanopartículas de Lennard-Jones com tamanhos variando entre 200 e 1500 átomos, clusters binários de Lennard-Jones com até 100 átomos, clusters binários de metais de transição $(\mathrm{AgPd})_{55}$ descritos pelo potencial de Sutton-Chen, clusters de alumínio puros com até 30 átomos descritos por DFT, e clusters de alumínio com até 15 átomos dopados com um átomo de cobre, também descritos por DFT. Através da otimização global sem bias de todas essas partículas, o método BHMC revisado foi capaz de reproduzir com sucesso os mínimos globais putativos mais recentes disponíveis na literatura obtidos por diversas técnicas de otimização global, e também foi capaz de identificar mínimos globais previamente desconhecidos. Além disso, em comparação com o método BHMC padrão, o método RBHMC mostrou maior eficiência para muitos dos sistemas investigados. As ideias contidas na metodologia apresentada constituem uma ferramenta valiosa para auxiliar investigações teóricas visando uma melhor compreensão da estrutura atômica de clusters e nanopartículas.

Palavras-chave: Otimização global. Clusters. Nanopartículas. Teoria do funcional da densidade. 



\section{ABSTRACT}

RONDINA, G. G. New ideas for the Basin-Hopping Monte Carlo method applied to the global optimization of Clusters and Nanoparticles. 2013. 163 p. Dissertação (Mestrado em Ciências) - Instituto de Física de São Carlos, Universidade de São Paulo, São Carlos, 2013.

In this work it is introduced and evaluated a set of new ideas to increase the efficiency of the Basin-Hopping Monte Carlo (BHMC) method applied to the global optimization of clusters and nanoparticles, which resulted in the revised BHMC method. Within this method, care was taken to keep the main features of the standard BHMC method, which are the transformation of the potential energy surface into a set of basins of attraction, and the use of Monte Carlo sampling employing the Metropolis criterion. The ideas behind the revised BHMC method include a large set of local and non-local operators built specifically for clusters and nanoparticles which allow a greater mobility over the potential energy surface along of the search for the global minimum, two strategies for selecting the operators, and a structural filter operator to remove unphysical solutions. The efficiency of the presented method was evaluated by applying it to a large number of clusters and nanoparticles of various sizes, comprising systems described both by empirical potentials and by first-principles within the formalism of density functional theory (DFT). The systems that were investigated were Lennard-Jones and Sutton-Chen clusters with up to 148 atoms, a set of Lennard-Jones nanoparticles with sizes from 200 to 1500 atoms, binary Lennard-Jones clusters with up to 100 atoms, binary transition metal clusters $(\mathrm{AgPd})_{55}$ described by the Sutton-Chen potential, pure aluminum clusters with up to 30 atoms described by DFT, and aluminum clusters with up to 15 atoms doped with a copper atom, also described by DFT. Through the unbiased global optimization of all those particles, the revised BHMC method was able to successfully reproduce the most recent putative global minima available in the literature obtained by several different global optimization techniques, and moreover, it was able to identify previously unkown global minima. Furthermore, in comparison with the standard BHMC method, the RBHMC method proved to be more efficient for many of the systems that were investigated. The ideas comprised within the presented methodology characterize a valuable tool for aiding theoretical investigations leading to a better understanding of the atomic structure of clusters and nanoparticles.

Keywords: Global optimization. Clusters. Nanoparticles. Density functional theory. 



\section{LISTA DE FIGURAS}

Figura 2.1 - Região de uma superfície de energia potencial hipotética para um sistema com dois graus de liberdade. Alguns dos mínimos locais estão marcados com letras de $A$ a $F$, sendo $A$ o mínimo global, e a linha conectando os mínimos $\mathrm{D}$ e $\mathrm{E}$ representando um caminho de transição. As coordenadas e energia são dadas em unidades arbitrárias.

Figura 2.2 - Região de uma SEP contendo múltiplos funis, marcados como A, B e C. Três sequências monotônicas são exibidas, I, II e III, e os mínimos locais pertencentes a cada sequência estão denotados com suas respectivas cores. As sequências I e II pertencem ao funil primário.

Figura 2.3 - Exemplos de superfícies de energia potencial (em vermelho) e respectivos grafos de desconectividade (em azul). Figura publicada originalmente por Wales e Bogdan (1).

Figura 2.4 - Grafo de desconectividade para o sistema $\mathrm{LJ}_{13}$ incluindo 1467 mínimos locais distintos. Energias dadas em unidades de $\epsilon$, a profundidade do poço de energia do potencial de Lennard-Jones. A estrutura de mínimo global é ilustrada. Figura adaptada das referências $(2,3) \ldots$. . . . . . . . 54

Figura 3.1 - Método BHMC padrão.

Figura 3.2 - Método BHMC revisado. (a) Funcionamento do método para uma SEP hipotética, empregando operadores locais e não-locais. (b) Efeito da transformação da SEP em um conjunto de basins de atração. . . . . . . . .

Figura 3.3 - Operadores locais empregados no método RBHMC. (a) Operador de deslocamento cartesiano (CDO). (b) Operador de deslocamento em relação ao centro geométrico (GCDO). 
Figura 3.4 - Operadores não-locais empregados no método RBHMC. (a) Operador twist (TO). (b) Operador angular (AO). (c) Operador angular de superfície (SAO). (d) Operador interior (IO). (e) Operador de troca (EO). (f) Operador de troca geométrico (GEO). (g) Operador crossover (CO). 69

Figura 4.1 - Fluxograma do algoritmo do método RBHMC implementado na ferramenta GOP.. . . . . . . . . . . . . . . . . . . . . . . . . . 80

Figura 5.1 - Energia total por átomo em unidades de $\epsilon$ dos mínimos globais dos clusters $\mathrm{LJ}_{N}(N=2-148)$. Os resultados deste trabalho utilizando o método RBHMC são comparados com dados de referência da literatura (4). . . . 90

Figura 5.2 - Estruturas de mínimo global de alguns clusters $\mathrm{LJ}_{N}(N=38,55,75,98$, $102,147)$.

Figura 5.3 - Número de coordenação efetiva médio (ECN), comprimento de ligação ponderado médio $\left(d_{a v}\right)$, e função de estabilidade relativa $\left(\Delta_{2} E\right)$ das estruturas de mínimo global dos clusters $\mathrm{LJ}_{N}(N=2-148)$.

Figura 5.4 - Estruturas de mínimo global de algumas NPs LJ ${ }_{N}(N=200,300,400$, $500,1000,1500)$ identificadas com o método RBHMC. Para os casos $\mathrm{LJ}_{1000}$ e $\mathrm{LJ}_{1500}$, as estruturas encontradas com o método RBHMC são comparadas com os mínimos globais putativos da literatura $(5,6)$. . . . 97

Figura 5.5 - Energia total por átomo em unidades de $\epsilon$ dos mínimos globais dos clusters $\mathrm{SC}_{N}(N=3-148)$. Os resultados deste trabalho utilizando o método RBHMC são comparados com dados de referência da literatura $(4,7)$. . 99

Figura 5.6 - Número de coordenação efetiva médio (ECN), comprimento de ligação ponderado médio $\left(d_{a v}\right)$, e função de estabilidade relativa $\left(\Delta_{2} E\right)$ das estruturas de mínimo global dos clusters $\mathrm{SC}_{N}(N=3-148) \ldots \ldots$. . . 101

Figura 5.7 - Estruturas de mínimo global de clusters $\mathrm{SC}_{N}(N=13,38,55,122,125$, 147).

Figura 5.8 - Estruturas de mínimo global dos clusters $B L J_{99}$ e $B L J_{100}$ para a razão $\sigma^{B B} / \sigma^{A A}=1.30$. Estruturas encontradas com o método RBHMC comparada com estruturas da literatura $(8,9) \ldots$. . . . . . . . . . . 105 
Figura 5.9 - Propriedades dos clusters $\mathrm{Ag}_{55-n} \mathrm{Pd}_{n}$ em função do número de átomos de Pd. De cima para baixo, número de coordenação efetiva médio (ECN), comprimento de ligação ponderado médio $\left(d_{a v}\right)$, energia de excesso $\left(E_{\text {exc }}\right)$ e parâmetro de composição $(\sigma) \ldots \ldots$. . . . . . . . . . . . 108

Figura 5.10 - Estruturas de mínimo global dos clusters $\mathrm{Ag}_{55-n} \mathrm{Pd}_{n}$ para $n=0,1,13$, 23, 42, 54, 55. Átomos de Ag em cinza escuro e Pd em cinza claro. . . . 109

Figura 6.1 - Estruturas dos clusters $\mathrm{Al}_{N}(N=2-30)$ identificadas com o método RBHMC-DFT.

Figura 6.2 - Propriedades dos clusters $\mathrm{Al}_{N}(N=2-30)$ encontrados com RBHMCDFT. Comparação resultados de cálculos DFT-GGA-PBE realizados em clusters de referência (10). De cima para baixo, função de estabilidade relativa $\left(\Delta_{2} E\right)$, energia de ligação por átomo $\left(\mathrm{E}_{b}\right)$, número de coordenação efetiva médio (ECN), comprimento de ligação ponderado médio $\left(d_{a v}\right)$, momento magnético total $\left(m_{t o t}\right)$ e gap energético HOMO-LUMO, respectivamente.

Figura 6.3 - Estruturas dos clusters $\mathrm{Al}_{N-1} \mathrm{Cu}(N=2-15)$ identificadas com o método RBHMC-DFT.

Figura 6.4 - Propriedades dos clusters $\mathrm{Al}_{N-1} \mathrm{Cu}(N=2-15)$ encontrados com RBHMC-DFT comparadas com as propriedades dos clusters $\mathrm{Al}_{N}(N=$ $2-15)$. De cima para baixo, função de estabilidade relativa $\left(\Delta_{2} E\right)$, energia de atomização por átomo $\left(E_{a t m}\right)$, número de coordenação efetiva médio $(\mathrm{ECN})$, comprimento de ligação ponderado médio $\left(d_{a v}\right)$, momento magnético total $\left(m_{t o t}\right)$ e gap energético HOMO-LUMO, respectivamente. Nos gráficos do ECN médio e $d_{a v}$ médio são mostradas também as respectivas propriedades do átomo de $\mathrm{Cu}$.

Figura 6.5 - Estruturas coletadas ao longo de 350 passos de Metropolis com o operador SFO desabilitado (quadrados preenchidos em azul, gráficos superior e central). As estruturas estão ordenadas de maneira crescente em relação ao tempo computacional. As estruturas que teriam sido rejeitadas pelo SFO estão marcadas com círculos preenchidos em vermelho. No gráfico inferior a diferença de energia entre cada estrutura e a estrutura de menor energia entre as 350 é mostrada $(\Delta E) \ldots \ldots \ldots \ldots \ldots$ 
Figura B.1 - Algoritmo em pseudocódigo do método steepest descent adaptativo. . . . 152

Figura B.2 - Algoritmo em pseudocódigo do método Broyden-Fletcher-Goldfarb-Shanno utilizando inicialização com matriz identidade. . . . . . . . . . . . . . 155 


\section{LISTA DE TABELAS}

Tabela 5.1 - Energias totais e grupo pontual de simetria (GP) das estruturas de mínimo global dos clusters $\mathrm{LJ}_{N}(N=2-148) \ldots \ldots . \ldots . . \ldots 91$

Tabela 5.2 - Tempo médio para o primeiro encontro calculado a partir de 100 aplicações independentes do método RBHMC para clusters $\mathrm{LJ}_{38}, \mathrm{LJ}_{55}, \mathrm{LJ}_{75}$ e $\mathrm{LJ}_{98}$ empregando os esquemas estático e dinâmico de seleção de operadores. Resultados recentes utilizando o método BHMC padrão e o método BHMC simetrizado (11) são mostrados para fins de comparação. . . . . . . 94

Tabela 5.3 - Energias totais dos mínimos globais das $\operatorname{NPs~LJ}_{N}(N=200, \ldots, 1500)$. As energias encontradas com o método RBHMC são comparadas com valores de referência.

Tabela 5.4 - Energias totais e grupo pontual de simetria (GP) das estruturas de mínimo global dos clusters $\mathrm{SC}_{N}(N=3-148)$.

Tabela 5.5 - Dados referentes aos clusters BLJ com energias menores que as menores energias reportadas na literatura $(4,8,9,12-14)$ para as composições e valores da razão $\sigma^{B B} / \sigma^{A A}$ indicados. Para cada tamanho são mostradas a diferença de energia em relação aos dados de referência $\left(E_{\text {tot }}-E_{\text {tot }}^{\text {Ref }}\right)$, os grupos pontuais das estruturas encontradas neste trabalho (GP) e os grupos pontuais das estruturas da literatura cujas energias foram melhoradas $\left(\mathrm{GP}^{\mathrm{Ref}}\right)$.

Tabela 5.6 - Parametrização com correções quânticas do potencial de Sutton-Chen descrevendo a interação entre pares de átomos $\mathrm{Ag}$ e $\mathrm{Pd}(15)$. . . . . . . . 106

Tabela 5.7 - Energias totais dos mínimos globais dos clusters binários $\mathrm{Ag}_{55-n} \mathrm{Pd}_{n}$ descritos pelo potencial de SC para todos os valores possíveis de $n$. 
Tabela 6.1 - Comparação das estruturas obtidas por meio do método RBHMC-DFT com as estruturas de mínimo global mais recentes da literatura (10). Para os tamanhos disponíveis para comparação, são mostradas as diferenças de energia, definida como $\Delta E=E_{\text {tot }}^{R B H M C-D F T}-E_{\text {tot }}^{R e f}$, e as simetrias de grupo pontual $(\mathrm{GP}) \ldots \ldots \ldots . \ldots . \ldots 116$

Tabela C.1 - Mínimos globais dos clusters $\mathrm{BLJ}_{N}(N=5-100)$ com $\sigma^{B B} / \sigma^{A A}=$ 1.05 encontrados com o método RBHMC para as composições indicadas. Energias totais e o grupos pontuais de simetria (GP) são mostrados. . . . 158

Tabela C.2 - Mínimos globais dos clusters $\mathrm{BLJ}_{N}(N=5-100)$ com $\sigma^{B B} / \sigma^{A A}=$ 1.10 encontrados com o método RBHMC para as composições indicadas. Energias totais e o grupos pontuais de simetria (GP) são mostrados. . . . 159

Tabela C.3 - Mínimos globais dos clusters $\mathrm{BLJ}_{N}(N=5-100)$ com $\sigma^{B B} / \sigma^{A A}=$ 1.15 encontrados com o método RBHMC para as composições indicadas. Energias totais e o grupos pontuais de simetria (GP) são mostrados. . . . 160

Tabela C.4 - Mínimos globais dos clusters $\mathrm{BLJ}_{N}(N=5-100)$ com $\sigma^{B B} / \sigma^{A A}=$ 1.20 encontrados com o método RBHMC para as composições indicadas. Energias totais e o grupos pontuais de simetria (GP) são mostrados. . . . 161

Tabela C.5 - Mínimos globais dos clusters $\mathrm{BLJ}_{N}(N=5-100)$ com $\sigma^{B B} / \sigma^{A A}=$ 1.25 encontrados com o método RBHMC para as composições indicadas. Energias totais e o grupos pontuais de simetria (GP) são mostrados. . . . 162

Tabela C.6 - Mínimos globais dos clusters $\mathrm{BLJ}_{N}(N=5-100)$ com $\sigma^{B B} / \sigma^{A A}=$ 1.30 encontrados com o método RBHMC para as composições indicadas. Energias totais e o grupos pontuais de simetria (GP) são mostrados. . . . 163 


\section{LISTA DE ABREVIATURAS}

$\mathrm{AO}$

BFGS

BHMC

$\mathrm{BO}$

CDO

$\mathrm{CO}$

DFT

ECN

EO

GCDO

GC

GEO

GGA

GOP

GP

$\mathrm{HK}$

HOMO

10

KS

LDA

LJ

LUMO

NP

OJ

PBE
Angular operator

Broyden-Fletcher-Goldfarb-Shanno

Basin-Hopping Monte Carlo

Born-Oppenheimer

Cartesian displacement operator

Crossover operator

Density functional theory

Effective coordination number

Exchange operator

Geometric center displacement operator

Gradientes conjugados

Geometric exchange operator

Generalized gradient approximation

Global Optimization Package

Grupo pontual de simetria

Hohenberg-Kohn

Highest occupied molecular orbital

Interior operator

Kohn-Sham

Local density approximation

Lennard-Jones

Lowest unoccupied molecular orbital

Nanopartícula

Occasional jumps

Funcional de troca e correlação de Perdew, Burke e Ernzerhof 
RBHMC Revised Basin-Hopping Monte Carlo

SAO

Surface angular operator

$\mathrm{SC}$

Sutton-Chen

SDA

Steepest descent adaptativo

SDP

Steepest descent path

SEP

Superfície de energia potencial

SFO

Structural filter operator

TMPE

Tempo médio para o primeiro encontro

TO

Twist operator 


\section{LISTA DE SÍMBOLOS}

$\begin{array}{ll}\mathrm{LJ}_{N} & \text { Cluster ou nanopartícula de Lennard-Jones de uma espécie com } N \text { átomos } \\ E_{t o t} & \text { Energia total } \\ \epsilon^{\alpha \beta} & \text { Parâmetro de energia dos potenciais de Lennard-Jones e Sutton-Chen } \\ \sigma^{\alpha \beta} & \text { Parâmetro de distâncias do potencial de Lennard-Jones } \\ a^{\alpha \beta} & \text { Parâmetro de distância do potencial de Sutton-Chen } \\ c_{i} & \text { Parâmetro adimensional do potencial de Sutton-Chen } \\ m^{\alpha \beta} & \text { Expoente do termo de muitos corpos do potencial de Sutton-Chen } \\ n^{\alpha \beta} & \text { Expoente do termo de pares do potencial de Sutton-Chen } \\ \mathbf{R} & \text { Coordenadas atômicas ou nucleares } \\ \mathbf{r} & \text { Coordenadas eletrônicas } \\ k_{B} & \text { Constante de Boltzmann } \\ \mathrm{SC}_{N} & \text { Cluster de Sutton-Chen com } N \text { átomos } \\ \mathrm{BLJ}_{N} & \text { Cluster binário de Lennard-Jones com } N \text { átomos } \\ (\text { AgPd })_{55} & \text { Cluster de Ag e Pd com } 55 \text { átomos descrito pelo potencial de Sutton-Chen } \\ \mathrm{Al}_{N} & \text { Cluster de alumínio com } N \text { átomos } \\ \mathrm{Al}_{N-1} \mathrm{Cu} & \text { Cluster de alumínio dopado com um átomo de cobre, totalizando } N \text { átomos } \\ d_{a v} & \text { Comprimento de ligação ponderado médio } \\ \Delta_{2} E & \text { Função de estabilidade relativa } \\ m_{t o t} & \text { Momento magnético total } \\ E_{H O M O-L U M O} & \text { Gap energético entre os orbitais HOMO e LUMO } \\ E_{e x c} & \text { Energia de excesso } \\ E_{b} & \\ E_{a t m} & \end{array}$





\section{SUMÁRIO}

1 Introdução $\quad 27$

1.1 Clusters e nanopartículas . . . . . . . . . . . . . . . . 27

1.2 Determinação estrutural . . . . . . . . . . . . . . . . . . 28

1.3 Objetivos . . . . . . . . . . . . . . . . . . . . 32

1.4 Organização do trabalho . . . . . . . . . . . . . . . . . 32

2 Superfície de Energia Potencial 35

2.1 Tratamento clássico . . . . . . . . . . . . . . . . . . . . . . 35

2.1.1 Potencial de Lennard-Jones . . . . . . . . . . . . . . . . . . . 36

2.1.2 Potencial de Sutton-Chen . . . . . . . . . . . . . . . . . 37

2.2 Tratamento quântico . . . . . . . . . . . . . . . . . . . . . . . . . . . 38

2.2.1 Aproximação de Born-Oppenheimer . . . . . . . . . . . . . . . . . 40

2.2.2 Teoria do funcional da densidade . . . . . . . . . . . . . . . . 41

2.2.3 Método de Kohn-Sham . . . . . . . . . . . . . . . . . . 43

2.2.4 Funcional de troca e correlação . . . . . . . . . . . . . . . . . 45

2.2 .5 Funções de base . . . . . . . . . . . . . . . . . . . . . . . . . . 47

2.3 Características da superfície de energia potencial . . . . . . . . . . . 48

2.4 Topologia da superfície de energia potencial . . . . . . . . . . . . 50

2.4.1 Sequências monotônicas . . . . . . . . . . . . . . . . . . 51

2.4.2 Grafos de desconectividade . . . . . . . . . . . . . . . 52 
2.5 Paradoxo de Levinthal . . . . . . . . . . . . . . . . . . . 55

3 Método Basin-Hopping Monte Carlo Revisado 57

3.1 Método Basin-Hopping Monte Carlo padrão . . . . . . . . . . . . . 57

3.1.1 Dificuldades . . . . . . . . . . . . . . . . . . 60

3.2 Método Basin-Hopping Monte Carlo Revisado . . . . . . . . . . . . . . . 61

3.3 Inicialização aleatória . . . . . . . . . . . . . . . . . . 62

3.4 Minimização local . . . . . . . . . . . . . . . . . . . 63

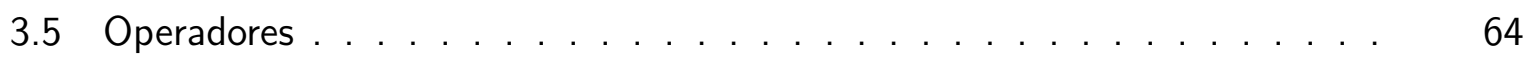

3.5.1 Operadores locais ........................ 66

3.5.1.1 Operadores de deslocamento atômico . . . . . . . . . 67

3.5.2 Operadores não-locais . . . . . . . . . . . . . . . 68

3.5.2.1 Operador twist . . . . . . . . . . . . . 69

3.5.2.2 Operador angular ................. 70

3.5.2.3 Operador angular de superfície . . . . . . . . . 70

3.5.2.4 Operador interior ................. 71

3.5.2.5 Operador de troca . . . . . . . . . . . . 71

3.5.2.6 Operador de troca geométrico . . . . . . . . . . 72

3.5.2.7 Operador crossover . . . . . . . . . . . . . 72

3.5.3 Operadores auxiliares . . . . . . . . . . . . . . . . 73

3.5.3.1 Operador de saltos ocasionais . . . . . . . . . . 73

3.5.3.2 Operador de filtro estrutural . . . . . . . . . . . 74

3.6 Taxa de aceitação e emprego dos operadores . . . . . . . . . . . . . 75

4 Global Optimization Package $\quad 77$

4.1 Implementação . . . . . . . . . . . . . . . . . . . . 77

4.1.1 Algoritmo principal . . . . . . . . . . . . . . . . . . . . 78

4.1.2 Algoritmo do método RBHMC . . . . . . . . . . . . 79 
4.1 .3 Potenciais empíricos . . . . . . . . . . . . . . . . . . . . 82

4.1 .4 Operadores . . . . . . . . . . . . . . . . . . . . . 84

4.1.5 Interface com o pacote FHI-aims . . . . . . . . . . . . 86

5 Estudo de Casos: Clusters de Lennard-Jones e Sutton-Chen 89

5.1 Clusters de Lennard-Jones . . . . . . . . . . . . . . . . . . . . . . 89

5.2 Nanopartículas de Lennard-Jones . . . . . . . . . . . . . . . . . . . 95

5.3 Clusters de Sutton-Chen . . . . . . . . . . . . . . . . . . . . . . . . . . . 98

5.4 Clusters binários de Lennard-Jones . . . . . . . . . . . . . . . . . . 102

5.5 Clusters binários de metais de transição $-(\mathrm{AgPd})_{55} \ldots \ldots$. . . . . . . . 105

5.6 Sumário . . . . . . . . . . . . . . . . . . . . . . . . . . . . . . . . . 110

6 Estudo de Casos: Clusters de Alumínio Descritos pela DFT 113

6.1 Clusters de alumínio puros . . . . . . . . . . . . . . . . . . . . . 113

6.2 Clusters de alumínio dopados com um átomo de cobre . . . . . . . . . . . 119

6.3 Análise do operador SFO . . . . . . . . . . . . . . . . . . . . 124

6.4 Sumário . . . . . . . . . . . . . . . . . . . . . . . . . . . 126

7 Conclusões $\quad 129$

REFERÊNCIAS

APÊNDICE A - Número de Coordenação Efetiva 149

A.1 Definição . . . . . . . . . . . . . . . . . . . . . . . . . . . . . . . . . . . 149

APÊNDICE B - Métodos de Otimização Local 151

B.1 Método steepest descent adaptativo . . . . . . . . . . . . . . . 151

B.2 Método dos gradientes conjugados . . . . . . . . . . . . . 152

B.3 Método Broyden-Fletcher-Goldfarb-Shanno . . . . . . . . . . . . 153 


\section{CAPÍTULO 1}

\section{Introdução}

Neste capítulo são apresentadas as motivações para o estudo de clusters e nanopartículas, uma revisão geral do problema de determinar suas estruturas e alguns métodos para abordá-lo, bem como os objetivos e organização do presente trabalho.

\subsection{Clusters e nanopartículas}

Clusters e nanopartículas são aglomerados atômicos contendo átomos de uma ou mais espécies químicas. No âmbito deste trabalho, clusters são definidos como aglomerados contendo de 2 a 199 átomos, e nanopartículas (NPs) são definidas como aglomerados contendo mais de 200 átomos. Estas partículas*, em especial aquelas correspondentes à sistemas metálicos, têm sido objetos de inúmeros estudos durante as últimas décadas, dando origem a um amplo campo de pesquisa que se estende por diversas áreas, incluindo física, química, biologia e engenharia. Esse intenso interesse deve-se ao fato de apresentarem propriedades distintas em comparação com bulks, como propriedades ópticas $(16)$, catalíticas $(17,18)$, magnéticas $(19,20)$ e eletrônicas $(21)$.

Estudos teóricos e experimentais envolvendo partículas metálicas permitem que os mecanismos responsáveis por suas propriedades químicas e físicas sejam compreendidos e controlados, abrindo possibilidades para inúmeras aplicações tecnológicas. Por exemplo, em um estudo realizado por El-Sayed et al. (22) foi verificado que NPs de ouro ( $\mathrm{Au}$ ) conjugadas com anticorpos específicos desempenham a função de agentes seletivos fototérmicos, auxiliando na identificação e posterior destruição de células cancerígenas. Morones et al. (23) realizaram a descoberta de propriedades bactericidas em NPs de prata $(\mathrm{Ag})$ com diâmetros entre 1 e 100 nm, sendo os efeitos mais pronunciados naquelas cujos diâmetros estão entre 1 e 10

*Ao longo deste texto o termo partícula será utilizado para se referir tanto a clusters quanto a NPs quando a discussão tratar aspectos comuns a ambos os sistemas. 
nm. Em outro estudo, Pan et al. (24) investigaram experimentalmente NPs de ródio (Rh) confinadas no interior de nanotubos de carbono e observaram um aumento significativo na produção de etanol por catálise em comparação com o uso de NPs de Rh suportadas em substratos óxidos. Outras aplicações de partículas metálicas incluem dispositivos eletrônicos e opto-eletrônicos, materiais termoelétricos, células fotovoltaicas, e transporte e administração de compostos farmacêuticos.

As propriedades peculiares dessas partículas ainda não são plenamente compreendidas, porém sabe-se que elas dependem significativamente de seus tamanhos, formatos (geometrias) e composições, em grande parte devido a efeitos de confinamento quântico $(25,26)$. Narayanan e El-Sayed (27) mostraram que o formato de NPs de platina (Pt) desempenham um papel importante em sua atividade catalítica, com a energia de ativação variando significativamente entre NPs esféricas, tetraédricas e cúbicas. Em um estudo recente, Scholl et al. (28) investigaram as propriedades plasmônicas de partículas individuais de $\mathrm{Ag}$ com tamanhos variando entre 2 e $20 \mathrm{~nm}$ e verificaram um desvio de regime clássico para quântico à medida que o tamanho das partículas é reduzido, especialmente abaixo de $10 \mathrm{~nm}$. Propriedades como temperatura e calor latente de fusão $(29,30)$, calor de adsorção (31) e magnetização (32) também dependem do tamanho e formato das partículas. Além disso, em partículas pequenas (em média menores que $10 \mathrm{~nm}$ ) as propriedades variam abruptamente entre tamanhos ligeiramente diferentes, variando de maneira mais uniforme à medida que tamanhos maiores são considerados, eventualmente convergindo para as propriedades de bulk.

\subsection{Determinação estrutural}

Estando as propriedades de uma partícula intimamente relacionadas à sua estrutura, então uma tarefa fundamental é determinar qual é a estrutura atômica. Técnicas experimentais para abordar esse problema incluem difração eletrônica e de raios $\mathrm{X}$, microscopia eletrônica de transmissão de alta resolução, espectroscopia de massa e espectroscopia de perda de energia de elétrons. Contudo, experimentos considerados isoladamente não são suficientes para acessar todas as características morfológicas relevantes dos sistemas, em especial nos casos em que o número de átomos é da ordem de dezenas. Dados obtidos experimentalmente muitas vezes só podem ser interpretados com o auxílio de modelos teóricos e resultados de simulações (33). De fato, a ciência de clusters e NPs é um campo em que experimento, teoria e simulação caminham lado a lado (34).

Em seu estado fundamental, uma partícula assume uma estrutura atômica que minimiza 
sua energia total, que, à temperatura zero, é dada pela superfície de energia potencial (SEP) associada ao sistema, a qual relaciona às posições atômicas um valor de energia bem definido. Portanto, o problema de determinar a estrutura de uma partícula de $N$ átomos consiste em minimizar sua função de energia total, $E_{\text {tot }}\left(\mathbf{R}_{1}, \mathbf{R}_{2}, \ldots, \mathbf{R}_{N}\right)$, em relação às $3 N$ variáveis correspondentes às componentes das posições atômicas de cada átomo, i.e., $\mathbf{R}_{i}=\left(R_{i x}, R_{i y}, R_{i z}\right)$ para o átomo $i(i=1,2, \ldots, N)$. Essa minimização é um problema de otimização global, uma vez que o objetivo é determinar qual estrutura atômica possui uma energia que corresponde ao mínimo global da SEP.

Métodos matemáticos que são normalmente utilizados para otimizar funções de algumas poucas variáveis, como o método de Newton, permitem que apenas mínimos locais sejam identificados, de modo que para se determinar o mínimo global empregando somente tais métodos é preciso identificar todos os mínimos locais e compará-los entre si. Tal estratégia só pode ser aplicada para sistemas pequenos, tipicamente menores que 10 átomos, casos em que a energia total não depende de uma grande quantidade de variáveis. Isso deve-se ao fato de que à medida que mais átomos são considerados, o número de mínimos locais cresce exponencialmente, e a SEP cresce em complexidade (35-37). Nesses casos, a identificação de todos os mínimos locais é impraticável, uma característica que faz com que o problema de otimização global de partículas seja classificado como NP-difícil na terminologia de complexidade computacional, o que significa que não existem algoritmos capazes de encontrar o mínimo global de uma SEP em um tempo que dependa polinomialmente de $N(38,39)$. As dificuldades associadas à determinação estrutural, portanto, são claras.

Diversos métodos de otimização global foram desenvolvidos ao longo dos anos para tratar o problema de exploração da SEP em busca do mínimo global. Dentre esses, um dos primeiros foi o método simulated annealing, no qual uma simulação de Monte Carlo ou dinâmica molecular à alta temperatura é inicialmente utilizada para explorar a SEP, e então ocorre um resfriamento, restringindo a busca para regiões de menor energia. Apesar de sucesso em outros contextos, quando empregado para partículas esse método não obteve um sucesso expressivo, e foi capaz de encontrar apenas um mínimo global previamente desconhecido entre clusters de Lennard-Jones, para o caso $\mathrm{LJ}_{24}$, um sistema considerado simples de ser otimizado do ponto de vista de outros métodos (37). Outra metodologia que merece destaque é o método de algoritmos inspirado no processo de evolução natural, no qual procura-se evoluir uma população de partículas por diversas gerações, através das quais elas são submetidas algoritmos de mutação, cruzamento e seleção (40-43). Algoritmos genéticos foram empregados com sucesso em diversas classes de sistemas, como clusters de metais transição $(44,45)$, clusters de moléculas de água (46), clusters de Lennard-Jones $(11,41)$, e clusters binários diversos $(47,48)$. 
Dada a complexidade do problema, a maioria dos métodos de otimização global faz uso de técnicas estocásticas aliadas a métodos determinísticos. Muitos métodos também introduzem bias na busca, o que significa que características desejadas na solução final são utilizadas para influenciar a exploração. Isso por acontecer, por exemplo, ao iniciar uma otimização global a partir de uma solução conhecida, fazendo com que a exploração da SEP parta de uma região de baixa energia. O problema, nesse caso, é que o uso de bias pode impedir que soluções inesperadas sejam encontradas, e.g., um mínimo global com características diferentes daquelas utilizadas para influenciar a busca. Uma alternativa é realizar a otimização sem bias, partindo de uma estrutura inicial completamente aleatória e procurando deixar que a busca visite regiões distintas da SEP. Otimização global sem bias é mais desafiadora, já que a região da SEP onde a busca é iniciada pode estar separada por altas barreiras de energia daquela onde se localiza o mínimo global, porém pode levar à descoberta de soluções não antecipadas. Além disso, métodos sem bias são mais fáceis de transferir para outras classes de sistema, uma vez que introduzem menos dependências específicas do sistema para o qual foram desenvolvidos.

Sobre os mínimos globais encontrados através de otimização global, é importante notar que metodologias existentes não são capazes de garantir com absoluta certeza que uma solução encontrada corresponde de fato ao mínimo global da SEP. Por essa razão, os mínimos globais reportados na literatura são sempre classificados como putativos. Outra consequência é que ao revisar a literatura da área é comum encontrar artigos reportando mínimos globais com energias inferiores a outros reportados em artigos anteriores que focaram-se nos mesmos sistemas. Além disso, trabalhos descrevendo novas metodologias capazes de identificar mínimos globais inéditos costumam receber bastante atenção dentro da área.

Uma metodologia de otimização global que obteve sucesso expressivo nas últimas duas décadas é o método de Basin-Hopping Monte Carlo (BHMC), classificado entre os métodos que alteram a topologia da SEP a fim de obter uma superfície mais fácil de ser explorada. O método foi introduzido por Li e Scheraga (49) como uma abordagem ao problema de múltiplos mínimos encontrado no estudo de enovelamento de proteínas, explorando a SEP por meio de uma combinação de técnicas estocásticas de pesquisa global e minimizações locais determinísticas. Posteriormente, o método foi adaptado ${ }^{\dagger}$ por Wales e Doye (50) para o tratamento de partículas descritas pelo potencial de Lennard-Jones com até 110 átomos, e obteve sucesso em identificar estruturas de mínimo global inéditas. Desde então, o método BHMC padrão tem sido aplicado a diversos tipos de partículas, modeladas por diferentes modelos de interações interatômicas, como potenciais empíricos, métodos semi-empíricos e

†Com o objetivo de evitar confusão de nomenclatura com o método introduzido neste trabalho, onde necessário, o método apresentado por Wales e Doye na referência (50) é denominado BHMC padrão ao longo deste texto. 
métodos de primeiros princípios.

Apesar dos muitos sucessos e de ter se estabelecido como uma técnica valiosa na área de clusters e NPs, o método BHMC padrão não representa a solução definitiva para o problema de otimização global de partículas. Pode-se citar aqui o fato de resultados publicados originalmente por Wales e Doye para clusters de Lennard-Jones terem sido superados por metodologias posteriores, como no caso do trabalho de Leary e Doye (51), no qual o emprego de um método baseado no BHMC padrão levou à descoberta de um mínimo global inédito para o cluster $\mathrm{LJ}_{98}$. Outro exemplo de como o método BHMC padrão apresenta pontos fracos pode ser visto no caso de clusters binários de Lennard-Jones. Utilizando BHMC padrão, Doye e Meyer (12) realizaram um estudo sistemático desses sistemas e reportaram mínimos globais putativos para clusters contendo até 100 átomos, mas posteriormente outros autores $(8,9,14)$ foram capazes de encontrar muitas estruturas com energias menores através de outras metodologias.

Além disso, para partículas cujas interações interatômicas são descritas por primeiros princípios, em particular dentro do formalismo da teoria do funcional da densidade (DFT density functional theory), o emprego do método BHMC tem sido mais modesto. Isso se deve ao fato de que o tratamento quântico envolve cálculos custosos e que precisam ser ajustados cuidadosamente para garantir convergência e consistência, fatores que podem representar obstáculos à exploração da SEP por meio da avaliação de muitas configurações diferentes, como acontece no método BHMC padrão. Por essa razão, nota-se em muitas ocasiões que os autores optam por abordagens alternativas, como, por exemplo, utilizar BHMC com potenciais empíricos para selecionar um grupo de candidatos a mínimo global, e então refinar as estruturas candidatas utilizando cálculos quânticos (52-56).

Em geral, trabalhos que empregam BHMC acoplado diretamente com métodos de primeiros princípios focam-se em clusters de poucos átomos e limitam-se a analisar apenas alguns tamanhos selecionados (57-61). Nota-se, também, que o emprego do método BHMC padrão visando a otimização sistemática de clusters de tamanhos diversos descritos por primeiros princípios frequentemente é realizado em conjunto com outros métodos de otimização global $(10,62-64)$, ou com algum tipo de bias introduzido na busca (65-69). Nesses casos, o método BHMC raramente é a única metodologia utilizada, o que leva à conclusão de que a confiabilidade e usabilidade do método BHMC padrão implementado sem bias não está plenamente consolidada, principalmente quando se trata de em partículas descritas por interações quânticas, e em particular pela DFT. 


\subsection{Objetivos}

Este trabalho tem o objetivo de introduzir ideias e estratégias para aperfeiçoar o método BHMC padrão para a otimização global de clusters e NPs. O método aperfeiçoado, denominado aqui de BHMC revisado (RBHMC - Revised Basin-Hopping Monte Carlo), visa trazer maior eficiência para a otimização global sem bias de partículas descritas tanto potenciais empíricos, quanto pelo formalismo de primeiros princípios da DFT. Ao longo do trabalho de mestrado foi desenvolvido integralmente um pacote de otimização global denominado GOP (Global Optimization Package), com o qual foi possível aplicar e avaliar a metodologia desenvolvida. Para tal, o método RBHMC foi aplicado a um grande número de partículas de diferentes tamanhos e descritas por diferentes modelos de interação interatômica. A aplicação do método RBHMC a diferentes sistemas confere ao trabalho um segundo objetivo, que é o estudo de algumas propriedades das estruturas de mínimo global identificadas com o método.

\subsection{Organização do trabalho}

O capítulo 2 contém uma revisão teórica de SEPs, tanto do ponto de vista clássico quanto quântico. No capítulo 3 o método BHMC padrão é introduzido e seus pontos fracos são discutidos, e em seguida o método RBHMC, que constitui a principal contribuição deste trabalho, é apresentado e tratado em detalhes. No capítulo 4 o pacote GOP é discutido com foco na implementação do método RBHMC. O capítulo 5 aborda um estudo de casos no qual o método RBHMC foi aplicado a clusters de Lennard-Jones e Sutton-Chen com até 148 átomos, NPs de Lennard-Jones contendo até 1500 átomos, diversos tipos de clusters binários de Lennard-Jones (BLJ) com até 100 átomos, e clusters binários de Sutton-Chen contendo 55 átomos. No capítulo 6 é apresentado um segundo estudo de casos no qual o método RBHMC foi aplicado a clusters descritos pela DFT, sendo esses clusters puros de alumínio $\mathrm{Al}$ ) com até 30 átomos, e clusters de $\mathrm{Al}$ de até 15 átomos dopados com um átomo de cobre (Cu). Finalmente, no capítulo 7 é feito um sumário dos principais pontos apresentados e são expostas as conclusões gerais que podem ser tiradas deste trabalho.

Informações adicionais e de suporte estão presentes nos apêndices. No apêndice A é feita uma introdução ao conceito de número de coordenação efetiva, utilizado nos capítulos 5 e 6 . $O$ apêndice $B$ contém uma breve discussão sobre os métodos de minimização local empregados em conjunto com o método RBHMC. No apêndice $C$ estão inclusos dados referentes a todos 
os mínimos globais dos clusters BLJ obtidos com o método RBHMC. O DVD anexo a este trabalho contém todas as estruturas de mínimo global encontradas pelo método RBHMC. 


\section{CAPÍTULO 2}

\section{Superfície de Energia Potencial}

Neste capítulo são apresentadas metodologias para descrever a interação entre os átomos em uma partícula, que em última instância definem a topologia da SEP. Em seguida, algumas características gerais e topológicas de SEPs são discutidas e relacionadas com o problema de otimização global de partículas.

\subsection{Tratamento clássico}

Em um sistema de $N$ átomos à temperatura zero, sua a energia total do estado fundamental é dada por uma função que associa às $3 N$ coordenadas, $\mathbf{R}$, um valor de energia potencial. Essa associação define a SEP, um objeto de $3 N$ dimensões imerso em um espaço $(3 N+1)$-dimensional. A energia total pode ser escrita como,

$$
E_{t o t}(\mathbf{R})=\sum_{i=1}^{N} V_{1}\left(\mathbf{R}_{i}\right)+\sum_{i=1}^{N} \sum_{j>i}^{N} V_{2}\left(\mathbf{R}_{i}, \mathbf{R}_{j}\right)+\sum_{i}^{N} \sum_{j>i}^{N} \sum_{k>j}^{N} V_{3}\left(\mathbf{R}_{i}, \mathbf{R}_{j}, \mathbf{R}_{k}\right)+\cdots,
$$

onde $V_{1}$ é o potencial que representa o efeito de forças externas atuando no sistema, $V_{2}$ é o potencial de interação entre dois átomos, $V_{3}$ representa a interação entre três átomos, e assim sucessivamente (70). Na ausência de potenciais externos, $V_{1}=0$, a energia total devese apenas às interações interatômicas, que podem ser truncadas em determinados termos de acordo com o sistema em questão, e.g., para líquidos e moléculas muitas vezes é suficiente incluir apenas termos de interação de pares (71).

Ao longo do século $\mathrm{XX}$ foram propostas diversas formas funcionais para os potenciais $V_{i}(\mathbf{R})$ $(i=2,3, \ldots)$, a maioria de natureza empírica. Estes potenciais empíricos possuem parâmetros livres que devem ser determinados a partir de dados experimentais ou de cálculos quânticos, e são construídos para reproduzir comportamentos conhecidos de líquidos, gases ou sólidos em bulk. Apesar de modelarem tais sistemas com razoável precisão, potenciais empíricos 
não são capazes de descrever completamente a física de partículas. Porém, são ferramentas úteis para desvendar características morfológicas, e do ponto de vista de otimização global, serviram como base para o desenvolvimento de diversas metodologias. O principal problema com potenciais empíricos é que não levam em conta graus de liberdade eletrônicos e efeitos quânticos, características essenciais que governam o comportamento de partículas. Para sanar este problema é preciso empregar métodos quânticos de primeiros princípios, conforme é discutido na seção 2.2 .

A seguir são apresentados os potenciais empíricos de Lennard-Jones (LJ) (71-73) e SuttonChen (SC) $(15,74)$, utilizados neste trabalho. O emprego desses potenciais se justifica do ponto de vista de desenvolvimento de metodologia pois são descritos por formas funcionais simples, possuem pequenos conjuntos de parâmetros, são fáceis de serem implementados e são computacionalmente eficientes. Além disso, existe uma vasta coleção de resultados para partículas descritas por tais potenciais (4), facilitando a avaliação do método RBHMC.

\subsubsection{Potencial de Lennard-Jones}

No potencial de LJ energia total deve-se apenas a termos de interação entre pares, dada por

$$
E_{\text {tot }}^{L J}=\frac{1}{2} \sum_{i=1}^{N} \sum_{\substack{j=1 \\ j \neq i}}^{N} V_{2}\left(\mathbf{R}_{i j}\right)
$$

onde

$$
V_{2}\left(\mathbf{R}_{i j}\right)=4 \epsilon^{\alpha \beta}\left[\left(\frac{\sigma^{\alpha \beta}}{R_{i j}}\right)^{12}-\left(\frac{\sigma^{\alpha \beta}}{R_{i j}}\right)^{6}\right]
$$

Na equação $2.1 .3, R_{i j}=\left|\mathbf{R}_{i j}\right|$, onde $\mathbf{R}_{i j}=\mathbf{R}_{j}-\mathbf{R}_{i}$, e $\alpha$ e $\beta$ correspondem às espécies químicas dos átomos $i$ e $j$, respectivamente. $O$ parâmetro $\sigma^{\alpha \beta}$ é a distância abaixo da qual a energia de interação é positiva (i.e., há repulsão), e é normalmente associado ao comprimento de ligação entre átomos das espécies $\alpha$ e $\beta$. O parâmetro $\epsilon^{\alpha \beta}$ determina a profundidade do poço de potencial e está associado à intensidade da interação. A energia de interação entre pares possui uma cauda atrativa para grandes distâncias $R_{i j}$, atinge um valor mínimo para $R_{i j}=2^{1 / 6} \sigma^{\alpha \epsilon}$, denominada distância de equilíbrio do potencial, passa por zero em $R_{i j}=\sigma^{\alpha \beta}$ e aumenta rapidamente à medida que $R_{i j}$ se reduz para valores menores que $\sigma^{\alpha \beta}$.

O termo proporcional a $R_{i j}^{-12}$ é dominante para distâncias curtas e modela a repulsão existente entre os átomos quando estes são colocados muito próximos um do outro. A origem física desse termo remete ao princípio de exclusão de Pauli, segundo o qual a energia do sistema 
aumenta abruptamente quando as nuvens eletrônicas que envolvem os átomos se sobrepõe, uma vez que estados eletrônicos de maior energia passam a ser ocupados. Para distâncias longas o termo dominante é proporcional a $R_{i j}^{-6}$ e constitui a parte atrativa do potencial, responsável pela coesão do sistema. Este termo modela forças de dispersão de van der Waals, que são relativamente fracas, porém dominantes em sistemas de camada fechada, e.g., gases nobres.

Os parâmetros $\sigma^{\alpha \beta}$ e $\epsilon^{\alpha \beta}$ são determinados a partir de resultados experimentais (72, 75) ou cálculos quânticos (76). Estes parâmetros são obtidos para sistemas de uma única espécie (i.e., $\sigma^{\alpha \alpha}, \sigma^{\beta \beta}$, etc), e os seus valores para interações entre pares de diferentes átomos são determinados através de regras de combinação. Neste trabalho é empregada a regra de combinação de Lorentz (77) para o parâmetro $\sigma^{\alpha \beta}$ e a regra de Berthelot (78) para o parâmetro $\epsilon^{\alpha \beta}$, definidas como $\sigma^{\alpha \beta}=\frac{\sigma^{\alpha \alpha}+\sigma^{\beta \beta}}{2}$ e $\epsilon^{\alpha \beta}=\sqrt{\epsilon^{\alpha \alpha} \epsilon^{\beta \beta}}$, respectivamente.

Métodos de minimização local da SEP exigem o conhecimento da força total exercida em cada átomo, uma vez que pontos estacionários da SEP são aqueles em que esta força se anula para todos os átomos. No potencial de LJ, a força total em um átomo $i$ é dada por

$$
\mathbf{F}_{i}^{L J}=-\nabla_{\mathbf{R}_{i}} E_{t o t}^{L J}=-\sum_{\substack{j=1 \\ j \neq i}}^{N} 24 \epsilon^{\alpha \beta}\left[2\left(\frac{\sigma^{\alpha \beta}}{R_{i j}}\right)^{12}-\left(\frac{\sigma^{\alpha \beta}}{R_{i j}}\right)^{6}\right] \frac{\mathbf{R}_{i j}}{R_{i j}^{2}} .
$$

\subsubsection{Potencial de Sutton-Chen}

O potencial de SC é um potencial do tipo Finnis-Sinclair (79) empregado para modelar sistemas metálicos em bulk, pois consegue descrever com boa precisão o caráter deslocalizado de ligações metálicas. Dentro desse potencial, a energia total é dada por

$$
E_{t o t}^{S C}=\sum_{i=1}^{N}\left[\frac{1}{2} \sum_{\substack{j=1 \\ j \neq i}}^{N} V_{2}\left(\mathbf{R}_{i j}\right)-c_{i} \sqrt{V_{i, N}(\mathbf{R})}\right],
$$

com

$$
V_{2}\left(\mathbf{R}_{i j}\right)=\epsilon^{\alpha \beta}\left(\frac{a^{\alpha \beta}}{R_{i j}}\right)^{n^{\alpha \beta}}, V_{i, N}(\mathbf{R})=\sum_{\substack{j=1 \\ j \neq i}}^{N}\left(\epsilon^{\alpha \beta}\right)^{2}\left(\frac{a^{\alpha \beta}}{R_{i j}}\right)^{m^{\alpha \beta}},
$$

onde termo de pares, $V_{2}$, é responsável pela repulsão interatômica, dominante para curtas distâncias. O termo $V_{i, N}$ é um termo de muitos corpos responsável pela coesão metálica no sistema, e serve como um modelo para a densidade eletrônica. 
O parâmetro $\epsilon^{\alpha \beta}$ fornece a escala de energia e é obtido a partir dos valores experimentais para a energia de coesão. O parâmetro $a^{\alpha \beta}$ é fixado como o parâmetro de rede de uma rede cúbica de face centrada ( $\mathrm{fcc}$ ) e fornece a escala de todas as dimensões, e $c_{i}$ é um parâmetro adimensional que escala o termo atrativo do potencial e é obtido a partir de uma aproximação de primeira ordem para a soma de Ewald das contribuições repulsivas. Os parâmetros $m^{\alpha \beta}$ e $n^{\alpha \beta}$ servem como fatores de escala para as leis de potência que controlam os termos de atração e repulsão. Para sistemas de uma única espécie (i.e., $\alpha=\beta$ ), estes dois últimos parâmetros são inteiros obedecendo a condição $m^{\alpha \alpha}<n^{\alpha \alpha}$, que é imposta pela condição de estabilidade elástica. Além disso, a restrição $m^{\alpha \beta} \geq 6$ também é imposta para que se obtenha valores mais próximos dos experimentais para o módulo de bulk.

Os valores para os cinco parâmetros do potencial de SC são obtidos para sistemas em bulk de uma única espécie, sendo que para obter seus valores para sistemas de múltiplas espécies são empregadas regras de combinação, de maneira análoga ao que é feito com o potencial de LJ. Utilizando as regras de combinação de Lorentz e Berthelot, obtém-se* $a^{\alpha \beta}=\frac{a^{\alpha \alpha}+a^{\beta \beta}}{2}$, $\epsilon^{\alpha \beta}=\sqrt{\epsilon^{\alpha \alpha} \epsilon^{\beta \beta}}, n^{\alpha \beta}=\frac{n^{\alpha \alpha}+n^{\beta \beta}}{2}$, e $m^{\alpha \beta}=\frac{m^{\alpha \alpha}+m^{\beta \beta}}{2}$. A força total em um átomo $i$ é dada por, $\mathbf{F}_{i}^{S C}=-\left[\epsilon^{\alpha \beta} n^{\alpha \beta}\left(\frac{a^{\alpha \beta}}{R_{i j}}\right)^{n^{\alpha \beta}}-\frac{1}{2}\left(\epsilon^{\alpha \beta}\right)^{2} m^{\alpha \beta}\left(\frac{c_{i}}{\sqrt{V_{i, N}(\mathbf{R})}}+\frac{c_{j}}{\sqrt{V_{j, N}(\mathbf{R})}}\right)\left(\frac{a^{\alpha \beta}}{R_{i j}}\right)^{m^{\alpha \beta}}\right] \frac{\mathbf{R}_{i j}}{R_{i j}^{2}}$

\subsection{Tratamento quântico}

A compreensão do comportamento microscópico de átomos, moléculas, sólidos e partículas é possível através do estudo das interações dos seus elementos constituintes básicos, núcleos e elétrons. O ponto de partida para obter a energia total de um sistema contendo $N$ elétrons e $M$ núcleos é a equação de Schrödinger, que em sua forma independente do tempo e não relativística é escrita como

$$
\hat{H} \Psi(\mathbf{r}, \mathbf{R})=E \Psi(\mathbf{r}, \mathbf{R})
$$

onde $\mathbf{r}=\left\{\mathbf{r}_{1}, \mathbf{r}_{2}, \ldots, \mathbf{r}_{N}\right\}$ representa as coordenadas eletrônicas, e $\mathbf{R}=\left\{\mathbf{R}_{1}, \mathbf{R}_{2}, \ldots, \mathbf{R}_{M}\right\}$ as coordenadas nucleares. O Hamiltoniano não relativístico $\hat{H}$ corresponde a um problema de muitos corpos e contém todas as interações que caracterizam o sistema, e é definido como

$$
\hat{H}(\mathbf{r}, \mathbf{R})=\hat{T}_{n}(\mathbf{R})+\hat{T}_{e}(\mathbf{r})+\hat{V}_{n-e}(\mathbf{r}, \mathbf{R})+\hat{V}_{e-e}(\mathbf{r}, \mathbf{R})+\hat{V}_{n-n}(\mathbf{R}) .
$$

*O parâmetro $c_{i}$ não precisa ser combinado pois está associado apenas a um único átomo. 
O primeiro termo do operador Hamiltoniano corresponde à energia cinética nuclear, dado por

$$
\hat{T}_{n}(\mathbf{R})=-\sum_{\alpha=1}^{M} \frac{\hbar^{2}}{2 M_{\alpha}} \nabla_{\mathbf{R}_{\alpha}}^{2},
$$

onde $M_{\alpha}$ é a massa do núcleo $\alpha$, e a diferenciação implícita no operador Laplaciano, $\nabla_{\mathbf{R}_{\alpha}}^{2}$, deve ser realizada em relação às coordenadas do $\alpha$-ézimo núcleo na posição $\mathbf{R}_{\alpha}$. O segundo termo do operador $\hat{H}$ denota a energia cinética dos elétrons,

$$
\hat{T}_{e}(\mathbf{r})=-\sum_{i=1}^{N} \frac{\hbar^{2}}{2 m_{e}} \nabla_{\mathbf{r}_{i}}^{2},
$$

onde $m_{e}$ é a massa de repouso do elétron e a diferenciação implícita no operador Laplaciano, $\nabla_{\mathbf{r}_{i}}^{2}$, deve ser realizada em relação às coordenadas do $i$-ézimo elétron na posição $\mathbf{r}_{i}$. O terceiro termo corresponde à energia potencial devido à interação eletrostática entre os elétrons e os núcleos, escrito como

$$
\hat{V}_{n-e}(\mathbf{r}, \mathbf{R})=-\frac{1}{4 \pi \epsilon_{0}} \sum_{\alpha=1}^{M} \sum_{i=1}^{N} \frac{Z_{\alpha} e^{2}}{\left|\mathbf{R}_{\alpha}-\mathbf{r}_{i}\right|},
$$

onde $\epsilon_{0}$ é a constante de permissividade do vácuo, $Z_{\alpha}$ corresponde ao número atômico do $\alpha$-ézimo núcleo, e $e$ é a carga fundamental. O quarto termo denota a energia potencial de interação eletrostática entre elétrons,

$$
\hat{V}_{e-e}(\mathbf{r})=\frac{1}{8 \pi \epsilon_{0}} \sum_{i=1}^{N} \sum_{\substack{j=1 \\ j \neq i}}^{N} \frac{e^{2}}{\left|\mathbf{r}_{i}-\mathbf{r}_{j}\right|} .
$$

Finalmente, o quinto termo representa a energia potencial de interação eletrostática entre os núcleos,

$$
\hat{V}_{n-n}(\mathbf{R})=\frac{1}{8 \pi \epsilon_{0}} \sum_{\alpha=1}^{M} \sum_{\substack{\beta=1 \\ \beta \neq \alpha}}^{M} \frac{Z_{\alpha} Z_{\beta} e^{2}}{\left|\mathbf{R}_{\alpha}-\mathbf{R}_{\beta}\right|} .
$$

Para simplificar a notação no restante desta seção é conveniente adotar unidades atômicas. Nesse sistema de unidades os comprimentos são dados em bohr, as energias são dadas em Hartree, e $|e|=1, m_{e}=1$ e $\hbar=1$. Utilizando também o sistema de unidades gaussiano para as interações eletrostáticas, tem-se $4 \pi \epsilon_{0}=1$. Além disso, a notação $O$ será empregada para se referir ao autovalor (energia) do operador $\hat{O}$, exceto para o caso do operador Hamiltoniano, cuja energia associada será denotada por $E$. 


\subsubsection{Aproximação de Born-Oppenheimer}

Uma das primeiras aproximações aplicadas ao problema da solução da equação de Schrödinger independente do tempo é a aproximação de Born-Oppenheimer (80) (BO), que permite o desacoplamento dos movimentos nucleares e eletrônicos, acoplados originalmente devido ao termo $\hat{V}_{n-e}(\mathbf{r}, \mathbf{R})$. A aproximação BO fornece excelentes resultados para um grande número de sistemas, em particular para os sistemas tratados neste trabalho. Essa aproximação baseiase no fato dos núcleos serem muito mais massivos que os elétrons (três ordens de grandeza a mais), e de um ponto de vista dinâmico, de existir uma separação significante na escala de tempo de resposta dos núcleos e dos elétrons. Dentro dessa aproximação os núcleos são tratados como objetos estacionários, em relação aos quais os elétrons se arranjam instantaneamente para o seu estado fundamental dada cada configuração nuclear.

A aproximação BO é dada através de um ansatz para a função de onda total, expresso por

$$
\Psi(\mathbf{r}, \mathbf{R})=\chi(\mathbf{R}) \psi(\mathbf{r} ;\{\mathbf{R}\}),
$$

onde a função de onda total $\Psi(\mathbf{r}, \mathbf{R})$ foi escrita como um produto de uma função de onda eletrônica, $\psi(\mathbf{r} ;\{\mathbf{R}\})$, e outra nuclear, $\chi(\mathbf{R})$. A função de onda eletrônica corresponde aos estados eletrônicos para as posições nucleares fixas em $\mathbf{R}$, dependendo destas apenas de forma paramétrica. A dependência paramétrica, expressa pela notação $\{\mathbf{R}\}$, significa que a cada configuração nuclear está associada uma função de onda eletrônica diferente, e uma energia eletrônica diferente. Substituindo na equação 2.2.1 o ansatz dado pela equação 2.2.8 é possível separar o Hamiltoniano em um Hamiltoniano eletrônico e outro nuclear, i.e., $\hat{H}=\hat{H}_{e}+\hat{H}_{n}$, e portanto duas equações de Schrödinger, uma eletrônica e outra nuclear, dadas respectivamente por

$$
\hat{H}_{e} \psi(\mathbf{r} ;\{\mathbf{R}\})=E_{e} \psi(\mathbf{r} ;\{\mathbf{R}\}),
$$

e

$$
\hat{H}_{n} \chi(\mathbf{R})=E_{n} \chi(\mathbf{R}) .
$$

Como os núcleos são considerados fixos, no Hamiltoniano eletrônico o termo cinético nuclear pode ser desprezado, assim como o termo potencial correspondente às interações eletrostáticas entre os núcleos, que torna-se uma constante. O Hamiltoniano eletrônico corresponde então a um problema de $N$ elétrons na presença de um campo externo gerado por $M$ núcleos fixos, sendo dado por

$$
\hat{H}_{e}(\mathbf{r})=\hat{T}_{e}(\mathbf{r})+\hat{V}_{n-e}(\mathbf{r} ;\{\mathbf{R}\})+\hat{V}_{e-e}(\mathbf{r})
$$


A solução da equação 2.2.9 resulta na obtenção da energia eletrônica, $E_{e}(\{\mathbf{R}\})$, para as coordenadas nucleares $\mathbf{R}$ fixas. Esta energia desempenha o papel de um potencial eletrônico que é sentido pelos núcleos, e aparece explicitamente no Hamiltoniano nuclear, que fica

$$
\hat{H}_{n}(\mathbf{R})=\hat{T}_{n}(\mathbf{R})+\hat{V}_{n-n}(\mathbf{R})+E_{e}(\{\mathbf{R}\}) .
$$

Substituindo o operador Hamiltoniano nuclear na equação 2.2.10, tem-se

$$
\left[\hat{T}_{n}(\mathbf{R})+\hat{V}_{B O}(\mathbf{R})\right] \chi(\mathbf{R})=E_{n} \chi(\mathbf{R})
$$

onde

$$
\hat{V}_{B O}(\mathbf{R})=\hat{V}_{n-n}(\mathbf{R})+E_{e}(\{\mathbf{R}\}),
$$

e portanto, os núcleos sentem um potencial efetivo dado por $\hat{V}_{B O}$, denominado superfície de Born-Oppenheimer, uma SEP sob influência da qual os núcleos se movem. Esta situação é análoga ao que ocorre no caso clássico, discutido no início deste capítulo, onde associa-se uma energia total a cada geometria determinada pelas posições atômicas. Do ponto de vista de exploração da SEP, tanto o caso clássico quanto o quântico podem ser tratados de maneiras similares, o que favorece o desenvolvimento de metodologias gerais de otimização global.

O problema principal na determinação da SEP é a solução da equação de Schrödinger independente do tempo para a função de onda eletrônica, equação 2.2.9, dentro da aproximação de BO. Sua solução analítica só é possível para alguns poucos sistemas, uma vez que é difícil tratar o acoplamento dos elétrons, dado pelo termo de interação $\hat{V}_{e-e}(\mathbf{r})$. Portanto, é necessário empregar de outros níveis de aproximações que vem sendo desenvolvidas desde o surgimento da mecânica quântica. Neste trabalho o método utilizado é dado pelo formalismo da DFT, que ao invés de procurar a função de onda do estado fundamental do sistema, foca-se na determinação da densidade eletrônica do estado fundamental.

\subsubsection{Teoria do funcional da densidade}

Metodologias envolvendo a densidade eletrônica apareceram logo que surgiu a mecânica quântica, no final da década de 20 do século passado. A DFT, porém, colocou essas metodologias em uma base teórica mais sólida, vindo se estabelecer apenas na década de 60 , decorrente dos trabalhos de Hohenberg e Kohn (81), e de Kohn e Sham (82). Nessa teoria, a grandeza fundamental deixa de ser a função de onda para muitos elétrons e passa a ser a densidade eletrônica, que ao contrário da função de onda, tem um significado físico muito bem definido. Por ser uma grandeza que corresponde a um observável, a densidade eletrônica 
é uma função real, e além disso, depende apenas de 3 coordenadas espaciais, $\mathbf{r}=(x, y, z)$. Essas características são atrativos de métodos de densidade eletrônica, já que a função de onda, por sua vez, é uma função complexa de $3 N$ variáveis, i.e., coordenadas espaciais de todos os elétrons.

A base teórica da DFT é composta por dois teoremas propostos e demonstrados por Hohenberg e Kohn (HK), enunciados a seguir e cujas demonstrações podem ser encontradas na literatura $(81,83)$. Os teoremas consideram um sistema de $N$ elétrons interagentes em um potencial externo dado por $V_{n-e}(\mathbf{r})$. A discussão apresentada aqui considera um sistema sem polarização de spin, e uma extensão da DFT que inclui o tratamento de polarização de spin pode ser encontrada na literatura (83).

Teorema 2.2.1. (Primeiro Teorema de HK) Quaisquer observáveis de um sistema descrito por mecânica quântica, incluindo a energia total, podem ser calculados, em princípio de maneira exata, a partir da densidade eletrônica do estado fundamental.

Teorema 2.2.2. (Segundo Teorema de HK) A densidade eletrônica do estado fundamental pode ser calculada, em princípio de maneira exata, aplicando um método variacional à energia total em relação à densidade eletrônica. Dessa maneira, a densidade eletrônica que minimiza a energia total é a densidade correta do estado fundamental.

Do primeiro teorema, segue que o conhecimento da densidade eletrônica, $n(\mathbf{r})$, determina o potencial externo, $V_{n-e}$, a energia cinética dos elétrons, $T_{e}$, e a energia de interação entre os elétrons, $V_{e-e}$. Assim, a energia do estado fundamental pode ser escrita como um funcional único da densidade,

$$
E_{e}[n(\mathbf{r})]=T_{e}[n(\mathbf{r})]+V_{n-e}[n(\mathbf{r})]+V_{e-e}[n(\mathbf{r})]
$$

ou,

$$
E_{e}[n(\mathbf{r})]=\int d^{3} r n(\mathbf{r}) V_{n-e}(\mathbf{r})+F_{H K}[n(\mathbf{r})],
$$

onde $F_{H K}[n(\mathbf{r})]=T_{e}[n(\mathbf{r})]+V_{e-e}[n(\mathbf{r})]$ corresponde ao funcional de $\mathrm{HK}$, que agrupa os termos de energia eletrônicos e é sempre o mesmo para qualquer sistema de elétrons. Além disso, o número total de elétrons também fica determinado pela densidade,

$$
N=\int d^{3} r n(\mathbf{r})
$$

Do segundo teorema, segue que há uma condição de minimização para o funcional de energia, $\delta E_{e}[n(\mathbf{r})]=0$, que precisa ser satisfeita para se obter a densidade eletrônica do estado fundamental, obedecendo o vínculo imposto pela equação 2.2.17. Utilizando o método 
de multiplicadores de Lagrange para incluir esse vínculo na condição de minimização, esta se torna

$$
\delta\left[E_{e}[n(\mathbf{r})]-\mu\left(\int d^{3} r n(\mathbf{r})-N\right)\right]=0,
$$

onde $\mu$ é o multiplicador de Lagrange associado ao vínculo. A equação acima leva à equação de Euler-Lagrange dada por

$$
\frac{\delta E_{e}[n(\mathbf{r})]}{\delta n(\mathbf{r})}=V_{n-e}(\mathbf{r})+\frac{\delta F_{H K}[n(\mathbf{r})]}{\delta n(\mathbf{r})}=\mu
$$

que é a equação que fundamenta a DFT. Essa formulação matemática é exata e torna a densidade eletrônica a variável fundamental. Porém, os teoremas não fornecem uma prescrição da forma exata do funcional $F_{H K}[n(\mathbf{r})]$, que é difícil de ser determinado devido aos efeitos de troca e correlação eletrônica oriundos do acoplamento entre os elétrons. O método de Kohn-Sham aborda esse problema e fornece uma maneira prática de determinar o funcional de HK.

\subsubsection{Método de Kohn-Sham}

Uma das dificuldades para determinar o funcional $F_{H K}[n(\mathbf{r})]$ reside no fato de não existir uma maneira exata de escrever a energia cinética dos elétrons interagentes, $T_{e}[n(\mathbf{r})]$, como funcional da densidade eletrônica. Todavia, é simples determinar a energia cinética de um sistema de elétrons não interagentes a partir de sua função de onda, caso esta for conhecida. A proposta de Kohn e Sham (KS) (82) consiste em abordar o problema de elétrons interagentes utilizando um sistema de elétrons não interagentes, que não possui interações eletrostáticas entre os elétrons, e cuja densidade eletrônica é idêntica à densidade do sistema original. No método de $\mathrm{KS}$, o funcional de energia total é escrito como

$$
E_{e}[n(\mathbf{r})]=T_{0}[n(\mathbf{r})]+V_{n-e}[n(\mathbf{r})]+V_{e-e}[n(\mathbf{r})]+E_{x c}[n(\mathbf{r})]
$$

onde $T_{0}[n(\mathbf{r})]$ é a energia do sistema não interagente, $V_{n-e}[n(\mathbf{r})]$ é a energia atribuída à interação eletrostática entre elétrons e núcleos, e $V_{e-e}$ corresponde à energia devido à interação eletrostática entre os elétrons. Esta última energia contém uma contribuição energética de autointeração artificial, originária do potencial de Coulomb clássico no qual a densidade eletrônica interage consigo mesma. O termo $E_{x c}[n(\mathbf{r})]$, denominado funcional de troca e correlação, inclui todas as contribuições energéticas que não estão explícitas na equação 2.2.20 e são necessárias para que o sistema não interagente possua a mesma densidade eletrônica do sistema interagente. Esse funcional contém a energia de troca eletrônica, energia de correlação eletrônica, 
correção para a autointeração eletrostática, e correção para a energia cinética devido ao erro que se comete ao considerar a energia cinética do sistema interagente como a de um sistema não interagente.

As funções de onda dos elétrons do sistema não interagentes são denominadas orbitais de $\mathrm{KS}, \phi_{i}^{K S}(\mathbf{r})$, e obedecem à condição de ortonormalidade,

$$
\int d^{3} r \phi_{i}^{K S *}(\mathbf{r}) \phi_{j}^{K S}(\mathbf{r})=\delta_{i j}
$$

onde $\delta_{i j}$ é a função delta de Kronecker, sendo a relação entre os orbitais de KS e a densidade eletrônica dada por

$$
n(\mathbf{r})=\sum_{i}^{N}\left|\phi_{i}^{K S}(\mathbf{r})\right|^{2} .
$$

Segue do primeiro teorema de HK que os orbitais de KS dependem implicitamente da densidade eletrônica. Portanto, para determinar os orbitais associados à densidade eletrônica do estado fundamental, segue do segundo teorema de HK que é preciso minimizar o funcional de energia total dado pela equação 2.2.20 em relação aos orbitais de KS, considerando os vínculos dados pela equação 2.2.21. Empregando mais uma vez o método de multiplicadores de Lagrange, a condição de minimização fica expressa por

$$
\delta\left[E_{e}[n(\mathbf{r})]-\sum_{i}^{N} \epsilon_{i}^{K S}\left(\int d^{3} r \phi_{i}^{K S *}(\mathbf{r}) \phi_{i}^{K S}(\mathbf{r})-1\right)\right]=0,
$$

onde $\epsilon_{i}^{K S}$ são os multiplicadores de Lagrange associados aos vínculos. Efetuando as derivadas funcionais, obtém-se um conjunto de equações que devem ser satisfeitas pelos orbitais de KS, denominado equação de KS e dada por

$$
h \phi_{i}^{K S}(\mathbf{r})=\varepsilon_{i}^{K S} \phi_{i}^{K S}(\mathbf{r})
$$

onde $h$ é chamado de Hamiltoniano de $\mathrm{KS}$, um Hamiltoniano mono-eletrônico dado por

$$
h=-\frac{1}{2} \nabla_{i}^{2}+V_{e f f}(\mathbf{r}),
$$

e $V_{\text {eff }}$ é denominado potencial efetivo de $\mathrm{KS}$, escrito como $V_{\text {eff }}[n(\mathbf{r})]=V_{n-e}[n(\mathbf{r})]+$ $V_{e-e}[n(\mathbf{r})]+V_{x c}[n(\mathbf{r})]$. O termo $V_{x c}[n(\mathbf{r})]$ é o potencial de troca e correlação, cuja definição é

$$
V_{x c}[n(\mathbf{r})]=\frac{\delta E_{x c}[n(\mathbf{r})]}{\delta n(\mathbf{r})}
$$

A equação de KS corresponde a um conjunto de equações de Schrödinger de uma partícula, que podem ser resolvidas uma vez conhecido o potencial efetivo de KS. O procedimento 
prático para a determinação da densidade do estado fundamental utilizando a equação de KS é o seguinte: (i) construção de uma densidade inicial que respeita o vínculo $N=\int d^{3} r n(\mathbf{r})$; (ii) construção do potencial efetivo de $\mathrm{KS}, V_{\text {eff }}[n(\mathbf{r})]$, para a densidade inicial proposta; (iii) determinação dos orbitais de KS através da solução da equação de KS; (iv) cálculo da nova densidade usando a equação 2.2.22. Esse procedimento iterativo é autoconsistente, uma vez que o potencial efetivo de KS depende da densidade eletrônica. O cálculo é efetuado por certo um número de passos eletrônicos, até que a diferença entre as duas últimas densidades obtidas satisfaça algum critério de convergência. Quando este critério não é satisfeito, as duas últimas densidades são combinadas a fim de construir uma nova densidade para o próximo passo.

Assim que o cálculo autoconsistente descrito no parágrafo anterior é concluído, é possível utilizar a densidade eletrônica encontrada e os autovalores $\epsilon_{i}^{K S}$ para determinar a energia total do estado fundamental do sistema eletrônico a partir das equações 2.2 .20 e 2.2.24, que fica

$$
E_{e}[n(\mathbf{r})]=\sum_{i=1}^{N} \epsilon_{i}^{K S}-\frac{1}{2} \iint d^{3} r d^{3} r^{\prime} \frac{n(\mathbf{r}) n\left(\mathbf{r}^{\prime}\right)}{\left|\mathbf{r}-\mathbf{r}^{\prime}\right|}+E_{x c}[n]-\int d^{3} r n(\mathbf{r}) V_{x c}[n(\mathbf{r})],
$$

considerando que o funcional de troca e correlação, $E_{x c}[n(\mathbf{r})]$, seja conhecido. Uma vez determinada a energia total do sistema eletrônico, é possível obter a energia total do sistema completo, de $N$ elétrons interagentes e $M$ núcleos fixos, usando a equação

$$
E_{t o t}(\mathbf{R})=\frac{1}{2} \sum_{\alpha=1}^{M} \sum_{\substack{\beta=1 \\ \beta \neq \alpha}}^{M} \frac{Z_{\alpha} Z_{\beta}}{\left|\mathbf{R}_{\alpha}-\mathbf{R}_{\beta}\right|}+E_{e}(\{\mathbf{R}\})
$$

portanto, a SEP sobre a qual os núcleos se movem (equação 2.2.14) fica determinada.

\subsubsection{Funcional de troca e correlação}

O formalismo de KS fornece uma abordagem prática para resolver o problema de um sistema de elétrons interagentes. Em princípio, se uma expressão exata for conhecida para o funcional de troca e correlação, é possível determinar, de maneira exata, a densidade do estado fundamental. O fato é que a energia de troca é conhecida de maneira exata apenas para um gás de elétrons homogêneo, e mesmo nesse caso o termo de correlação só é conhecido dentro de certos limites. Na prática o que se faz é construir aproximações para $E_{x c}[n(\mathbf{r})]$ utilizando conceitos de teorias de muitos corpos, e ao longo dos anos diferentes gerações de funcionais foram desenvolvidas, possibilitando o cálculo de propriedades de diferentes materiais, variando em precisão e custo computacional. É costumeiro separar o funcional de troca e correlação em um termo de troca e outro de correlação, $E_{x c}[n(\mathbf{r})]=E_{x}[n(\mathbf{r})]+E_{c}[n(\mathbf{r})]$, e então construir 
aproximações para cada um dos termos separadamente.

Uma das primeiras aproximações para o funcional de troca e correlação é dada pela aproximação da densidade local (LDA - Local Density Approximation) (84), que aproxima localmente a densidade eletrônica pela densidade do gás de elétrons homogêneo. Funcionais que incluem correções semi-locais de primeira ordem são dados pela aproximação do gradiente generalizado (GGA - Generalized Gradient Generalizado). Dentro dessa aproximação, o funcional de troca e correlação é escrito como

$$
E_{x c}^{G G A}[n(\mathbf{r})]=\int d^{3} r f(n(\mathbf{r}),|\nabla n(\mathbf{r})|)
$$

onde $f(n(\mathbf{r}),|\nabla n(\mathbf{r})|)$ é uma função qualquer da densidade e do seu gradiente. Existem diversas sugestões para esta função, tanto derivadas por primeiros princípios, quanto obtidas por métodos semi-empíricos e contendo parâmetros ajustáveis. Neste trabalho foi empregado o funcional de Perdew, Burke e Ernzerhof, que leva o nome de PBE (85).

No funcional GGA-PBE o funcional de troca é dado por

$$
E_{x}^{P B E}[n(\mathbf{r})]=\int d^{3} r n(\mathbf{r}) \epsilon_{x}^{h o m}(n(\mathbf{r})) F_{x}(s),
$$

onde $\epsilon^{\text {hom }}(n(\mathbf{r}))$ corresponde à densidade de energia de troca exata de um gás de elétrons homogêneo,

$$
\epsilon_{x}^{h o m}(n(\mathbf{r}))=-\frac{3}{4}\left(\frac{3 n(\mathbf{r})}{\pi}\right)^{1 / 3},
$$

e a função $F_{x}(s)$ é definida como

$$
F_{x}(s)=1+\kappa-\frac{\kappa}{1+\frac{\mu}{\kappa} s^{2}}, \quad \mu=\frac{\beta \pi^{2}}{3},
$$

$\operatorname{com} \beta=0.066725, \kappa=0.804$. O termo $s(\mathbf{r})$ corresponde ao gradiente reduzido adimensional, que fornece uma medida da taxa de variação da densidade na escala de comprimento de Fermi local, e é definido como

$$
s(\mathbf{r})=\frac{|\nabla n(\mathbf{r})|}{2 k_{F} n(\mathbf{r})},
$$

onde $k_{F}$ é o número de onda de Fermi, dado por $k_{F}=\left[3 \pi^{2} n(\mathbf{r})\right]^{1 / 3}$.

O funcional de correlação é dado por

$$
E_{c}^{P B E}[n(\mathbf{r})]=\int d^{3} r n(\mathbf{r})\left[\epsilon_{c}^{h o m}\left(r_{s}\right)+H_{c}\left(r_{s}, t\right)\right]
$$

onde $\epsilon_{c}^{\text {hom }}$ é uma aproximação para a densidade de energia de correlação do gás de elétrons 
homogêneo, para a qual é empregada a fórmula de Perdew e Wang (84),

$$
\epsilon_{c}^{\text {hom }}\left(r_{s}\right)=-2 A_{1}\left(1+A_{2} r_{s}\right) \ln \left(1+\frac{1}{2 A_{1} F\left(r_{s}\right)}\right)
$$

sendo $r_{s}$ o raio de Wigner-Seitz, definido como $r_{s}=\left(\frac{3}{4 \pi n}\right)^{1 / 3}$, e

$$
F\left(r_{s}\right)=B_{1} r_{s}^{1 / 2}+B_{2} r_{s}+B_{3} r_{s}^{3 / 2}+B_{4} r_{s}^{2}
$$

onde os parâmetros $A_{1}, B_{1}$ e $B_{2}$ são escolhidos de modo a reproduzir a correlação do gás de elétrons homogêneo no limite de altas densidades, para o qual existe uma expressão exata, e $A_{2}, B_{3}$ e $B_{4}$ são ajustados de modo a proporcionar o melhor fit para resultados numéricos do limite de baixas densidades. O termo $H_{c}\left(r_{s}, t\right)$ na equação 2.2.34 é definido como

$$
H_{c}\left(r_{s}, t\right)=\gamma \ln \left[1+\frac{\beta}{\gamma} t^{2}\left(\frac{1+A t^{2}}{1+A t^{2}+A^{2} t^{4}}\right)\right]
$$

onde

$$
\gamma=\frac{1-\ln 2}{\pi^{2}}, \quad A\left(r_{s}\right)=\frac{\beta}{\gamma}\left(\gamma e^{-\epsilon_{c}^{h o m} / \gamma}-1\right)^{-1}, \quad t(\mathbf{r})=\frac{|\nabla n(\mathbf{r})|}{2 k_{s} n(\mathbf{r})}, \quad k_{s}=\sqrt{\frac{4 k_{f}}{\pi}} .
$$

\subsubsection{Funções de base}

A maneira usual de resolver a equação de $\mathrm{KS}$ em softwares de estrutura eletrônica é expandir os orbitais $\phi_{i}^{K S}$ em um conjunto finito de funções de base conhecidas que seja suficiente para representar os orbitais dentro de uma precisão desejada, isto é,

$$
\phi_{i}^{K S}(\mathbf{r})=\sum_{j} c_{i j} \varphi_{j}(\mathbf{r})
$$

Inserindo o ansatz dado pela equação 2.2.39 na equação 2.2.24 e multiplicando a equação resultante por $\varphi_{i}$, obtém-se um problema geral de autovalor para os coeficientes da expansão, dado por

$$
\sum_{j} h_{i j} c_{j l}=\epsilon_{l} \sum_{j} s_{i j} c_{j l}
$$

onde $h_{i j}=\left\langle\varphi_{i}|\hat{h}| \varphi_{j}\right\rangle$ é o elemento de matriz do Hamiltoniano de $\mathrm{KS}$, e $s_{i j}=\left\langle\varphi_{i} \mid \varphi_{j}\right\rangle$ é o elemento da matriz de sobreposição.

Neste trabalho o software utilizado para cálculos DFT é o pacote FHI-aims (86), que utiliza como funções de base um conjunto de orbitais numéricos centrados nos átomos (NAO 
- numeric atomic-centered orbitals), que assumem o seguinte formato

$$
\varphi_{i}(\mathbf{r})=\frac{u_{i}(r)}{r} Y_{l m}(\vartheta, \phi)
$$

onde o termo radial, $u_{i}(r)$ é tabelado numericamente e $Y_{l m}(\vartheta, \phi)$ são harmônicos esféricos.

Em códigos de estrutura eletrônica que tratam todos os elétrons explicitamente (all electron), como é o caso do FHI-aims, o uso de NAOs traz uma série de vantagens. Uma delas é que ao utilizar uma base mínima de NAO que é exata para átomos livres, o formato dos orbitais nas proximidades do núcleo é bem descrito mesmo para sistemas de átomos ligados. Outra vantagem é que as funções radiais podem ser localizadas por um potencial de confinamento, permitindo que o algoritmo computacional tenha uma complexidade próxima de $O(N)$. As funções radiais $u_{i}(r)$ obedecem uma equação análoga à equação de Schrödinger, dada por

$$
\left[-\frac{1}{2} \frac{d^{2}}{d r^{2}}+\frac{l(l+1)}{r^{2}}+v_{i}(r)+v_{c u t}(r)\right] u_{i}(r)=\epsilon_{i} u_{i}(r),
$$

onde $v_{i}(r)$ é o potencial que dá a forma da função radial, e $v_{c u t}(r)$ é o potencial de confinamento, o qual garante um decaimento suave para zero das funções de base e suas derivadas.

No pacote $\mathrm{FHI}$-aims, as funções de base a serem utilizadas, bem como as propriedades dos potenciais $v_{i}$ e $v_{c u t}$, podem ser definidas pelo usuário durante a configuração de um cálculo DFT. Neste trabalho são utilizados dois conjuntos de funções de base padrões do FHI-aims, denominados light e tight. Mais detalhes sobre suas parametrizações podem ser encontradas na literatura $(86,87)$.

\subsection{Características da superfície de energia potencial}

Como é possível notar pelas seções anteriores, mesmo para sistemas simples, contendo um número relativamente pequeno de átomos e elétrons, a SEP é um objeto complexo, uma vez que busca descrever as interações entre todos os átomos do sistema, incluindo tanto interações de curto alcance quanto longo alcance. No restante desta seção é feita uma discussão das principais maneiras de caracterizar uma SEP e suas propriedades.

Através da SEP é possível determinar um grande número de propriedades estruturais, dinâmicas e termodinâmicas relativas ao sistema correspondente (37). Metologias que visam determinar tais propriedades usualmente focam-se na análise dos pontos estacionários da SEP, nos quais as forças atuando sobre os átomos se anulam, sendo os pontos estacionários de 
maior interesse aqueles que correspondem aos mínimos locais. Configurações mecanicamente estáveis correspondem a pontos de mínimo local, nos quais perturbações na configuração do sistema fazem com que a energia total aumente.

Um conceito importante relacionado aos pontos estacionários é o de caminho de descida mais ingrime (SDP - steepest descent path). Partindo de uma configuração qualquer, um SDP é definido como o caminho que se obtém movendo-se de forma descendente na SEP, seguindo a direção da força total em cada ponto até que o gradiente da energia se anule. O caminho resultante na SEP é definido de forma única, e cada ponto do espaço de configurações com gradiente não nulo pertence a exatamente um só caminho. O conjunto de pontos da SEP que possuem um SDP levando a um mesmo mínimo local é definido como um basin de atração. Configurações que pertencem ao mesmo basin de atração são aquelas que quando relaxadas localmente resultarão na mesma estrutura de mínimo local. Uma vez que os SDP são únicos, diferentes basins não se sobrepõe e definem regiões de alcance dos mínimos locais.

Outros pontos estacionários de interesse da SEP são os que correspondem à estruturas de transição, associados aos pontos cela da superfície, também chamados de estados de transição. Um caminho conectando dois mínimos locais sobre o qual a energia é minimizada em relação a outros possíveis caminhos é definido como um conjunto de pontos de transição, ou um caminho de transição, e este sempre cruza um ponto de cela da SEP. A partir de um estado de transição, localizado em um ponto de cela com gradiente nulo, partem dois SDPs em direções opostas, cada qual levando a um dos mínimos locais conectados pelo caminho de transição.

Uma das principais dificuldades envolvidas no estudo de uma SEP é que seu número de pontos estacionários cresce exponencialmente conforme o número de átomos aumenta (35$37,88)$. Por essa razão, a tarefa de explorar a SEP é custosa, seja ela em busca do mínimo global, seja com o intuito de enumerar mínimos locais e caminhos de transição. Assim, metodologias eficientes de otimização, em especial otimização global, possuem importância fundamental do ponto de vista de compreender o comportamento de sistemas atômicos.

Na figura 2.1 é exibida uma região de uma SEP hipotética para um sistema com duas coordenadas livres, com alguns dos mínimos locais denotados pelas letras de $\mathrm{A}$ a $\mathrm{F}$ na projeção das curvas de nível. O mínimo A é um mínimo global, enquanto os pontos conectando os mínimos locais $\mathrm{D}$ e $\mathrm{E}$ correspondem a um caminho de transição. Convém notar que a SEP ilustrada na figura é mais simples que uma SEP real, na qual geralmente há muitas enrugações e uma maior quantidade de mínimos locais caminhos de transição.

As propriedades termodinâmicas de equilíbrio podem ser determinadas localmente para isômeros correspondendo a mínimos locais, ou através de médias globais no ensemble defi- 
nido pela SEP, levando em conta as energias relativas dos mínimos e volumes de espaços de configurações localizados nas proximidades dos mínimos. Os mínimos locais podem, ainda, serem tratados como mínimos de energia livre, permitindo que funções de partição sejam modeladas para cada um deles com o uso de densidades estados harmônicas ou outras aproximações (37). As conexões entre os mínimos, determinadas pelos caminhos de transição, são relevantes quando o objetivo é estudar a dinâmica do sistema, como taxas de reações e condições que permitem transições entre diferentes isômeros (89). De maneira geral, é possível caracterizar a SEP e extrair informações relevantes utilizando apenas os seus pontos estacionários. Analisar propriedades estruturais, termodinâmicas e dinâmicas de um sistema em termos dos mínimos locais e estados de transição equivale a reduzir a exploração da SEP a um problema de otimização, no qual o objetivo é encontrar os mínimos e pontos de cela $(1,3)$.

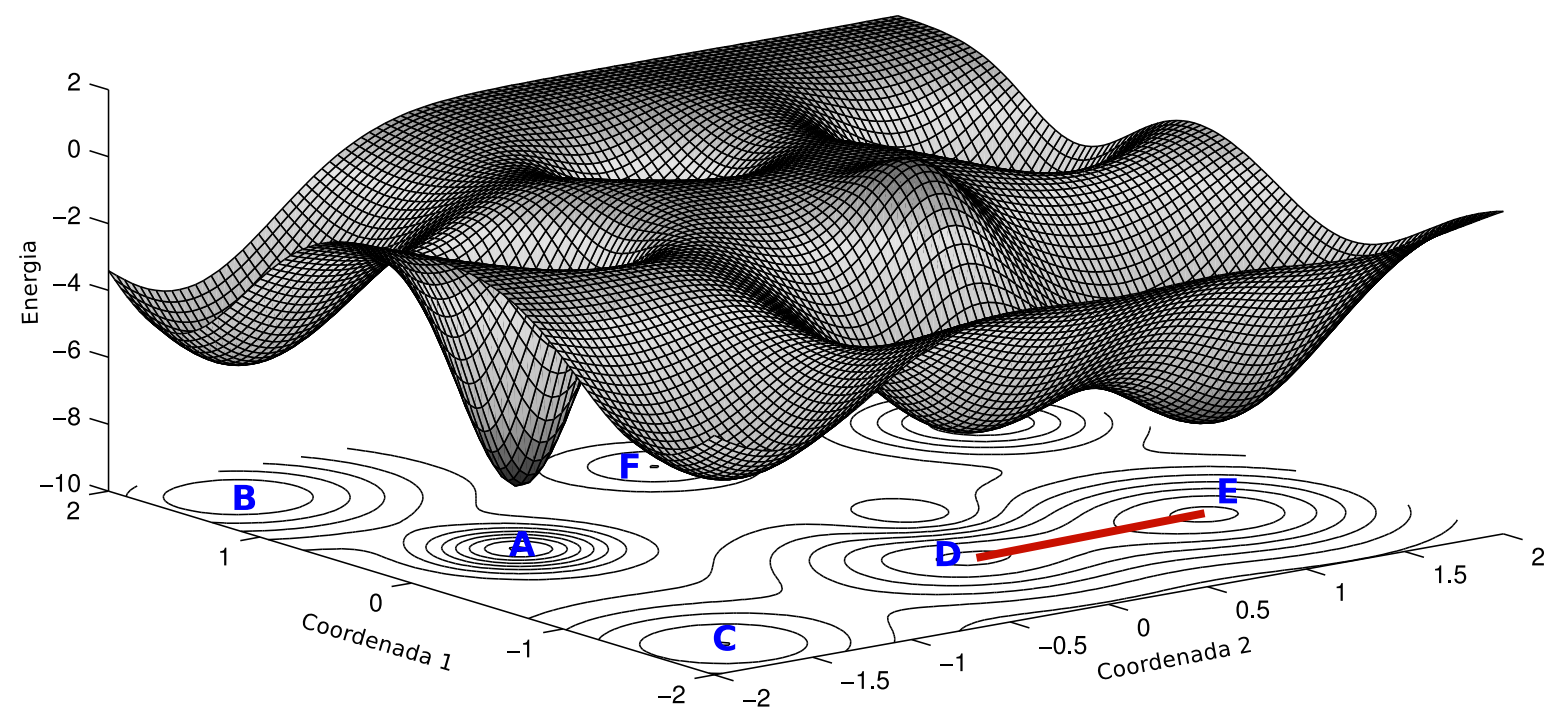

Figura 2.1 - Região de uma superfície de energia potencial hipotética para um sistema com dois graus de liberdade. Alguns dos mínimos locais estão marcados com letras de $A$ a $F$, sendo A o mínimo global, e a linha conectando os mínimos D e E representando um caminho de transição. As coordenadas e energia são dadas em unidades arbitrárias.

\subsection{Topologia da superfície de energia potencial}

O estudo da topologia da SEP é importante pois técnicas de visualização tradicionais (e.g., um gráfico) são impraticáveis para funções que dependem de um grande número de variáveis. Uma vez que os pontos estacionários da SEP fornecem informações acerca do comportamento do sistema, é comum definir a topologia da superfície em termos destes pontos. Destacam- 
se duas abordagens complementares, sequências monotônicas e grafos de desconectividade, ambas envolvendo a identificação de mínimos locais conectados por caminhos de transição.

\subsubsection{Sequências monotônicas}

Este conceito foi introduzido por Kunz e Berry $(90,91)$, e uma sequência monotônica é definida como um conjunto ordenado de mínimos locais conectados por caminhos de transição, cujas energias decrescem monotonicamente. Assim, uma sequência monotônica pode ser vista como um caminho passando por diversos mínimos locais de uma região e terminando em um mínimo relativamente profundo. Um grupo de sequências monotônicas que terminam no mesmo mínimo local é denominado funil ou região de alcance daquele mínimo. Uma sequência monotônica que termina no mínimo global é denominada primária, e um grupo de sequências primárias é denominado funil primário ou região de alcance do mínimo global. Além disso, uma determinada configuração pode pertencer a múltiplos funis, diferente do que ocorre no caso de basins. Exemplos de sequências monotônicas e funis podem ser vistos na figura 2.2.

A otimização global de uma SEP é facilitada quando o sistema em questão apresenta um único funil convergindo para o mínimo global, uma vez que a topologia da superfície favorece a relaxação para este mínimo. Em contraste com este cenário, a busca pelo mínimo global em uma SEP que apresenta múltiplos funis possui dificuldades inerentes. Nesse caso, as chances de sucesso são maiores quando a exploração finalmente atinge o funil primário, todavia, caso a busca esteja confinada a outro funil, as chances de atingir o funil primário são pequenas pois requer a necessidade de a transpôr altas barreiras de energia. Tomando o exemplo da figura 2.2 e considerando a exploração concentrada no funil $\mathrm{C}$, a fim de explorar o funil primário $A$ é necessário sobrepor a barreira de energia separando os funis $B$ e $C$, e então a barreira separando A e B.

Sequências monotônicas permitiram que fossem obtidas as primeiras evidências sobre como sistemas distintos relaxam para o mínimo global a partir de uma configuração de alta energia. Utilizando o método simulated annealing para identificar e enumerar pontos estacionário da SEP, Ball et al. (92) construíram sequências monotônicas para os clusters $\operatorname{Ar}_{19}$ e $(\mathrm{KCl})_{32}$ descritos pelo potencial de LJ. Para o sistema $\mathrm{Ar}_{19}$ verificou-se que que uma taxa de resfriamento de $10^{9} \mathrm{~K} / \mathrm{s}$ faz com que a busca fique aprisionada em um mínimo local na maior parte das simulações, o que indica que esta taxa é muito elevada para simular com precisão a relaxação. Em contrapartida, para o cluster $(\mathrm{KCl})_{32}$ foi possível encontrar o mínimo global mesmo com uma taxa de $10^{12} \mathrm{~K} / \mathrm{s}$. Através das sequências monotônicas determinou-se que na região de alcance do mínimo global para da SEP do cluster $\operatorname{Ar}_{19}$ existem mínimos locais profundos, 
separados do mínimo global por altas barreiras energéticas, o que explica o aprisionamento da busca. Já as sequências do sistema $(\mathrm{KCl})_{32}$ revelam que os mínimos locais estão separados por barreiras de energia pequenas, mais fácies de serem transpostas, permitindo assim que o sistema atinja o mínimo global mesmo com uma elevada taxa de resfriamento na simulação.

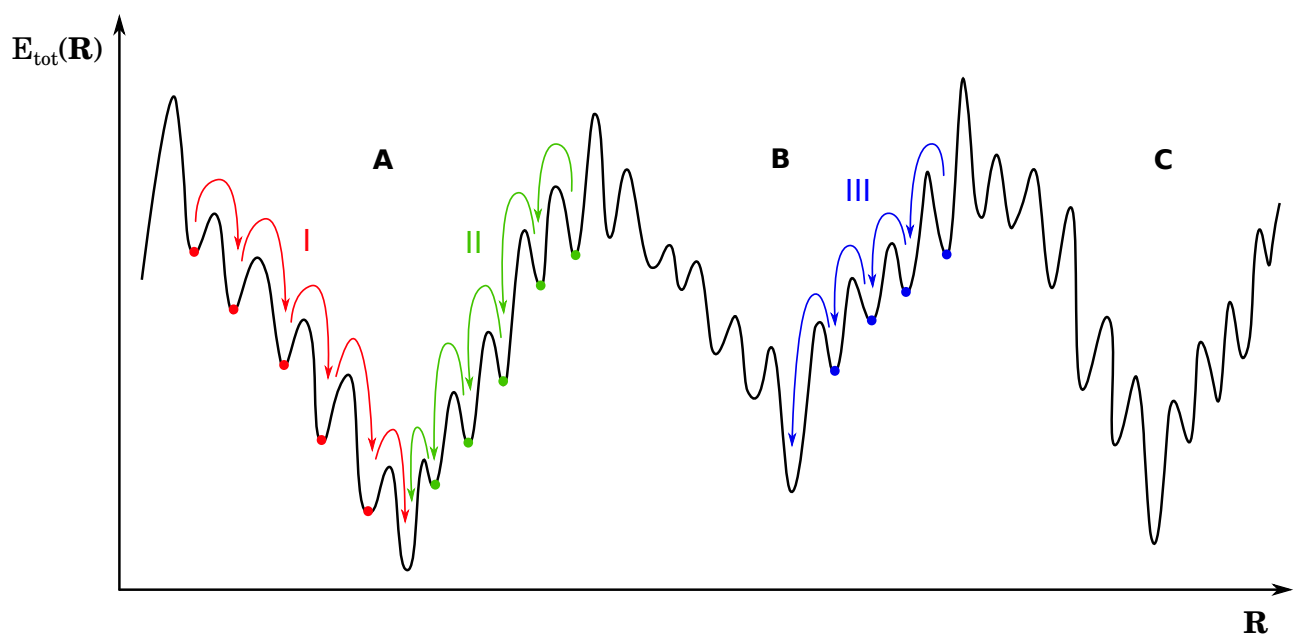

Figura 2.2 - Região de uma SEP contendo múltiplos funis, marcados como A, B e C. Três sequências monotônicas são exibidas, I, II e III, e os mínimos locais pertencentes a cada sequência estão denotados com suas respectivas cores. As sequências I e II pertencem ao funil primário.

\subsubsection{Grafos de desconectividade}

Uma maneira alternativa de descrever a topologia global da SEP é a abordagem de grafos de desconectividade, proposta originalmente por Becker e Karplus (93) e amplamente explorada por Wales e colaboradores $(1,3,94-97)$. A vantagem deste método em relação à sequências monotônicas reside no fato deste permitir que as conexões entre os mínimos locais sejam visualizadas com maior facilidade. Para construir um grafo de desconectividade é necessário construir um banco de dados de mínimos locais e estados de transição que os conectam. Para sistemas grandes é impraticável incluir todos os possíveis mínimos locais neste banco de dados, porém é possível utilizar apenas um subconjunto representativo que preserva as principais características da SEP (1).

$\mathrm{Na}$ construção de um grafo de desconectividade, dada uma energia $E_{\alpha}$, os mínimos locais situados abaixo de $E_{\alpha}$ podem estar associados a diferentes superbasins. Dois mínimos pertencentes ao mesmo superbasin podem ser conectados por caminhos de transição que não excedem a energia $E_{\alpha}$, enquanto caminhos conectando mínimos de diferentes superbasins necessariamente passam por um estado de transição com energia superior a $E_{\alpha}$. Se dois mínimo 
locais podem ser conectados por mais de um caminho de transição, apenas o caminho de menor energia é levado em consideração, pois este determina a energia mínima que torna os mínimos mutuamente acessíveis. Para $E_{\alpha}$ correspondendo à energia mais baixa da SEP existe apenas um superbasin, que inclui apenas o mínimo global. Para energias sucessivamente mais altas, um número maior de superbasins é observado à medida que mais mínimos locais são alcançados. Conforme $E_{\alpha}$ se torna grande o suficiente para ultrapassar altas barreiras de energia, os superbasins se unem, até que para uma determinada energia é possível definir um único superbasin contendo todos os mínimos locais da SEP.

Esta análise introduz uma escala de energia dada por diferentes valores $E_{\alpha}$ que separam a SEP em vários níveis de superbasins. O grafo de desconectividade é construído analisando os superbasins para um conjunto de valores de $E_{\alpha}$, e.g., $E_{1}<E_{2}<E_{3}<\ldots<E_{n}$, no qual $E_{1}$ é a energia que define o superbasin contendo o mínimo global e $E_{n}$ define o superbasin contendo todos os mínimos locais. O eixo vertical do grafo é associado à energia, com valores decrescentes de cima para baixo, e cada superbasin definido pela energia $E_{\alpha}$ $(\alpha=1,2,3, \ldots, n)$ é associado a um nó ou vértice do grafo. Nós associados a superbasins de energia $E_{\alpha}$ são tratados como nós filhos do nó correspondente ao superbasin de energia $E_{\alpha+1}$ $\left(E_{\alpha}<E_{\alpha+1}\right)$, e conectados a este através de arestas. Uma vantagem deste tipo de grafo é que o comprimento das arestas na direção vertical está diretamente relacionado à profundidade ou magnitude das barreiras de energia separando diferentes mínimos locais, permitindo assim que as características topológicas da SEP sejam distinguidas com maior clareza.
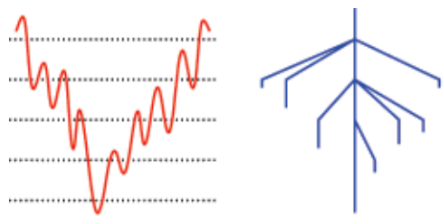

(a)

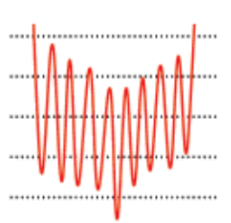

(b)

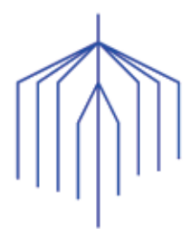

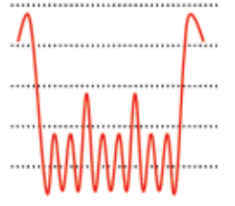

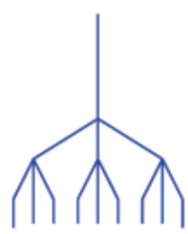

(c)

Figura 2.3 - Exemplos de superfícies de energia potencial (em vermelho) e respectivos grafos de desconectividade (em azul). Figura publicada originalmente por Wales e Bogdan (1).

A figura 2.3 ilustra três diferentes cenários, cada um com uma representação da SEP e do respectivo grafo de desconectividade gerado para cinco valores de energia, denotados pelas linhas pontilhadas. Na figura 2.3-(a) a SEP é composta por um único funil ingrime com um mínimo global bem definido e as barreiras de energia associadas às transições para mínimos de menor energia são relativamente baixas. A SEP da figura 2.3-(b) apresenta ainda um único funil associado a um mínimo global bem definido, contudo, este funil é mais suave que no caso 
(a), e as barreiras de energia são maiores. Já a figura 2.3-(c), por sua vez, oferece um cenário diferente dos outros dois, caracterizado por diversos mínimos locais de energias comparáveis e duas ou mais escalas de energia distintas definindo barreiras entre eles, e portanto possui uma estrutura hierárquica mais enrugada e diferenciada das outras duas.

Os cenários ilustrados na figura 2.3 apresentam diferentes graus de dificuldade em relação à otimização global. Na situação (a), como as barreiras de energia são pequenas, verifica-se uma relaxação eficiente para o mínimo global para um intervalo grande de temperaturas, e métodos de otimização global não teriam grandes dificuldades em encontrar a estrutura de mínimo global. A relaxação no cenário (b) requer temperaturas maiores em relação ao (a), pois as barreiras de energia são mais acentuadas. No cenário (c) o mínimo global é mais difícil de ser atingido pois há uma competição entre os diversos mínimos locais de baixas energias, e é a situação que apresenta maiores desafios para os métodos de otimização global. Em geral, a busca pelo mínimo global é mais difícil para casos em que o mínimo global reside em um funil separado por altas barreiras de energia de outros funis da SEP. Tal situação pode ser visualizada ao considerar os dois picos centrais mais acentuados da figura 2.3-(c) como tendo maiores energias, separando assim a SEP em três regiões.

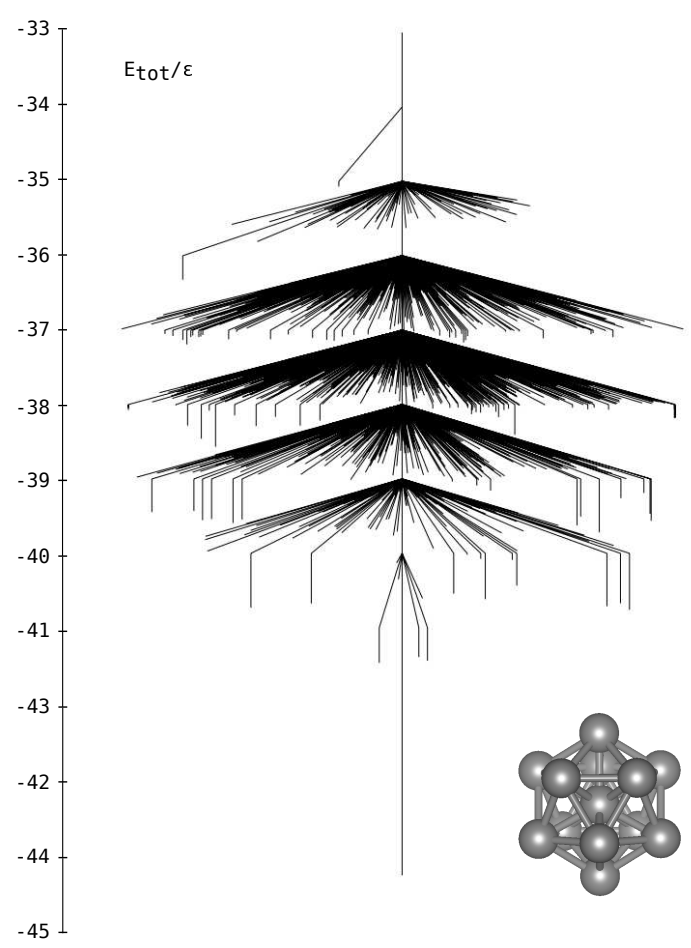

Figura 2.4 - Grafo de desconectividade para o sistema $L_{13}$ incluindo 1467 mínimos locais distintos. Energias dadas em unidades de $\epsilon$, a profundidade do poço de energia do potencial de Lennard-Jones. A estrutura de mínimo global é ilustrada. Figura adaptada das referências $(2,3)$. 
Na figura 2.4 é mostrado o grafo de desconectividade para o cluster $L J_{13}$. Nesse exemplo é possível notar que o funil primário, associado ao mínimo global, representa a região dominante da SEP, e que as barreiras de energia entre diferentes superbasins são relativamente pequenas, o que justifica o baixo grau de dificuldade em encontrar a estrutura de mínimo global para esse sistema. Esta situação é análoga ao caso apresentado na figura 2.3-(a).

\subsection{Paradoxo de Levinthal}

Dada a dependência exponencial do número de mínimos de um SEP com o número de graus de liberdade do sistema, pode-se concluir que uma cadeia de peptídeos ao se enovelar em uma proteína possui uma enorme quantidade de conformações estáveis possíveis. Este fato levou Cyrus Levinthal (98) a observar que se o enovelamento de uma proteína ocorresse de forma aleatória, na qual mínimos correspondentes à conformações estáveis fossem visitados sequencialmente com a mesma probabilidade durante a relaxação natural do sistema, então o processo demoraria um tempo muito longo, estimado mais longo que a idade do universo. Na realidade, porém, verifica-se que uma proteína atinge sua configuração enovelada de maior estabilidade em uma escala de tempo de microsegundos. Esta contradição é conhecida como paradoxo de Levinthal, e se aplica igualmente a sistemas cujo número de graus de liberdade da SEP implique em uma grande quantidade de mínimos locais, incluindo clusters e NPs (99).

Muitas argumentações foram propostas para tentar resolver este paradoxo (100-102) e uma delas em especial apresenta grande aceitação por ser simples e intuitiva, sendo baseada na análise topológica de SEPs. A topologia da SEP sugere que a relaxação para o mínimo global não é aleatória, pois as conformações possíveis possuem diferentes pesos estatísticos no ensemble termodinâmico, e também porque as conformações não estão dispostas de maneira aleatória no espaço de configurações (103). A observação de Levinthal assume, incorretamente, que a SEP é achatada, como um campo de golfe no qual um dos buracos corresponde ao estado nativo da proteína, i.e., o mínimo global (104). Uma análise detalhada da SEP, porém, revela que a organização em diferentes funis impõe uma topologia similar a vales e montanhas, com uma tendência de relaxação para o mínimo global, ou um bias energético. Uma vez que o processo de relaxação passe a acontecer dentro de um dos funis dominantes da SEP, o sistema segue caminhos bem definidos que buscam reduzir a energia total, passando por um número reduzido de mínimos locais até que atinja a região de mais baixa energia do funil.

Através de modelos simples que incorporam este bias energético é possível demonstrar 
que o tempo de relaxação reduz-se a escalas com maior significado físico, resolvendo-se assim o paradoxo de Levinthal $(105,106)$. Além disso, essa argumentação baseada em topologia sugere que um método de otimização global eficiente não pode fazer uma busca completamente aleatória no espaço de configurações, mas sim priorizar regiões em que há uma tendência energética em direção do mínimo global através da introdução de algum tipo de inteligência na busca. 


\section{CAPÍTULO 3}

\section{Método Basin-Hopping Monte Carlo Revisado}

Neste capítulo é apresentada uma revisão do método BHMC padrão aplicado à clusters e NPs, o qual constitui a base da metodologia desenvolvida neste trabalho, o método RBHMC, apresentado em seguida.

\subsection{Método Basin-Hopping Monte Carlo padrão}

O método BHMC pertence à classe de técnicas de transformação de superfície, na qual a SEP sofre transformações com objetivo de tornar sua exploração global mais simples $(37,50$, 103). Essas técnicas incluem suavização da SEP, redução do número de mínimos locais e dos estados de transição. Diferente da maioria das técnicas dessa classe, porém, a transformação da SEP realizada no método BHMC não altera a posição dos mínimos locais, e consequentemente, a posição do mínimo global, não sendo necessário empregar um procedimento para mapear a superfície transformada de volta para a original, uma tarefa que nem sempre é fácil de ser realizada (50).

No método BHMC a SEP, $E_{\text {tot }}(\mathbf{R})$, é transformada através do mapeamento de cada um dos seus pontos sobre um mínimo local, realizado por métodos de minimização local. Essa transformação dá origem a uma nova SEP, definida como

$$
\tilde{E}_{\text {tot }}(\mathbf{R})=\min \left(E_{\text {tot }}(\mathbf{R})\right)
$$

onde 'min' representa a minimização local. Esse procedimento mapeia a superfície original em uma definida pelos basins de atração, que particionam todo o espaço de configurações e não se sobrepõe, e portanto fazem com que a SEP transformada assuma a topologia de um conjunto de platôs localizados nos níveis dos mínimos locais da SEP original. Dessa maneira, 
o mínimo global da SEP transformada tem a mesma energia que o mínimo global da SEP original, portanto ao invés de realizar a otimização global de $E_{\text {tot }}(\mathbf{R})$, é possível otimizar $\tilde{E}_{\text {tot }}(\mathbf{R})$, uma tarefa mais simples pois o número de estruturas possíveis na SEP transformada é menor que na original. Além disso, a transformação da SEP elimina barreiras de energia para transições de mínimos de menor energia, facilitando a exploração da SEP e acelerando a dinâmica do sistema. A figura 3.1 ilustra o efeito da transformação da SEP realizada no método BHMC.

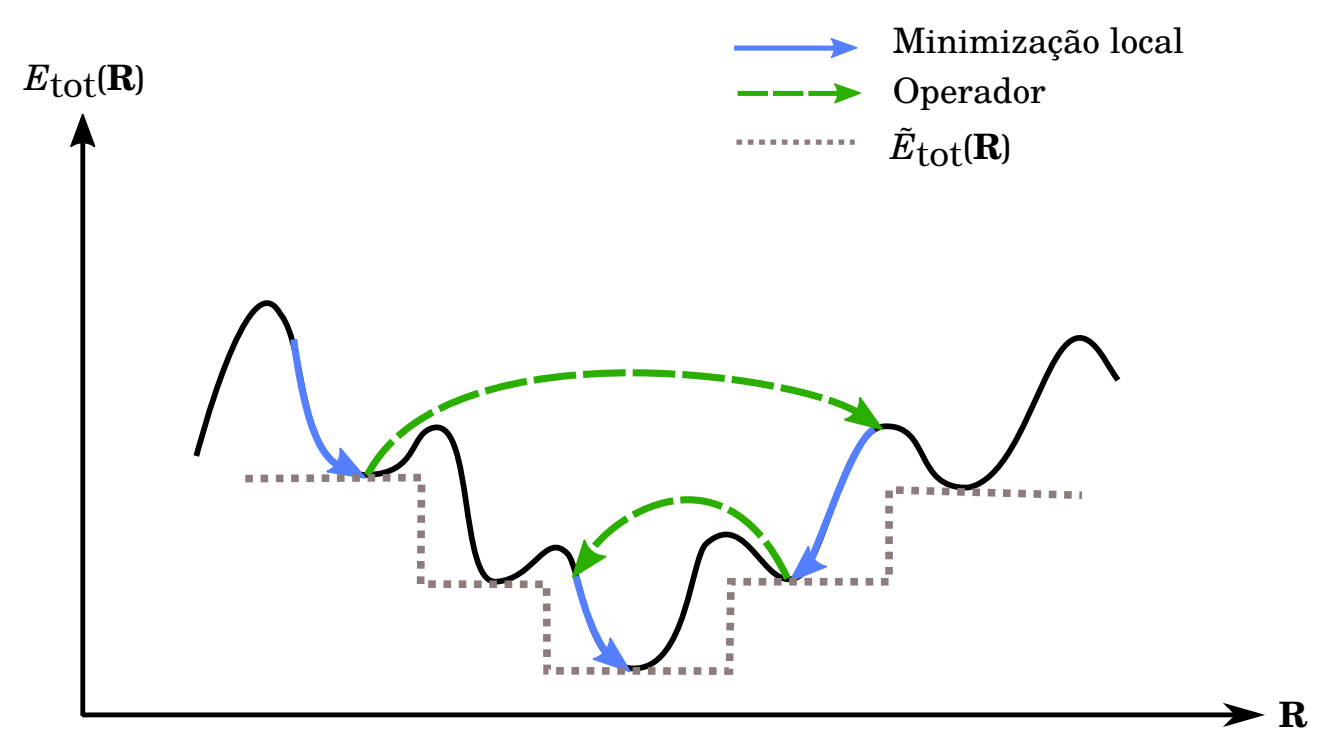

Figura 3.1 - Método BHMC padrão.

No método BHMC a exploração da SEP é realizada através de um processo de amostragem Monte Carlo. Uma estrutura inicial é gerada aleatoriamente e então suas coordenadas são minimizadas localmente, correspondendo portanto a um mínimo local aleatório da SEP modificada. A cada passo do método BHMC, a configuração atual, $\mathbf{R}$, é perturbada e uma nova configuração, $\mathbf{R}^{\prime}$, é gerada e minimizada localmente. Essa perturbação se dá através da aplicação de um operador que realiza deslocamentos aleatórios nos átomos em torno das suas posições atuais, e tem como objetivo mover a busca de um mínimo local para outro. A nova configuração, $\mathbf{R}^{\prime}$, é aceita segundo o critério de Metropolis. Sendo $E=E(\mathbf{R})$ a energia da configuração atual, e $E^{\prime}=E\left(\mathbf{R}^{\prime}\right)$ a energia da nova configuração, a configuração $\mathbf{R}^{\prime}$ é aceita pelo critério de Metropolis caso $E^{\prime} \leq E$. Caso $E^{\prime}>E$, então a nova configuração é aceita com probabilidade $\exp \left(-\Delta E / k_{B} T\right)$, onde $\Delta E=E^{\prime}-E, k_{B}$ é a constante de Boltzmann, e $T$ é a temperatura de amostragem do processo de Monte Carlo. Quando uma nova configuração é aceita ela se torna a configuração atual, i.e., $\mathbf{R}=\mathbf{R}^{\prime}$, e a busca continua a partir do ponto $\mathbf{R}^{\prime}$ na SEP. Em caso de rejeição, a estrutura $\mathbf{R}^{\prime}$ é descartada e a exploração continua a partir de $\mathbf{R}$. 
As implementações do método BHMC padrão usualmente empregam apenas o operador de deslocamentos descrito acima, porém é possível introduzir mais operadores que aumentam as chances de sucesso do método em encontrar o mínimo global, uma vez que aumentam a mobilidade sobre a SEP, sendo esta uma das contribuições do presente trabalho. É importante destacar que o procedimento de mapeamento da SEP dado pela equação 3.1.1 é aplicado somente às configurações visitadas durante a busca, e não à SEP como um todo, porém do ponto de vista de busca, é como se toda a SEP fosse transformada.

Devido à transformação da SEP em um conjunto de basins de atração, os deslocamentos realizados no método BHMC são consideravelmente maiores que os deslocamentos utilizados no método Monte Carlo tradicional (50), uma vez que pequenos deslocamentos resultarão em novas configurações que, ao serem minimizadas localmente, corresponderão ao mesmo basin de atração da configuração original. Esses deslocamentos de maior magnitude seriam impossíveis no método de Monte Carlo tradicional, onde é preciso manter o sistema em uma situação de quase-equilíbrio para que não ocorra a violação do balanceamento detalhado e das condições da hipótese ergódica. No método BHMC visando otimização global, porém, o objetivo não é fazer uma amostragem estatística a fim de calcular médias termodinâmicas do sistema, mas sim encontrar o mínimo global da SEP.

Para fins de exploração, a temperatura presente no critério de Metropolis é um parâmetro artificial, responsável por controlar a busca segundo o método de Monte Carlo. Apesar disso, uma escolha ótima da temperatura depende do sistema e da SEP em questão, uma vez que a temperatura deve permitir que barreiras de energia separando diferentes regiões da SEP possam ser transpostas, e tais barreiras claramente dependem do sistema em estudo. No método BHMC padrão, onde apenas deslocamentos atômicos são realizados, a temperatura é o único parâmetro externo, uma vez que a magnitude dos deslocamentos pode ser ajustada para permitir uma taxa de aceitação desejada para novas configurações $(37,50)$. Essa abordagem simples, na qual os parâmetros dos operadores são controlados a fim de manter uma taxa de aceitação definida, torna-se impraticável quando mais operadores estão presentes

O método BHMC padrão foi aplicado inicialmente por Wales e Doye para clusters $\mathrm{LJ}_{N}$ com até $N=110$ átomos, e permitiu que mínimos globais inéditos fossem descobertos para $N=69,78,107$ (50) . Outros sistemas descritos por potenciais empíricos tratados com BHMC incluem clusters de metais de transição com até 80 átomos descritos pelo potencial de SC (7), clusters de Al (107), de Si (108), de água (109), entre outros. 


\subsubsection{Dificuldades}

Apesar dos muitos sucessos no âmbito de potenciais empíricos, a taxa de sucesso* para casos difíceis em geral é baixa. Por exemplo, utilizando busca sem bias, Wales e Doye (50) não foram capazes de identificar o mínimo global do cluster $L_{75}$ com o método BHMC padrão. Locatelli e Schoen (110) reportaram taxas de sucesso de $0.4 \%, 0.8 \%$ e $0.6 \%$ para os casos $\mathrm{LJ}_{75}, \mathrm{LJ}_{76}$ e $\mathrm{LJ}_{98}$, respectivamente. Para esses três casos, Iwamatsu e Okabe (111) atingiram taxas de sucesso de $1 \%, 5 \%$ e $10 \%$, respectivamente, enquanto para $\mathrm{LJ}_{102}, \mathrm{LJ}_{103}$ e $\mathrm{LJ}_{104}$ a taxa de sucesso não passou de $3 \%$ com o método BHMC padrão. Em um estudo recente, Wales e colaboradores (11) reportaram que é possível atingir uma taxa de sucesso de $100 \%$ para o método BHMC padrão no caso de clusters de LJ, porém empregando uma técnica múltiplas reinicializações, na qual a busca é reinicializada aleatoriamente com frequência. Essa estratégia, porém, não pode ser empregada de maneira tão direta para partículas descritas por DFT, uma vez que uma reinicialização implica no descarte de todos os passos de Metropolis realizados até o momento em que ela ocorre, uma prática inviável no caso de cálculos custosos. Para clusters $\mathrm{Ag}_{42} \mathrm{Pd}_{13}$ descritos pelo potencial de SC, Kim et al. (112) reportaram uma taxa de sucesso de $0 \%$ utilizando o método BHMC padrão, e de apenas $18.3 \%$ utilizando esse método com a introdução de um novo operador.

Além de baixas taxas de sucesso, é possível notar que muitos dos mínimos globais encontrados pelo método BHMC padrão e reportados na literatura foram superados por estudos posteriores empregando outros métodos de otimização global. Por exemplo, Doye e Meyer (12) publicaram mínimos globais de um total de 576 clusters de LJ binários obtidos com o método BHMC padrão, ao passo que em trabalhos posteriores 104 desses mínimos foram superados por resultados obtidos por outros autores utilizando outras metodologias de otimização global $(8,9,14)$.

As deficiências do método BHMC para casos mais difíceis, como $\mathrm{LJ}_{75}$ e $\mathrm{LJ}_{98}$, devem-se à baixa mobilidade sobre a SEP. Em particular, esses casos considerados difíceis apresentam SEPs com múltiplos funis, na qual o funil do mínimo global situa-se em uma região segregada por altas barreiras de energia, de modo que deslocamentos atômicos não são capazes de levar a busca para este funil uma vez que ela fique aprisionada em outra região. Para tentar solucionar este, alguns autores introduziram operadores adicionais $(111,112)$, porém de maneira esparsa,

\footnotetext{
*Como o método BHMC é um método estocástico, uma das maneiras de quantificar sua eficiência é através da taxa de sucesso. Essa taxa se refere ao número de aplicações do método que são capazes de reproduzir mínimos globais putativos reportados na literatura dentro de um conjunto finito de aplicações. Por exemplo, uma taxa de sucesso de $10 \%$ indica que a cada 100 aplicações, foi possível obter os mínimos globais esperados em 10 delas, em média.
} 
nunca excedendo dois ou três operadores, e não apresentando novas estratégias para aplicá-los. Por essas razões, essas melhorias pontuais não foram suficientes para fazer com que o método BHMC padrão atingisse elevadas taxas de sucesso para cenários de SEPs com múltiplos funis.

Para sistemas descritos por DFT, o número de trabalhos empregando apenas o método BHMC padrão ainda é pouco expressivo e geralmente envolve clusters de poucos átomos (57$60,113)$. Encontram-se também na literatura trabalhos que empregam uma estratégia mista, na qual a otimização com BHMC é feita em uma SEP empírica ou semi-empírica, e então candidatos a mínimo global são refinados com cálculos de DFT (52-56, 114, 115). Essa abordagem pode apresentar bons resultados para alguns casos específicos, porém não é geral uma vez que o mínimo global da SEP empírica em geral não coincide com o mínimo global da SEP descrita por mecânica quântica. Alguns trabalhos combinam o método BHMC padrão com outros métodos, empregando tanto potenciais empíricos (116) quanto formalismos de primeiros princípios (10), porém não constituem abordagens gerais e envolvem bias específicos dos sistemas abordados.

No caso de partículas descritas por primeiros princípios, o número modesto de trabalhos empregando o método BHMC padrão é um reflexo das dificuldades existentes no método. Como cálculos de DFT são muito mais custosos computacionalmente que cálculos envolvendo potenciais empíricos, baixas taxas de sucesso implicam na necessidade de uma quantidade maior de cálculos para atingir o mínimo global.

\subsection{Método Basin-Hopping Monte Carlo Revisado}

Tendo em vista as dificuldades discutidas na seção anterior, este trabalho propõe o método RBHMC, uma versão aperfeiçoada do método BHMC padrão. Neste método as ideias básicas do método BHMC padrão são mantidas, isto é, a SEP original a ser explorada é transformada através de minimizações locais (equação 3.1.1), e a SEP transformada é explorada através de uma amostragem de Monte Carlo utilizando o critério de Metropolis. A ideia da metodologia por trás do RBHMC é manter a base do método BHMC padrão, porém introduzir novas estratégias que permitem que as dificuldades sejam superadas.

As estratégias introduzidas no método RBHMC consistem em: (i) um procedimento mais criterioso de inicialização aleatória das partículas, porém sem bias; (ii) o emprego de um grande conjunto de operadores para gerar novas configurações, categorizados em operadores locais e não-locais, e que aumentam a mobilidade da busca sobre a SEP, reduzindo as chances de 
aprisionamento em regiões de mínimos locais profundos; (iii) estratégias para aplicar os operadores de maneira eficiente, tirando proveito das melhores características de cada operador; (iv) um operador de filtro estrutural que identifica e remove soluções improváveis, particularmente útil para RBHMC-DFT (isto é, RBHMC aplicado à partículas descritas por DFT).

\subsection{Inicialização aleatória}

A configuração aleatória inicial é gerada distribuindo-se $N$ pontos aleatoriamente em uma caixa esférica ou cúbica, ambas de volumes iguais. O raio da esfera é calculado de acordo com a equação abaixo, adaptada da referência (117),

$$
R=2 R_{c}\left[\frac{1}{2}+\left(\frac{3 N}{4 \pi \sqrt{2}}\right)^{1 / 3}\right]
$$

onde $R_{c}$ é a média do raio covalente das $M$ espécies químicas, isto é,

$$
R_{c}=\frac{1}{M} \sum_{\alpha=1}^{M} R_{c}^{\alpha}
$$

Na equação 3.3.2, $R_{c}^{\alpha}$ é o raio covalente da espécie química $\alpha$, cujo valor pode ser encontrado na referência (118) para $Z=1-96$. No caso de partículas descritas por potenciais empíricos de LJ e SC com unidades reduzidas, $R_{c}$ é tomado como a média da metade da distância de cada átomo ao seu vizinho mais próximo. O termo de raiz cúbica na equação 3.3.1 é necessário para obter o comportamento de escala correto para volume da partícula em função do número de átomos.

Configurações iniciais com átomos sobrepostos ou desconectados da partícula são improváveis fisicamente. Tais casos são particularmente prejudiciais para cálculos DFT, uma vez que tornam difícil a convergência do cálculo auto-consistente da densidade eletrônica. A fim de evitar isso, as posições atômicas aleatoriamente inicializadas são submetidas à condição de que a distância de qualquer átomo $i$ ao seu vizinho mais próximo $j, R_{i j}=\left|\mathbf{R}_{j}-\mathbf{R}_{i}\right|$, deve satisfazer a relação

$$
(1-\gamma) R_{c}^{\alpha \beta}<R_{i j}<(1+\gamma) R_{c}^{\alpha \beta}
$$

onde $\gamma$ é um parâmetro ajustável, $\alpha$ e $\beta$ correspondem às espécies químicas dos átomos $i$ e $j$, respectivamente, e $R_{c}^{\alpha \beta}=R_{c}^{\alpha}+R_{c}^{\beta}$.

A condição de inicialização apresentada acima não é estritamente necessária para partículas 
descritas pelos potenciais de LJ ou SC, já que nesses casos as energias e forças associadas são calculadas através de equações analíticas, e a maioria dos procedimentos de minimização local são capazes de lidar com gradientes de alta magnitude na SEP, i.e., átomos muito próximos, ou átomos desconectados. Todavia, mesmo para LJ e SC a condição de inicialização favorece partículas iniciais com energias mais próximas da energia de mínimo global. Testes realizados com RBHMC-DFT indicam que uma escolha de $\gamma$ entre 0.2 e 0.4 favorece boas configurações iniciais.

\subsection{Minimização local}

Métodos de minimização local são procedimentos determinísticos que partem de um ponto arbitrário localizado sobre a SEP e guiam o sistema para o mínimo local mais próximo daquele ponto. Para tal, esses métodos procuram seguir caminhos descendentes sobre a SEP, utilizando como informações o valor da função e possivelmente suas derivadas. Em princípio, a minimização local empregada no método RBHMC pode ser de qualquer natureza. A única exigência é que garanta que, quando aplicado em uma configuração qualquer, uma configuração correspondente a um mínimo local seja obtida. Existe uma grande variedade de métodos de minimização local na literatura (119-121), e neste trabalho foram empregados três métodos nos estudos de casos apresentados nos capítulos 5 e 6 . Esse métodos são descritos brevemente abaixo, e em mais detalhes no apêndice $B$.

\section{- Steepest descent adaptativo (SDA)}

Este método é baseado no steepest descent clássico, no qual a função é minimizada seguindo o caminho de descida mais ingrime, dado pelo negativo do seu gradiente. No caso de minimização local da SEP associada a uma partícula, os átomos são deslocados na direção das forças, até que um ponto de forças nulas é alcançado. O método SDA recebe este nome pois ajusta os tamanhos dos passos dados sobre a SEP de maneira automática ao longo da minimização, ao invés de empregar um procedimento de minimização linear na direção das forças.

\section{- Gradientes conjugados (GC)}

No método GC, a direção de busca sobre a SEP em cada passo da minimização local é determinada pela direção conjugada ao gradiente, levando em conta os valores do gradiente nas iterações anteriores. Este método apresenta convergência para o mínimo local em um número menor de passos em comparação com o método SDA, porém tem 
dificuldades em regiões mal condicionadas da SEP, em especial em regiões que não podem ser aproximadas por uma função harmônica. Para evitar esse problema, nesse trabalho o método SDA é utilizado por alguns passos iniciais a fim de atingir uma região bem condicionada, e então GC é invocado para realizar o restante da minimização.

\section{- Broyden-Fletcher-Goldfarb-Shanno (BFGS)}

Este método é baseado no método de Newton e utiliza as segundas derivadas da função para encontrar seus pontos estacionários. Para funções de muitas dimensões, como uma SEP, o cálculo da matriz Hessiana pode ser custoso e muitas vezes impraticável. Para resolver este problema, no método BFGS a matriz Hessiana é aproximada a partir do gradiente, e leva em conta um histórico de gradientes obtidos em iterações anteriores. O método BFGS tem desempenho ótimo quando a região nas proximidades de um mínimo local pode ser considerada, em boa aproximação, como uma função harmônica. É comum utilizar o método SDA por alguns passos iniciais para atingir uma região bem condicionada antes de aplicar o método BFGS, assim como é feito no método GC.

Para clusters de LJ e SC com até 148 átomos, o método de minimização local empregado foi o SDA, o qual, pelos testes realizados, garante bom desempenho para esta faixa de tamanhos e fornece resultados comparáveis com dados da literatura em até 6 e 4 casas decimais para LJ e SC, respectivamente. Para NPs de LJ com $N \geq 200$ átomos, o método empregado foi a versão de Dai-Liao (122) do método GC, uma vez que verificou-se que para partículas de LJ este método é mais eficiente que outras variantes do método GC (123). Esses dois métodos, SDA e GC, foram implementados no pacote de otimização global desenvolvido ao longo deste trabalho de mestrado. Para os cálculos de DFT, o método empregado foi o BFGS conforme implementado no pacote de estrutura eletrônica FHI-aims $(86,120)$.

\subsection{Operadores}

Um dos principais fatores governando o desempenho do método RBHMC é a maneira com que novas configurações são geradas ao longo da otimização global para serem submetidas ao critério de Metropolis, uma vez que é através das novas configurações aceitas que o método é capaz de explorar diferentes basins de atração da SEP. A tarefa de gerar novas configurações fica a cargo dos operadores, e neste trabalho é proposta a combinação de um grande conjunto de operadores, indo além de simples deslocamentos atômicos presentes na maioria das implementações do método BHMC padrão. Dentro do método RBHMC identificam-se dois grupos 
de operadores, locais e não-locais, que trabalham em conjunto para aumentar a mobilidade da busca sobre a SEP.

(a)

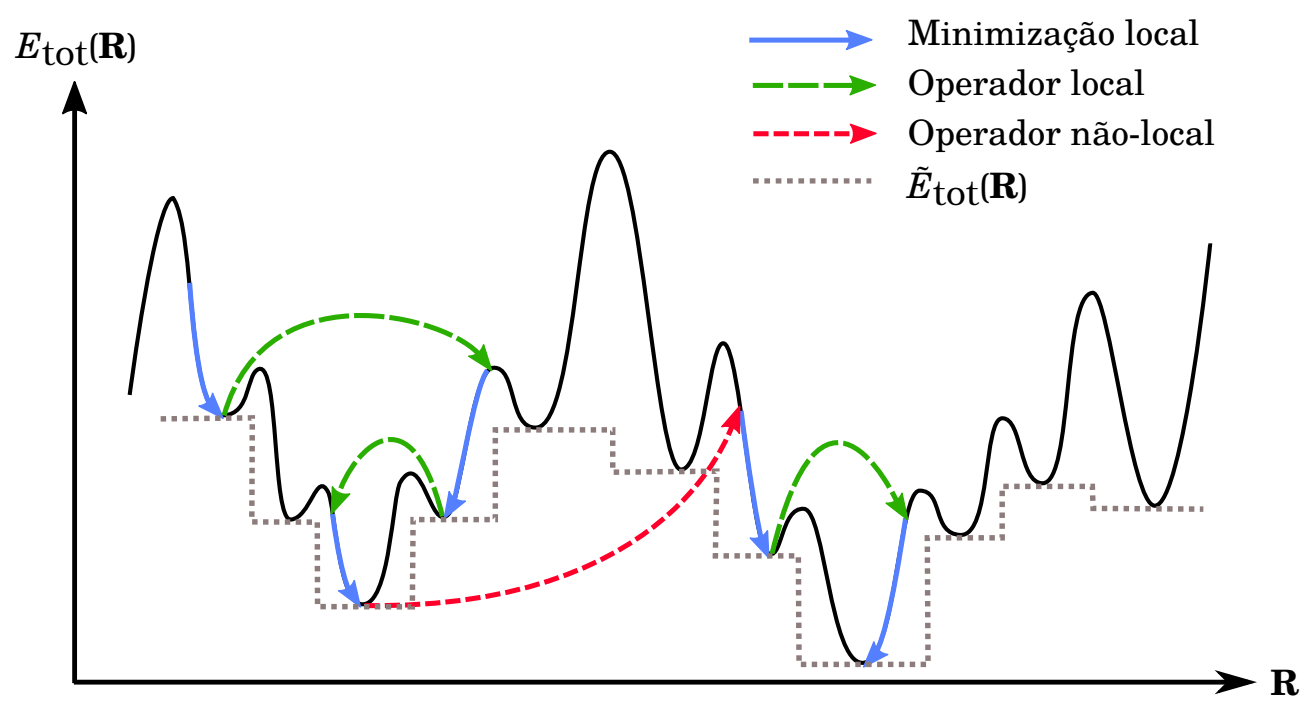

(b)

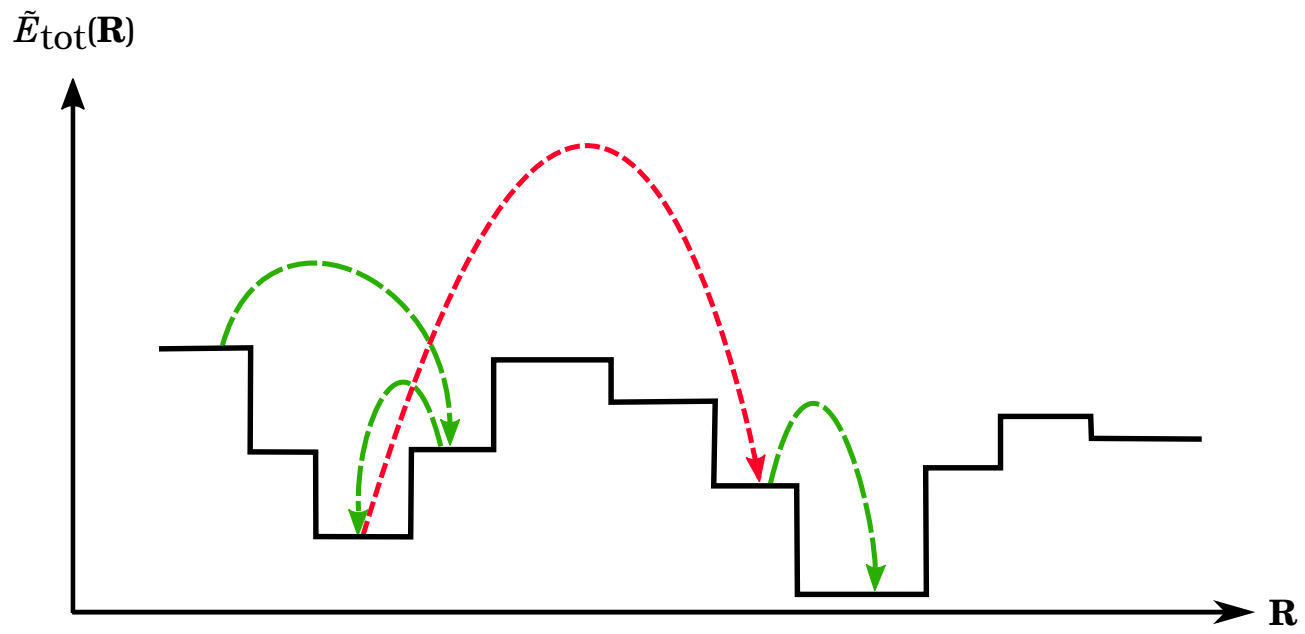

Figura 3.2 - Método BHMC revisado. (a) Funcionamento do método para uma SEP hipotética, empregando operadores locais e não-locais. (b) Efeito da transformação da SEP em um conjunto de basins de atração.

Operadores não-locais são aqueles que produzem novas configurações consideravelmente diferentes das configurações que são lhes são fornecidas, e portanto são responsáveis por dirigir a busca para diferentes regiões da SEP em poucos passos. Por outro lado, operadores locais geram novas configurações através de deslocamentos atômicos em torno das posições originais de cada átomo, produzindo alterações estruturais mais modestas em relação às configurações fornecidas, e assim permitem que cada região da SEP seja explorada exaustivamente. A ideia desta abordagem é que operadores locais sozinhos levam muitos passos para mover a busca para 
diferentes regiões da SEP separadas por altas barreiras de energia, e portanto os operadores não-locais facilitam essa mobilidade. Essa estratégia busca superar as dificuldades impostas pela topologia da SEP, como no caso de múltiplos funis com o funil primário segregado por uma alta barreira de energia, uma situação em que o método BHMC padrão possui dificuldades. Na figura 3.2 é possível observar as diferenças entre os dois tipos de operadores na exploração da SEP, e também a transformação aplicada à SEP para mapeá-la em um conjunto de platôs determinados pelos mínimos locais.

Além de operadores locais e não-locais, um terceiro tipo de operador se faz presente nesta metodologia. Esses operadores, denominados auxiliares, incluem dois operadores que trabalham em conjunto com os outros e servem para aumentar as chances de sucesso de localizar o mínimo global. A diferença em relação aos outros dois tipos descritos acima é que os operadores auxiliares utilizam as estruturas geradas pelos outros operadores para alterar a dinâmica da otimização, não sendo eles próprios capazes de gerar novas estruturas.

De acordo com a literatura pesquisada, nenhuma metodologia de otimização global baseada no método BHMC combina um conjunto tão vasto de operadores de maneira geral, aplicável tanto para partículas descritas por potenciais empíricos quanto por DFT, e mantendo o critério de Metropolis inalterado. Há alguns estudos que empregam diversos operadores em conjunto com o método BHMC padrão (124-126), porém em número menor e sem tanta variedade em comparação com os operadores apresentados nesta metodologia, e também sem apresentar estratégias claras sobre como combinar os diversos operadores de maneira eficiente.

\subsubsection{Operadores locais}

Os operadores locais são ilustrados na figura 3.3 e discutidos a seguir.

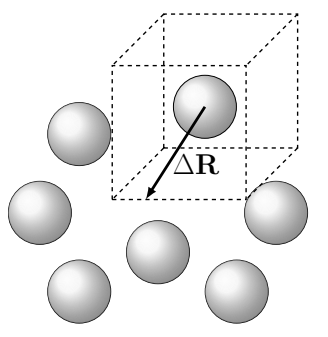

(a)

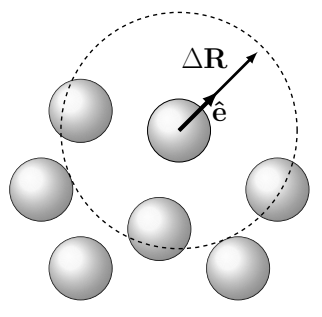

(b)

Figura 3.3 - Operadores locais empregados no método RBHMC. (a) Operador de deslocamento cartesiano (CDO). (b) Operador de deslocamento em relação ao centro geométrico (GCDO). 


\subsubsection{Operadores de deslocamento atômico}

Nesta classe encontram-se dois operadores que atuam em um conjunto de coordenadas atômicas, $\mathbf{R}$, e deslocam cada átomo em torno de suas posições originais, isto é,

$$
\mathbf{R}_{i}^{\prime}=\mathbf{R}_{i}+\Delta \mathbf{R}_{i}
$$

onde $\mathbf{R}_{i}$ e $\mathbf{R}_{i}^{\prime}$ correspondem à antiga posição e nova posição do átomo $i$, respectivamente, enquanto $\Delta \mathbf{R}_{i}$ determina a magnitude e direção do deslocamento.

Neste trabalho são utilizadas duas abordagens para o cálculo dos deslocamentos $\Delta \mathbf{R}_{i}$. Um dos operadores, chamado aqui de operador de deslocamento cartesiano (CDO - cartesian displacement operator), é uma versão modificada do operador de deslocamento atômico encontrado em implementações do método $\operatorname{BHMC}$ padrão $(50,60)$ e do método de Monte Carlo (73). Para o CDO, o deslocamento de um átomo $i$ é definido como

$$
\Delta \mathbf{R}_{i}=S R_{i j}\left([-1,+1]_{x} \hat{\mathbf{x}}+[-1,+1]_{y} \hat{\mathbf{y}}+[-1,+1]_{z} \hat{\mathbf{z}}\right)
$$

onde $S$ é um parâmetro constante e $R_{i j}$ é a distância do átomo $i$ ao vizinho mais próximo $j$, calculado dinamicamente ao longo da otimização. O parâmetro $R_{i j}$ tem o papel de um fator de escala dinâmico que leva em conta variações na magnitude do comprimento de ligações ao determinar a magnitude do deslocamento. Este parâmetro tem um papel importante, por exemplo, ao deslocar átomos próximos da superfície, e para partículas compostas por átomos de mais de uma espécie química, nais quais os comprimentos de ligação entre diferentes tipos de átomos são, em geral, diferentes. A notação $[-1,+1]$ representa um número aleatório originário de uma distribuição uniforme no intervalo entre -1 e +1 , que é diferente para cada componente do deslocamento. A definição de $\Delta \mathbf{R}_{i}$ dada pela pela equação 3.5.2 permite que os deslocamentos tenham magnitude entre 0 e $S d_{i j}$, e apenas o parâmetro $S$ precisa ser fornecido para o operador (i.e., parâmetro de entrada).

O segundo operador, chamado de operador de deslocamento em relação ao centro geométrico (GCDO - geometric center displacement operator), leva em consideração a distância do átomo $i$ ao centro geométrico da partícula ao determinar a magnitude do deslocamento. Um operador de deslocamentos dessa natureza é raramente empregado na literatura, e a versão apresentada aqui é uma generalização do operador introduzido por Kim et al. (112). O GCDO é definido pela equação abaixo,

$$
\Delta \mathbf{R}_{i}=\left[\left(\alpha_{\max }-\alpha_{\min }\right)\left(\frac{R_{i}}{R_{\max }}\right)^{w}+\alpha_{\min }\right] R_{i j} \hat{\mathbf{e}}_{i}\left(\theta_{i}, \phi_{i}\right),
$$


onde os parâmetros constantes $\alpha_{\min }$ e $\alpha_{\max }$ representam fatores que limitam a magnitude mínima e máxima do deslocamento, respectivamente. $R_{i}$ corresponde à distância do átomo $i$ ao centro geométrico da partícula, $R_{\max }$ corresponde ao raio da partícula, definido como a maior distância de um átomo ao centro geométrico, e $R_{i j}$ é a distância entre o átomo $i$ e o seu vizinho mais próximo $j$. Assim, o termo $\left(\frac{R_{i}}{R_{\max }}\right)^{w}$ faz com que o deslocamento dependa da distância do átomo $i$ ao centro geométrico, e o parâmetro $w$ determina o peso dessa dependência. Esse operador é baseado na expectativa física de que átomos em diferentes regiões da partícula sofram deslocamentos diferentes, e.g., átomos da superfície podem se deslocar mais que átomos mais internos. O vetor unitário $\hat{\mathbf{e}}_{i}\left(\theta_{i}, \phi_{i}\right)$ dá a direção radial do deslocamento, e é determinado aleatoriamente através da escolha aleatória dos ângulos esféricos $\theta_{i}$ e $\phi_{i}$ nos intervalos $[0, \pi]$ e $[0,2 \pi]$, respectivamente. Em contraste com o operador CDO definido pela equação 3.5.2, o operador GCDO definido pela equação 3.5.3 requer que três parâmetros externos sejam fornecidos, isto é, $\alpha_{\min }, \alpha_{\max }$ e $w$.

Testes realizados com os operadores CDO e GCDO indicam que os seguintes valores permitem um bom desempenho dos operadores para diferentes classes de sistema: $0.3 \leq S \leq$ $0.4,0.2 \leq \alpha_{\min } \leq 0.35,0.45 \leq \alpha_{\max } \leq 0.6$, e $w=2$. Tais valores podem ser encarados como uma primeira tentativa na busca do mínimo global, e podem ser otimizados para render um desempenho melhor de acordo com as características específicas do sistema, e.g., espécies químicas, número de átomos, potencial de interação, etc.

O número de átomos deslocados pelos operadores CDO e GCDO é um parâmetro fornecido, que pode variar de 1 a $N$. Uma vez definido este número, os átomos podem ser selecionados de acordo com dois critérios, seleção aleatória, ou seleção baseada na contribuição energética de cada átomo para a energia total, i.e., selecionando átomos com maior energia (124). A seleção aleatória pode ser utilizada tanto para partículas descritas por potenciais empíricos quanto por DFT, todavia a seleção baseada na energia só é possível para o caso de potenciais empíricos, uma vez que a decomposição da energia total obtida com DFT em contribuições atômicas individuais não é uma tarefa simples de ser realizada.

\subsubsection{Operadores não-locais}

Os operadores não-locais são ilustrados na figura 3.4 e discutidos a seguir. 


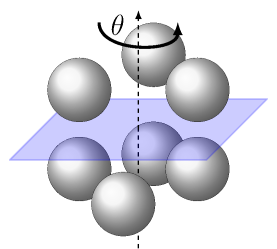

(a)

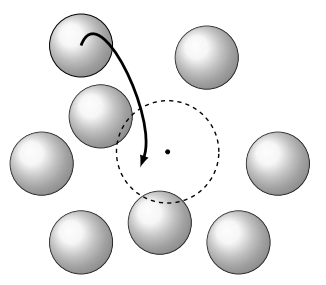

(d)

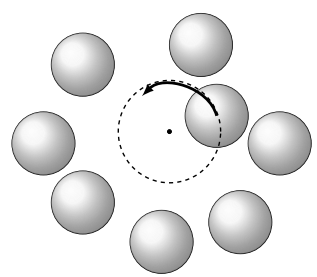

(b)

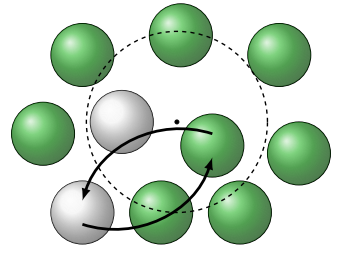

(e)

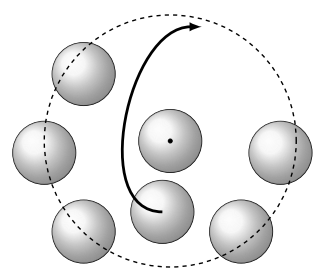

(c)

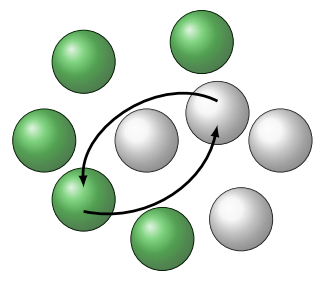

$(f)$

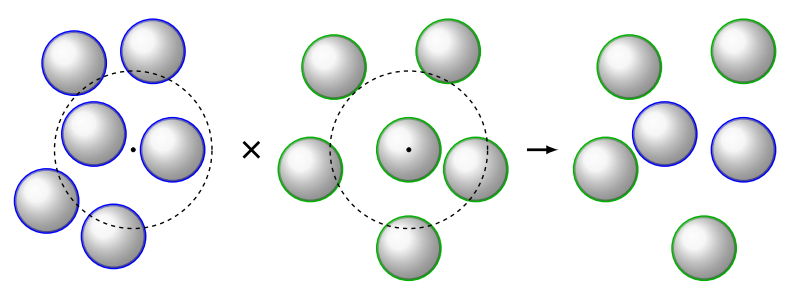

(g)

Figura 3.4 - Operadores não-locais empregados no método RBHMC. (a) Operador twist (TO). (b) Operador angular (AO). (c) Operador angular de superfície (SAO). (d) Operador interior $(\mathrm{IO})$. (e) Operador de troca (EO). ( $\mathrm{f}$ ) Operador de troca geométrico (GEO). (g) Operador crossover (CO).

\subsubsection{Operador twist}

Em contraste com os operadores locais, o operador twist (TO - twist operator) tem o objetivo de introduzir mudanças estruturais mais significativas na partícula. O princípio de atuação do operador é rotacionar uma parcela dos átomos da partícula em torno de um eixo obtido aleatoriamente (43). O operador considera a partícula como sendo aproximadamente esférica e a separa em duas regiões, não necessariamente contendo o mesmo número de átomos, através de um plano definido aleatoriamente. Após a secção, todos os átomos de uma das regiões são rotacionados em torno do eixo que atravessa o centro geométrico da partícula e que é perpendicular ao plano. O TO requer que dois parâmetros sejam fornecidos, $\beta$ e $\theta_{\max }$. O parâmetro $\beta$ deve estar entre 0 e 1 e serve para limitar a região na qual o plano aleatório 
pode ser aplicado, evitando que o plano de secção seja aplicado nas extremidades da partícula, e assim evitando que uma das regiões contenha um número muito pequeno de átomos. $\mathrm{O}$ parâmetro $\theta_{\max }$ define o ângulo máximo da rotação, e deve estar compreendido entre 0 e $2 \pi$. Testes realizados apontam que $0.4 \leq \beta \leq 0.8$ e $\frac{\pi}{6} \leq \theta_{\max } \leq \pi$ oferecem boa performance para o operador, mas assim como no caso dos parâmetros dos operadores de deslocamento, os parâmetros podem ser otimizados para cada sistema em particular.

\subsubsection{Operador angular}

O operador angular (AO - angular operator) foi introduzido por Wales e Doye (50) e foi ignorado pela maioria dos trabalhos empregando o método BHMC ao longo dos anos, com algumas exceções (116). Este operador seleciona um ou mais átomos e os posiciona aleatoriamente sobre uma esfera de raio igual à distância de cada átomo ao centro geométrico da partícula, i.e., $R_{i}$ para um átomo $i$, realizando portanto movimentos angulares nos átomos e mantendo suas distâncias relativas ao centro inalteradas. A escolha dos átomos pelo $A O$ pode ser tanto aleatória quanto baseada em energia, como no caso dos operadores CDO e GCDO. Este operador é eficiente para preencher sítios vazios dentro da partícula, e uma recomendação para o número de átomos afetados pelo operador é entre $1 \%$ e $5 \%$ do total de átomos.

\subsubsection{Operador angular de superfície}

O operador angular de superfície (SAO - surface angular operator) tem um funcionamento similar ao do operador angular descrito acima. O SAO seleciona um ou mais átomos aleatoriamente e os coloca em posições aleatórias sobre a superfície da partícula, e.g., posicionando o átomo $i$ na posição $R_{\max } \hat{\mathbf{e}}_{i}\left(\theta_{i}, \phi_{i}\right)(14)$. Os critérios de seleção dos átomos são os mesmos que para o OA. O papel do SAO é de preencher sítios desocupados na superfície da partícula, e tem melhor desempenho para o caso de partículas cujo mínimo global tem estrutura aproximadamente esférica (e.g., icosaedro completo). Mesmo para casos em que a estrutura de mínimo global não tem simetria aproximadamente esférica, o SAO pode ser útil para favorecer a movimentação da busca para regiões não exploradas da SEP. 


\subsubsection{Operador interior}

Em contraste com o SAO, que move átomos para a superfície da partícula, o operador interior (IO - interior operator) desloca os átomos mais distantes do centro geométrico para posições aleatórias na região central da partícula $(14,127)$, aumentando as chances de preencher sítios desocupados na região interna. Essa região é definida por um parâmetro que dá o raio máximo de uma esfera centrada no centro geométrico, e deve deve estar compreendido entre $1 \%$ e $10 \%$ do raio da partícula para melhores resultados. O número ideal de átomos a serem movidos depende das características particulares do sistema e da estabilidade da região interna, e uma vez que a região interna assume sua configuração de mínimo global, o operador perde parte de sua eficiência. Uma recomendação é configurar o operador para deslocar cerca de $1 \%$ a $5 \%$ do número total de átomos e então avaliar o desempenho da otimização global, fazendo ajustes caso sejam necessários.

Além de preencher sítios desocupados próximos do centro da partícula, o IO leva para a região interna átomos que estejam parcialmente desconectados, i.e., cujas distâncias aos vizinhos mais próximos excedam muito os comprimentos de ligação típicos, e portanto tem o efeito de suavizar a superfície. Este operador é mais indicado para sistemas descritos por potenciais empíricos, já que quando os átomos são movidos para o centro da partícula, há grandes chances de dois átomos ficarem muito próximos. Essa situação não apresenta grandes problemas para potenciais empíricos, porém no caso de DFT ela introduz dificuldades no cálculo auto-consistente da densidade eletrônica.

\subsubsection{Operador de troca}

Em partículas com mais de uma espécie química, barreiras de difusão introduzem uma dificuldade extra na identificação do mínimo global, uma vez que essas barreiras limitam a mobilidade dos átomos. Para resolver esse problema, o operador de troca (EO - exchange operator) seleciona pares distintos de átomos $i$ e $j$ de espécies químicas diferentes $\alpha$ e $\beta$, respectivamente, e então realiza uma troca das espécies entre os dois átomos, isto é, $\left(\mathbf{R}_{i}^{\alpha}, \mathbf{R}_{j}^{\beta}\right) \longrightarrow\left(\mathbf{R}_{i}^{\beta}, \mathbf{R}_{j}^{\alpha}\right)$, significando que o átomo $i$ passa a ser da espécie $\beta$, enquanto o átomo $j$ passa a ser da espécie $\alpha$. O único parâmetro desse operador é o número de pares a serem trocados a cada aplicação do operador. O operador EO é fundamental para a obtenção de estruturas de mínimos globais de partículas compostas por mais de uma espécie química. Em testes realizados com 
a implementação desenvolvida no trabalho, a ausência desses operadores torna praticamente impossível localizar mínimos globais de partículas binárias com $N \geq 20$ átomos.

\subsubsection{Operador de troca geométrico}

O operador de troca descrito acima seleciona pares de átomos $i$ e $j$ aleatoriamente para realizar as trocas de espécies químicas. Essa estratégia é geral e útil em muitos casos, mas para certos tipos de estruturas prevalentes em clusters e NPs é possível empregar um outro tipo de operador, que faz trocas mais criteriosas, porém mantendo a possibilidade de ser aplicado à qualquer sistema com mais de uma espécie. O operador de troca geométrico (GEO - geometric exchange operator) escolhe cada par de átomos $i$ e $j$ tal que o átomo $i$ esteja na região central da partícula, e o átomo $j$ esteja na região mais externa, com as posições dos dois átomos $i$ e $j$ satisfazendo as condições $R_{i}<\lambda R_{\max }$ e $R_{j}>\lambda R_{\max }$, onde $\lambda$ é um parâmetro fornecido no intervalo $[0,1]$, tipicamente $\lambda=0.5$. Outro parâmetro necessário, assim como no caso do EO, é o número de pares a serem trocados em cada aplicação do operador, e tanto para o EO quanto para o GEO, é recomendável trocar entre $1 \%$ e $3 \%$ dos átomos da partícula em cada aplicação.

Este operador tem boa eficiência para levar átomos de uma determinada espécie da superfície para o centro, e vice-versa, todavia, uma vez que a região central atinge sua composição mais estável o operador perde parte de sua eficiência. Testes realizados indicam que para a grande maioria dos sistemas binários estudados neste trabalho o GEO contribui significativamente com a otimização global.

\subsubsection{Operador crossover}

O operador crossover (CO - crossover operator) consiste na combinação de duas partículas para obter duas novas partículas, uma técnica popular em algoritmos genéticos $(43,128)$. Na metodologia apresentada aqui, o $\mathrm{CO}$ atua em duas partículas diferentes, $A^{\prime}$ e $B^{\prime}$, denominadas partículas pais, cujas coordenadas respectivas são $\mathbf{R}^{A}$ e $\mathbf{R}^{B}$. Essas duas partículas são então combinadas para produzir duas novas partículas, $A^{\prime}$ e $B^{\prime}$, denominadas partículas filhas, com configurações $\mathbf{R}^{A^{\prime}}$ e $\mathbf{R}^{B^{\prime}}$, respectivamente. A partícula $A$ é obtida do banco de dados das partículas de menor energia encontradas ao longo da otimização. A partícula $B$ é a última 
configuração aceita pelo critério de Metropolis. As duas partículas filhas geradas, $A^{\prime}$ e $B^{\prime}$, são então minimizadas localmente e aquela de menor energia é mantida, e a otimização global procede a partir dessa configuração.

Existem diversas técnicas de fazer a combinação das partículas $A$ e $B$ para gerar $A^{\prime}$ e $B^{\prime}$ (43). Neste trabalho é empregada uma combinação geométrica, na qual a partícula $A^{\prime}$ é formada com a região central da partícula $A$ e a região de superfície da partícula $B$, enquanto a partícula $B^{\prime}$ é formada pela região de superfície da partícula $A$ e a região central da partícula $B$, tomando os devidos cuidados para que as partículas filhas tenham o mesmo número de átomos das partículas pais.

Este operador procura combinar características de duas regiões já exploradas da SEP a fim de dirigir a busca para uma região ainda não explorada. Diferente de todos os operadores discutidos até agora, o CO não é um operador que deve ser utilizado frequentemente, devendo ser aplicado somente após um número considerável de passos de Metropolis, tipicamente entre 50 e 1000 passos. Este número é um parâmetro que deve ser fornecido, e além dele é preciso fornecer um fator de corte que separa a partícula em duas regiões, análogo ao parâmetro $\lambda$ no GEO.

\subsubsection{Operadores auxiliares}

Os operadores auxiliares, descritos a seguir, não são capazes de gerar novas estruturas, mas apenas guiam a otimização global com base nas estruturas que lhes são fornecidas.

\subsubsection{Operador de saltos ocasionais}

O operador de saltos ocasionais (OJ - occasional jumps), introduzido por Iwamatsu e Okabe (111), tem como objetivo evitar que a busca fique aprisionada em um mínimo local profundo da SEP. O operador aceita um número consecutivo de novas configurações resultantes da aplicação dos operadores locais e não-locais, independente da diferença de energia entre cada nova configuração e a configuração atual da busca. Essa abordagem é equivalente a fazer $T \rightarrow \infty$ no critério de Metropolis durante alguns passos consecutivos, aceitando assim qualquer configuração incondicionalmente. Quando habilitado, o operador OJ é acionado apenas quando o critério de Metropolis rejeita novas configurações por um número fixo de passos consecutivos. Essa estratégia é baseada na ideia que se um determinado operador 
não é capaz de gerar configurações que fazem a busca escapar de um mínimo local profundo, outros operadores podem ser capazes. Assim, é importante permitir que todos os operadores habilitados na execução tenham a chance de agir antes do operador OJ ser acionado.

O operador OJ exige dois parâmetros, um deles é o número de rejeições do critério de Metropolis, e o outro corresponde ao número de aplicações consecutivas do operador. Esses parâmetros em geral dependem do tamanho do sistema e das características da SEP, mas é conveniente que o primeiro parâmetro seja escolhido de modo que todos os outros operadores, locais e não-locais, sejam empregados antes de que o operador OJ seja acionado.

É importante notar, também, que o número de rejeições até a ativação do operador OJ deve ser escolhido levando em conta a temperatura utilizada no critério de Metropolis, já que temperaturas mais altas reduzem as chances de aprisionamento em regiões profundas da SEP, porém não permitem que cada região seja explorada exaustivamente. Em particular, para temperaturas muito baixas, e.g., próximas de zero, o operador OJ é essencial, já que nesse caso a maioria das estruturas aceitas são aquelas que reduzem a energia do sistema, correspondendo a uma busca descendente na SEP. Sem o operador OJ, esse tipo de busca falha em encontrar o mínimo global caso o funil explorado não seja o funil primário.

\subsubsection{Operador de filtro estrutural}

Os operadores locais e não-locais geram uma nova configuração, $\mathbf{R}^{\prime}$, dada uma configuração inicial, R. Contudo, esses operadores não garantem que as novas configurações sejam fisicamente aceitáveis, e.g., não impõe restrições sobre os comprimentos de ligação das novas configurações. Dessa maneira, é possível que as novas configurações tenham átomos muito próximos um dos outros, ou átomos completamente desconectados da partícula, ou seja, configurações improváveis. Essas configurações patológicas apresentam sérios problemas para cálculos de primeiros princípios, em particular para cálculos na DFT, uma vez que tornam a convergência do cálculo auto-consistente da densidade eletrônica difícil de ser atingida. Mesmo em situações em que a convergência é possível, é necessário um grande tempo computacional para alcançá-la.

Para evitar esses possíveis problemas, o operador de filtro estrutural (SFO - structural filter operator) emprega o mesmo critério de distâncias interatômicas utilizado na inicialização aleatória da partícula (seção 3.3). Cada nova configuração gerada pelos operadores locais ou não-locais é submetida ao critério $(1-\eta) R_{c}^{\alpha \beta}<d_{i j}<(1+\eta) R_{c}^{\alpha \beta}$, onde $\eta$ é um parâmetro que 
controla o grau de restrição do filtro. Utilizando este critério, o SFO aceita ou rejeita as configurações resultantes dos outros operadores. Se uma configuração é rejeitada, então o mesmo operador, local ou não-local, é aplicado novamente, e sua nova configuração é submetida outra vez ao SFO. Esse processo se repete até que o SFO aceite uma das configurações, ou até que um número máximo de rejeições seja atingido, também fornecido como parâmetro. Quando este número máximo de rejeições é alcançado, o algoritmo passa a utilizar o próximo operador na sequência fornecida de operadores. No capítulo 6 é apresentada uma análise do SFO para um caso particular, onde são discutidos valores razoáveis para o parâmetro $\eta$ e estratégias de uso do operador.

\subsection{Taxa de aceitação e emprego dos operadores}

Certos valores para a taxa de aceitação do critério de Metropolis são recomendados para a amostragem de SEPs de alta dimensionalidade, como 0.234 e $0.50(73,129)$. No método BHMC padrão, que emprega principalmente deslocamentos atômicos, é possível fazer com que a taxa de aceitação para uma determinada temperatura fique próxima de um valor desejado através do ajuste da magnitude dos deslocamentos $\Delta \mathbf{R}_{i}$, bem como do número de átomos deslocados (60). Porém, o uso de um grande conjunto de operadores com propriedades locais e não-locais introduz uma dificuldade fundamental nesse tipo de abordagem para controlar a taxa de aceitação, uma vez que há um grande número de parâmetros envolvidos. Assim, controlar todos os parâmetros dos operadores a fim de controlar a taxa de aceitação é pouco viável.

Além disso, existe outra dificuldade, referente à escala de energia dos operadores, que pode ser diferente para diferentes operadores. Por exemplo, um operador que atua sobre uma configuração e realiza apenas modificações estruturais sutis, ou que atua apenas em uma pequena parcela do total de átomos da partícula, irá gerar uma nova configuração cuja energia não difere significativamente da energia da configuração original. Em contrapartida, um operador que realiza mudanças maiores na estrutura da partícula, ou que atua em todos os átomos, provavelmente produzirá uma estrutura cuja energia difere significativamente da energia da configuração original. Como as novas configurações geradas por todos os operadores estão sujeitas ao mesmo critério de Metropolis, i.e., com uma mesma temperatura, então a taxa de aceitação de diferentes operadores possivelmente não é a mesma.

Para superar estas dificuldades, a metodologia proposta aqui inclui duas estratégias de combinar os operadores locais e não-locais: uma estratégia estática e uma dinâmica. Ambas 
estratégias se baseiam na ideia de que ao utilizar um grande conjunto de operadores locais e não-locais, é melhor abordar o problema relacionado à taxa de aceitação reconhecendo que nem todos os operadores terão a mesma eficiência em todas as situações, e então priorizar aqueles que são mais eficientes ao longo da otimização global. Nas duas estratégias é necessário fornecer uma lista sequencial de operadores locais e não-locais intercalados. Na estratégia estática, cada operador da lista é aplicado por um número fixo de passos de Metropolis antes do algoritmo proceder para o próximo operador, sendo que para cada operador este número fixo de passos pode ser diferente. Uma vez que a lista é percorrida completamente, isto é, todos os operadores são aplicados pelos números de passos fornecidos, o algoritmo retorna ao início da lista e os aplica novamente. No esquema dinâmico, ao invés de um número fixo de passos por operador, cada um é aplicado até que um número fixo de rejeições do critério de Metropolis seja atingido, e assim como na estratégia estática, a lista é percorrida de maneira cíclica.

A estratégia dinâmica é a que em geral fornece melhores resultados, e é baseada na ideia de que cada operador deve ter a chance de ser empregado até que se torne ineficiente, que é quando as configurações geradas pelo operador são rejeitadas consecutivamente pelo critério de Metropolis. Assim, um operador que não mostre eficiência para um determinado sistema em uma etapa da otimização é aplicado um número mínimo de vezes antes do algoritmo proceder para o operador seguinte na lista, enquanto um operador eficiente tem a chance de ser aplicado mais vezes. Nesse esquema, a importância dos operadores pode variar ao longo da otimização, pois em algumas regiões da SEP certos operadores podem ser mais eficientes que outros, e.g., operadores que produzem novas estruturas com alterações estruturais significativas podem ser mais eficientes no início da otimização, mas podem perder importância quando a busca estiver próxima do mínimo global. 


\section{CAPÍTULO 4}

\section{Global Optimization Package}

Neste capítulo são apresentados os detalhes mais importantes do pacote GOP (Global Optimization Package), que contém a implementação computacional do método RBHMC.

\subsection{Implementação}

O pacote GOP, desenvolvido integralmente durante execução deste trabalho de mestrado, é implementado na linguagem $\mathrm{C}$ e tem cerca de 12 mil linhas de código. Desde o início do desenvolvimento adotou-se uma arquitetura modular, visando sempre a flexibilidade do código e a possibilidade de expandi-lo sem grandes dificuldades. O GOP suporta a otimização global de partículas descritas pelos potenciais de LJ e SC, implementados diretamente no código, e também partículas descritas por DFT, através de uma interface do GOP com o pacote de estrutura eletrônica FHI-aims (86). Os resultados dos estudos de casos apresentados nos capítulos 5 e 6 foram obtidos com o pacote GOP.

O desenvolvimento focou-se, inicialmente, nos potenciais empíricos de LJ e SC, que possuem expressões analíticas simples para energias e forças e permitiram que a metodologia fosse desenvolvida e testada de maneira eficiente. O código desenvolvido é serial, uma vez que o foco principal do trabalho é avaliar a metodologia proposta, e também porque cálculos envolvendo potenciais empíricos de LJ e SC não exigem elevado tempo computacional. Posteriormente, para acelerar os cálculos de partículas maiores, algumas partes do código foram paralelizadas utilizando a biblioteca OpenMP (130), porém apenas de maneira trivial, e.g., laços nos cálculos de forças e energias com potenciais empíricos. Para partículas descritas por DFT, a minimização local e o cálculo de energias é realizado pelo pacote FHI-aims, que já é paralelizado e possui excelente escalabilidade, de modo que as porções seriais do GOP nesse caso possuem impacto muito pequeno no desempenho de um cálculo RBHMC-DFT. 


\subsubsection{Algoritmo principal}

Este algoritmo refere-se às tarefas de alto nível executadas pelo programa principal do pacote GOP (função main). A primeira tarefa que o programa realiza é a leitura dos arquivos de entrada, contendo todos os parâmetros para o cálculo de otimização global (arquivo input) e possivelmente estruturas iniciais (arquivo input_atoms). Após a leitura desses arquivos, os seus dados são validados e então toda a memória necessária é alocada. A memória é alocada dinamicamente e inclui vetores de partículas iniciais, matrizes de distâncias, lista de operadores, etc. No arquivo input é preciso definir um parâmetro referente ao potencial utilizado para descrever as interações atômicas. Caso esse parâmetro corresponda aos potenciais de LJ ou SC, algumas matrizes adicionais são alocadas, como matrizes de forças e matrizes de contribuições energéticas entre pares de átomos.

Caso o potencial de interação especificado no arquivo de entrada seja DFT, são realizadas as inicializações de estruturas de dados necessárias para a interface entre o GOP e o pacote FHI-aims, como por exemplo a definição do número de tarefas MPI que serão utilizadas pelo FHI-aims, localização do arquivo executável do FHI-aims e do arquivo de entrada que precisa ser fornecido para o FHI-aims (control.in) contendo os parâmetros para o cálculo DFT. Em seguida algumas inicializações gerais são feitas, como inicialização da lista de operadores, inicialização do gerador de números aleatórios, cálculo e inicialização do raio da esfera utilizada para a inicialização aleatória das partículas, etc.

A próxima tarefa realizada é a inicialização aleatória ou leitura das partículas que serão utilizadas como ponto de partida da otimização global. O GOP trabalha inicialmente com $N_{i}$ partículas, onde $N_{i} \geq 1$. No arquivo de entrada input é possível especificar se as $N_{i}$ partículas iniciais serão lidas do arquivo input_atoms, e.g., permitindo que um novo cálculo seja iniciado a partir da configuração final de outro cálculo, ou se as partículas serão inicializadas aleatoriamente de acordo com o procedimento descrito na seção 3.3.

Após a leitura ou inicialização das $N_{i}$ partículas, estas são minimizadas localmente e suas energias são calculadas. No caso de potenciais de LJ e SC, a minimização local é realizada com o algoritmo indicado no arquivo de entrada. No caso do potencial ser DFT, então as $N_{i}$ partículas são submetidas ao FHI-aims para o cálculo de estrutura eletrônica, energia total, e minimização local utilizando o algoritmo especificado no arquivo control.in, e.g., BFGS. O resultado final são $N_{i}$ partículas correspondentes a mínimos locais, com energias totais bem determinadas. Estas partículas então são ordenadas de maneira ascendente em relação às energias e colocadas em um vetor. 


\subsubsection{Algoritmo do método RBHMC}

Este é o algoritmo correspondente à implementação do método RBHMC no pacote GOP, e pode ser visto na figura 4.1. O algoritmo recebe como entrada o vetor com $N_{i}$ configurações* iniciais, inicializadas aleatoriamente e já minimizadas localmente. Apenas a configuração de menor energia é mantida e serve como ponto inicial do algoritmo RBHMC. Essa estratégia permite que um número razoável de configurações sejam inicializadas aleatoriamente e que o algoritmo já inicie a partir de uma configuração com energia relativamente baixa (e.g., entre $2 \%$ e $10 \%$ acima da energia de mínimo global). O número inicial de configurações, $N_{i}$, não deve ser muito elevado, usualmente entre 10 e 100, dependendo do tamanho da partícula a ser otimizada, uma vez que para partículas maiores a minimização local pode ser custosa e é mais eficaz realizar alguns passos de Metropolis adicionais à inicializar muitas configurações.

Três tipos de configurações são definidas ao longo da busca. A configuração atual da busca, $C_{a}$ com energia $E_{a}$, é a última configuração aceita pelo critério de Metropolis e a que é submetida aos operadores para a geração de novas configurações. Estas, por sua vez, são armazenadas na variável $C_{t}$ ao longo da otimização, com energia $E_{t}$. Além disso, a configuração de menor energia encontrada até um determinado momento da busca é armazenada em $C_{m}$, com energia $E_{m}$. Antes do laço principal do algoritmo RBHMC iniciar, a configuração inicial de menor energia do vetor de $N_{i}$ estruturas, $C_{0}$, é atribuída à $C_{a}$ e $C_{m}$, uma vez que é a configuração de mais baixa energia até o momento, e também é a configuração atual da busca. Nesse momento ocorre também a inicialização da lista de operadores que serão utilizados pelo algoritmo.

Uma vez iniciado o laço principal, cada iteração corresponde a um passo de Metropolis. A primeira verificação feita é se no passo atual deve ser aplicado o operador $\mathrm{CO}$, de acordo com o intervalo de passos para aplicação deste operador definido no arquivo de entrada (e.g., a cada 500 passos). Este operador, ao ser aplicado, combina as estruturas $C_{a}$ e $C_{m}$ para gerar uma nova estrutura $C_{t}$. Como $C_{a}=C_{m}$ no primeiro passo, o operador CO só pode ser aplicado a partir do segundo passo. Caso o operador CO não seja habilitado no passo atual (ou não esteja ativado para nenhum passo), então o operador atual da lista de operadores, armazenado em $O P$, é aplicado à estrutura $C_{a}$. Em qualquer um dos casos, seja a aplicação do operador $\mathrm{CO}$ ou de um operador tentativa usual, a estrutura resultante é armazenada em $C_{t}$.

* Neste capítulo, os termos configuração e partícula são utilizados como sinônimos, porém, rigorosamente, uma configuração é o conjunto de coordenadas atômicas de uma partícula, i.e., $\mathbf{R}$. 


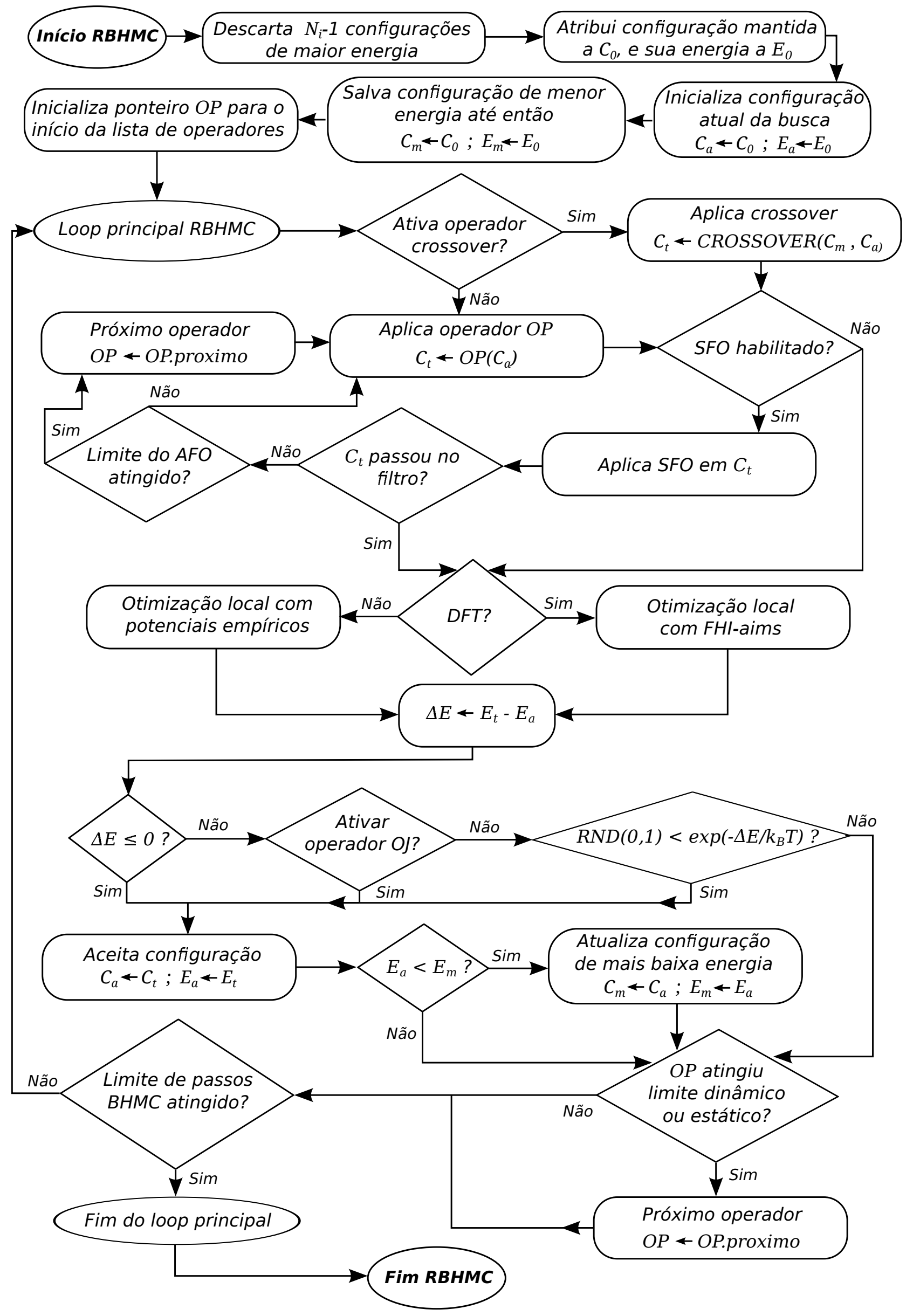

Figura 4.1 - Fluxograma do algoritmo do método RBHMC implementado na ferramenta GOP. 
Caso o operador de filtro estrutural, SFO, esteja habilitado, então a estrutura $C_{t}$ é submetida a ele. Se esta for rejeitada, então o operador que gerou a estrutura é aplicado novamente até que a estrutura seja aceita pelo SFO ou um limite de rejeições, definido no arquivo de entrada, seja atingido. Se o limite é atingido, então o próximo operador da lista é tentado, até que eventualmente uma configuração $C_{t}$ seja aceita pelo filtro. É preciso notar, porém, que caso o parâmetro $\eta$ do filtro seja muito restritivo, e.g., $\eta \approx 0$, então é provável que nenhum operador seja capaz de gerar uma estrutura que passe pelo filtro. Portanto, é importante uma escolha criteriosa do parâmetro $\eta$. Pelos testes realizados com o GOP, escolher este parâmetro no intervalo $\eta=0.3-0.5$ evita a situação indesejada de $100 \%$ de taxa de rejeição do filtro.

Uma vez a configuração $C_{t}$ gerada e aceita pelo SFO, caso esteja habilitado, é necessário realizar a minimização local dessa configuração e fazer o cálculo de sua energia total. Caso o potencial escolhido para a descrição das interações interatômicas seja um dos dois potenciais empíricos suportados, LJ ou SC, então a minimização local é realizada por algum dos algoritmos de minimização implementados no código, SDA ou GC. Por outro lado, se foi especificado no arquivo de entrada que as interações são dadas por DFT, então o GOP executa o FHI-aims com a configuração $C_{t}$ como entrada. O resultado final desta etapa é a configuração $C_{t}$ minimizada e com a energia total correspondente ao mínimo local armazenada em $E_{t}$.

Em seguida, a diferença entre a energia da configuração $C_{t}$ e da configuração atual da busca, $C_{a}$, é calculada, isto é, $\Delta E=E_{t}-E_{a}$. Se o operador de saltos ocasionais, OJ, estiver habilitado, e se o passo atual for um dos passos em que ele deve ser ativado, então a configuração $C_{t}$ é aceita pelo algoritmo. Caso o operador OJ não esteja habilitado, ou não esteja ativado no passo atual, então o critério de Metropolis é empregado para determinar se $C_{t}$ será aceita. Se $\Delta E \leq 0$, então ocorre a aceitação, o que significa que configurações $C_{t}$ que reduzem a energia em relação à configuração atual são sempre aceitas. Caso $\Delta E>0$, então $C_{t}$ é aceita com probabilidade dada pelo fator de Boltzmann, isto é, $\exp \left(-\Delta E / k_{B} T\right)$. Na prática, basta sortear um número aleatório de uma distribuição uniforme definida no intervalo $[0,1]$ e comparar com o fator de Boltzmann. Se este número aleatório for menor que o termo exponencial, a configuração é aceita. Caso contrário, é rejeitada.

Uma vez que a configuração $C_{t}$ tenha sido aceita, ela se torna a configuração atual da busca, $C_{a}$. Uma segunda verificação é feita a fim de determinar se esta nova configuração tem a menor energia encontrada até o momento na busca. Em caso positivo, a configuração $C_{t}$ é salva também em $C_{m}$, e sua energia salva em $E_{m}$. Em seguida é verificado se o limite de aplicações do operador atual, $O P$, foi atingido. Caso o limite definido no arquivo de entrada foi estático, então basta verificar o número de vezes que o operador atual foi aplicado consecutivamente. Esse número de aplicações é armazenado em um contador, o qual é zerado 
sempre que um operador é aplicado pela primeira vez no ciclo. Se o limite definido foi dinâmico, então a verificação é feita em relação a um contador que armazena as rejeições consecutivas de um mesmo operador, isto é, sempre que uma configuração gerada por um determinado operador é rejeitada pelo critério de Metropolis, esse contador é incrementado, e quando uma configuração é aceita, o contador é zerado. Quando o limite de aplicações do operador é atingido, seja ele dinâmico ou estático, o algoritmo faz $O P$ apontar para o próximo operador na sequência, avançando na lista de operadores. Como a lista é definida de maneira circular, os operadores são utilizados ciclicamente, cada um aplicado até o seu limite.

Finalmente, o algoritmo verifica se o número máximo de passos de Metropolis foi atingido e finaliza o laço principal em caso positivo. Este número refere-se ao número total de passos executados e deve ser especificado no arquivo de entrada. É possível também definir um segundo número máximo de passos, este dinâmico, referente aos passos consecutivos em que uma configuração de menor energia não foi encontrada, i.e., número de passos decorridos desde a última atualização de $C_{m}$. Por exemplo, é possível realizar uma otimização global por no máximo 1000, porém que é interrompida caso a busca não encontre uma configuração com energia mais baixa que $E_{m}$ por 200 passos consecutivos.

Ao término do laço principal, a configuração armazenada em $C_{m}$ será aquela correspondente ao mínimo global putativo encontrado pelo GOP, com energia $E_{m}$. Uma observação que não está presente no fluxograma da figura 4.1 é que ao longo da busca as configurações $C_{t}, C_{a}$ e $C_{m}$ são armazenadas em disco com suas respectivas energias. Além disso, também são armazenados dados correspondentes à taxa de aceitação geral do critério de Metropolis, taxas de rejeição e aceitação de cada operador, além de outras informações que permitem uma análise detalhada do desempenho da otimização global.

\subsubsection{Potenciais empíricos}

A versão atual do GOP suporta os potenciais empíricos de LJ e SC, porém o código foi construído de modo que a inclusão de novos potenciais seja simplificada. Tal característica foi atingida empregando dois conceitos de engenharia de software conhecidos como encapsulamento e polimorfismo (131). Encapsulamento se refere a uma função que realiza seu trabalho como se fosse uma caixa preta, sem alterar o ambiente externo, e sem que aquele que chama a função precise saber como ela é implementada. Uma vez a interface da função estando bem definida, isto é, especificado-se o que a função recebe e o que ela retorna, não há a necessidade de saber o seu funcionamento interno. Polimorfismo é quando uma mesma função pode realizar tarefas diferentes de acordo com o contexto em que ela é chamada. Esses dois conceitos 
são comumente suportados por linguagens de programação orientadas a objetos, como $\mathrm{C}++$ ou Java. Porém, a linguagem utilizada para implementar o GOP é $C$, que não oferece suporte nativo a esses e outros conceitos de orientação a objetos. Contudo, apesar de não suportá-los diretamente, a linguagem $C$ é flexível o suficiente para permitir que eles sejam implementados, e.g., utilizando estruturas, uniões, ponteiros para funções e funções de acesso e modificação de variáveis locais.

A implementação de um potencial empírico qualquer no GOP tem três componentes principais: uma função para o cálculo da energia total, uma função para o cálculo das forças, e matrizes de parâmetros do potencial contendo os valores tabelados para cada espécie química que o potencial é capaz de modelar. A noção de encapsulamento é implementada fazendo com que as funções para o cálculo de energia e forças afetem somente um conjunto de variáveis definidas localmente em arquivos específicos relacionados aos potenciais. É possível, por exemplo, que o cálculo da energia envolva chamadas a diversas funções auxiliares e envolva estruturas de dados complexas, porém a interface é sempre a mesma: dada uma configuração (conjunto de coordenadas), retornar o valor da energia. O código que chama a função para o cálculo da energia não deve se preocupar em como o cálculo é realizado, ou se é realizado de maneira ótima, desde que entenda como é a interface da função e use-a corretamente.

A mesma discussão se aplica ao cálculo das forças, e também ao acesso às matrizes de parâmetros dos potenciais. Estas matrizes são definidas localmente, e é possível acessálas apenas através de funções especiais, definidas globalmente, que recebem um parâmetro desejado e retornam seu valor, ou associam ao parâmetro desejado um valor passado a elas. Em linguagens orientadas a objetos essa noção de variáveis e funções locais e globais é expressa normalmente em outros termos, como variáveis e funções privadas e públicas, respectivamente. A maneira de conseguir o mesmo efeito na linguagem $C$ é utilizar definições adequadas em arquivos fonte separados, empregar corretamente arquivos cabeçalho para definir interfaces para as funções, e também através do emprego criterioso das palavras-chave extern e static.

O conceito de polimorfismo, por sua vez, é implementando através de ponteiros para as funções que realizam o cálculo de energia e das forças associadas a uma configuração. Ao invés de permear o código com comandos condicionais em cada trecho onde é necessário realizar tais cálculos, basta realizar chamadas aos ponteiros para as funções. Estes ponteiros são inicializados quando começa a execução do GOP, e a eles são atribuídos os endereços das funções correspondentes ao potencial informado no arquivo de entrada. Assim, o código referente ao algoritmo RBHMC, por exemplo, não precisa se preocupar em diferenciar entre os potenciais existentes na hora de realizar o cálculo de energia. Basta a ele utilizar o ponteiro para a função de energia total que a chamada será sempre correta. 
O uso de encapsulamento e de polimorfismo não só torna a programação mais segura e menos propensa a problemas de dependência de dados e variáveis, mas também facilita a expansão do código para suportar outros potenciais empíricos. Ao adicionar um novo potencial, basta codificar suas funções de energia e forças em um arquivo específico para potenciais, e então exportar a interface para essas funções através de um cabeçalho bem definido, respeitando a padronização da interface empregada para os outros potenciais. Esse novo potencial pode então ser utilizado fazendo pequenas modificações na inicialização dos ponteiros para as funções, sem que haja a necessidade de alterar partes significativas do código, em particular partes do código que não se referem aos potenciais empíricos. Assim, a legibilidade do código é mantida, e sua manutenção é facilitada.

\subsubsection{Operadores}

A implementação dos operadores segue a mesma estratégia das implementações dos potenciais empíricos. Os detalhes de implementação ficam escondidos de outras funções, que se comunicam com os operadores através de chamadas bem definidas. Essa estratégia permite que a adição de novos operadores seja simplificada consideravelmente. Cada operador é implementado como uma função que recebe dois parâmetros, um ponteiro para a configuração original e outro para onde será armazenada a nova configuração, sendo a única exceção o operador $\mathrm{CO}$, que recebe duas configurações originais que são combinaras e dão origem a duas novas configurações. Alguns detalhes de implementação dos operadores são apresentados a seguir.

\section{- Operador de deslocamento cartesiano, operador de deslocamento em relação} ao centro geométrico, operador angular e operador angular de superfície

Esses operadores podem agir sob $M$ átomos, $1 \leq M \leq N$, sob dois critérios: seleção de $M$ átomos de maneira aleatória ou baseada em energia, sendo esta última disponível apenas para potenciais empíricos. No caso de seleção baseada em energia, os $N$ átomos são ordenados em relações às suas energias e então os $M$ átomos com maior energia são selecionados. Já no caso de seleção aleatória, há três diferentes possibilidades: (i) se $M=1$, o algoritmo escolhe um átomo aleatoriamente; (ii) se $M=N$, todos os átomos são considerados e não é preciso empregar nenhum procedimento aleatório; (iii) se $1<M<N$, então todos os $N$ átomos são colocados em um vetor, o qual é permutado aleatoriamente através do algoritmo de Fisher-Yates (132), e então os $M$ primeiros átomos do vetor são escolhidos. A opção por tratar as três possibilidades 
separadamente deve-se ao fato de ser desnecessário fazer permutações aleatórias, que emprega um algoritmo com complexidade assintótica $O(N)$, para os casos $M=1 \mathrm{e}$ $M=N$. Nesses casos a seleção tem complexidade $O(1)$.

\section{- Operador twist}

A secção da partícula por um plano aleatório é realizada primeiramente transladando a partícula de modo que o centro geométrico coincida com a origem do sistema de coordenadas. Então é aplicada uma rotação aleatória, definida pela matriz de rotação $R(\phi, \psi, \theta)$, na qual números aleatórios de uma distribuição uniforme no intervalo $[0,2 \pi]$ são atribuídos aos ângulos $\phi, \psi$ e $\theta$. Em seguida, um número $\beta R_{\max }[-1,+1]$ é utilizado para definir um nível no eixo $z$, correspondendo a um plano que divide a partícula em duas regiões, uma delas com átomos cuja coordenada $z$ é maior ou igual ao número aleatório, e outra com átomos cuja coordenada $z$ é menor. Finalmente, aos átomos de uma das porções é aplicada uma rotação aleatória de um ângulo $\left[0, \theta_{\max }\right]$ em torno do eixo $z$. O procedimento de centralizar a partícula e submetê-la a uma rotação aleatória simplifica a implementação do plano aleatório.

\section{- Operador interior}

O algoritmo do operador $\mathrm{IO}$ primeiramente ordena os $N$ átomos da partícula de acordo com suas distâncias ao centro geométrico, e então seleciona os átomos mais distantes e os move para uma esfera centrada no centro geométrico cujo raio é uma fração do raio da partícula, $R_{\max }$.

\section{- Operador de troca e operador de troca geométrico}

Esses operadores selecionam pares de átomos de espécies diferentes e para cada par faz uma troca de espécies. Para evitar que os operadores efetuem mais de uma troca envolvendo os mesmos átomos em uma única aplicação, uma estratégia simples de implementação é marcar os átomos que já foram trocados com um flag, que é então verificado ao realizar novas trocas durante a mesma aplicação dos operadores. Caso o número de trocas requisitado exceda o número máximo de pares possíveis envolvendo átomos que não foram trocados, então são trocados apenas os pares possíveis. Por exemplo, se a partícula contém 2 átomos do tipo $A$ e 4 átomos do tipo $B$, é possível formar apenas 2 pares do tipo $A B$ de modo a efetuar apenas uma troca para cada átomo do tipo $B$. Nesse caso, se for requisitado no arquivo de entrada que os operadores efetuem mais de duas trocas em cada aplicação, apenas duas são realizadas. 


\subsubsection{Interface com o pacote $\mathrm{FHI}$-aims}

Cálculos de estrutura eletrônica, em particular dentro do formalismo de DFT, exigem um grande esforço de implementação e testes. Durante o desenvolvimento do GOP optou-se por utilizar um pacote externo já testado e com boa reputação na literatura, uma vez que a implementação de um pacote de estrutura eletrônica estaria muito além do escopo deste trabalho. O pacote escolhido foi o FHI-aims (86), que possui excelente escalabilidade em ambientes paralelos. Do ponto de vista do estudo de clusters e NPs, uma vantagem deste pacote reside no fato de que ele emprega orbitais numéricos centrados nos átomos como o conjunto de funções de bases sobre o qual os orbitais de Kohn-Sham são expandidos, sendo, portanto, uma opção ideal para cálculos envolvendo sistemas não periódicos (133).

A integração entre o GOP e o pacote FHI-aims encontrou um obstáculo inicial devido ao fato do FHI-aims não oferecer uma biblioteca para acessar suas funções internas. Caso o FHIaims oferecesse uma interface de programação de aplicação (API - application programming interface), bastaria chamar diretamente do GOP as rotinas e funções do FHI-aims, seguindo as convenções de parâmetros definidas pela interface. Como tal API não existe, a maneira encontrada para integrar ambos os pacotes foi através da criação de processos filhos, a partir do GOP, responsáveis por chamarem diretamente o executável do FHI-aims, e empregando arquivos em disco para a comunicação entre o GOP e FHI-aims.

Quando o GOP precisa chamar o FHI-aims para cálculos de DFT, seja durante a inicialização das configurações, seja durante o laço principal do algoritmo RBHMC, ele escreve a estrutura atômica da configuração em um arquivo cujo formato pode ser processado pelo FHI-aims. O GOP então utiliza a chamada de sistema fork para criar um novo processo filho, idêntico ao seu próprio processo, porém com número de identificação de processo diferente, e então utiliza a chamada waitpid para se bloquear até que o processo filho termine sua execução. No processo filho, o código do FHI-aims é invocado através da chamada execvp, e então passa a executar e lê os arquivos de entrada necessários, incluindo a estrutura da configuração preparada pelo GOP. Ao longo de sua execução, o FHI-aims salva sua saída em um arquivo em disco chamado aims.out, que futuramente é processado pelo GOP. Assim que o $\mathrm{FHI}$-aims termina de executar, o processo filho que o executava envia um sinal para 0 GOP, que está bloqueado, avisando que este pode acordar e continuar com a execução. A comunicação para sincronizar os processos é feita através da chamada kill empregando um sinal definido para este propósito, SIGUSR1. Esta comunicação garante que o FHI-aims só comece a executar quando o GOP houver preparado o contexto corretamente, como arquivos de entrada e estruturas de dados necessárias, e também garante que o GOP volte a executar 
somente quando o $\mathrm{FHI}$-aims for finalizado no processo filho.

Além do arquivo contendo a estrutura atômica, o FHI-aims espera encontrar o arquivo control.in, no qual as configurações do cálculo de DFT devem estar especificadas, como conjunto de funções de bases que serão utilizadas e parâmetros controlando o cálculo autoconsistente da densidade eletrônica. Este arquivo deve ser preparado pelo usuário e não é modificado pelo GOP, que tem apenas o papel de deixá-lo no local correto onde, a cada execução, o FHI-aims vai encontrá-lo e processá-lo. Além do arquivo control.in, o usuário precisa fornecer outras três informações que serão utilizadas pelo GOP para realizar a chamada ao $\mathrm{FHI}$-aims, sendo elas o local onde o arquivo binário do $\mathrm{FHI}$-aims pode ser encontrado, o comando utilizado para executar o FHI-aims em um ambiente paralelo MPI (tipicamente o caminho para o comando mpirun), e o número de threads MPI utilizadas pelo FHI-aims. A maneira usual de especificar essas três informações é através das variáveis de ambiente GOP_AIMS_BIN, GOP_MPI_BIN e GOP_MPI_NP, respectivamente, que são lidas pelo GOP.

O processamento do arquivo de saída do FHI-aims é realizado pelo GOP com auxílio da biblioteca libpcre (134), que permite o processamento eficiente de grandes arquivos de texto e a extração de informações utilizando expressões regulares. O uso dessa biblioteca não só facilita a extração das informações relevantes, como também permite que no futuro novas informações sejam extraídas sem dificuldades, simplesmente codificando novas expressões regulares. Para maior eficiência, o GOP faz a leitura do arquivo de saída do FHI-aims em blocos, utilizando a chamada read, e então aplica as expressões regulares em cada bloco. Como a biblioteca libpcre é orientada à linhas, o GOP possui uma mecânica para garantir que os blocos lidos contenham apenas linhas completas.

As expressões regulares necessárias para extrair a energia final da partícula calculada com o FHI-aims, bem como sua estrutura atômica resultante, são criadas e compiladas durante a inicialização do GOP. Além da energia final e estrutura atômica, outra informação relevante que é extraída do arquivo de saída do FHI-aims é o estado final do cálculo, assim o GOP pode determinar se o cálculo de DFT finalizou com sucesso ou não, e.g., se houve problemas de convergência. Quando o FHI-aims falha por alguma razão dentro do algoritmo RBHMC, o GOP descarta o passo atual e reaplica o operador $O P$ à configuração $C_{a}$, de modo a gerar uma nova configuração $C_{t}$ que é submetida ao FHI-aims outra vez. Testes realizados indicam que sempre que há uma falha no FHI-aims com uma determinada configuração, essa estratégia permite que na segunda ou terceira tentativa com novas configurações $C_{t}$, o $\mathrm{FHI}$-aims termine com sucesso. 


\section{CAPÍTULO 5}

\section{Estudo de Casos: Clusters de Lennard-Jones e Sutton-Chen}

Neste capítulo são apresentados os resultados de um estudo de casos para os potenciais empíricos de LJ e SC utilizando o método RBHMC implementado no GOP. Os sistemas estudados são clusters $\mathrm{LJ}_{N}(N=2-148), \mathrm{NPs} \mathrm{LJ}_{N}(N=200,250,300,350,400,450$, $500,1000,1500)$, clusters $\mathrm{SC}_{N}(N=3-148)$, clusters $\mathrm{BLJ}_{N}(N=3-100)$ com átomos de diferentes tamanhos, e clusters binários $(\mathrm{AgPd})_{55}$ com todas as composições possíveis descrito pelo potencial SC.

\subsection{Clusters de Lennard-Jones}

Clusters de LJ constituem um conjunto de testes importante para avaliar o desempenho de metodologias de otimização global. Além disso, pelo fato do potencial de LJ ter uma formulação simples, esses clusters servem como uma rota de estudo para investigar as conexões entre as propriedades estruturais, dinâmicas e termodinâmicas de um sistema e a SEP. Essas propriedades tem sido o alvo de numerosos estudos teóricos, e muitas das morfologias presentes em estruturas de mínimo global de clusters de LJ foram observadas experimentalmente em clusters de átomos cobrindo boa parte da tabela periódica (37).

O método RBHMC aplicado à clusters $\mathrm{LJ}_{N}(N=2-148)$ foi configurado para utilizar uma única configuração inicial (essa estratégia também foi empregada para todos os outros sistemas estudados neste trabalho), a temperatura foi fixada em $k_{B} T=1.6$, que por testes preliminares mostrou-se eficiente, oferecendo um equilíbrio entre exploração local e global. Os operadores $\mathrm{OJ}$ e CO foram desabilitados, pois verificou-se que para clusters $\mathrm{LJ}_{N}$ na faixa de tamanhos considerada, esses operadores não contribuem significativamente ao longo da otimização. A sequência de operadores utilizada foi GCDO, TO, CDO, CDO, SAO, GCDO, 
$A O, C D O, I O$, porém não é uma sequência definitiva e pode ser otimizada para cada sistema em particular, sendo o fator mais importante a disposição intercalada de operadores locais e não-locais. A estratégia dinâmica foi utilizada para a aplicação dos operadores. O número de passos de Metropolis variou entre $10^{2}$ e $10^{5}$, de acordo com o tamanho do sistema (mais passos para sistemas com mais átomos). Em relação aos parâmetros do potencial (equação 2.1.3), unidades reduzidas foram utilizadas, onde $\epsilon=1$ e $\sigma=1^{*}$.

Como pode ser visto na figura 5.1, os mínimos globais encontrados com o método RBHMC para clusters $\mathrm{LJ}_{N}(N=2-148)$ estão em total acordo com os melhores dados referentes aos mínimos globais putativos disponíveis na literatura e coletados no Cambridge Cluster Database (4).

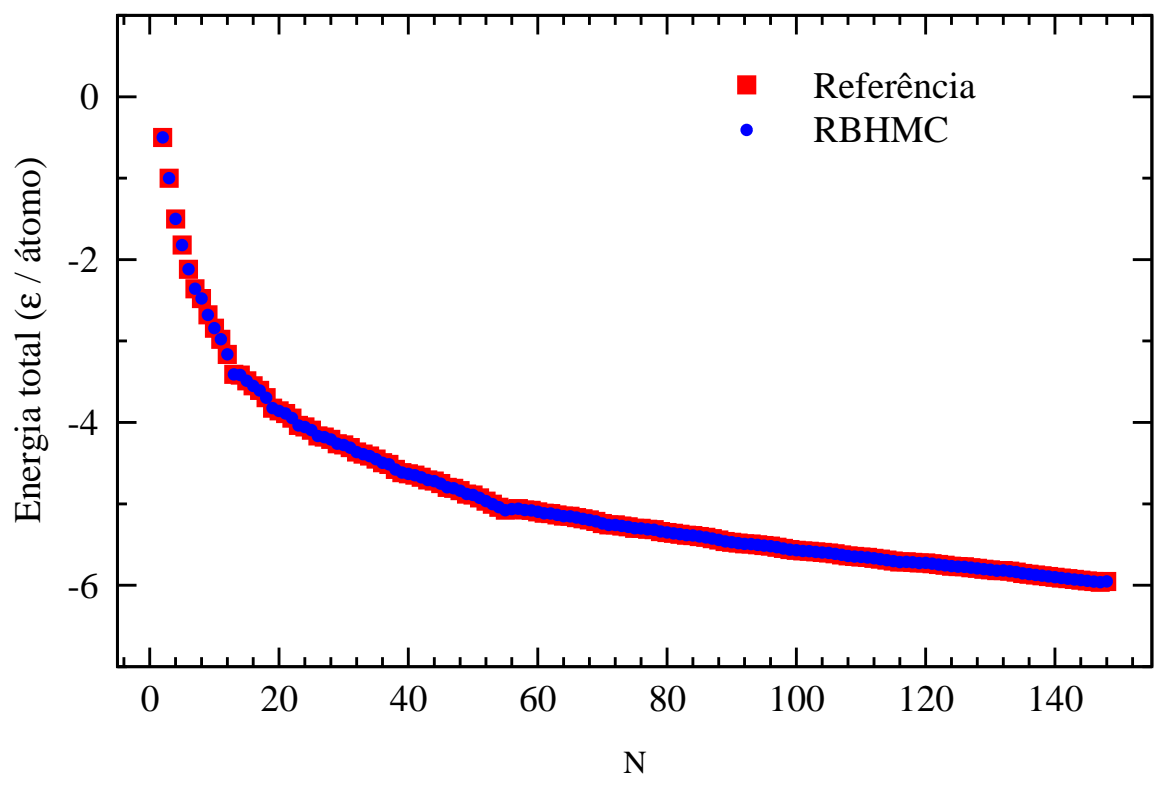

Figura 5.1 - Energia total por átomo em unidades de $\epsilon$ dos mínimos globais dos clusters $\mathrm{LJ}_{N}(N=$ 2 - 148). Os resultados deste trabalho utilizando o método RBHMC são comparados com dados de referência da literatura (4).

Na tabela 5.1 são mostradas as energias totais e grupos pontuais de simetria para cada cluster. Na faixa de tamanhos considerada, a maioria das estruturas são baseadas no icosaedro de Mackay (135), sendo que icosaedros completos foram identificados para os casos $L J_{13}, L J_{55}$ e $L J_{147}$. Nesses casos os icosaedros se fecham perfeitamente (i.e., não são truncados) e as estruturas são formadas por camadas completas. No caso $\mathrm{LJ}_{13}$, o átomo central é envolvo em uma camada com 12 átomos, enquanto para $\mathrm{LJ}_{55}$ há uma camada adicional com 42 átomos envolvendo o átomo central e a primeira camada de 12 átomos. No cluster $\mathrm{LJ}_{147}$ encontra-se *Em clusters em que $\alpha=\beta$, os índices de espécies dos parâmetros serão omitidos. 
Tabela 5.1 - $\quad$ Energias totais e grupo pontual de simetria (GP) das estruturas de mínimo global dos clusters $\mathrm{LJ}_{N}(N=2-148)$.

\begin{tabular}{|c|c|c|c|c|c|c|c|c|}
\hline$N$ & Energia $(\epsilon)$ & GP & $N$ & Energia $(\epsilon)$ & GP & $N$ & Energia $(\epsilon)$ & GP \\
\hline 2 & -1.000000 & $D_{\infty h}$ & 51 & -251.253964 & $C_{2 v}$ & 100 & -557.039820 & $C_{s}$ \\
\hline 3 & -3.000000 & $D_{3 h}$ & 52 & -258.229991 & $C_{3 v}$ & 101 & -563.411308 & $C_{2 v}$ \\
\hline 4 & -6.000000 & $T_{d}$ & 53 & -265.203016 & $C_{2 v}$ & 102 & -569.363652 & $C_{2 v}$ \\
\hline 5 & -9.103852 & $D_{3 h}$ & 54 & -272.208631 & $C_{5 v}$ & 103 & -575.766131 & $C_{s}$ \\
\hline 6 & -12.712062 & $O_{h}$ & 55 & -279.248470 & $I_{h}$ & 104 & -582.086642 & $C_{2 v}$ \\
\hline 7 & -16.505384 & $D_{5 h}$ & 56 & -283.643105 & $C_{3 v}$ & 105 & -588.266501 & $C_{1}$ \\
\hline 8 & -19.821489 & $C_{s}$ & 57 & -288.342625 & $C_{s}$ & 106 & -595.061072 & $C_{1}$ \\
\hline 9 & -24.113360 & $C_{2 v}$ & 58 & -294.378148 & $C_{3 v}$ & 107 & -602.007110 & $C_{s}$ \\
\hline 10 & -28.422532 & $C_{3 v}$ & 59 & -299.738070 & $C_{2 v}$ & 108 & -609.033011 & $C_{s}$ \\
\hline 11 & -32.765970 & $C_{2 v}$ & 60 & -305.875476 & $C_{s}$ & 109 & -615.411166 & $C_{1}$ \\
\hline 12 & -37.967600 & $C_{5 v}$ & 61 & -312.008896 & $C_{2 v}$ & 110 & -621.788224 & $C_{s}$ \\
\hline 13 & -44.326801 & $I_{h}$ & 62 & -317.353901 & $C_{s}$ & 111 & -628.068416 & $C_{s}$ \\
\hline 14 & -47.845157 & $C_{3 v}$ & 63 & -323.489734 & $C_{1}$ & 112 & -634.874626 & $C_{s}$ \\
\hline 15 & -52.322627 & $C_{2 v}$ & 64 & -329.620147 & $C_{s}$ & 113 & -641.794704 & $C_{s}$ \\
\hline 16 & -56.815742 & $C_{s}$ & 65 & -334.971532 & $C_{2}$ & 114 & -648.833100 & $C_{s}$ \\
\hline 17 & -61.317995 & $C_{2}$ & 66 & -341.110599 & $C_{1}$ & 115 & -655.756307 & $C_{5 v}$ \\
\hline 18 & -66.530949 & $C_{5 v}$ & 67 & -347.252007 & $C_{s}$ & 116 & -662.809353 & $C_{5 v}$ \\
\hline 19 & -72.659782 & $D_{5 h}$ & 68 & -353.394542 & $C_{1}$ & 117 & -668.282701 & $C_{1}$ \\
\hline 20 & -77.177043 & $C_{2 v}$ & 69 & -359.882566 & $C_{5 v}$ & 118 & -674.769635 & $C_{s}$ \\
\hline 21 & -81.684571 & $C_{2 v}$ & 70 & -366.892251 & $C_{5 v}$ & 119 & -681.419158 & $C_{s}$ \\
\hline 22 & -86.809782 & $C_{s}$ & 71 & -373.349661 & $C_{5 v}$ & 120 & -687.021982 & $C_{1}$ \\
\hline 23 & -92.844472 & $D_{3 h}$ & 72 & -378.637253 & $C_{s}$ & 121 & -693.819577 & $C_{1}$ \\
\hline 24 & -97.348815 & $C_{s}$ & 73 & -384.789377 & $C_{s}$ & 122 & -700.939379 & $C_{1}$ \\
\hline 25 & -102.372663 & $C_{s}$ & 74 & -390.908500 & $C_{s}$ & 123 & -707.802109 & $C_{s}$ \\
\hline 26 & -108.315616 & $T_{d}$ & 75 & -397.492331 & $D_{5 h}$ & 124 & -714.920896 & $C_{s}$ \\
\hline 27 & -112.873584 & $C_{2 v}$ & 76 & -402.894866 & $C_{s}$ & 125 & -721.303235 & $C_{s}$ \\
\hline 28 & -117.822402 & $C_{s}$ & 77 & -409.083517 & $C_{2 v}$ & 126 & -727.349853 & $C_{1}$ \\
\hline 29 & -123.587371 & $D_{3 h}$ & 78 & -414.794401 & $C_{s}$ & 127 & -734.479629 & $C_{2 v}$ \\
\hline 30 & -128.286571 & $C_{2 v}$ & 79 & -421.810897 & $C_{2 v}$ & 128 & -741.332100 & $C_{1}$ \\
\hline 31 & -133.586422 & $C_{s}$ & 80 & -428.083564 & $C_{s}$ & 129 & -748.460647 & $C_{s}$ \\
\hline 32 & -139.635524 & $C_{2 v}$ & 81 & -434.343643 & $C_{2 v}$ & 130 & -755.271073 & $C_{1}$ \\
\hline 33 & -144.842719 & $C_{s}$ & 82 & -440.550425 & $C_{1}$ & 131 & -762.441558 & $C_{2 v}$ \\
\hline 34 & -150.044528 & $C_{2 v}$ & 83 & -446.924094 & $C_{2 v}$ & 132 & -768.042203 & $C_{1}$ \\
\hline 35 & -155.756643 & $C_{1}$ & 84 & -452.657214 & $C_{1}$ & 133 & -775.023203 & $C_{s}$ \\
\hline 36 & -161.825363 & $C_{s}$ & 85 & -459.055799 & $C_{3 v}$ & 134 & -782.206157 & $C_{3 v}$ \\
\hline 37 & -167.033672 & $C_{1}$ & 86 & -465.384493 & $C_{1}$ & 135 & -790.278120 & $I_{h}$ \\
\hline 38 & -173.928427 & $O_{h}$ & 87 & -472.098165 & $C_{s}$ & 136 & -797.453259 & $C_{5 v}$ \\
\hline 39 & -180.033185 & $C_{5 v}$ & 88 & -479.032630 & $C_{s}$ & 137 & -804.631473 & $C_{2 v}$ \\
\hline 40 & -185.249839 & $C_{s}$ & 89 & -486.053911 & $C_{3 v}$ & 138 & -811.812780 & $C_{3 v}$ \\
\hline 41 & -190.536277 & $C_{s}$ & 90 & -492.433908 & $C_{s}$ & 139 & -818.993848 & $C_{2 v}$ \\
\hline 42 & -196.277534 & $C_{s}$ & 91 & -498.811060 & $C_{s}$ & 140 & -826.174676 & $C_{s}$ \\
\hline 43 & -202.364664 & $C_{s}$ & 92 & -505.185309 & $C_{3 v}$ & 141 & -833.358586 & $C_{5 v}$ \\
\hline 44 & -207.688728 & $C_{1}$ & 93 & -510.877688 & $C_{1}$ & 142 & -840.538610 & $C_{s}$ \\
\hline 45 & -213.784862 & $C_{1}$ & 94 & -517.264131 & $C_{1}$ & 143 & -847.721698 & $C_{2 v}$ \\
\hline 46 & -220.680330 & $C_{2 v}$ & 95 & -523.640211 & $C_{1}$ & 144 & -854.904499 & $C_{3 v}$ \\
\hline 47 & -226.012256 & $C_{1}$ & 96 & -529.879146 & $C_{1}$ & 145 & -862.087012 & $C_{2 v}$ \\
\hline 48 & -232.199529 & $C_{s}$ & 97 & -536.681383 & $C_{1}$ & 146 & -869.272573 & $C_{5 v}$ \\
\hline 49 & -239.091864 & $C_{3 v}$ & 98 & -543.665361 & $T_{d}$ & 147 & -876.461207 & $I_{h}$ \\
\hline 50 & -244.549926 & $C_{s}$ & 99 & -550.666526 & $C_{2 v}$ & 148 & -881.072971 & $C_{s}$ \\
\hline
\end{tabular}


uma terceira camada com 92 átomos envolvendo o átomo central e as duas camadas interiores. As estruturas que fogem do tipo icosaedro são $\mathrm{LJ}_{38}, \mathrm{LJ}_{79}, \mathrm{LJ}_{116}$, baseadas em uma estrutura de octaedro truncado, $L J_{98}$, que forma um tetraedro de Leary (51), e $L J_{75}, L J_{76}, L J_{77}, L J_{102}$, $\mathrm{LJ}_{103}$ e $\mathrm{LJ}_{104}$, cujas geometrias são baseadas no decaedro de Marks $(33,136)$. Algumas dessas estruturas são exibidas na figura 5.2.

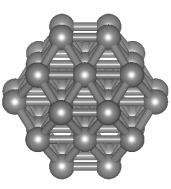

$\mathrm{LJ}_{38}$

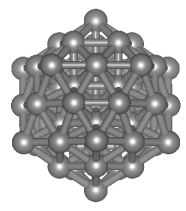

$\mathrm{LJ}_{55}$

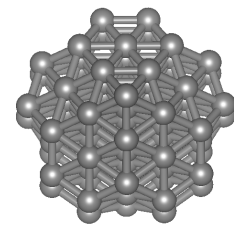

$\mathrm{LJ}_{75}$

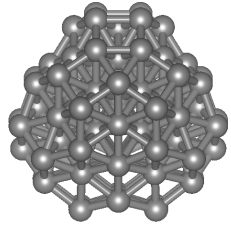

$\mathrm{LJ}_{98}$

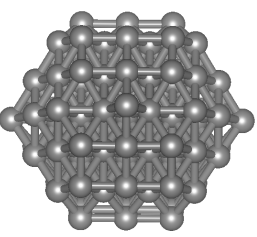

$\mathrm{LJ}_{102}$

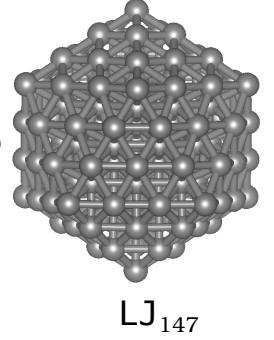

Figura 5.2 - Estruturas de mínimo global de alguns clusters $\mathrm{LJ}_{N}(N=38,55,75,98,102,147)$.

Na figura 5.3 são mostradas algumas propriedades estruturais dos clusters $L J_{N}$, como o número de coordenação efetiva médio (ECN - effective coordination number), comprimento de ligação ponderado médio, $d_{a v}$, e função de estabilidade relativa, $\Delta_{2} E(N)$. As definições de ECN e $d_{a v}$ são dadas no apêndice $\mathrm{A}$. A função $\Delta_{2} E(N)$ fornece uma medida da estabilidade de um cluster de $N$ átomos em relação aos clusters de tamanhos vizinhos, com $N-1$ e $N+1$ átomos. Ela é definida como uma diferença finita de energias,

$$
\Delta_{2} E(N)=E(N+1)+E(N-1)-2 E(N),
$$

onde $E(N+1)$ e $E(N-1)$ correspondem às energias totais dos clusters com tamanhos $N+1$ e $N-1$, respectivamente, e $E(N)$ é a energia total do cluster de $N$ átomos. Configurações associadas ao picos na função $\Delta_{2} E$ são consideradas como estruturalmente estáveis, e para clusters de espécies químicas reais é possível estabelecer uma correlação entre os picos de $\Delta_{2} E$ e tamanhos de clusters que são encontrados com maior abundância em experimentos. Como é necessário utilizar os dois vizinhos, $N+1$ e $N-1$, para determinar o valor de $\Delta_{2} E$ para cada tamanho $N$, a função de estabilidade relativa foi calculada apenas para os clusters $L J_{N}$ de tamanhos $N=3-147$.

Como pode ser visto na figura 5.3, o valor do ECN médio cresce com o número de átomos. Para tamanhos menores o crescimento é mais acelerado, até que começa a saturar por volta de $N=20$, tendendo para um valor de coordenação efetiva média próximo de 9.30 para $N=148$. A coordenação do bulk infinito de LJ é 12 , portanto o ECN médio de 9.30 para o cluster $\mathrm{LJ}_{148}$ indica que efeitos de superfície ainda são significativos para esse tamanho. Apesar de algumas variações modestas na curva do ECN médio, como um pequeno bico para 
$N=13$, e um leve decréscimo para $N=31$, ela apresenta um comportamento suave até atingir a saturação. A curva associada a $d_{a v}$ possui características interessantes, como uma queda brusca para $N=31$, ilustrando uma transição estrutural favorecendo geometrias mais compactas a partir deste tamanho. A partir de $N=31$ o valor de $d_{a v}$ apresenta poucas variações com o tamanho dos clusters, sendo as mais significativas aquelas associadas aos clusters cujas geometrias não são do tipo icosaedro de Mackay, entre as quais destacam-se estruturas mais compactas para $\mathrm{LJ}_{38}, \mathrm{LJ}_{75}, \mathrm{LJ}_{76}, \mathrm{LJ}_{77}, \mathrm{LJ}_{98}, \mathrm{LJ}_{102}, \mathrm{LJ}_{103}$ e $\mathrm{LJ}_{104}$. Os picos mais salientes da função de estabilidade relativa correspondem às estruturas de maior simetria na faixa de tamanhos $N=2-148$, sendo elas $\mathrm{LJ}_{13}, \mathrm{LJ}_{55}$ e $\mathrm{LJ}_{147}$. Essas estruturas possuem grupo pontual de simetria $I_{h}$ e suas geometrias são do tipo icosaedro completo.

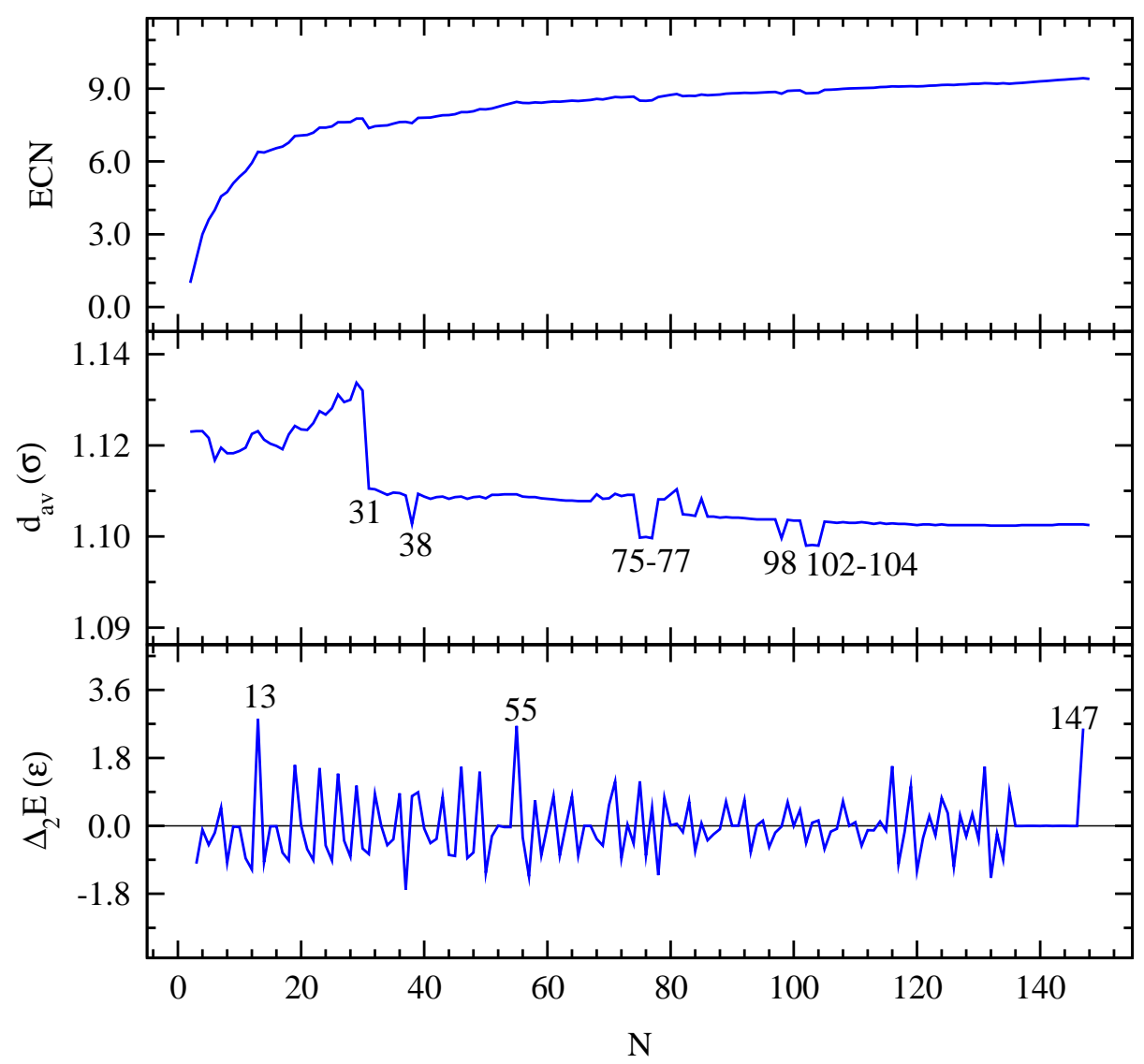

Figura 5.3 - Número de coordenação efetiva médio (ECN), comprimento de ligação ponderado médio $\left(d_{a v}\right)$, e função de estabilidade relativa $\left(\Delta_{2} E\right)$ das estruturas de mínimo global dos clusters $\mathrm{LJ}_{N}(N=2-148)$.

Os casos em que as geometrias diferem do tipo icosaedro de Mackay são considerados mais desafiadores do ponto de vista de otimização global, pois apresentam SEPs com múltiplos funis, nas quais o funil associado ao mínimo global é cercado de altas barreiras de energia. Entre esses casos, foram selecionados os clusters $\mathrm{LJ}_{38}, \mathrm{LJ}_{75}$ e $\mathrm{LJ}_{98}$ para comparar o desempenho 
dos esquemas estático e dinâmico de aplicação de operadores. Além disso, o cluster $\mathrm{LJ}_{55}$, com geometria do tipo icosaedro, também foi utilizado para ilustrar a maior facilidade em encontrar o seu mínimo global. A comparação consistiu de dois conjuntos de 100 execuções independentes do GOP para cada um dos quatro tamanhos selecionados $(N=38,55,75,98)$.

Em um dos conjuntos o esquema estático de seleção de operadores foi adotado, enquanto no outro adotou-se o esquema dinâmico. Todas as execuções foram realizadas até que o mínimo global putativo para cada sistema fosse obtido, portanto uma taxa de sucesso de $100 \%$ foi atingida para todos os casos. Para cada sistema e esquema de seleção de operadores, o tempo médio para o primeiro encontro (TMPE) foi calculado, e este consiste simplesmente no número médio de passos necessários para localizar o mínimo global para aquele sistema em particular. É de valia notar que no caso do método RBHMC, o TMPE também indica o número médio de minimizações locais que foram realizadas, uma vez que a cada passo é realizada uma minimização local. Os resultados da comparação são exibidos na tabela 5.2, na qual também figuram dados recentes disponíveis na literatura (11), para fins de avaliação da metodologia apresentada neste trabalho.

Tabela 5.2 - Tempo médio para o primeiro encontro calculado a partir de 100 aplicações independentes do método RBHMC para clusters $\mathrm{LJ}_{38}, \mathrm{LJ}_{55}, \mathrm{LJ}_{75}$ e $\mathrm{LJ}_{98}$ empregando os esquemas estático e dinâmico de seleção de operadores. Resultados recentes utilizando o método BHMC padrão e o método BHMC simetrizado (11) são mostrados para fins de comparação.

\begin{tabular}{ccccc}
\hline $\boldsymbol{N}$ & $\begin{array}{c}\text { RBHMC } \\
\text { estático }\end{array}$ & $\begin{array}{c}\text { RBHMC } \\
\text { dinâmico }\end{array}$ & $\begin{array}{c}\text { BHMC } \\
\text { padrão (11) }\end{array}$ & $\begin{array}{c}\text { BHMC } \\
\text { simetrizado (11) }\end{array}$ \\
\hline 38 & 1045 & 647 & 1271 & 34 \\
55 & 79 & 77 & 92 & 103 \\
75 & 78161 & 60583 & 61668 & 338 \\
98 & 8365 & 7413 & 48301 & 563 \\
\hline
\end{tabular}

Os dados da tabela 5.2 permitem que se observe a diferença no grau de dificuldade em encontrar a estrutura de mínimo global para o caso de um sistema do tipo icosaedro $\left(\mathrm{LJ}_{55}\right)$ em comparação com os casos baseados em outra geometrias. Para os quatro tamanhos considerados, o esquema dinâmico de seleção de operadores se mostrou mais eficiente em termos do TMPE, porém as diferenças são modestas, exceto para o cluster $\mathrm{LJ}_{75}$, caso em que o esquema dinâmico superou o estático em 18 mil passos, em média. Os TMPEs obtidos com o esquema dinâmico são menores que aqueles reportados na literatura empregando o método BHMC padrão, com uma diferença mais pronunciada para o cluster $L J_{98}$, para o qual o método RBHMC utilizando o esquema dinâmico superou o método BHMC padrão em 40 mil passos. Esses resultados mostram vantagens em termos de eficiência do método RBHMC em relação ao método BHMC padrão. 
Todavia, o método RBHMC não foi capaz de superar o método BHMC simetrizado, introduzido recentemente na literatura (11) e cuja ideia principal é explorar a SEP favorecendo configurações de busca de alta simetria, porém sem privilegiar qualquer simetria em particular. Este método simetrizado é baseado em um princípio de máxima simetria, derivado a partir de observações de que as estruturas de mínimo global para clusters de LJ apresentam elevado grau de simetria, ou pelo menos boa simetria aproximada em comparação com outros isômeros de baixa energia. A conclusão que se pode tirar dessa comparação é que, para o caso de clusters de LJ, a exploração baseada em operadores aleatórios, como é feita no método RBHMC, apresenta desempenho inferior a um esquema de busca que privilegia configurações simétricas. Contudo, é preciso atentar para o fato de que o princípio de máxima simetria no qual o método BHMC simetrizado se baseia leva em conta apenas clusters de LJ, de maneira que método foi criado visando apenas a otimização global de clusters de LJ. O método RBHMC, porém, constitui uma abordagem geral que, em princípio, apresenta bom desempenho para diferentes tipos de sistemas.

O teste comparativo discutido acima permite a conclusão de que o método RBHMC conforme implementado no pacote GOP pode atingir uma taxa de sucesso de $100 \%$ para todos os clusters $\mathrm{LJ}_{N}(N=2-148)$ dentro de um número razoável de passos, uma vez que mesmo para os casos mais desafiadores foi possível obter essa taxa de sucesso. Esse resultado pode ser comparado com estudos anteriores, mencionado na seção 3.1.1, como, por exemplo, o estudo realizado por Locatelli e Schoen (110), no qual os autores obtiveram uma taxa de sucesso de $94 \%$ para o cluster $\mathrm{LJ}_{75}$ utilizando um esquema de otimização de duas etapas, fundamentalmente diferente do método BHMC, e uma taxa de sucesso de $0.4 \%$ empregando o método BHMC padrão.

\subsection{Nanopartículas de Lennard-Jones}

Do ponto de vista de uma metodologia de otimização global, é conveniente tratar NPs com centenas ou milhares de átomos para se ter uma ideia de como a metodologia se comporta para sistemas que vão além de algumas dezenas de átomos. Além disso, o estudo de NPs com centenas ou milhares de átomos permite que se compreenda melhor a transição entre o comportamento de um sistema finito e o comportamento encontrado no bulk. Como um exemplo pode-se citar o bulk de argônio (Ar) modelado pelo potencial de LJ, que apresenta simetria cristalina fcc, enquanto NPs de Ar contendo centenas a milhares de átomos apresentam estruturas de mínimo global com geometrias do tipo icosaedro. Northby et al. (137) 
investigaram esses sistemas para determinar em que tamanho aproximado as $N P s \operatorname{Ar}_{N}$ com geometria do tipo cuboctaedro fcc possuem energias inferiores às estruturas com geometria do tipo icosaedro, e verificaram que esse fato ocorre a partir de $N=9184$.

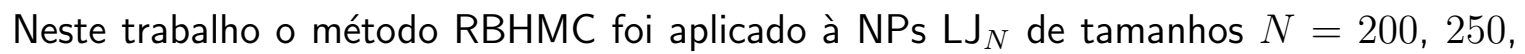
$300,350,400,450,500,1000)$. A otimização global foi realizada à temperatura $k_{B} T=1.6$, o operador OJ foi desabilitado, o operador CO foi habilitado e configurado para agir a cada 1000 passos, uma vez que testes preliminares indicaram que este operador aumenta a eficiência da otimização das NPs de LJ. A sequência de operadores utilizada foi a mesma para os clusters $\mathrm{LJ}_{N}(N=2-148)$, e a estratégia dinâmica foi empregada. Os parâmetros do potencial LJ foram fixos em $\epsilon=1$ e $\sigma=1$, i.e., unidades reduzidas.

Mesmo com pesquisa extensas na literatura de clusters e NPs de LJ, não foi possível encontrar estudos sistemáticos utilizando o método BHMC padrão investigando $N P s ~ L J_{N}$ para tamanhos $N \geq 250$ átomos. Apesar disso, um número razoável de estudos abordaram o problema de otimização global de NPs LJ com mais de 250 átomos, porém por meio de diferentes técnicas de otimização $(5,6,138-141)$. As energias totais dos mínimos globais identificados com o método RBHMC estão presentes na tabela 5.3, juntamente com os melhores resultados disponíveis na literatura. Para cada tamanho foram realizadas 100 aplicações independentes do algoritmo RBHMC, cada qual com 50 mil passos de Metropolis.

Para os tamanhos $N \leq 500$ as energias totais dos mínimos globais identificados neste trabalho estão em completo acordo com resultados publicados previamente na literatura. Os mínimos globais das NPs $\mathrm{LJ}_{200}, \mathrm{LJ}_{250}, \mathrm{LJ}_{300}$ e $\mathrm{LJ}_{350}$ foram encontrados em pelo menos duas aplicações do método RBHMC em menos de 20 mil passos. Já nos casos $L J_{400}, L_{450}$ e $\mathrm{LJ}_{500}$, os mínimos globais reportados na literatura foram encontrados em apenas uma das 100 aplicações.

As energias totais mais baixas encontradas para as $N P s ~ L J_{1000}$ e $L J_{1500}$ diferem das energias de mínimos globais da literatura em $0.12 \%$ e $0.28 \%$, respectivamente. Esse resultado deve ser avaliado levando-se em conta que o método RBHMC parte de configurações totalmente aleatórias e não possui qualquer bias inicial. Além disso, segundo Goedecker (142), a estrutura de mínimo global da NP $L_{1000}$ somente foi identificada após milhões de passos de um algoritmo do tipo basin-hopping acoplado com dinâmica molecular, enquanto nenhum método sem bias foi encontrou o mínimo global da NP $L_{1500}$. Apesar da metodologia deste trabalho não ter sido capaz de identificar os mínimos globais dessas duas NPs, os resultados estão próximos do esperado e foram conseguidos em um número relativamente pequeno de passos (milhares, e não milhões), e assim, pode-se concluir que o método RBHMC fornece uma rota para a 
determinação estrutural de NPs com milhares de átomos, um problema não trivial.

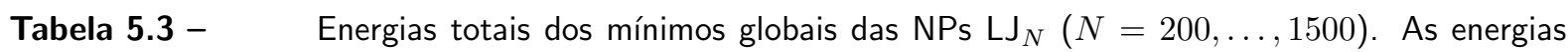
encontradas com o método RBHMC são comparadas com valores de referência.

\begin{tabular}{cccc}
\hline $\boldsymbol{N}$ & $\begin{array}{c}\text { RBHMC } \\
E_{\text {tot }}^{\mathrm{LJ}}(\epsilon)\end{array}$ & $\begin{array}{c}\text { Referência } \\
E_{\text {tot }}^{\mathrm{LJ}}(\epsilon)\end{array}$ & $\begin{array}{c}\text { Diferença } \\
(\%)\end{array}$ \\
\hline 200 & -1229.184776 & $-1229.184776^{a}$ & 0 \\
250 & -1579.794975 & $-1579.794975^{b}$ & 0 \\
300 & -1942.106775 & $-1942.106775^{a}$ & 0 \\
350 & -2293.181867 & $-2293.181867^{c}$ & 0 \\
400 & -2651.675335 & $-2651.675335^{c}$ & 0 \\
450 & -3015.164293 & $-3015.164293^{c}$ & 0 \\
500 & -3382.693487 & $-3382.693487^{d}$ & 0 \\
1000 & -7119.993439 & $-7128.821829^{e}$ & 0.12 \\
1500 & -10932.433410 & $-10962.585028^{f}$ & 0.28 \\
\hline
\end{tabular}

${ }^{a}$ Referência (138) ${ }^{b}$ Referência (139) ${ }^{c}$ Referência (140) ${ }^{d}$ Referência (141)

${ }^{e}$ Referência (5) ${ }^{f}$ Referência (6)

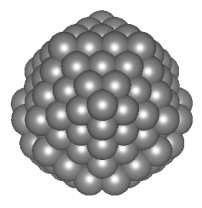

$\mathrm{LJ}_{200}$

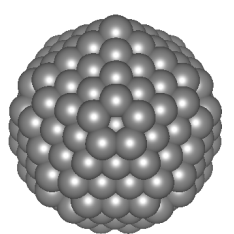

$\mathrm{LJ}_{300}$

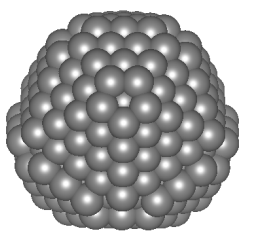

$\mathrm{LJ}_{400}$

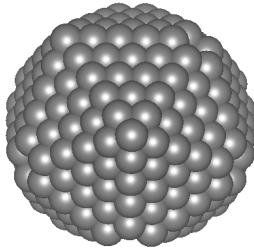

$\mathrm{LJ}_{500}$

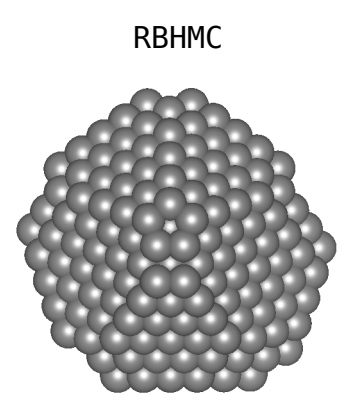

$\mathrm{LJ}_{1000}$

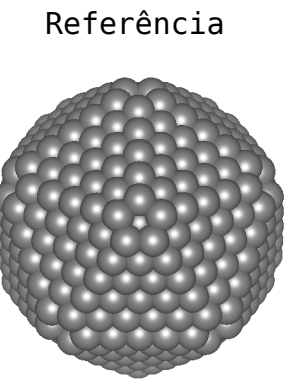

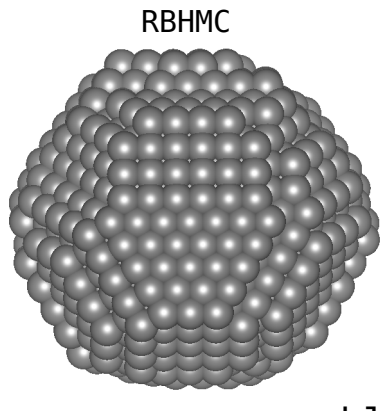

$\mathrm{LJ}_{1500}$

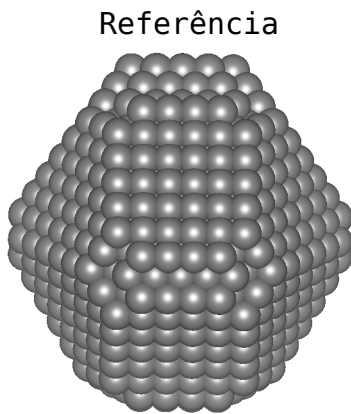

Figura 5.4 - Estruturas de mínimo global de algumas $N P s \mathrm{LJ}_{N}(N=200,300,400,500,1000$, 1500 ) identificadas com o método RBHMC. Para os casos $L J_{1000}$ e $L J_{1500}$, as estruturas encontradas com o método RBHMC são comparadas com os mínimos globais putativos da literatura $(5,6)$.

Nas NPs com tamanhos $N \leq 500$, casos em que o método RBHMC foi capaz de encontrar os mínimos globais corretos, as geometrias são do tipo icosaedro truncados. Para os casos em 
que o método RBHMC não foi capaz de encontrar os mínimos globais putativos, i.e., $L J_{1000}$ e $\mathrm{LJ}_{1500}$, as estruturas identificadas apresentam algum ordenamento e faces planares, apesar de não possuírem simetria (grupo pontual $C_{1}$ ). Os mínimos globais putativos reportados por outros autores possuem geometria do tipo icosaedro para o caso $\mathrm{LJ}_{1000}$, e geometria baseada no decaedro de Marks no caso da NP $L_{1500}$. Uma inspeção cuidadosa das estruturas encontradas pelo método RBHMC revela que os padrões geométricos de icosaedro e decaedro fazem-se presentes, porém as estruturas possuem algumas regiões menos compactas em relação às estruturas dos mínimos globais putativos, apresentando algumas vacâncias e grupos de átomos de superfície protuberantes. Tais defeitos são responsáveis pelas energias totais mais altas em comparação com as energias da literatura. Algumas das estruturas das NPs de LJ são mostradas na figura 5.4 .

\subsection{Clusters de Sutton-Chen}

O potencial de SC, em comparação com o potencial de LJ, apresenta melhores descrições dos comportamentos observados em superfícies de metais de transição. Isso se deve à forma do potencial, que diferente do potencial de LJ, possui um termos de muitos corpos para aproximar o caráter deslocalizado de ligações metálicas. Por exemplo, para Rh e Pt o potencial de SC prediz corretamente os mecanismos de migração de átomos em superfícies (143). Outro estudo verificou que energias de superfícies, bem como seus processos de relaxação e reconstrução, são bem aproximados pelo potencial de SC para metais de transição fcc (144). Assim, é interessante utilizar esse potencial para modelar clusters de metais de transição, onde efeitos de superfícies desempenham um papel importante. Além disso, há uma grande quantidade de mínimos globais putativos para clusters de SC disponíveis na literatura $(7,145)$, facilitando a avaliação do método RBHMC.

$\mathrm{O}$ método $\mathrm{RBHMC}$ foi aplicado à clusters $\mathrm{SC}_{N}$ com tamanhos $N=3-148$. A otimização global empregou os mesmos parâmetros que aqueles usados para os clusters $\mathrm{LJ}_{N}(N=2-$ 148), i.e., mesma temperatura, sequência de operadores, estratégia dinâmica de aplicação de operadores, etc. Os parâmetros do potencial de SC (equação 2.1.6) assumiram valores em unidades reduzidas, $\epsilon=1$ e $a=1$. Os outros três parâmetros, $c, n$ e $m$ assumiram os valores que descrevem $\mathrm{Rh}$ e $\mathrm{Ag}$ em bulk, sendo eles $c=144.41, n=12$ e $m=6$. Dessa maneira é possível converter os resultados finais em unidades reduzidas (energia total, distâncias interatômicas, etc.) para valores reais descrevendo clusters de Rh e Ag através de uma reescala de energia e distância. 
Para clusters $\mathrm{SC}_{N}$ com $n=12$ e $m=16$ existem na literatura $(4,7)$ apenas dados de referência para os tamanhos $N=3-80$, e em comparação com esses dados, os mínimos globais e suas respectivas energias totais encontradas com o método RBHMC estão em pleno acordo (figura 5.5). Para o intervalo de tamanhos $N=81-148$ não existem dados de referência, e os resultados deste trabalho servem como complemento à literatura, enriquecendo-a. As energias totais e grupos pontuais de simetria para os clusters $\mathrm{SC}_{N}(N=3-148)$ podem ser vistos na tabela 5.4 .

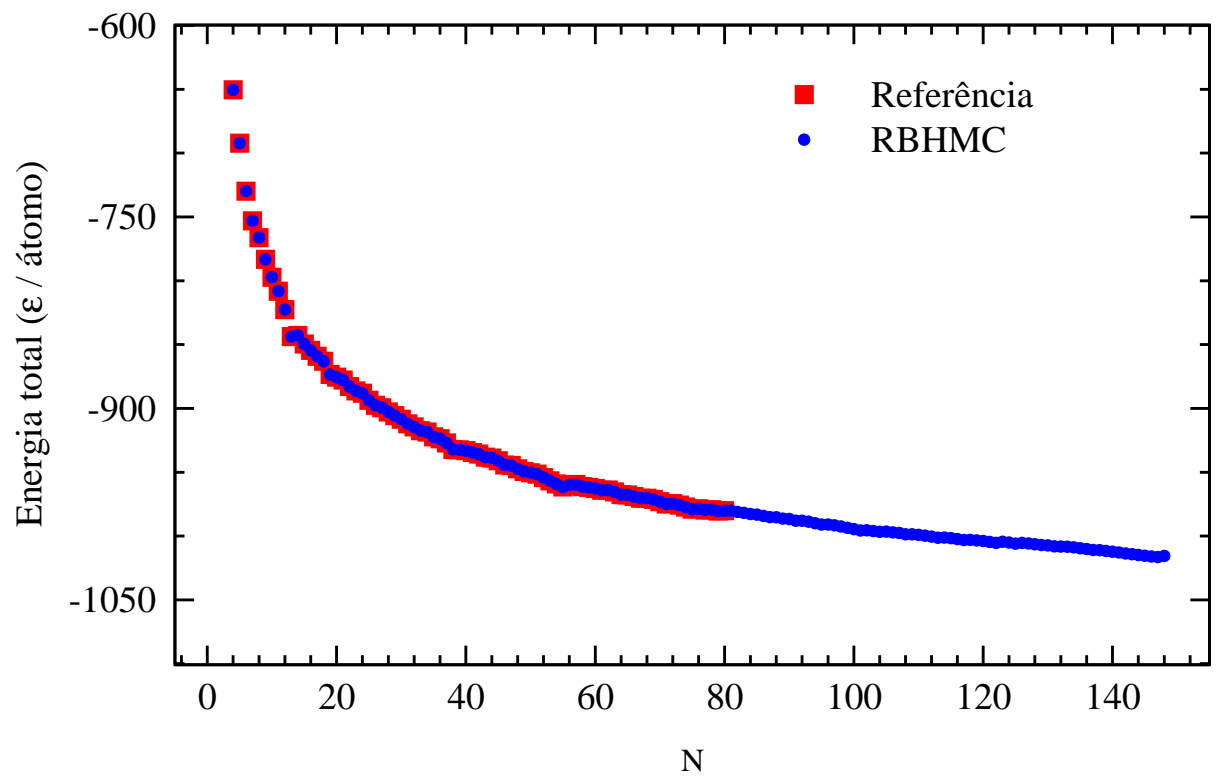

Figura 5.5 - Energia total por átomo em unidades de $\epsilon$ dos mínimos globais dos clusters $\mathrm{SC}_{N}(N=$ $3-148)$. Os resultados deste trabalho utilizando o método RBHMC são comparados com dados de referência da literatura $(4,7)$.

Na figura 5.6 são exibidas as curvas do $\mathrm{ECN}$ médio, $d_{a v}$ e $\Delta_{2} E$ para os clusters $\mathrm{SC}_{N}$. $\mathrm{O}$ comportamento do ECN é similar àquele encontrado nos clusters de LJ discutidos na seção anterior, com a saturação iniciando a partir de $N=20$ e tendendo para valores inferiores a 12 , que é a coordenação do bulk de SC, indicando que efeitos de superfície ainda são relevantes para $N=148$. O comportamento da curva para $d_{a v}$, porém, é diferente daquele verificado no caso de clusters de LJ. Para clusters de SC no intervalo de tamanhos considerado não há uma queda brusca no valor de $d_{a v}$, mas sim uma tendência de saturação relativamente suave. É possível notar que o valor de $d_{a v}$ tende a saturar em torno de 0.70 , enquanto para clusters de LJ a saturação é em torno de 1.10, o que significa que clusters de SC são mais compactos que clusters de LJ, fato que deve-se ao termo de muitos corpos presentes no potencial de SC, que aumenta a coesão dos átomos. 
Tabela 5.4 - Energias totais e grupo pontual de simetria (GP) das estruturas de mínimo global dos clusters $\mathrm{SC}_{N}(N=3-148)$.

\begin{tabular}{|c|c|c|c|c|c|c|c|c|}
\hline$N$ & Energia $(\epsilon)$ & GP & $N$ & Energia $(\epsilon)$ & GP & $N$ & Energia $(\epsilon)$ & GP \\
\hline 3 & -1704.6905 & $D_{3 h}$ & 52 & -49616.1377 & $C_{3 v}$ & 101 & -100559.4244 & $D_{5 h}$ \\
\hline 4 & -2601.8447 & $T_{d}$ & 53 & -50706.4665 & $C_{2 v}$ & 102 & -101540.5033 & $C_{2 v}$ \\
\hline 5 & -3461.3452 & $D_{3 h}$ & 54 & -51796.0777 & $C_{5 v}$ & 103 & -102597.7356 & $C_{s}$ \\
\hline 6 & -4378.8875 & $O_{h}$ & 55 & -52884.6806 & $I_{h}$ & 104 & -103649.9534 & $C_{2 v}$ \\
\hline 7 & -5271.2947 & $D_{5 h}$ & 56 & -53756.6516 & $C_{3 v}$ & 105 & -104635.8467 & $C_{s}$ \\
\hline 8 & -6129.7564 & $D_{2 d}$ & 57 & -54700.1733 & $C_{s}$ & 106 & -105688.1268 & $C_{1}$ \\
\hline 9 & -7048.7552 & $C_{2 v}$ & 58 & -55753.8515 & $C_{3 v}$ & 107 & -106740.5143 & $C_{2 v}$ \\
\hline 10 & -7972.0971 & $C_{3 v}$ & 59 & -56751.4572 & $T_{d}$ & 108 & -107858.3157 & $C_{s}$ \\
\hline 11 & -8889.9627 & $C_{2 v}$ & 60 & -57763.6760 & $C_{s}$ & 109 & -108842.6864 & $C_{s}$ \\
\hline 12 & -9871.2458 & $C_{5 v}$ & 61 & -58809.0448 & $C_{2 v}$ & 110 & -109901.9289 & $C_{1}$ \\
\hline 13 & -10968.5082 & $I_{h}$ & 62 & -59765.2180 & $C_{2 v}$ & 111 & -110957.4546 & $C_{1}$ \\
\hline 14 & -11798.8479 & $C_{3 v}$ & 63 & -60822.3826 & $C_{s}$ & 112 & -112049.4453 & $C_{s}$ \\
\hline 15 & -12742.9841 & $C_{2 v}$ & 64 & -61925.6244 & $C_{2 v}$ & 113 & -113152.7706 & $C_{2 v}$ \\
\hline 16 & -13672.6475 & $C_{s}$ & 65 & -62903.7387 & $C_{2 v}$ & 114 & -114133.5363 & $C_{s}$ \\
\hline 17 & -14606.3231 & $C_{2}$ & 66 & -63959.3105 & $C_{s}$ & 115 & -115191.0000 & $C_{1}$ \\
\hline 18 & -15535.3810 & $C_{s}$ & 67 & -65011.2767 & $C_{2 v}$ & 116 & -116271.2648 & $C_{3 v}$ \\
\hline 19 & -16595.0561 & $D_{5 h}$ & 68 & -65980.5983 & $C_{3 v}$ & 117 & -117360.6586 & $C_{s}$ \\
\hline 20 & -17510.9209 & $C_{2 v}$ & 69 & -67020.4042 & $C_{1}$ & 118 & -118345.0657 & $C_{s}$ \\
\hline 21 & -18433.0300 & $C_{1}$ & 70 & -68114.9462 & $C_{s}$ & 119 & -119404.3767 & $C_{1}$ \\
\hline 22 & -19422.7209 & $C_{s}$ & 71 & -69216.6518 & $C_{2 v}$ & 120 & -120467.7085 & $C_{2 v}$ \\
\hline 23 & -20383.3977 & $D_{3 h}$ & 72 & -70171.4663 & $C_{1}$ & 121 & -121552.3108 & $C_{s}$ \\
\hline 24 & -21315.4208 & $C_{2 v}$ & 73 & -71225.8547 & $C_{2 v}$ & 122 & -122655.8679 & $C_{2 v}$ \\
\hline 25 & -22339.6319 & $C_{3 v}$ & 74 & -72318.7243 & $C_{5 v}$ & 123 & -123541.9028 & $C_{1}$ \\
\hline 26 & -23337.2211 & $D_{3 h}$ & 75 & -73421.0521 & $D_{5 h}$ & 124 & -124626.0202 & $C_{s}$ \\
\hline 27 & -24284.3891 & $C_{s}$ & 76 & -74375.6975 & $C_{s}$ & 125 & -125746.3797 & $C_{s}$ \\
\hline 28 & -25276.9501 & $C_{3 v}$ & 77 & -75430.9852 & $C_{2 v}$ & 126 & -126679.9830 & $C_{1}$ \\
\hline 29 & -26263.2779 & $C_{2 v}$ & 78 & -76385.4318 & $C_{1}$ & 127 & -127734.1834 & $C_{s}$ \\
\hline 30 & -27253.8536 & $C_{2 v}$ & 79 & -77456.0255 & $D_{3 h}$ & 128 & -128822.8084 & $C_{1}$ \\
\hline 31 & -28274.4371 & $C_{2 v}$ & 80 & -78414.6271 & $C_{s}$ & 129 & -129900.0012 & $C_{s}$ \\
\hline 32 & -29265.3320 & $C_{2 v}$ & 81 & -79387.8066 & $C_{s}$ & 130 & -130945.4633 & $C_{1}$ \\
\hline 33 & -30274.9603 & $C_{2 v}$ & 82 & -80447.8861 & $C_{s}$ & 131 & -132064.2300 & $C_{2 v}$ \\
\hline 34 & -31231.7697 & $C_{2 v}$ & 83 & -81496.0015 & $C_{2 v}$ & 132 & -133082.8459 & $C_{s}$ \\
\hline 35 & -32280.3945 & $C_{2 v}$ & 84 & -82549.7178 & $C_{s}$ & 133 & -134102.6010 & $C_{1}$ \\
\hline 36 & -33253.9352 & $C_{s}$ & 85 & -83567.9388 & $C_{s}$ & 134 & -135184.3688 & $C_{3 v}$ \\
\hline 37 & -34302.6067 & $C_{3 v}$ & 86 & -84650.1108 & $C_{s}$ & 135 & -136297.7226 & $C_{s}$ \\
\hline 38 & -35419.9804 & $O_{h}$ & 87 & -85700.4419 & $C_{s}$ & 136 & -137387.0536 & $C_{s}$ \\
\hline 39 & -36364.8587 & $C_{4 v}$ & 88 & -86698.6229 & $C_{1}$ & 137 & -138488.2876 & $C_{3 v}$ \\
\hline 40 & -37324.3708 & $C_{s}$ & 89 & -87782.6574 & $C_{3 v}$ & 138 & -139518.7051 & $C_{3 v}$ \\
\hline 41 & -38316.5698 & $C_{s}$ & 90 & -88793.5148 & $C_{1}$ & 139 & -140620.0856 & $C_{2 v}$ \\
\hline 42 & -39301.6696 & $C_{s}$ & 91 & -89911.5273 & $C_{3 v}$ & 140 & -141721.4124 & $C_{s}$ \\
\hline 43 & -40341.8543 & $C_{s}$ & 92 & -90899.2953 & $C_{1}$ & 141 & -142822.8554 & $C_{5 v}$ \\
\hline 44 & -41310.9157 & $C_{1}$ & 93 & -91957.1142 & $C_{1}$ & 142 & -143923.9871 & $C_{s}$ \\
\hline 45 & -42345.0912 & $C_{s}$ & 94 & -93046.3936 & $C_{s}$ & 143 & -145025.2322 & $C_{2 v}$ \\
\hline 46 & -43436.2827 & $C_{2 v}$ & 95 & -94148.7083 & $C_{2 v}$ & 144 & -146126.4115 & $C_{3 v}$ \\
\hline 47 & -44405.1884 & $C_{1}$ & 96 & -95128.9315 & $C_{s}$ & 145 & -147227.5242 & $C_{2 v}$ \\
\hline 48 & -45470.1069 & $C_{2 v}$ & 97 & -96185.7908 & $C_{1}$ & 146 & -148328.7496 & $C_{5 v}$ \\
\hline 49 & -46521.2131 & $C_{3 v}$ & 98 & -97261.2225 & $C_{s}$ & 147 & -149430.0837 & $I_{h}$ \\
\hline 50 & -47518.6719 & $D_{3 h}$ & 99 & -98363.7087 & $C_{s}$ & 148 & -150308.0658 & $C_{s}$ \\
\hline 51 & -48522.4267 & $C_{2 v}$ & 100 & -99456.3734 & $C_{5 v}$ & & & \\
\hline
\end{tabular}


No intervalo $N=18-50$ é possível notar uma competição entre os dois tipos de geometria que prevalecem nos clusters de SC, decaedro e icosaedro, com algumas exceções, como $\mathrm{SC}_{38}$, que apresenta geometria do tipo octaedro. Estruturas do tipo decaedro são mais compactas e apresentam um $d_{a v}$ menor que o das estruturas do tipo octaedro. A competição entre esses dois tipos pode ser vista na oscilação que ocorre na curva do $d_{a v}$ no intervalo mencionado. No intervalo $N=51-62$ há uma predominância de estruturas do tipo icosaedro truncado, sendo a única exceção a estrutura para $N=59$, que é do tipo decaedro truncado. Para $N=63-128$ o tipo geométrico dominante nas estruturas é o decaedro, e para $N=129$ - 135 há uma nova competição entre icosaedro e decaedro, sendo que para $N \geq 136$ a geometria do icosaedro truncado prevalece. O intervalo $N=129-135$ pode ser encarado como uma região de transição da fase decaedro para uma fase icosaedro.

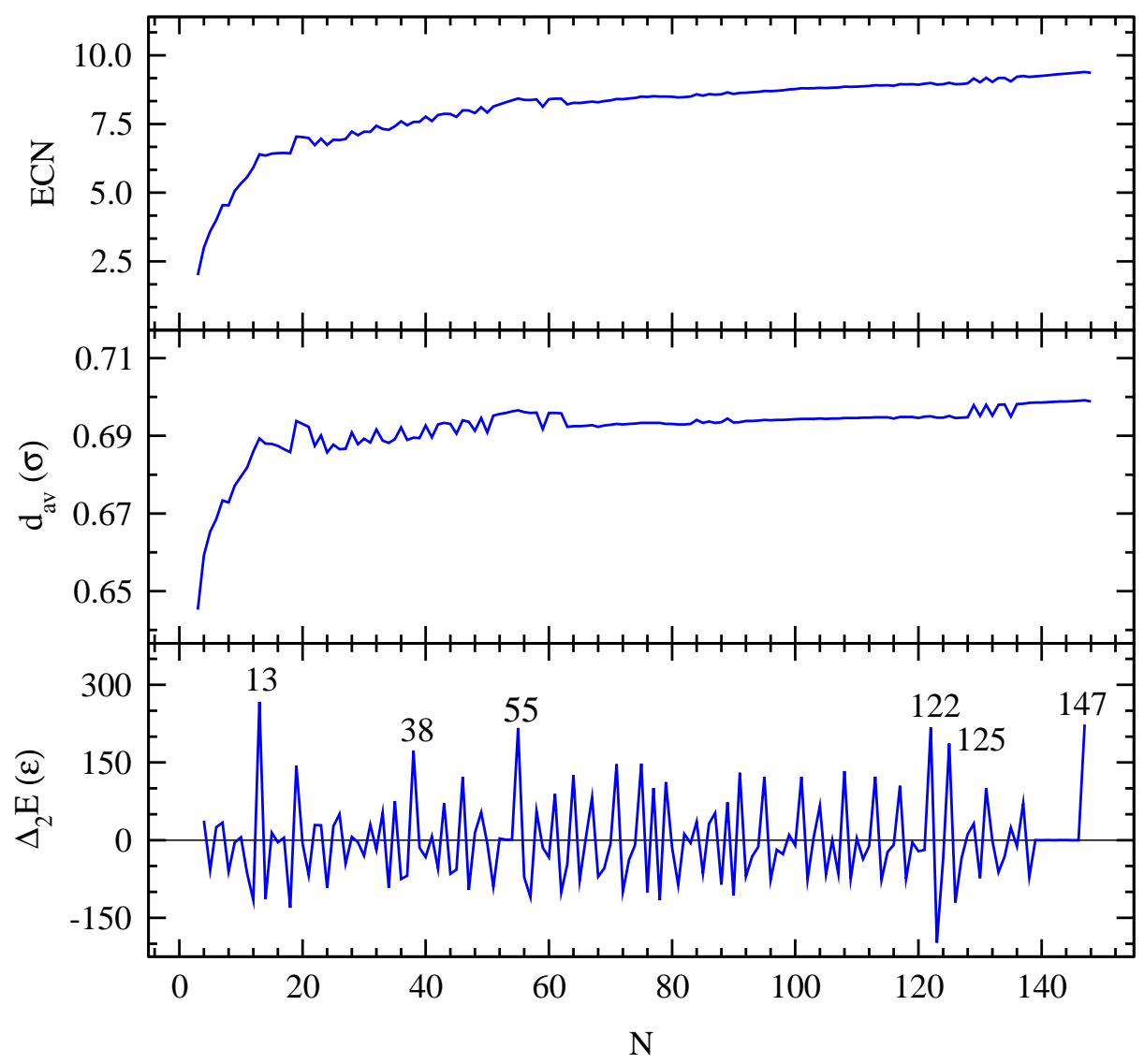

Figura 5.6 - Número de coordenação efetiva médio (ECN), comprimento de ligação ponderado médio $\left(d_{a v}\right)$, e função de estabilidade relativa $\left(\Delta_{2} E\right)$ das estruturas de mínimo global dos clusters $\mathrm{SC}_{N}(N=3-148)$

A curva da função $\Delta_{2} E$ para clusters de SC apresenta mais picos pronunciados que no caso dos clusters de LJ. Os clusters $\mathrm{SC}_{13}, \mathrm{SC}_{55}$ e $\mathrm{SC}_{147}$ possuem estrutura do tipo icosaedro 
completo, assim como no caso de clusters de LJ de mesmos tamanhos, e são particularmente estáveis. Também são estáveis os clusters $\mathrm{SC}_{122}$ e $\mathrm{SC}_{125}$, porém estes não correspondem a icosaedros completos, e sim decaedros truncados. Assim, enquanto os clusters do tipo icosaedro completo com grupo pontual de simetria $I_{h}$ são bastante estáveis, há clusters estáveis de baixa simetria, como é o caso do clusters $\mathrm{SC}_{125}$, que possui apenas simetria bilateral (grupo pontual $C_{s}$ ). As estruturas de maior estabilidade relativa são mostradas na figura 5.7 . De maneira geral, não é possível estabelecer uma relação entre alta simetria e a estabilidade relativa para clusters de SC. Apesar de não existir dados para comparação para tamanhos $N>80$, a curva de estabilidade mostrada na figura 5.6 tem um aspecto qualitativo similar àquele encontrado por Grigoryan et al. (146) para clusters $\mathrm{Cu}_{N}(N=2-145)$ descritos pelo método embedded-atom.
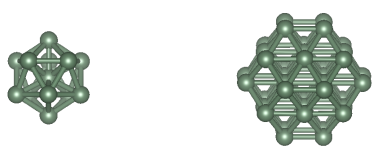

$\mathrm{SC}_{13}$

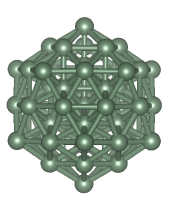

$\mathrm{SC}_{55}$

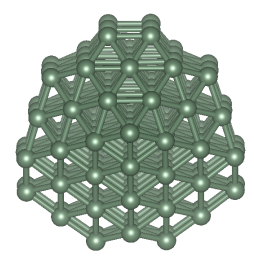

$\mathrm{SC}_{122}$

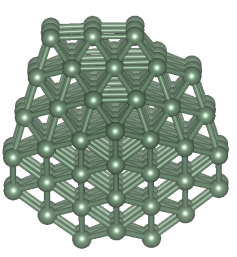

$\mathrm{SC}_{125}$

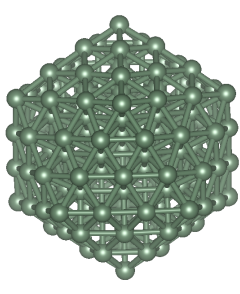

$\mathrm{SC}_{147}$

Figura $5.7-\quad$ Estruturas de mínimo global de clusters $\mathrm{SC}_{N}(N=13,38,55,122,125,147)$.

\subsection{Clusters binários de Lennard-Jones}

Em anos recentes, diversos estudos tiveram como foco a otimização global de clusters $\operatorname{BLJ}(8,9,12-14,147)$, o que os torna bons candidatos para avaliar o desempenho do método RBHMC. Além disso, nano-ligas metálicas são assunto de crescente interesse tecnológico, e representam desafios para métodos teóricos, pois a introdução de novos graus de liberdade, i.e., composição, aumenta o número de mínimos locais da SEP. Com o fim de avaliar a metodologia e simplificar os cálculos, neste trabalho o método RBHMC foi aplicado a clusters $\mathrm{BLJ}_{N}$ com tamanhos $N=5-100$ e utilizando composições fixas, i.e., em cada cluster o número de átomos $N_{A}$ e $N_{B}$, correspondentes às espécies químicas $A$ e $B$, respectivamente, foram mantidos fixos ao longo das otimizações. As composições empregadas foram as mesmas utilizadas por Doye e Meyer em seu estudo investigando clusters BLJ (12). Para ser justo com os dados da literatura, os melhores resultados para estas composições foram coletadas em um conjunto, o qual foi comparado com os resultados do método RBHMC. 
Unidades reduzidas foram utilizadas para os parâmetros do potencial de LJ. O parâmetro de escala de energia foi fixado em $\epsilon=1$ para interação entre quaisquer pares de átomos, i.e., $\epsilon^{A A}=\epsilon^{B B}=\epsilon^{A B}=1$. O parâmetro de distância foi fixado em $\sigma^{A A}=1$, e $\sigma^{B B}$ variou entre 1.05 e 1.30 em passos de 0.05 , portanto seis tipos de sistemas foram estudados. Para cada razão $\sigma^{B B} / \sigma^{A A}$ o método $\mathrm{RBHMC}$ foi aplicado à clusters $\mathrm{BLJ} \mathrm{J}_{N}$ com tamanhos $N=5-100$ (total de 576 clusters BLJ). A temperatura da otimização global foi mantida em $k_{B} T=0.1$, uma vez que verificou-se que os operadores de troca, EO e GEO, possuem uma escala de energia consideravelmente menor em comparação aos outros operadores, e portanto uma temperatura menor auxilia na eficiência desses operadores. Os outros operadores não são afetados consideravelmente, uma vez que seus parâmetros podem ser ajustados com maior liberdade. Devido à baixa temperatura, o operador $\mathrm{OJ}$ foi habilitado para realizar 4 saltos a cada 2500 rejeições consecutivas do critério de Metropolis. A sequência de operadores utilizada foi CDO, TO, GCDO, AO, EO, SAO, GCDO, IO, GEO, e o esquema dinâmico foi utilizado. O operador CO não foi habilitado. Cada sistema foi submetido à 100 aplicações do método RBHMC, cada uma com 50 mil passos.

Na tabela 5.5 são exibidos os resultados para os casos em que o método RBHMC foi capaz de identificar estruturas de mínimos globais com energias mais baixas que as energias das estruturas do conjunto mencionado no primeiro parágrafo. Para as composições indicadas na tabela 5.5, as energias respectivas são as menores já identificadas. Avaliando este resultado à luz do fato de que clusters BLJ vem sendo estudados extensivamente ao longo da última década por meio das mais diversas técnicas de otimização global, é possível concluir que o método RBHMC configura uma contribuição significativa para a área. Vale mencionar, todavia, que para a mairia dos casos (cerca de 50\%) reportados na tabela 5.5 existem estruturas com outras composições que possuem energia mais baixa que as reportadas aqui.

Em relação aos clusters não mostrados na tabela 5.5, o método RBHMC encontrou resultados idênticos aos já existentes na literatura para a grande maioria dos casos. As duas únicas exceções foram os clusters $\mathrm{BLJ}_{99}$ e $\mathrm{BLJ}_{100} \operatorname{com} \sigma^{B B} / \sigma^{A A}=1.30$, para os quais as meIhores energias dos mínimos globais putativos conhecidas são $-597.592233 \epsilon$ e $-604.796307 \epsilon$, respectivamente, identificadas por Kolossváry (8) e Sicher (9) utilizando métodos diferentes de BHMC. Neste trabalho as energias encontradas para os respectivos sistemas foram $-597.350577 \epsilon \mathrm{e}-604.233674 \epsilon$. Ainda assim, as estruturas encontradas pelo método RBHMC possuem energia menor que as estruturas encontradas por Doye e Meyer (12) utilizando o método BHMC padrão, em particular, $1.253040 \epsilon$ e $1.948576 \epsilon$ menores para os clusters BLJ $J_{99}$ e $B L J_{100}$, respectivamente. Apesar das diferenças em relação às melhores estruturas da literatura serem pequenas em ambos os casos (erros relativos de $0.40 \%$ e $0.93 \%$, respectivamente), 
Tabela 5.5 - Dados referentes aos clusters BLJ com energias menores que as menores energias reportadas na literatura $(4,8,9,12-14)$ para as composições e valores da razão $\sigma^{B B} / \sigma^{A A}$ indicados. Para cada tamanho são mostradas a diferença de energia em relação aos dados de referência ( $E_{\text {tot }}-E_{\text {tot }}^{\text {Ref }}$ ), os grupos pontuais das estruturas encontradas neste trabalho (GP) e os grupos pontuais das estruturas da literatura cujas energias foram melhoradas (GPRef $)$.

\begin{tabular}{|c|c|c|c|c|c|c|}
\hline$N$ & $N_{A}$ & $N_{B}$ & $\sigma^{B B} / \sigma^{A A}$ & $E_{\text {tot }}-E_{\text {tot }}^{\text {Ref }}(\epsilon)$ & GP & GPRef \\
\hline 31 & 6 & 25 & 1.05 & -0.016397 & $C_{s}$ & $C_{1}$ \\
\hline 36 & 8 & 28 & 1.05 & -0.007331 & $C_{1}$ & $C_{s}$ \\
\hline 38 & 8 & 30 & 1.05 & -0.051613 & $T_{d}$ & $C_{s}$ \\
\hline 43 & 9 & 34 & 1.05 & -0.197553 & $C_{1}$ & $C_{1}$ \\
\hline 90 & 31 & 59 & 1.05 & -0.216358 & $C_{1}$ & $C_{s}$ \\
\hline 97 & 34 & 63 & 1.05 & -0.292010 & $C_{1}$ & $C_{1}$ \\
\hline 46 & 12 & 34 & 1.10 & -0.021177 & $C_{1}$ & $C_{1}$ \\
\hline 47 & 13 & 34 & 1.10 & -0.013075 & $C_{s}$ & $C_{s}$ \\
\hline 63 & 14 & 49 & 1.10 & -0.266481 & $C_{1}$ & $C_{1}$ \\
\hline 64 & 14 & 50 & 1.10 & -0.203841 & $C_{1}$ & $C_{s}$ \\
\hline 65 & 15 & 50 & 1.10 & -0.109876 & $C_{s}$ & $C_{1}$ \\
\hline 66 & 14 & 52 & 1.10 & -0.227975 & $C_{s}$ & $C_{1}$ \\
\hline 73 & 19 & 54 & 1.10 & -0.853502 & $C_{3 v}$ & $C_{s}$ \\
\hline 76 & 21 & 55 & 1.10 & -0.043272 & $C_{1}$ & $C_{1}$ \\
\hline 77 & 23 & 54 & 1.10 & -0.095686 & $C_{1}$ & $C_{1}$ \\
\hline 83 & 25 & 58 & 1.10 & -0.377999 & $C_{1}$ & $C_{1}$ \\
\hline 84 & 25 & 59 & 1.10 & -0.530894 & $C_{1}$ & $C_{1}$ \\
\hline 85 & 25 & 60 & 1.10 & -0.369416 & $C_{1}$ & $C_{1}$ \\
\hline 86 & 25 & 61 & 1.10 & -0.581781 & $C_{1}$ & $C_{1}$ \\
\hline 64 & 19 & 45 & 1.15 & -0.427895 & $C_{2}$ & $C_{1}$ \\
\hline 66 & 20 & 46 & 1.15 & -0.000003 & $C_{s}$ & $C_{s}$ \\
\hline 74 & 24 & 50 & 1.15 & -0.074097 & $C_{1}$ & $C_{1}$ \\
\hline 80 & 25 & 55 & 1.15 & -0.299893 & $C_{1}$ & $C_{1}$ \\
\hline 81 & 26 & 55 & 1.15 & -0.125538 & $C_{s}$ & $C_{s}$ \\
\hline 90 & 27 & 63 & 1.15 & -1.018939 & $C_{s}$ & $C_{1}$ \\
\hline 91 & 27 & 64 & 1.15 & -0.250191 & $C_{s}$ & $C_{s}$ \\
\hline 92 & 30 & 62 & 1.15 & -0.077081 & $C_{2}$ & $C_{2 h}$ \\
\hline 93 & 30 & 63 & 1.15 & -0.056132 & $C_{1}$ & $C_{1}$ \\
\hline 94 & 30 & 64 & 1.15 & -0.455720 & $C_{1}$ & $C_{1}$ \\
\hline 97 & 30 & 67 & 1.15 & -0.049591 & $C_{1}$ & $C_{1}$ \\
\hline 64 & 22 & 42 & 1.20 & -0.141792 & $C_{1}$ & $C_{1}$ \\
\hline 70 & 25 & 45 & 1.20 & -0.080800 & $C_{1}$ & $C_{1}$ \\
\hline 71 & 26 & 45 & 1.20 & -0.229092 & $C_{s}$ & $C_{s}$ \\
\hline 73 & 26 & 47 & 1.20 & -0.011210 & $C_{s}$ & $C_{1}$ \\
\hline 87 & 30 & 57 & 1.20 & -0.097749 & $C_{1}$ & $C_{1}$ \\
\hline 88 & 30 & 58 & 1.20 & -0.641740 & $C_{1}$ & $C_{1}$ \\
\hline 92 & 33 & 59 & 1.20 & -0.373245 & $C_{s}$ & $C_{1}$ \\
\hline 93 & 34 & 59 & 1.20 & -0.151219 & $C_{1}$ & $C_{1}$ \\
\hline 94 & 35 & 59 & 1.20 & -0.234816 & $C_{1}$ & $C_{1}$ \\
\hline 95 & 36 & 59 & 1.20 & -0.162482 & $C_{1}$ & $C_{1}$ \\
\hline 96 & 37 & 59 & 1.20 & -1.013945 & $C_{1}$ & $C_{1}$ \\
\hline 97 & 34 & 63 & 1.20 & -2.242207 & $C_{1}$ & $C_{1}$ \\
\hline 98 & 34 & 64 & 1.20 & -1.782928 & $C_{1}$ & $C_{1}$ \\
\hline 99 & 34 & 65 & 1.20 & -1.282524 & $C_{1}$ & $C_{1}$ \\
\hline 100 & 34 & 66 & 1.20 & -0.960988 & $C_{1}$ & $C_{1}$ \\
\hline 76 & 29 & 47 & 1.25 & -0.042182 & $C_{1}$ & $C_{s}$ \\
\hline 95 & 36 & 59 & 1.25 & -0.066490 & $C_{1}$ & $C_{1}$ \\
\hline 96 & 37 & 59 & 1.25 & -0.072292 & $C_{s}$ & $C_{1}$ \\
\hline 97 & 38 & 59 & 1.25 & -0.972608 & $C_{1}$ & $C_{1}$ \\
\hline 98 & 40 & 58 & 1.25 & -0.551555 & $C_{1}$ & $C_{1}$ \\
\hline 99 & 40 & 59 & 1.25 & -0.535199 & $C_{1}$ & $C_{1}$ \\
\hline 100 & 40 & 60 & 1.25 & -0.225851 & $C_{1}$ & $C_{1}$ \\
\hline 95 & 40 & 55 & 1.30 & -0.004635 & $C_{1}$ & $C_{2 v}$ \\
\hline 98 & 42 & 56 & 1.30 & -0.264534 & $C_{1}$ & $C_{1}$ \\
\hline
\end{tabular}


as estruturas possuem geometrias consideravelmente diferentes. As estruturas fornecidas pelo método RBHMC são aproximadamente esféricas, enquanto aquelas da literatura se aproximam de esferoides prolatos com eixos polares bem acentuados. Para ambos os casos foram realizadas cerca de 100 mil aplicações independentes do método RBHMC adicionais, cada uma com 80 mil passos, porém não foi possível reproduzir os mínimos globais da literatura. Esta deficiência pode ser atribuída ao fato dos operadores tentativa presentes no método RBHMC não favorecerem estruturas muito prolatas.

Na figura 5.8 são mostradas as estruturas dos clusters $B L J_{99}$ e $B L J_{100}\left(\sigma^{B B} / \sigma^{A A}\right)$ encontradas com o método RBHMC, e também são mostradas as melhores estruturas da literatura $(8,9)$ que o método RBHMC não conseguiu reproduzir, conforme a discussão do parágrafo anterior.

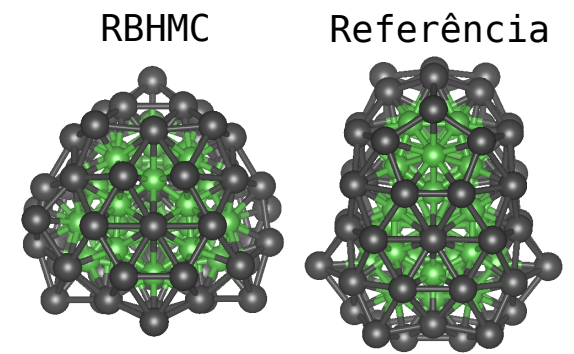

$\mathrm{BLJ}_{99}$
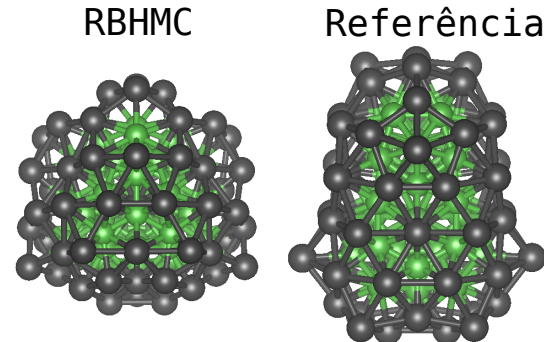

$\mathrm{BLJ}_{100}$

Figura 5.8 - Estruturas de mínimo global dos clusters BLJ $\mathrm{J}_{99}$ e $\mathrm{BLJ} \mathrm{J}_{100}$ para a razão $\sigma^{B B} / \sigma^{A A}=$ 1.30. Estruturas encontradas com o método RBHMC comparada com estruturas da literatura $(8,9)$.

\subsection{Clusters binários de metais de transição - $(\mathrm{AgPd})_{55}$}

O sistema $\mathrm{Ag}_{55-n} \mathrm{Pd}_{n}$ descrito pelo potencial de $\mathrm{SC}$ foi otimizado com o método RBHMC, com a composição variando desde $n=0$ (cluster puro de $\mathrm{Ag}$ ) até $n=55$ (cluster puro de Pd) em passos unitários. Os parâmetros do potencial de SC para esse sistema são mostrados na tabela 5.6. O método RBHMC foi aplicado à temperatura $k_{B} T=0.1$, com o operador CO desabilitado e o operador OJ habilitado para 3 saltos a cada 1000 rejeições consecutivas pelo critério de Metropolis. A sequência de operadores empregada foi CDO, SAO, TO, EO, AO, GCDO, IO, GEO, e o esquema dinâmico foi utilizado.

Para cada composição foram realizadas 100 aplicações independentes do método RBHMC, cada uma com 100 mil passos. Este grande número de passos, e também de aplicações, deve- 
Tabela 5.6 - Parametrização com correções quânticas do potencial de Sutton-Chen descrevendo a interação entre pares de átomos $\mathrm{Ag}$ e $\mathrm{Pd}$ (15).

\begin{tabular}{cccccc}
\hline Par de átomos & $\boldsymbol{n}$ & $\boldsymbol{m}$ & $\boldsymbol{c}$ & $\boldsymbol{\epsilon}(\mathrm{eV})$ & $\boldsymbol{a}(\boldsymbol{A})$ \\
\hline $\mathrm{Pd}-\mathrm{Pd}$ & 12 & 6 & 148.205 & $3.2864 \times 10^{-3}$ & 3.8813 \\
$\mathrm{Ag}-\mathrm{Ag}$ & 11 & 6 & 96.524 & $3.9450 \times 10^{-3}$ & 4.0691 \\
$\mathrm{Ag}-\mathrm{Pd}$ & 11.5 & 6 & - & $3.6007 \times 10^{-3}$ & 3.9752 \\
\hline
\end{tabular}

se ao fato de não haver dados de referência correspondentes às estruturas de mínimos globais associadas a todas as composições possíveis, portanto os resultados são desconhecidos a priori e uma busca extensa é recomendável para que haja confiança nos resultados finais. O objetivo desse estudo de caso é demonstrar como o método RBHMC pode ser útil para a investigação de nano-ligas metálicas. As energias totais para todas as composições podem ser vistas na tabela 5.7 .

Tabela 5.7 - Energias totais dos mínimos globais dos clusters binários $\mathrm{Ag}_{55-n} \mathrm{Pd}_{n}$ descritos pelo potencial de SC para todos os valores possíveis de $n$.

\begin{tabular}{lclc}
\hline Sistema & Energia (eV) & Sistema & Energia (eV) \\
\hline $\mathrm{Ag}_{55}$ & -137.43 & $\mathrm{Ag}_{27} \mathrm{Pd}_{28}$ & -162.71 \\
$\mathrm{Ag}_{54} \mathrm{Pd}_{1}$ & -138.75 & $\mathrm{Ag}_{26} \mathrm{Pd}_{29}$ & -163.46 \\
$\mathrm{Ag}_{53} \mathrm{Pd}_{2}$ & -139.83 & $\mathrm{Ag}_{25} \mathrm{Pd}_{30}$ & -164.19 \\
$\mathrm{Ag}_{52} \mathrm{Pd}_{3}$ & -140.91 & $\mathrm{Ag}_{24} \mathrm{Pd}_{31}$ & -164.92 \\
$\mathrm{Ag}_{51} \mathrm{Pd}_{4}$ & -141.99 & $\mathrm{Ag}_{23} \mathrm{Pd}_{32}$ & -165.64 \\
$\mathrm{Ag}_{50} \mathrm{Pd}_{5}$ & -143.04 & $\mathrm{Ag}_{22} \mathrm{Pd}_{33}$ & -166.37 \\
$\mathrm{Ag}_{49} \mathrm{Pd}_{6}$ & -144.08 & $\mathrm{Ag}_{21} \mathrm{Pd}_{34}$ & -167.05 \\
$\mathrm{Ag}_{48} \mathrm{Pd}_{7}$ & -145.11 & $\mathrm{Ag}_{20} \mathrm{Pd}_{35}$ & -167.72 \\
$\mathrm{Ag}_{47} \mathrm{Pd}_{8}$ & -146.12 & $\mathrm{Ag}_{19} \mathrm{Pd}_{36}$ & -168.40 \\
$\mathrm{Ag}_{46} \mathrm{Pd}_{9}$ & -147.13 & $\mathrm{Ag}_{18} \mathrm{Pd}_{37}$ & -169.07 \\
$\mathrm{Ag}_{45} \mathrm{Pd}_{10}$ & -148.11 & $\mathrm{Ag}_{17} \mathrm{Pd}_{38}$ & -169.74 \\
$\mathrm{Ag}_{44} \mathrm{Pd}_{11}$ & -149.07 & $\mathrm{Ag}_{16} \mathrm{Pd}_{39}$ & -170.40 \\
$\mathrm{Ag}_{43} \mathrm{Pd}_{12}$ & -150.03 & $\mathrm{Ag}_{15} \mathrm{Pd}_{40}$ & -171.07 \\
$\mathrm{Ag}_{42} \mathrm{Pd}_{13}$ & -150.99 & $\mathrm{Ag}_{14} \mathrm{Pd}_{41}$ & -171.73 \\
$\mathrm{Ag}_{41} \mathrm{Pd}_{14}$ & -151.79 & $\mathrm{Ag}_{13} \mathrm{Pd}_{42}$ & -172.39 \\
$\mathrm{Ag}_{40} \mathrm{Pd}_{15}$ & -152.60 & $\mathrm{Ag}_{12} \mathrm{Pd}_{43}$ & -173.06 \\
$\mathrm{Ag}_{39} \mathrm{Pd}_{16}$ & -153.41 & $\mathrm{Ag}_{11} \mathrm{Pd}_{44}$ & -173.63 \\
$\mathrm{Ag}_{38} \mathrm{Pd}_{17}$ & -154.21 & $\mathrm{Ag}_{10} \mathrm{Pd}_{45}$ & -174.21 \\
$\mathrm{Ag}_{37} \mathrm{Pd}_{18}$ & -155.01 & $\mathrm{Ag}_{9} \mathrm{Pd}_{46}$ & -174.78 \\
$\mathrm{Ag}_{36} \mathrm{Pd}_{19}$ & -155.82 & $\mathrm{Ag}_{8} \mathrm{Pd}_{47}$ & -175.36 \\
$\mathrm{Ag}_{35} \mathrm{Pd}_{20}$ & -156.61 & $\mathrm{Ag}_{7} \mathrm{Pd}_{48}$ & -175.93 \\
$\mathrm{Ag}_{34} \mathrm{Pd}_{21}$ & -157.40 & $\mathrm{Ag}_{6} \mathrm{Pd}_{49}$ & -176.50 \\
$\mathrm{Ag}_{33} \mathrm{Pd}_{22}$ & -158.20 & $\mathrm{Ag}_{5} \mathrm{Pd}_{50}$ & -177.08 \\
$\mathrm{Ag}_{32} \mathrm{Pd}_{23}$ & -158.99 & $\mathrm{Ag}_{4} \mathrm{Pd}_{51}$ & -177.65 \\
$\mathrm{Ag}_{31} \mathrm{Pd}_{24}$ & -159.74 & $\mathrm{Ag}_{3} \mathrm{Pd}_{52}$ & -178.22 \\
$\mathrm{Ag}_{30} \mathrm{Pd}_{25}$ & -160.49 & $\mathrm{Ag}_{2} \mathrm{Pd}_{53}$ & -178.78 \\
$\mathrm{Ag}_{29} \mathrm{Pd}_{26}$ & -161.24 & $\mathrm{Ag}_{1} \mathrm{Pd}_{54}$ & -179.35 \\
$\mathrm{Ag}_{28} \mathrm{Pd}_{27}$ & -161.97 & $\mathrm{Pd}_{55}$ & -179.92 \\
\hline
\end{tabular}


Neste ponto é conveniente introduzir algumas medidas quantitativas úteis na análise de clusters binários. O parâmetro de composição, $\sigma$, permite uma análise quantitativa da composição química de uma partícula e do grau de segregação entre as fases de diferentes espécies atômicas. Este parâmetro fornece uma ordem de combinação dos átomos da partícula, e pode ser utilizado para analisar o ordenamento de diferentes composições. Sua definição é dada por

$$
\sigma=\frac{N_{A g-A g}+N_{P d-P d}-N_{A g-P d}}{N_{A g-A g}+N_{P d-P d}+N_{A g-P d}},
$$

onde $N_{A g-A g}, N_{P d-P d}$ e $N_{A g-P d}$ correspondem ao número de ligações de primeiros vizinhos do tipo $\mathrm{Ag}-\mathrm{Ag}, \mathrm{Pd}-\mathrm{Pd}$ e Ag-Pd, respectivamente. Dessa maneira, o parâmetro $\sigma$ leva em conta interações de curto alcance, que são particularmente importante em sistemas compostos por metais de transição. $\mathrm{O}$ valor de $\sigma$ é aproximadamente +1 para partículas segregadas, próximo de 0 para uma mistura desordenada, e aproximadamente -1 para fases ordenadas misturadas, como no caso de uma nano-liga.

Outra propriedade útil é a energia de excesso, $E_{\text {exc }}$, que fornece uma medida da estabilidade de um sistema binário em relação às suas fases puras. Esta energia é definida como

$$
E_{e x c}=E_{t o t}\left(A g_{55-n} P d_{n}\right)-\left[\frac{(55-n)}{55} E_{t o t}^{A g}+\frac{n}{55} E_{t o t}^{P d}\right]
$$

onde $E_{t o t}\left(A g_{55-n} P d_{n}\right)$ é a energia total do cluster $A_{55-n} \mathrm{Pd}_{n}$, enquanto $E_{\text {tot }}^{A g}$ e $E_{\text {tot }}^{P d}$ são as energias totais dos clusters $\mathrm{Ag}_{55}$ e $\mathrm{Pd}_{55}$, respectivamente. Quando calculada para todas as composições possíveis, mínimo da curva de energia de excesso indica a composição mais estável de um sistema binário.

$\mathrm{Na}$ figura 5.9 são exibidas algumas propriedades dos clusters $(\mathrm{AgPd})_{55}$ em função das possíveis composições. Estas propriedades são o ECN médio, $d_{a v}, E_{e x c}$ e o parâmetro $\sigma$. Para todas as composições o tipo geométrico verificado é icosaedro completo. É interessante notar que devido à alta estabilidade de um cluster do tipo icosaedro completo puro, a introdução de uma nova espécie não é suficiente para deformar a estrutura de maneira significativa. $\mathrm{Na}$ verdade, como pode ser visto pelo formato parabólico da curva de energia de excesso, as fases compostas apresenta maior estabilidade em relação às fases puras, o que também explica o fato da geometria do tipo icosaedro completo ser mantida ao longo da variação da composição.

À medida que o número de átomos de Pd é aumentado, esses átomos tendem a ocupar sítios internos, reduzindo a tensão superficial, uma vez que os átomos de $\mathrm{Ag}$ possuem um maior raio atômico em comparação com os átomos de $\mathrm{Pd}$ (cerca de $5 \%$ maior dentro desta parametrização do potencial SC). Quando $n=1$, o único átomo de Pd ocupa o sítio central do icosaedro. Quando a composição atinge $n=13$, observa-se uma estrutura do tipo core-shell, 


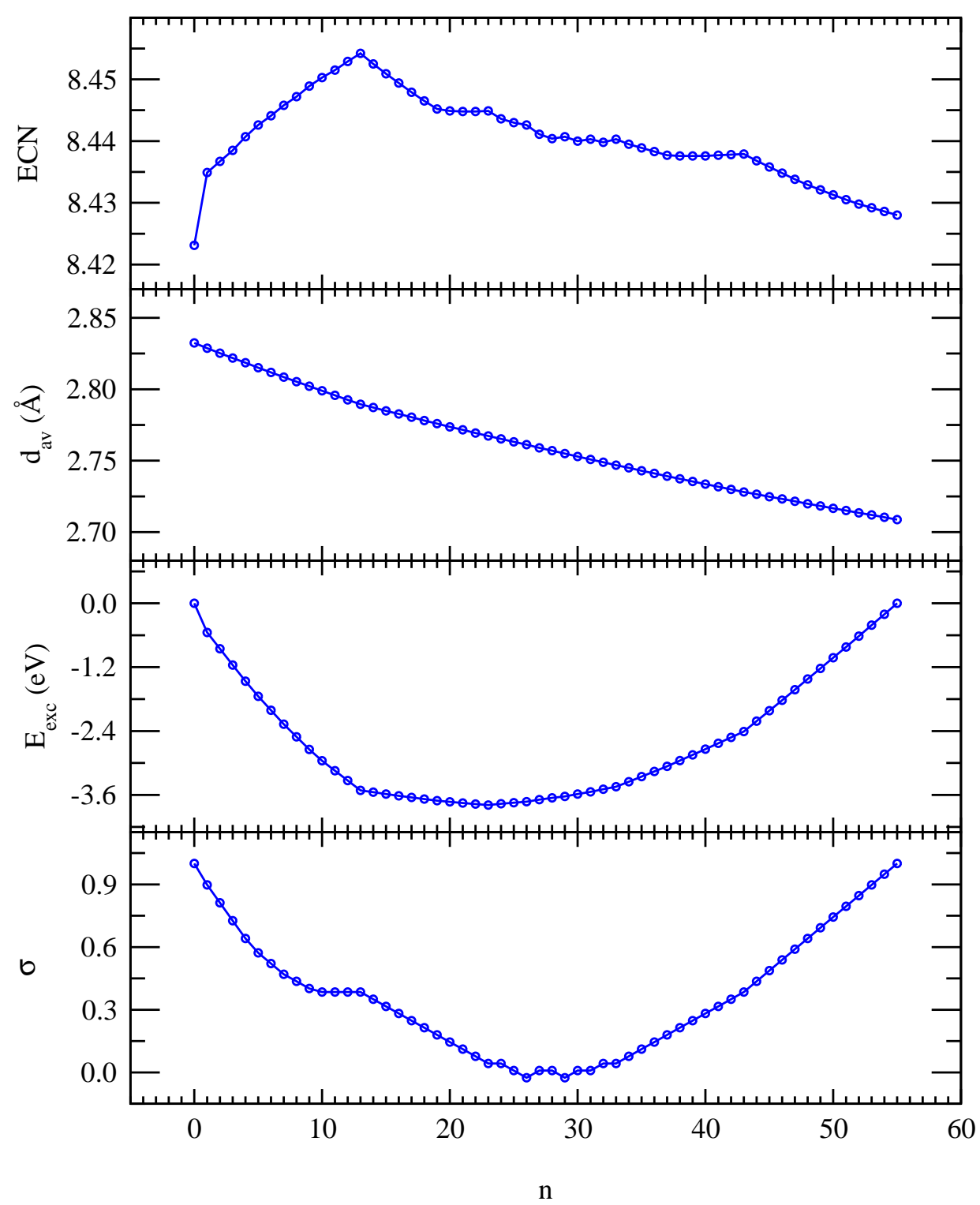

Figura 5.9 - Propriedades dos clusters $\mathrm{Ag}_{55-n} \mathrm{Pd}_{n}$ em função do número de átomos de $\mathrm{Pd}$. De cima para baixo, número de coordenação efetiva médio (ECN), comprimento de ligação ponderado médio $\left(d_{a v}\right)$, energia de excesso $\left(E_{e x c}\right)$ e parâmetro de composição $(\sigma)$.

com átomos de $\mathrm{Pd}$ ocupando a região interior da partícula (átomo central e primeira camada), e átomos de $\mathrm{Ag}$ a região superficial (segunda camada). Aumentando o número de átomos de $\mathrm{Pd}$, estes passam a ocupar também a região superficial. Quando a composição atinge $n=54$, o único átomo de $\mathrm{Ag}$ restante não ocupa um sítio interno, mas sim superficial.

Como todas as estruturas são icosaédricas, o ECN médio apresenta poucas variações para as diferentes composições, atingindo valor máximo para $n=13$, no qual o átomo central apresenta a coordenação efetiva do bulk de SC, que é 12 . O valor de $d_{a v}$ também apresenta variação modesta, com uma amplitude máxima de aproximadamente 1 Å. Esta variação pode 


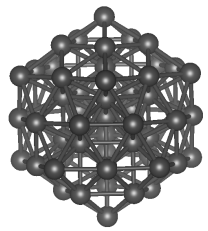

$\mathrm{Ag}_{55}$

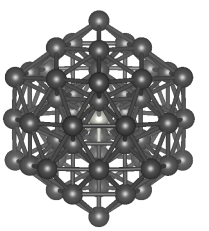

$\mathrm{Ag}_{54} \mathrm{Pd}_{1}$

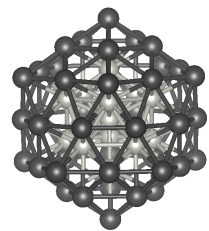

$\mathrm{Ag}_{42} \mathrm{Pd}_{13}$

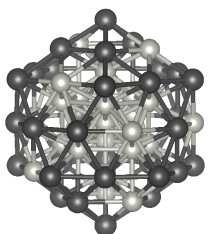

$\mathrm{Ag}_{32} \mathrm{Pd}_{23}$

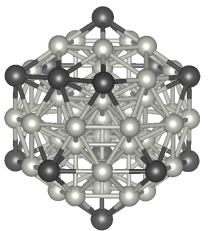

$\mathrm{Ag}_{13} \mathrm{Pd}_{42}$

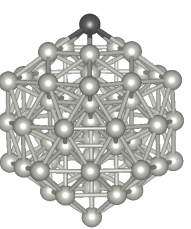

$\mathrm{Ag}_{1} \mathrm{Pd}_{54}$

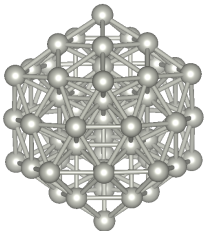

$\mathrm{Pd}_{55}$

Figura 5.10 - Estruturas de mínimo global dos clusters $\mathrm{Ag}_{55-n} \mathrm{Pd}_{n}$ para $n=0,1,13,23,42,54,55$. Átomos de $\mathrm{Ag}$ em cinza escuro e Pd em cinza claro.

ser correlacionada às pequenas distorções estruturais devido aos diferentes comprimentos de ligação entre pares $\mathrm{Ag}-\mathrm{Ag}, \mathrm{Pd}-\mathrm{Pg}$ e $\mathrm{Ag}-\mathrm{Pd}$, porém a geometria é mantida para todos os possíveis valores de $n$. A posição do mínimo da curva de energia de excesso indica que o cluster $\mathrm{Ag}_{32} \mathrm{Pd}_{23}$ é o que tem a composição mais estável, e portanto uma fase rica em $\mathrm{Ag}$ é favorecida. A curva do parâmetro $\sigma$ indica que quanto mais rico o cluster for em uma espécie, maior é a segregação entre as fases. Quando a composição se aproxima de $50 \%$ para cada espécie, a composição é desordenada, com átomos de $\mathrm{Ag}$ e $\mathrm{Pd}$ presentes nas regiões interna e superficial. É interessante notar o comportamento da curva em $n=13$, onde há um bico. Como esta composição corresponde a uma estrutura do tipo core-shell, há algum nível de segregação no cluster. Na figura 5.10 são exibidas as estruturas para algumas composições discutidas neste parágrafo e nos anteriores.

Para o caso particular $\mathrm{Ag}_{42} \mathrm{Pd}_{13}$, existem resultados de referência na literatura obtidos com um algoritmo BHMC padrão contendo apenas um operador de deslocamento atômico (112). Esta composição serve como uma maneira de avaliar o desempenho do método RBHMC em comparação com o método BHMC padrão em sua forma mais simples. Para este caso o método RBHMC encontrou uma estrutura core-shell do tipo icosaedro completo. A energia total deste mínimo global é -150.99 eV, que é $0.58 \mathrm{eV}$ menor que a energia reportada por Kim et al. (112). Estes autores também identificaram a estrutura icosaédrica do tipo core-shell, e a diferença de energia pode ser atribuída à diferenças sutis entre os métodos de minimização local utilizados nos dois trabalhos. É provável que a estrutura identificada pelos autores esteja bem próxima do mínimo global, sendo necessária uma minimização local mais restritiva para atingir a região mais baixa do poço que cerca o mínimo global.

Uma análise dos números de coordenação efetiva para todos os átomos da estrutura $\mathrm{Ag}_{42} \mathrm{Pd}_{13}$ identificada com o método $\mathrm{RBHMC}$ revela que o átomo de $\mathrm{Pd}$ central e os 12 átomos de $\mathrm{Pd}$ que o envolvem possuem coordenações efetivas iguais a 12.00 e 11.93, respectivamente. Já os átomos de $\mathrm{Ag}, 12$ deles se localizam nos vértices do icosaedro com coordenação efetiva de 5.96, enquanto os 30 restantes possuem coordenação efetiva igual a 7.95 e se lo- 
calizam nas faces do icosaedro. Esses átomos das faces possuem maior coordenação efetiva em comparação com aqueles dos vértices, uma vez que estão empacotados de forma mais compacta. Essa análise revela a simetria perfeita, sem distorções, da geometria de icosaedro completo encontrada para o cluster $\mathrm{Ag}_{42} \mathrm{Pd}_{13}$ descrito pelo potencial de $\mathrm{SC}$, correspondente ao grupo pontual $I_{h}$.

No mais, para cada composição considerada aqui foi possível obter o mesmo mínimo global em cada uma das 100 aplicações do método RBHMC, atingindo, assim, uma taxa de sucesso igual a $100 \%$ para todos os casos. Em particular, no caso do sistema $\mathrm{Ag}_{42} \mathrm{Pd}_{13}$ essa taxa de sucesso pode ser comparada com a taxa $18.3 \%$ atingida pelo método BHMC padrão, conforme reportado por Kim et al. (112). Além disso, esses autores reportaram um TMPE de 5829 passos de Metropolis para atingir o mínimo global desse sistema, enquanto neste trabalho - TMPE foi de 3050 passos. Esses resultados indicam que a metodologia apresentada neste trabalho possibilita um ganho significativo de eficiência para clusters binários descritos pelo potencial de SC.

\subsection{Sumário}

O método RBHMC conforme implementado no GOP foi capaz de reproduzir a grande maioria dos resultados da literatura. Para clusters de LJ com até 148 átomos todos os resultados foram reproduzidos, e uma análise onde o método foi aplicado a casos difíceis demonstrou que o esquema dinâmico torna a otimização global mais eficiente em comparação com o esquema estático. O método RBHMC se mostrou eficiente também para NPs de LJ com até 1500 átomos, atingindo o mínimo global para a maioria dos casos em um número razoável de passos. Os mínimos globais encontrados para clusters de SC contendo entre 3 e 81 átomos concordam com os dados de referência, e aqueles contendo entre 81 e 148 átomos são inéditos na literatura. Um total de 576 clusters BLJ foram otimizados, com tamanhos entre 5 e 100 átomos, e 54 dos mínimos globais encontrados apresentam energia menor que os mínimos globais putativos disponíveis na literatura para as mesmas composições. A otimização dos clusters binários de metais de transição $(\mathrm{AgPd})_{55}$ permitiram que a composição mais estável fosse determinada, e para o caso em que há dados de referência, $\mathrm{Ag}_{42} \mathrm{Pd}_{13}$, foi verificado que a eficiência do método RBHMC supera a do méteodo BHMC padrão.

Clusters de LJ e SC apresentam tipos geométricos semelhantes, e em ambos os casos há uma predominância de estruturas baseadas em icosaedro e decaedro. Até 148 átomos, foi verificado que efeitos de superfície ainda se fazem presentes para os dois potenciais, uma vez 
que a coordenação efetiva média ficou abaixo dos valores esperados para bulks. Clusters de SC possuem ligações mais curtas, na média, que os clusters de LJ, o que pode ser explicado pelo termo de coesão de muitos corpos do potencial de SC. Durante os cálculos de otimização com o método RBHMC notou-se uma maior facilidade na obtenção dos mínimos globais putativos para os clusters de SC, e nenhum caso desafiador foi encontrado, como ocorre para alguns tamanhos de clusters $\mathrm{LJ}_{N}$, e.g., $N=75,76,77$. Clusters binários apresentam a tendência energeticamente favorável de átomos com raios atômicos maiores permanecerem na região superficial, enquanto átomos menores se localizam na região interna, a fim de reduzir a tensão superficial. Essa característica pode ser observada nos clusters $(\mathrm{AgPd})_{55}$ para o caso de um único átomo de $\mathrm{Ag}\left(\mathrm{Ag}_{1} \mathrm{Pd}_{54}\right)$, o qual ocupa uma posição superficial de menor simetria, ao invés da posição central do icosaedro. Por outro lado, o átomo de $\mathrm{Pd}$, que tem raio atômico inferior ao do átomo de $\mathrm{Ag}$, ocupa a posição central no cluster $\mathrm{Ag}_{54} \mathrm{Pd}_{1}$. 


\section{CAPÍTULO 6}

\section{Estudo de Casos: Clusters de Alumínio Descritos pela DFT}

Neste capítulo é apresentado um estudo de casos no qual o método RBHMC-DFT foi aplicado à clusters de alumínio puros, $\mathrm{Al}_{N}(N=2-30)$, e dopados com um átomo de $\mathrm{Cu}$, $\mathrm{Al}_{N-1} \mathrm{Cu}(N=2-14)$. Uma análise que justifica o uso do operador SFO é discutido na seção final do capítulo.

\subsection{Clusters de alumínio puros}

Clusters de Al têm sido o objeto de diversos estudos teóricos*. Uma das razões deve-se ao fato de que as propriedades eletrônicas do bulk de Al podem ser descritas em um nível satisfatório de aproximação pelo modelo de elétrons livres jellium (149), e por isso tentou-se aplicar o mesmo modelo para clusters, porém há um debate na literatura acerca de quais tamanhos de clusters podem ser descritos satisfatoriamente utilizando este modelo (150-152). De um ponto de vista estrutural, modelos simples de interações são capazes de prever algumas estruturas de mínimo global que concordam com resultados experimentais e de cálculos quânticos, sendo o caso mais notável o cluster $\mathrm{Al}_{13}$, para o qual potenciais empíricos preveem o mínimo global com geometria do tipo icosaedro $(145,153)$. Do ponto de vista de DFT, clusters de $\mathrm{Al}$ exigem cálculos de custo relativamente baixo, uma vez que o átomo de $\mathrm{Al}$ possui apenas 13 elétrons, sendo 3 deles de valência, e portanto representam um sistema que pode ser estudado de maneira viável a fim de fornecer mais informações sobre propriedades estruturais e eletrônicas de clusters metálicos. O grande número de estudos teóricos significa também que há uma coleção rica de mínimos globais putativos disponíveis para comparação, o que viabiliza a avaliação do método RBHMC-DFT.

*Referência (148) e referências lá citadas. 
Os cálculos de DFT foram realizados com o pacote FHI-aims. Durante a otimização global com RBHMC-DFT, o conjunto de funções de base empregado foi light com funções do nível tier 1, que fornecem precisão suficiente para a exploração da SEP. O funcional de troca e correlação utilizado foi o GGA-PBE, o parâmetro de ocupação foi do tipo gaussiano, com valor $10^{-1} \mathrm{eV}$, o critério de convergência para a energia total foi $10^{-4} \mathrm{eV}$, e os átomos foram considerados em equilíbrio estável uma vez que todas as forças atingiram magnitude inferior a $10^{-2} \mathrm{ev} / \AA$. Após a obtenção dos mínimos globais utilizando RBHMC-DFT, as estruturas foram refinadas com cálculos adicionais de DFT, nos quais o funcional de troca e correlação foi mantido em GGA-PBE, porém o conjunto de bases foi expandido, empregando-se o conjunto tight com funções do nível tier 2. O parâmetro de ocupação foi do tipo gaussiano, com valor $10^{-2} \mathrm{eV}$, o critério para a energia total foi $10^{-5} \mathrm{eV}$, e critério para as forças foi $10^{-3} \mathrm{eV} / \AA$.

O método RBHMC foi configurado para iniciar a partir de uma configuração aleatória e a temperatura foi fixada em $k_{B} T=0.2$, que mostrou bons resultados em testes preliminares. Este valor é da ordem das diferenças de energia entre as configurações novas produzidas pelos operadores e as configurações originais. Os operadores $\mathrm{OJ}$ e $\mathrm{CO}$ foram desabilitados, uma vez que o número de passos de Metropolis executados foi da ordem de $10^{3}$, e desejou-se fazer uma exploração contínua utilizando apenas os operadores locais e não-locais. A sequência de operadores foi GCDO, TO, AO, CDO, SAO, empregando o esquema estático de aplicações. Apesar do esquema dinâmico se mostrar mais eficiente para clusters descritos por potenciais empíricos, foi inviável realizar tal análise para os clusters descritos por DFT. Além disso, os esquema estático é mais gerenciável e previsível, e por essas razões optou-se por ele nesse caso. O operador SFO foi habilitado com $\eta=0.4$.

As estruturas de menor energias dos clusters $\mathrm{Al}_{N}(N=2-30)$ identificadas com RBHMCDFT podem ser vistas na figura 6.1. Observando as estruturas, é possível perceber que há uma transição de estruturas planares para tridimensionais entre os clusters $\mathrm{Al}_{4}$ e $\mathrm{Al}_{5}$ (154). À medida que o tamanho aumenta, as estruturas tendem a se tornar mais compactas, e para 0 caso $\mathrm{Al}_{13}$ a estrutura tem geometria do tipo icosaedro completo, com uma pequena distorção de Jahn-Teller que é responsável por reduzir sua simetria de grupo pontual de $I_{h}$ para $D_{3 d}$.

Há um debate na literatura acerca da estrutura de mínimo global do cluster $\mathrm{Al}_{13}$. Como observado por Aguado e López (148), um pequeno número de estudos teóricos aponta a estrutura de menor energia como tendo geometria do tipo decaedro, enquanto um número mais expressivo de estudos aponta o icosaedro completo como estrutura mais estável energeticamente. A fim de verificar, neste trabalho a estrutura com geometria decaedral fornecida por Aguado e López foi submetida a um cálculo DFT-GGA-PBE, e verificou-se que ela possui uma energia que supera em $0.29 \mathrm{eV}$ a energia da estrutura icosaedral, confirmando assim a 
constatação da maioria dos estudos. Além disso, é possível verificar claramente pela figura 6.1 que as estruturas dos clusters entre $\mathrm{Al}_{14}$ e $\mathrm{Al}_{19}$ são baseadas no icosaedro completo encontrado para $\mathrm{Al}_{13}$.

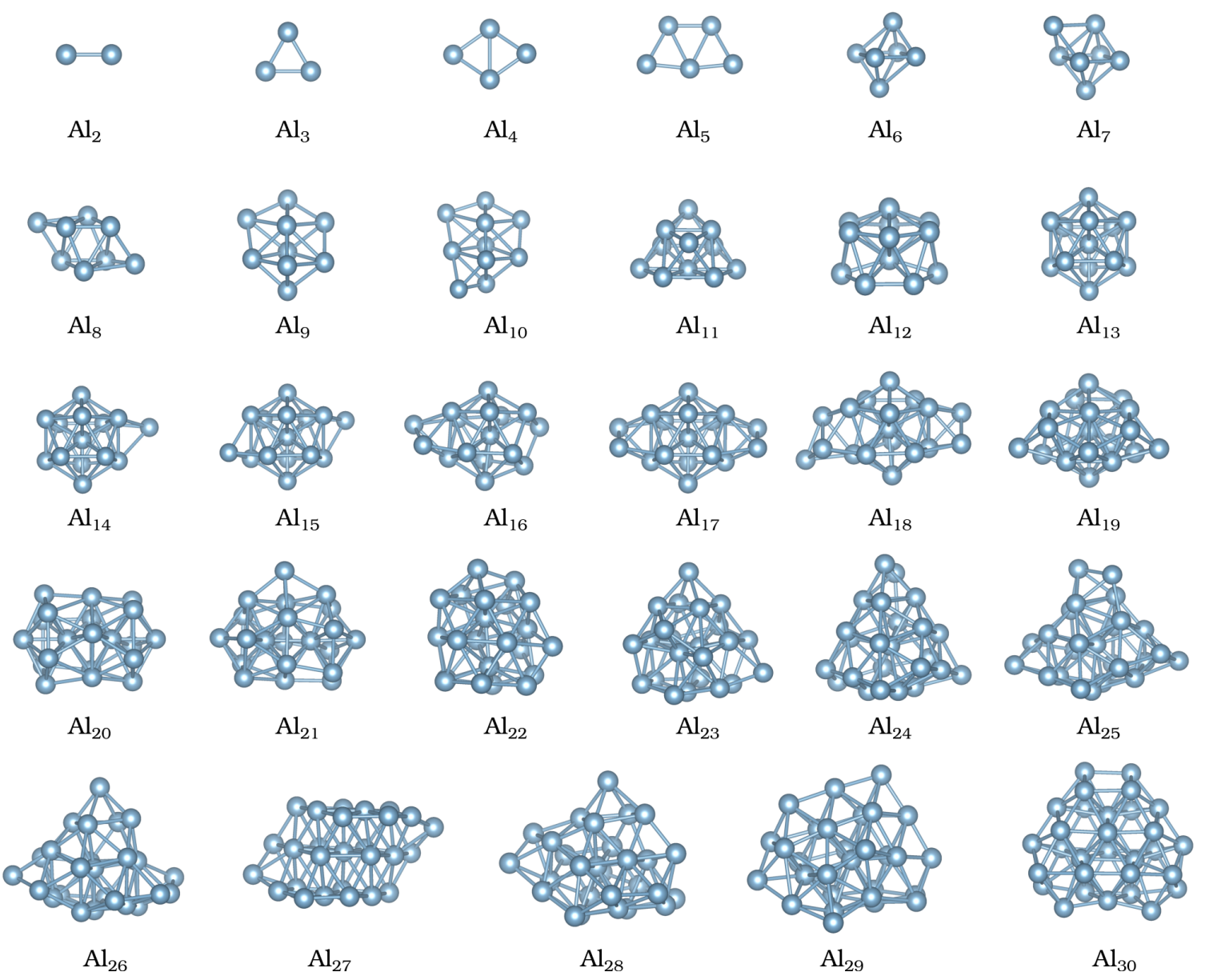

Figura 6.1 - Estruturas dos clusters $\mathrm{Al}_{N}(N=2-30)$ identificadas com o método RBHMC-DFT.

As estruturas de mais baixa energia encontradas neste trabalho foram comparadas com os mínimos globais putativos mais recentes publicados por Drebov e Ahlrichs (10) para a faixa de tamanhos considerada aqui. Um sumário desta comparação é apresentado na tabela 6.1, onde são mostradas a diferença de energia entre cada estrutura determinada com RBHMCDFT e a respectiva estrutura de referência (valores positivos indicam que a estrutura da literatura tem menor energia total). Devido à precisão permitida pelo conjunto de funções de base empregado no FHI-aims durante os cálculos de refinamento, adotou-se o critério de degenerescência segundo o qual duas estruturas são consideradas degeneradas caso a diferença de energia entre elas seja inferior a $1 \mathrm{meV} /$ átomo.

As estruturas encontradas com o método RBHMC-DFT concordam com as estruturas de 
referência na maior parte dos casos. A estrutura identificada neste trabalho para $\mathrm{Al}_{24}$ possui energia total $0.094 \mathrm{eV}$ mais baixa (3.92 meV/átomo) que a estrutura de referência, e parece ser uma estrutura inédita na literatura. Para os casos $\mathrm{Al}_{23}, \mathrm{Al}_{26}, \mathrm{Al}_{27}, \mathrm{Al}_{28}$ e $\mathrm{Al}_{30}$ não foi possível obter resultados melhores que os de referência, porém as diferenças nas energias são relativamente pequenas. É importante destacar que neste trabalho o método RBHMC partiu de estruturas completamente aleatórias, ao passo que os autores Drebov e Ahlrichs (10) utilizaram um esquema de otimização de duas etapas, combinando o método BHMC padrão com algoritmos genéticos para a obtenção dos seus resultados. Assim sendo, o fato do método RBHMC ter sido capaz de reproduzir a maior parte desses resultados, de maneira independente e sem bias, é um ponto favorável para a metodologia apresentada aqui.

Tabela 6.1 - $\quad$ Comparação das estruturas obtidas por meio do método RBHMC-DFT com as estruturas de mínimo global mais recentes da literatura (10). Para os tamanhos disponíveis para comparação, são mostradas as diferenças de energia, definida como $\Delta E=E_{\text {tot }}^{R B H M C-D F T}-E_{\text {tot }}^{R e f}$, e as simetrias de grupo pontual (GP).

\begin{tabular}{crrll}
\hline $\boldsymbol{N}$ & $\boldsymbol{\Delta} \boldsymbol{E}(\mathbf{e V})$ & $\boldsymbol{\Delta} \boldsymbol{E}(\mathbf{m e V} \boldsymbol{N} \boldsymbol{N})$ & $\mathbf{G P}$ & $\mathbf{G P}^{\text {Ref }}$ \\
\hline 2 & - & - & $D_{X h}$ & - \\
3 & - & - & $D_{3 h}$ & - \\
4 & - & - & $D_{2 h}$ & - \\
5 & 0.00014 & 0.03 & $C_{2 v}$ & $C_{2 v}$ \\
6 & 0.00004 & 0.01 & $D_{3 d}$ & $D_{3 d}$ \\
7 & -0.00003 & -0.01 & $C_{3 v}$ & $C_{3 v}$ \\
8 & 0.00008 & 0.01 & $C_{2 h}$ & $C_{2 h}$ \\
9 & 0.00014 & 0.02 & $C_{s}$ & $C_{s}$ \\
10 & 0.00018 & 0.02 & $C_{s}$ & $C_{s}$ \\
11 & 0.00049 & 0.04 & $C_{2 v}$ & $C_{2 v}$ \\
12 & 0.00874 & 0.73 & $C_{s}$ & $C_{1}$ \\
13 & 0.00010 & 0.01 & $D_{3 d}$ & $D_{3 d}$ \\
14 & -0.00004 & -0.01 & $C_{3 v}$ & $C_{3 v}$ \\
15 & 0.00031 & 0.02 & $C_{2 h}$ & $C_{2 h}$ \\
16 & 0.00013 & 0.01 & $C_{s}$ & $C_{s}$ \\
17 & 0.00010 & 0.01 & $D_{2 h}$ & $D_{2 h}$ \\
18 & 0.00017 & 0.01 & $C_{s}$ & $C_{s}$ \\
19 & 0.00097 & 0.05 & $C_{1}$ & $C_{1}$ \\
20 & 0.00013 & 0.01 & $C_{1}$ & $C_{s}$ \\
21 & 0.00026 & 0.01 & $C_{s}$ & $C_{s}$ \\
22 & 0.00007 & 0.01 & $C_{1}$ & $C_{1}$ \\
23 & 0.08765 & 3.81 & $C_{1}$ & $C_{3 v}$ \\
24 & -0.09409 & -3.92 & $C_{1}$ & $C_{1}$ \\
25 & 0.00096 & 0.04 & $C_{2}$ & $C_{2}$ \\
26 & 0.08931 & 3.44 & $C_{1}$ & $C_{1}$ \\
27 & 0.35435 & 13.12 & $C_{2}$ & $C_{s}$ \\
28 & 0.22989 & 8.21 & $C_{1}$ & $C_{2 v}$ \\
29 & 0.01397 & 0.48 & $C_{1}$ & $C_{2 v}$ \\
30 & 0.05557 & 1.85 & $C_{2}$ & $C_{1}$ \\
\hline & & & &
\end{tabular}

Na figura 6.2 são exibidas propriedades das estruturas identificadas com RBHMC-DFT e também propriedades de estruturas de referência (10) recalculadas com DFT-GGA-PBE. 
Essas propriedades são a função de estabilidade relativa $\left(\Delta_{2} E\right)$, energia de ligação por átomo $\left(E_{b}\right)$, número de coordenação efetiva médio, comprimento de ligação ponderado médio $\left(d_{a v}\right)$, momento magnético total $\left(m_{t o t}\right)$, e gap energético entre o orbital molecular ocupado mais alto (HOMO - highest occupied molecular orbital) e o orbital molecular não ocupado mais baixo (LUMO - lowest unoccupied molecular orbital).

Os picos verificados na curva de estabilidade relativa referentes aos clusters $\mathrm{Al}_{7}, \mathrm{Al}_{13} \mathrm{e}$ $\mathrm{Al}_{20}$ indicam que essas estruturas são as mais estáveis em relação aos seus respectivos clusters vizinhos em tamanho, e esses três tamanhos representam números mágicos, clusters que devem ser encontrados em experimentos com relativa abundância. Em geral, não existe uma correlação evidente entre a estabilidade relativa e as outras propriedades. Contudo, para esses três tamanhos mencionados onde se verificam os picos, pode-se notar valores ligeiramente maiores para $E_{b}$, ECN e $d_{a v}$ em relação aos tamanhos vizinhos, tornando a curvatura dessas curvas negativas nesses pontos. A energia de ligação e o comprimento de ligação médio do cluster $\mathrm{Al}_{30}$, são, respectivamente, $2.46 \mathrm{eV}$ e $2.69 \AA \AA$, ainda bem abaixo dos valores experimentais correspondentes verificados no bulk $(155,156)$, que são energia de coesão, cujo valor é $3.39 \mathrm{eV}$, e parâmetro de rede, com valor $4.05 \AA$ A . Isso indica que a convergência das propriedades dos clusters de $\mathrm{Al}$ para os valores de bulk é relativamente lenta, e em $N=30$ efeitos de tamanho finito ainda são significativos.

Os autores Cox et al. (157) investigaram as propriedades magnéticas de clusters $\mathrm{Al}_{N}$ até o tamanho $N=25$ utilizando experimentos de deflexão de Stern-Gerlach. Porém, devido as limitações experimentais eles foram capaz de determinar a multiplicidade de spin apenas para clusters com até 10 átomos. A multiplicidade é definida como $M=1+2 S$, onde $S=\frac{1}{2} n$, e $n$ corresponde ao número de elétrons desemparelhados. De acordo com os dados experimentais, clusters com um número ímpar de átomos possuem momento magnético igual a $1 \mu_{B}$, correspondendo as estados fundamentais de dubleto $(M=2)$, com um elétron desemparelhado, uma vez que cada átomo de Al contribui com 13 elétrons, i.e., número ímpar. Clusters com número par de átomos possuem momentos magnéticos iguais a $0 \mu_{B}$ ou $2 \mu_{B}$, correspondendo a estados fundamentais de singleto $(M=1)$ ou tripleto $(M=3)$, respectivamente.

As estruturas de estado fundamental encontradas com RBHMC-DFT concordam com os dados experimentais em todos os casos, exceto para $\mathrm{Al}_{6}$ e $\mathrm{Al}_{8}$, para os quais os experimentos indicam que possuem estados fundamentais de tripleto, enquanto neste trabalho foram encontrados singletos. Para estes dois casos foram realizados cálculos adicionais DFT-GGA-PBE fixando $S=1$. No caso $\mathrm{Al}_{6}$, foi verificado que o estado de tripleto tem uma energia total que é $0.007 \mathrm{eV}$ menor que a energia do estado de singleto, ou $1.15 \mathrm{meV} /$ átomo, e portanto ambos os estados são praticamente degenerados. No caso do cluster $\mathrm{Al}_{8}$, porém, verificou-se 


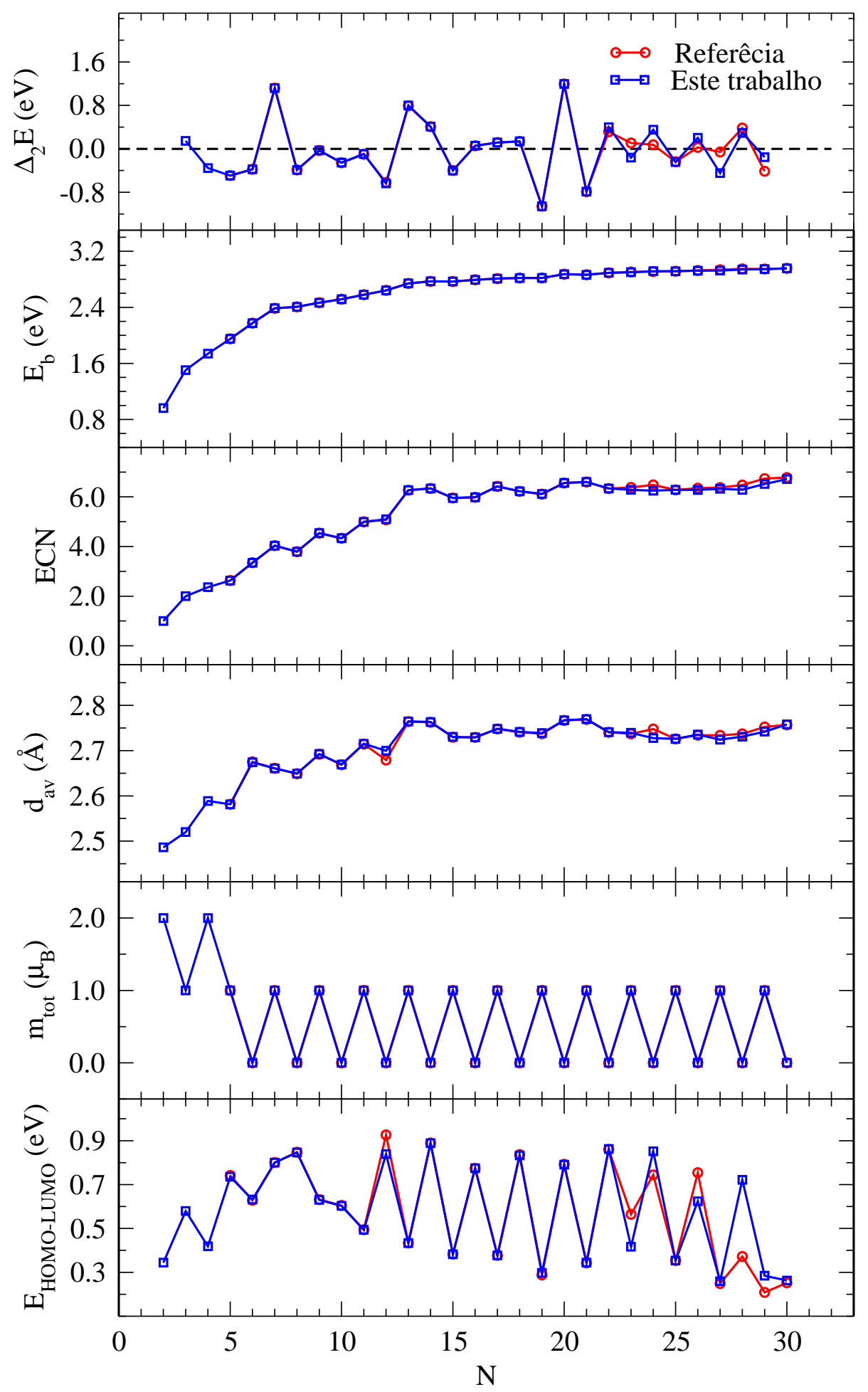

Figura 6.2 - Propriedades dos clusters $\mathrm{Al}_{N}(N=2-30)$ encontrados com RBHMC-DFT. Comparação resultados de cálculos DFT-GGA-PBE realizados em clusters de referência (10). De cima para baixo, função de estabilidade relativa $\left(\Delta_{2} E\right)$, energia de ligação por átomo $\left(\mathrm{E}_{b}\right)$, número de coordenação efetiva médio $(\mathrm{ECN})$, comprimento de ligação ponderado médio $\left(d_{a v}\right)$, momento magnético total $\left(m_{t o t}\right)$ e gap energético HOMO-LUMO, respectivamente. 
que o estado de tripleto possui energia total que é $0.19 \mathrm{eV}$ mais alta que a energia do estado de singleto, ou $23.24 \mathrm{meV} /$ átomo. Apesar da diferença ser modesta, indica que correspondem a estados não degenerados sob o critério de degenerescência adotado neste trabalho.

As diferenças nas propriedades não são muito acentuadas para os tamanhos em que o método RBHMC-DFT não foi capaz de identificar as mesmas estruturas que aquelas reportadas na literatura, e em geral as mesmas tendências são observadas, especialmente na curva de estabilidade relativa e no gap HOMO-LUMO. Na faixa entre $\mathrm{Al}_{11}$ e $\mathrm{Al}_{19}$ o perfil de gap é consistente com um padrão de alteração entre tamanhos ímpares e pares, com átomos de tamanhos pares apresentando um gap maior em relação aos tamanhos vizinhos, o que pode ser explicado por camadas eletrônicas fechadas. A diferença mais interessante entre os resultados obtidos neste trabalho e os resultados de referência se dá para o cluster $\mathrm{Al}_{28}$. $\mathrm{O}$ maior gap identificado aqui pode indicar que a estrutura encontrada com o método RBHMC-DFT apresentaria menor reatividade, e portanto seria mais estável. A confirmação desta hipótese, porém, requer cálculos e simulações adicionais, empregando um conjunto maior de funções de base.

\subsection{Clusters de alumínio dopados com um átomo de co- bre}

Diferentemente do que ocorre para o caso de clusters puros de $\mathrm{Al}$, não existe uma quantidade expressiva de mínimos globais putativos reportados na literatura para os clusters $\mathrm{Al}_{N-1} \mathrm{Cu}$, sendo os únicos tamanhos disponíveis para comparação $N=3-8$ (158) e $N=12-15$ (159163). As estruturas de menor energia identificadas na faixa de tamanhos $N=2-15$ são mostradas na figura 6.3. No caso de estruturas pequenas (até $N=5$ átomos) é mais conveniente fazer uma comparação de algumas propriedades estruturais ao invés de comparar as energias totais diretamente. Para $N>5$, onde possível, é feita uma comparação das energia totais identificadas neste trabalho com as energias totais de estruturas da literatura, recalculadas DFT-GGA-PBE.

Os parâmetros do método RBHMC foram os mesmos usados para o caso dos clusters puros, exceto pela sequência de operadores que foi modificada para incluir operadores de troca, ficando GCDO, EO, TO, AO, GEO, CDO, SAO, EO. Nesse caso, verificou-se que uma estratégia vantajosa é intercalar os operadores de troca com os restante dos operadores, dando mais oportunidades para a busca explorar mais possibilidades para a posição do átomo de $\mathrm{Cu}$. 
Os parâmetros dos cálculos DFT também foram mantidos, seguindo a mesma estratégia de realizar a otimização RBHMC-DFT utilizando o conjunto light com funções do nível tier 1, e então refinar os mínimos globais através de cálculos DFT-GGA-PBE utilizando o conjunto tight com funções do nível tier 2.

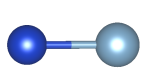

$\mathrm{AlCu}$

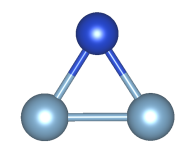

$\mathrm{Al}_{2} \mathrm{Cu}$

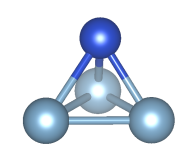

$\mathrm{Al}_{3} \mathrm{Cu}$

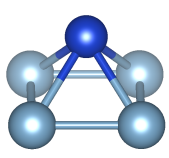

$\mathrm{Al}_{4} \mathrm{Cu}$

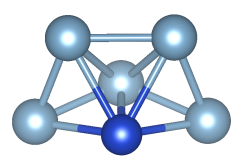

$\mathrm{Al}_{5} \mathrm{Cu}$

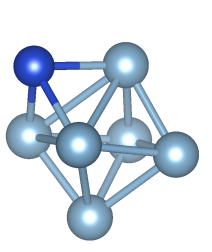

$\mathrm{Al}_{6} \mathrm{Cu}$

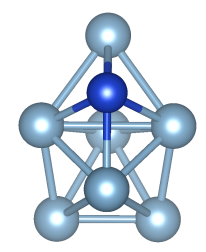

$\mathrm{Al}_{7} \mathrm{Cu}$

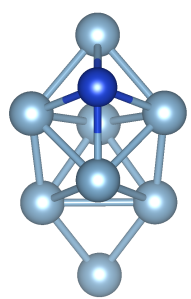

$\mathrm{Al}_{8} \mathrm{Cu}$

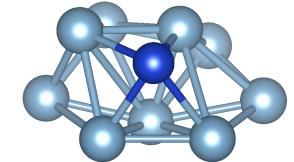

$\mathrm{Al}_{9} \mathrm{Cu}$

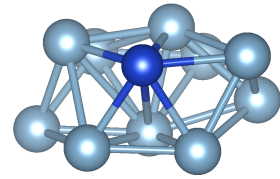

$\mathrm{Al}_{10} \mathrm{Cu}$

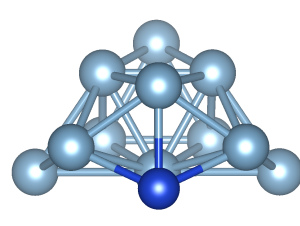

$\mathrm{Al}_{11} \mathrm{Cu}$

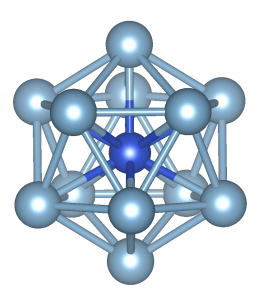

$\mathrm{Al}_{12} \mathrm{Cu}$

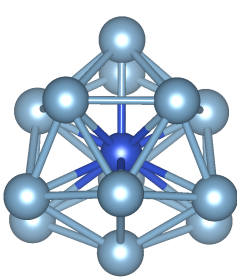

$\mathrm{Al}_{13} \mathrm{Cu}$

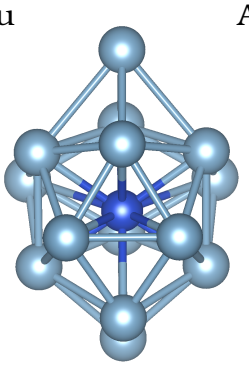

$\mathrm{Al}_{14} \mathrm{Cu}$

Figura 6.3 - Estruturas dos clusters $\mathrm{Al}_{N-1} \mathrm{Cu}(N=2-15)$ identificadas com o método RBHMCDFT.

O comprimento de ligação do cluster $\mathrm{AICu}$ encontrado foi $2.3381 \AA$, mais próximo do resultado experimental (164), que é $2.3389 \AA$, em comparação com o estudo teórico de Yang et. al (158) empregando DFT e o funcional B3LYP, no qual autores encontraram $2.4134 \AA$. No caso $\mathrm{Al}_{2} \mathrm{Cu}$, a estrutura triangular identificada tem o ângulo $\mathrm{Al}-\mathrm{Cu}-\mathrm{Al}$ igual a $64.55^{\circ}$ e a distância Al-Cu igual a $2.3692 \AA$, enquanto Yang et al. reportam os valores $62.94^{\circ}$ e $2.445 \AA$ para essas propriedades, respectivamente. A estrutura do cluster $\mathrm{Al}_{3} \mathrm{Cu}$ é similar à identificada na literatura, onde os autores reportam uma estrutura piramidal com um átomo de Cu sobre um triângulo equilátero planar formado pelos átomos de $\mathrm{Al}$, com lado medindo $2.658 \AA$. Com o método RBHMC-DFT uma estrutura piramidal também foi encontrada, porém a base constituída pelos átomos de Al tem a forma de um triângulo isósceles, e não equilátero, com lados de $2.623 \AA$ e $2.917 \AA$. A estrutura do cluster $\mathrm{Al}_{4} \mathrm{Cu}$ tem uma concordância maior 
com aquela da literatura, ambas formadas por uma pirâmide com base retangular, porém há algumas diferenças pequenas nos comprimentos de ligação. O mesmo ocorre para $\mathrm{Al}_{5} \mathrm{Cu}, \mathrm{a}$ mesma estrutura que a da literatura foi identificada porém com algumas pequenas diferenças nas propriedades estruturais. Essas pequenas diferenças em ângulos e comprimentos de ligação devem-se, principalmente, ao emprego de funcionais de troca e correlação diferentes, i.e., GGAPBE neste trabalho e B3LYP no trabalho de Yang et al (158).

O cluster $\mathrm{Al}_{6} \mathrm{Cu}$ encontrado tem energia total $0.82 \mathrm{eV}$ menor que o mínimo global reportado na literatura (11.72 meV/átomo), e ambos possuem estruturas diferentes. Um comportamento similar ocorre para o cluster $\mathrm{Al}_{7} \mathrm{Cu}$, para o qual estrutura de mínimo global identificada aqui tem energia total $0.06 \mathrm{eV}$ menor que a literatura (8.02 meV/átomo), e também possui estrutura distinta. $\mathrm{O}$ cluster $\mathrm{Al}_{8} \mathrm{Cu}$ possui uma estrutura muito similar ao $\mathrm{Al}_{7} \mathrm{Cu}$, e a adição de um átomo não descaracteriza a geometria. As estruturas dos clusters $\mathrm{Al}_{9} \mathrm{Cu}$ a $\mathrm{Al}_{11} \mathrm{Cu}$ possuem geometrias precursoras à geometria do tipo icosaedro, porém com o átomo de $\mathrm{Cu}$ localizado na superfície e não na posição central. No caso do cluster $\mathrm{Al}_{11} \mathrm{Cu}$, essa característica diverge do mínimo global reportado na literatura (160), no qual o átomo de Cu está centralizado. Já para o cluster $\mathrm{Al}_{12} \mathrm{Cu}$, o mínimo global identificado tem uma estrutura do tipo icosaedro completo levemente distorcido, com o átomo de Cu na posição central envolto por 12 átomos de $\mathrm{Al}$, concordando com outros estudos teóricos $(161,163)$. É possível notar que a geometria icosaedro do cluster $\mathrm{Al}_{13}$ é preservada mesmo com a substituição de um átomo de $\mathrm{Al}$ por um átomo de $\mathrm{Cu}$, graças a sua elevada estabilidade estrutural. A tendência do átomo de $\mathrm{Cu}$ permanecer centralizado e envolto por átomos de $\mathrm{Al}$ é verificada também nas estruturas $\mathrm{Al}_{13} \mathrm{Cu}$ e $\mathrm{Al}_{14} \mathrm{Cu}$. Do ponto de vista estrutural, como o átomo de $\mathrm{Cu}$ é cerca de $10 \%$ menor que o átomo de $\mathrm{Al}$, a posição central é energeticamente mais favorável pois reduz a tensão superficial.

$\mathrm{Na}$ figura 6.4 algumas propriedades dos clusters $\mathrm{Al}_{N-1} \mathrm{Cu}$ são comparadas com as respectivas propriedades dos clusters de Al puros. É possível notar que a função de estabilidade relativa, $\Delta_{2} E$, não sofre alterações significativas. O cluster de $N=7$ átomos, $\mathrm{Al}_{6} \mathrm{Cu}$, é relativamente estável, assim como o cluster $\mathrm{Al}_{7}$. As diferenças mais notáveis se dão para $N=13,14$. Ao contrário do que ocorre com o cluster $\mathrm{Al}_{13}$, o cluster $\mathrm{Al}_{12} \mathrm{Cu}$ tem menor estabilidade, mesmo apresentando uma estrutura cuja geometria é muito próxima de um icosaedro completo. O cluster $\mathrm{Al}_{13} \mathrm{Cu}$, por sua vez, apresenta uma grande estabilidade, apesar de sua estrutura do tipo icosaedro distorcido. A estabilidade eletrônica significativa do cluster $\mathrm{Al}_{13} \mathrm{Cu}$ supera a estabilidade estrutural do seu vizinho em tamanho, $\mathrm{Al}_{12} \mathrm{Cu}(159)$.

Estudos teóricos $(160,161)$ mostram que os elétrons 3d e 4s do átomo de Cu hibridizam significativamente os elétrons de valência do cluster $\mathrm{Al}_{13}$, causando uma redistribuição dos 


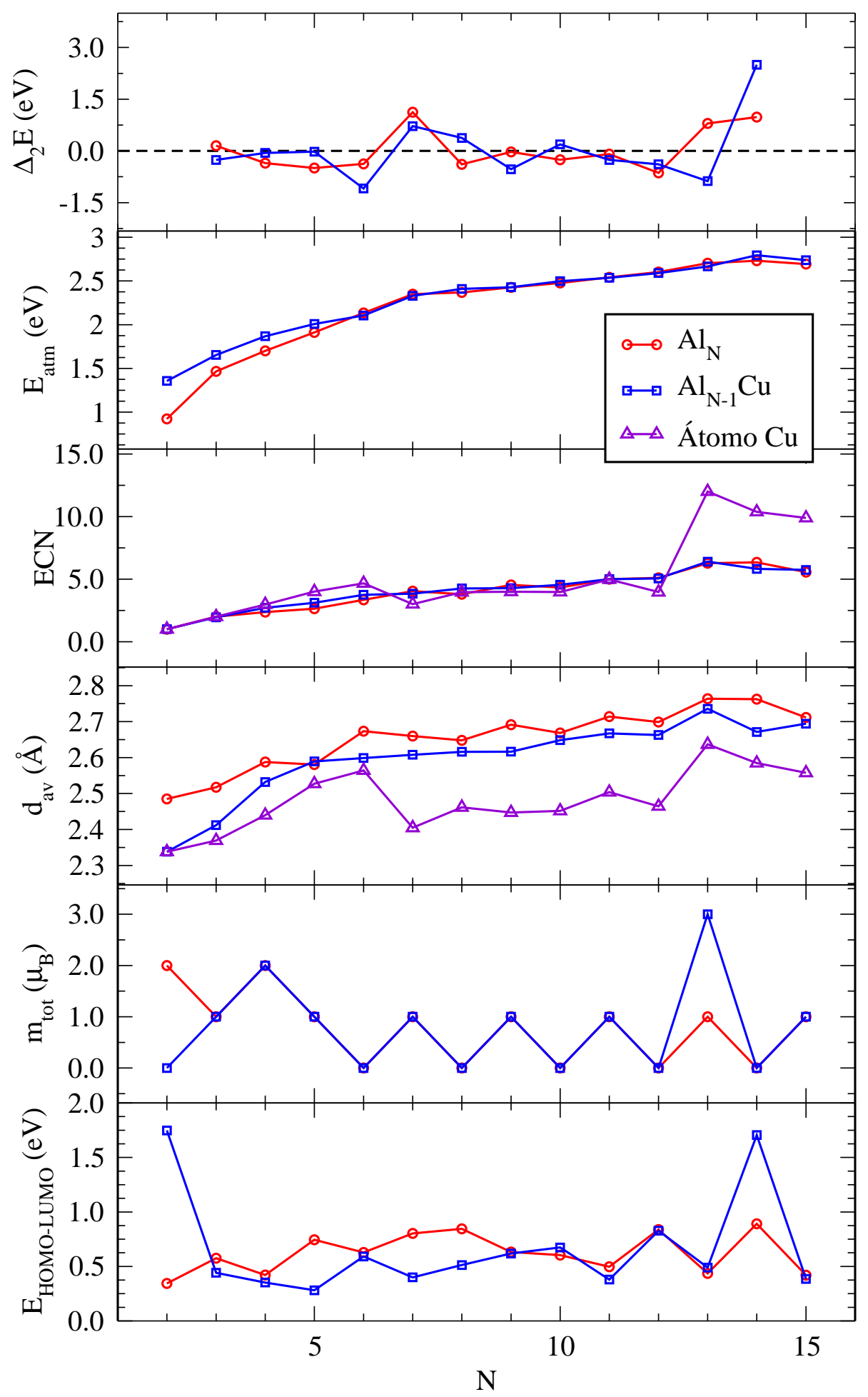

Figura 6.4 - Propriedades dos clusters $\mathrm{Al}_{N-1} \mathrm{Cu}(N=2-15)$ encontrados com RBHMC-DFT comparadas com as propriedades dos clusters $\mathrm{Al}_{N}(N=2-15)$. De cima para baixo, função de estabilidade relativa $\left(\Delta_{2} E\right)$, energia de atomização por átomo $\left(E_{a t m}\right)$, número de coordenação efetiva médio $(E C N)$, comprimento de ligação ponderado médio $\left(d_{a v}\right)$, momento magnético total $\left(m_{t o t}\right)$ e gap energético HOMO-LUMO, respectivamente. Nos gráficos do ECN médio e $d_{a v}$ médio são mostradas também as respectivas propriedades do átomo de $\mathrm{Cu}$. 
níveis de energia dos orbitais e resultando em um sistema que se comporta como um sistema de camada eletrônica fechada. Segundo modelos de fechamento de camada eletrônica derivados do jellium, clusters com 40 elétrons de valência devem ser particularmente estáveis, pois correspondem a sistemas com orbitais totalmente preenchidos. O átomo de $\mathrm{Cu}$ possui 11 elétrons de valência, sendo 10 deles 3d, e um 4s. Como os estados 3d são bastante localizados no íon (161), é possível assumir que o Cu se comporta como um átomo monovalente, i.e., considerar apenas a valência do estado $4 \mathrm{~s}$ (159), assim o cluster $\mathrm{Al}_{13} \mathrm{Cu}$ corresponderia a um sistema de camada fechada com 40 elétrons, e daí vem sua estabilidade (161).

A energia de atomização $\left(E_{a t m}\right)$ refere-se à energia necessária para dissociar por completo um cluster em seus átomos individuais, definida como a energia total do cluster subtraída da soma das energias dos átomos livres. As anergias de atomização mostradas na figura 6.4 são dadas por átomo para cada cluster respectivo, e nota-se que para os clusters dopados com Cu não há grandes variações em relação às energias de atomização dos clusters puros. Essa comparação pode ser estendida ao ECN médio, que apresenta comportamento similar para os clusters com dopante em relação aos clusters puros. É interessante observar que a coordenação efetiva média do átomo de Cu coincide aproximadamente com o ECN médio até $N=12$, porém a partir de $N=13$ ela aumenta significativamente, superando a média, o que pode ser explicado pelo fato do átomo de Cu migrar para uma posição central nos clusters $\mathrm{Al}_{12} \mathrm{Cu}, \mathrm{Al}_{13} \mathrm{Cu}$ e $\mathrm{Al}_{15} \mathrm{Cu}$. $\mathrm{O} d_{a v}$ médio é menor que nos clusters puros, indicando que as ligações são mais curtas, e em particular o átomo de $\mathrm{Cu}$ apresenta um comprimento de ligação médio menor que a média tomada sobre todos os átomos.

Em relação aos clusters $\mathrm{Al}_{N}$ no intervalo $N=2-15$, nota-se uma diferença apenas para $N=2,13$. A substituição de um átomo de $\mathrm{Al}$ no cluster $\mathrm{Al}_{2}$ por um átomo de $\mathrm{Cu}$ faz com que este dímero se torne não magnético, concordando com resultados teóricos (165) e experimentais (164). O momento magnético de $3 \mu_{B}$ encontrado para o cluster $\mathrm{Al}_{12} \mathrm{Cu}$ faz com que esse sistema seja considerado um super-átomo de camada aberta, com propriedades similares àquelas de um átomo com nível p semi-preenchido. Verifica-se, ainda, que nesse caso a regra de Hund de máxima multiplicidade é obedecida (161). No caso do gap energético HOMO-LUMO, as maiores divergências em relação aos clusters puros se dão para $N=2,14$, casos em que o gap mais acentuado indica menor reatividade e mais estabilidade. No caso do cluster $\mathrm{Al}_{13} \mathrm{Cu}$, sua camada eletrônica completamente fechada (160) é responsável pelo gap de $1.71 \mathrm{eV}$, que está de acordo com o estudo teórico de Kumar e Kawazoe (161). 


\subsection{Análise do operador SFO}

Para exemplificar o funcionamento do operador SFO, foi conduzida uma análise para o cluster $\mathrm{Al}_{15}$. Inicialmente, uma execução do método RBHMC-DFT foi realizada para esse cluster por 350 passos de Metropolis, utilizando os mesmos parâmetros que aqueles empregados para clusters $\mathrm{Al}_{N}(N=2-30)$, incluindo o esquema estático de seleção de operadores. A única diferença é que nessa execução inicial o operador SFO foi desabilitado. As 350 estruturas geradas ao longo da otimização global foram coletadas, i.e., cada nova configuração gerada pelos operadores em cada um dos passos de Metropolis. Um código implementando uma versão independente do operador SFO foi aplicado a cada uma dessas estruturas para dois parâmetros de filtro, $\eta=0.2$ e $\eta=0.4$, sendo o primeiro correspondente a um filtro mais restritivo, e o segundo a um filtro mais relaxado. Esta aplicação de um filtro independente visa simular, de maneira aproximada, os efeitos do operador SFO ao longo da otimização global, caso este estivesse habilitado.

As 350 estruturas coletadas foram ordenadas de maneira crescente de acordo com o tempo computacional gasto pelos cálculos DFT em cada uma delas, como pode ser visto nos gráficos superior e central da figura 6.5. As estruturas que foram rejeitadas pelo operador SFO aplicado de maneira independente, após o término da otimização global com RBHMC-DFT, são marcadas com círculos vermelhos preenchidos. No gráfico inferior são mostradas as diferenças de energia entre cada uma das estruturas e a estrutura com menor energia total identificada durante os 350 passos de Metropolis.

Como é possível observar, há uma clara correlação entre tempo computacional e as estruturas afetadas pelo filtro. As estruturas que exigem mais tempo computacional durante um cálculo DFT são aquelas que são mais prováveis de serem rejeitadas pelo filtro, indicando que tais estruturas requerem mais tempo pois possuem propriedades estruturais que dificultam a convergência do cálculo auto-consistente da densidade eletrônica, como átomos muito próximos um dos outros. O operador SFO, por sua vez, é capaz de identificar estas características estruturais indesejáveis. Para $\eta=0.2$, o filtro teria rejeitado cerca de $85 \%$ das estruturas, correspondendo a $95 \%$ do tempo computacional total gasto pelos cálculos DFT nas 350 estruturas. Para $\eta=0.4$, a taxa de rejeição do operador SFO seria de $28 \%$, correspondendo a $40 \%$ do tempo computacional total. Estes resultados indicam que o SFO, se habilitado, seria capaz de evitar cálculos custosos em determinados clusters estruturalmente mal condicionados e, com isso, reduzir o tempo computacional total da otimização global.

É válido se perguntar se o operador SFO não impede que o método RBHMC amostre 
uma boa variedade de estruturas durante a otimização, o que poderia reduzir a qualidade dos resultados finais. Essa questão pode ser respondida observando o gráfico inferior da figura 6.5, onde as diferenças de energia são mostradas. O aspecto de ruído do gráfico significa que mesmo considerando um intervalo de clusters pequeno, é possível obter variedade de estruturas em relação às suas energias totais. Portanto, restringir a amostragem à estruturas que requerem baixo tempo computacional é suficiente para manter uma certa pluralidade nos mínimos locais da SEP que são visitados pelo método RBHMC. É importante, porém, fazer essa restrição de maneira criteriosa. Com $\eta=0.2$ nota-se que a restrição é um tanto drástica, limitando a busca a um conjunto de estruturas com energias bastante similares. Utilizar $\eta=0.4$ é uma escolha melhor nesse caso, pois permite que estruturas suficientemente diferentes em energia sejam amostradas. Valores de $\eta$ na faixa $0.30-0.50$ são recomendados neste trabalho, porém um valor ótimo depende do sistema considerado.

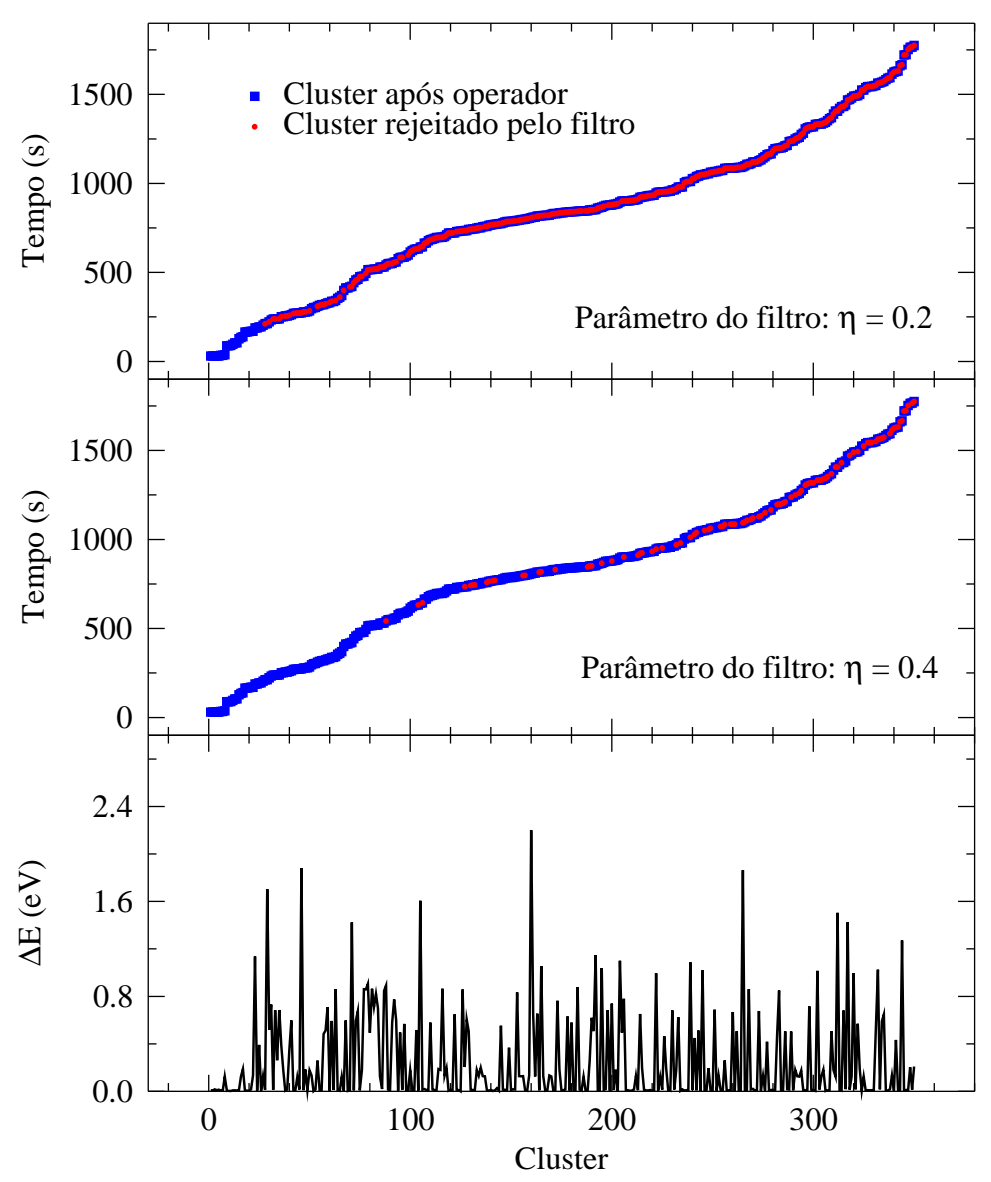

Figura 6.5 - Estruturas coletadas ao longo de 350 passos de Metropolis com o operador SFO desabilitado (quadrados preenchidos em azul, gráficos superior e central). As estruturas estão ordenadas de maneira crescente em relação ao tempo computacional. As estruturas que teriam sido rejeitadas pelo SFO estão marcadas com círculos preenchidos em vermelho. No gráfico inferior a diferença de energia entre cada estrutura e a estrutura de menor energia entre as 350 é mostrada $(\Delta E)$. 
O operador SFO também tem o propósito de evitar que cálculos com DFT sejam realizados em estruturas paras as quais a convergência do cálculo da densidade eletrônica não ocorre. Nesses casos, os cálculos tendem a demorar muitos até que a falha de convergência seja constatada, portanto constituem um esforço computacional perdido. No caso da otimização global do cluster $\mathrm{Al}_{15}$ com o SFO desabilitado, em 14 dos 350 passos de Metropolis ocorreu a falha na convergência dos cálculos com DFT. A execução foi configurada de modo que cada passo em que houve falha no cálculo DFT fosse reinicializado com uma nova aplicação do operador até que o passo terminasse com sucesso, de maneira que todos os 350 passos pudessem ser concluídos.

Uma segunda execução RBHMC-DFT foi realizada para o cluster $\mathrm{Al}_{15}$, só que desta vez com o operador SFO habilitado utilizando $\eta=0.4$, e com o restante dos parâmetros idênticos à execução anterior, inclusive mesma semente para o gerador de números aleatórios. Nessa segunda execução o mínimo global identificado foi o mesmo da primeira execução, na qual o operador SFO estava desabilitado, porém o tempo computacional total foi $53 \%$ menor. Essa comparação confirma a discussão anterior, o operador SFO é capaz de reduzir o tempo computacional da otimização sem sacrificar a qualidade do resultado. Além disso, nessa segunda execução não foi constatado nenhum problema de convergência na densidade eletrônica, também confirmando a argumentação exposta anteriormente.

\subsection{Sumário}

O método RBHMC foi capaz de identificar a maioria dos mínimos globais putativos reportados na literatura para $\mathrm{Al}_{N}(N=2-30)$. Para os casos em que isso não foi possível, as diferenças nas energias são pequenas, e as propriedades estruturais e eletrônicas apresentam tendências similares. Vale ressaltar que os melhores resultados da literatura (10) foram obtidos utilizando o método BHMC padrão para encontrar estruturas candidatas, que então serviram de ponto de partida para uma segunda otimização global, dessa vez utilizando algoritmos genéticos. Neste trabalho, apenas o método RBHMC foi utilizado, sem qualquer bias, partindo de configurações iniciais aleatorias. No caso de clusters $\mathrm{Al}_{N-1} \mathrm{Cu}(N=2-15)$, os resultados da literatura foram reproduzidos para os casos em que há dados para comparação, e foram encontradas estruturas de menor energia em comparação com estruturas de referência para os clusters $\mathrm{Al}_{6} \mathrm{Cu}$ e $\mathrm{Al}_{7} \mathrm{Cu}$.

A substituição de um átomo de $\mathrm{Al}$ por um átomo de $\mathrm{Cu}$ não acarreta em alterações muito significativas nas propriedades estruturais e eletrônicas dos clusters analisados. Em 
particular, a função de estabilidade relativa $\left(\Delta_{2} E\right)$ apresenta a mesma tendência para clusters puros e dopados no intervalo entre 2 e 15 átomos, assim como ocorre com a energia de atomização e ECN médio. Os comprimentos de ligação médios nos clusters dopados são ligeiramente inferiores em comparação com os clusters puros, o que pode ser explicado, em um primeiro momento, pela maior eletronegatividade do átomo de $\mathrm{Cu}$ em relação ao átomo de Al. Explicações mais satisfatórias serão possíveis através de uma análise detalhada das propriedades eletrônicas das estruturas encontradas, como potencial de ionização e densidade de estados local. As estruturas identificadas servirão como ponto de partida de estudos mais aprofundados envolvendo esses sistemas. 


\section{CAPÍTULO 7}

\section{Conclusões}

Neste trabalho foi apresentado o método RBHMC, que constitui uma metodologia composta por um conjunto de ideias e estratégias para melhorar o desempenho do método BHMC padrão para otimização de clusters e NPs. O método RBHMC tem natureza geral e destinase à otimização global de clusters e NPs cujas interações são descritas tanto por potenciais empíricos de LJ e SC, e de primeiros princípios pela DFT. A metodologia foi implementada no pacote GOP, desenvolvido integralmente durante este trabalho de mestrado, e que foi utilizado em uma série de estudos de casos para avaliar o desempenho do método RBHMC. O sucesso desse método deve-se à três ideias principais.

Primeiramente, a ideia principal consiste na exploração global da SEP utilizando um grande conjunto de operadores, classificados em dois grupos principais: operadores locais (CDO e GCDO) e operadores não-locais (TO, AO, SAO, IO, EO, GEO, OJ, CO). Os operadores locais fornecem a possibilidade de uma exploração localizada da SEP, através do emprego de deslocamentos atômicos de 1 a $N$ átomos em torno de suas posições originais. Os operadores não-locais, por sua vez, foram projetados para dirigir a exploração global para diferentes regiões da SEP, aumentando assim a mobilidade da busca e permitindo que altas barreiras de energia sejam superadas dentro de um número relativamente pequeno de passos. Operadores locais e não-locais trabalham em conjunto e favorecem grande eficiência quando são utilizados de maneira intercalada ao longo da otimização global. Essa estratégia baseia-se na expectativa de que, uma vez que uma região de baixa energia da SEP seja identificada por um operador não-local, os operadores locais sejam capazes de realizar uma pesquisa exaustiva nessa região, identificando o seu mínimo de menor energia e assim abaixando a energia total do sistema ainda mais.

Em segundo lugar, dois esquemas de aplicação dos operadores foram criados para melhorar a exploração da SEP, e também para lidar com o problema associado às diferentes taxas de aceitação e escalas de energia presente em uma estratégia de múltiplos operadores. No primeiro esquema, denominado estático, cada operador é aplicado por um número consecutivo de passos 
de Metropolis, o qual pode ser diferente para cada operador. No segundo esquema, chamado de dinâmico, cada operador é empregado na geração de novas configurações até que atinja um número máximo de rejeições consecutiva pelo critério de Metropolis. Segundo o esquema estático, um determinado operador pode contribuir significativamente para a obtenção do mínimo global de um sistema específico, enquanto que para outro sistema o mesmo operador pode não ter a mesma eficiência, já que nesse caso a exploração pode seguir um certo caminho sobre a SEP, no qual outros operadores sejam mais eficazes. O esquema dinâmico possui maior flexibilidade e tem maior eficiência, fazendo com que as melhores características de cada operador para um determinado sistema sejam exploradas ao máximo.

A terceira ideia que embasa o método RBHMC é o emprego de um operador de filtro (SFO) para eliminar soluções não-físicas que podem ser geradas pelos operadores não-locais, e até mesmo pelos operadores locais, no caso de deslocamentos atômicos envolvendo a maioria ou totalidade dos átomos de uma partícula. O operador SFO é particularmente importante para cálculos de otimização global em partículas cujas interações são descritas por DFT, uma vez que átomos sobrepostos ou desconectados da partícula introduzem problemas no cálculo auto-consistente da densidade eletrônica. Os estudos de casos realizados com clusters de $\mathrm{Al}$, tanto puros quanto dopados com um átomo de $\mathrm{Cu}$, mostraram que o operador de filtro contribui com exploração global e também reduz o tempo computacional total. Assim sendo, este operador tem fundamental importância para que o método RBHMC-DFT possua uma boa de sucesso.

Essas sugestões compõe a base do método RBHMC apresentado neste trabalho. Para avaliar o seu desempenho, foram realizados estudos de caso nos quais a metodologia, implementada no pacote GOP, foi aplicada a um variado conjunto de sistemas. Os mínimos globais putativos para clusters $\mathrm{LJ}_{N}(N=2-148)$ foram todos identificados, com uma taxa de sucesso competitiva para casos difíceis em comparação com dados de referência, e em alguns

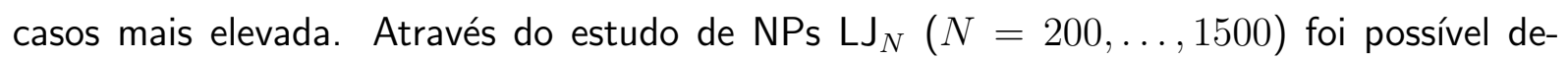
monstrar que a metodologia é capaz de lidar com partículas formadas por centenas a milhares de átomos, mesmo partindo de configurações iniciais completamente aleatórias. O conjunto de mínimos globais dos clusters $\mathrm{SC}_{N}$, antes disponíveis na literatura apenas para o intervalo $N=3-80$, foi estendido para $N=81-148$. Adicionalmente, seis conjuntos de clusters $\mathrm{BLJ}_{N}(N=5-100)$ e todas as composições possíveis do cluster $(\mathrm{AgPd})_{55}$ descrito pelo potencial de SC foram otimizadas com RBHMC, e os resultados mostram claramente que a metodologia consegue atingir elevadas taxas de sucesso ao lidar com sistemas complexos, sem, contudo, apresentar um aumento significativo no custo computacional em relação aos sistemas de uma única espécie e de mesmo tamanho. 
Além de todos estes cálculos envolvendo os potenciais empíricos de LJ e SC, o método RBHMC empregando DFT foi aplicado a clusters $\operatorname{Al}_{N}(N=2-30)$ e $\mathrm{Al}_{N-1} \mathrm{Cu}(N=$ $2-14$ ). A otimização global sem bias, partindo de configurações iniciais aleatórias, foi capaz de reproduzir a maior parte dos mínimos globais de referência da literatura, e também propriedades obtidas experimentalmente. Um mínimo global inédito do cluster $\mathrm{Al}_{24}$ foi identificado, fato que confirma que as propostas e estratégias apresentadas neste trabalho conferem ao método BHMC a característica de uma técnica de otimização global confiável e independente para o tratamento de partículas descritas por primeiros princípios.

Através da aplicação do método RBHMC a um grande conjunto de partículas consideravelmente distintas entre si, foi possível reproduzir a maior parte dos melhores resultados disponíveis na literatura. Em muitos casos, a metodologia atingiu maior eficiência em comparação com o método BHMC padrão e outras técnicas de otimização global. Os mínimos globais inéditos foram identificados para os clusters $\mathrm{Al}_{24}, \mathrm{Al}_{6} \mathrm{Cu}$ e $\mathrm{Al}_{7} \mathrm{Cu}$, mesmo estes sendo sistemas amplamente estudados ao longo da última década. Além disso, os principais resultados deste trabalho foram publicados no periódico Journal of Chemical Information and Modeling da American Chemistry Society (166). Portanto, é possível concluir que as estratégias e ideias introduzidas neste trabalho de mestrado fornecem uma contribuição relevante e de valor significativo para as áreas de otimização global e física de clusters e NPs. 


\section{REFERÊNCIAS}

1 WALES, D. J.; BOGDAN, T. V. Potential energy and free energy landscapes. Journal of Physical Chemistry, Washington, v. 110, n. 42, p. 20765-20776, 2006.

2 DOYE, J. P. K.; MILLER, M. A.; WALES, D. J. Evolution of the potential energy surface with size for Lennard-Jones clusters. Journal of Chemical Physics, Woodbury, v. 111, n. 18, p. 8417, 1999.

3 WALES, D. J. Decoding the energy landscape: extracting structure, dynamics and thermodynamics. Philosophical Transactions of The Royal Society A, v. 370, n. 1969, p. 28772899, 2012.

4 WALES, D. J.; DOYE, J. P. K.; DULLWEBER, A.; HODGES, M. P.; NAUMKIN, F. Y.; CALVO, F.; HERÁNDEZ-ROJAS, J.; MIDDLETON, T. F. The Cambridge Cluster Database (CCD). Disponível em <http://www-wales.ch.cam.ac.uk/CCD.html>. Acesso em: 4 out. 2013.

5 XIANG, Y.; CHENG, L.; CAI, W.; SHAO, X. Structural distribution of Lennard-Jones clusters containing 562 to 1000 atoms. Journal of Physical Chemistry A, v. 108, n. 44, p. 9516-9520, 2004.

$6 \mathrm{SHAO}, \mathrm{X}$; XIANG, Y.; CAI, W. Structural transition from icosahedra to decahedra of large Lennard-Jones clusters. Journal of Physical Chemistry A, v. 109, n. 23, p. 5193-5197, 2005.

7 DOYE, J. P. K.; WALES, D. J. Global minima for transition metal clusters described by Sutton-Chen potentials. New Journal of Chemistry, v. 22, n. 7, p. 733-744, 1998.

8 KOLOSSVÁRY, I.; BOWERS, K. J. Global optimization of additive potential energy functions: predicting binary Lennard-Jones clusters. Physical Review E, v. 82, n. 5, p. 056711, 2010.

9 SICHER, M.; MOHR, S.; GOEDECKER, S. Efficient moves for global geometry optimization methods and their application to binary systems. Journal of Chemical Physics, Woodbury, v. 134, n. 4, p. 044106, 2011. 
10 DREBOV, N.; AHLRICHS, R. Structures of $\mathrm{Al}_{n}$, its anions and cations up to $n=34$ : a theoretical investigation. Journal of Chemical Physics, Woodbury, v. 132, n. 16, p. 164703, 2010.

11 OAKLEY, M. T.; JOHNSTON, R. L.; WALES, D. J. Symmetrisation schemes for global optimisation of atomic clusters. Physical Chemistry Chemical Physics, v. 15, n. 11, p. 39653976, 2013.

12 DOYE, J. P. K.; MEYER, L. Mapping the magic numbers in binary Lennard-Jones clusters. Physical Review Letters, Woodbury, v. 95, n. 6, p. 063401, 2005.

13 CASSIOLI, A.; LOCATELLI, M.; SCHOEN, F. Global optimization of binary LennardJones clusters. Optimization Methods and Software, v. 24, n. 4-5, p. 819-835, 2009.

14 YE, T.; XU, R.; HUANG, W. Global optimization of binary Lennard-Jones clusters using three perturbation operators. Journal of Chemical Information and Modeling, v. 51, n. 3, p. 572-577, 2011.

15 ÇAĞIN, T.; QI., Y.; LI, H.; KIMURA, Y.; IKEDA, H.; JOHNSON, W. L.; GODDARD III, W. A. Calculation of mechanical, thermodynamic and transport properties of metallic glass formers. Materials Research Society Proceedings Series (MRS Fall Meeting), v. 554, p. 43-48, 1999. doi: 10.1557/PROC-554-43.

16 KELLY, K. L.; CORONADO, E.; ZHAO, L. L.; SCHATZ, G. C. The optical properties of metal nanoparticles: the influence of size, shape, and dielectric environment. Journal of Physical Chemistry B, v. 107, n. 3, p. 668-677, 2003.

17 ANDO, M.; KOBAYASHI, T.; HARUTA, M. Combined effects of small gold particles on the optical gas sensing by transition metal oxide films. Catalysis Today, v. 36, n. 1, p. 135-141, 1997.

18 ZHOU, W. P.; LEWERA, A.; LARSEN, R.; MASEL, R. I.; BAGUS, P. S.; WIECKOWSKI, A. Size effects in electronic and catalytic properties of unsupported palladium nanoparticles in electrooxidation of formic acid. Journal of Physical Chemistry B, v. 110, n. 27, p. 1339313398, 2006.

19 ZHANG, W.; GE, Q.; WANG, L. Structure effects on the energetic, electronic, and magnetic properties of palladium nanoparticles. Journal of Chemical Physics, Woodbury, v. 118, n. 13, p. 5793-5801, 2003.

20 BANSMANN, J. et al. Magnetic and structural properties of isolated and assembled clusters. Surface Science Reports, v. 56, n. 6-7, p. 189-275, 2005.

$21 \mathrm{LI}$, J.; LI, X.; ZHAI, H.-J.; WANG, L.-S. Au 2 $_{20}$ : a tetrahedral cluster. Science, Washington, v. 299, n. 5608, p. 864-867, 2003. 
22 EL-SAYED, I. H.; HUANG, X.; EL-SAYED, M. A. Surface plasmon resonance scaterring and absorption of anti-egfr antibody conjugated gold nanoparticles in cancer diagnostics: applications in oral cancer. Nano Letters, v. 5, n. 5, p. 829-834, 2005.

23 MORONES, J. R.; ELECHIGUERRA, J. L.; CAMACHO, A.; HOLT, K.; KOURI, J. B.; RAMÍREZ, J. T.; YACAMAN, M. J. The bactericidal effect of silver nanoparticles. Nanotechnology, v. 16, n. 10, p. 2346, 2005.

24 PAN, X.; FAN, Z.; CHEN, W.; DING, Y.; LUO, H.; BAO, X. Enhanced ethanol production inside carbon-nanotube reactors containing catalytic particles. Nature Materials, v. 6, n. 7, p. 507-511, 2007.

25 SCHAAFF, T. G.; SHAFIGULLIN, M. N.; KHOURY, J. T.; VEZMAR, I.; WHETTEN, R. L.; CULLEN, W. G.; FIRST, P. N. Isolation of smaller nanocrystal Au molecules: robust quantum effects in optical spectra. Journal of Physical Chemistry B, v. 101, n. 40, p. 78857891, 1997.

26 KRUIS, F. E.; FISSAN, H.; PELED, A. Synthesis of nanoparticles in the gas phase for electronic, optical and magnetic applications - a review. Journal of Aerosol Science, v. 25, n. 5-6, p. 511-535, 1998.

27 NARAYANAN, R.; EL-SAYED, M. A. Shape-dependent catalytic activity of platinum nanoparticles in colloidal solution. Nano Letters, v. 4, n. 7, p. 1343-1348, 2004.

$28 \mathrm{SCHOLL}$, J. A.; KOH, A. L.; DIONNE, J. A. Quantum plasmon resonances of individual metallic nanoparticles. Nature, London, v. 483, n. 7390, p. 421-427, 2012.

29 LAI, S. L.; GUO, J. Y.; PETROVA, V.; RAMANATH, G.; ALLEN, L. H. Size-dependent melting properties of small tin particles: nanocalorimetric measurements. Physical Review Letters, Woodbury, v. 77, n. 1, p. 99-102, 1996.

30 KOPPES, J. P.; MUZA, A. R.; STACH, E. A.; HANDWERKER, C. H. Comment on "Size-dependent melting properties of small tin particles: nanocalorimetric measurements". Physical Review Letters, Woodbury, v. 104, n. 18, p. 189601, 2010.

31 CAMPBELL, C. T.; PARKER, S. C.; STARR, D. E. The effect of size-dependent nanoparticle energetics on catalyst sintering. Science, Washington, v. 298, n. 5594, p. 811-814, 2002.

32 SEO, W. S.; JO, H. H.; PROF, K. L.; KIM, B.; OH, S. J.; PARK, J. T. Size-dependent magnetic properties of colloidal $\mathrm{Mn}_{3} \mathrm{O}_{4}$ and $\mathrm{MnO}$ nanoparticles. Angewandte Chemie International Edition, v. 43, n. 9, p. 1115-1117, 2004.

33 MARKS, L. D. Experimental studies of small particle structures. Reports on Progress in Physics, v. 57, n. 6, p. 603-649, 1994. 
34 BALETTO, F.; FERRANDO, R. Structural properties of nanoclusters: energetic, thermodynamic, and kinetic effects. Reviews of Modern Physics, Woodbury, v. 77, n. 1, p. 371-423, 2005.

35 TSAI, C. J.; JORDAN, K. D. Use of an eigenmode method to locate the stationary points on the potential energy surfaces of selected argon and water clusters. Journal of Physical Chemistry, Washington, v. 97, n. 43, p. 11227-11237, 1993.

36 STILLINGER, F. H. Exponential multiplicity of inherent structures. Physical Review E, v. 59 , n. 1, p. $48-51,1999$.

37 WALES, D. J. Energy landscapes. Cambridge: Cambridge University Press, 2003.

38 WILLE, L. T.; VENNIK, J. Computational complexity of the ground-state determination of atomic clusters. Journal of Physics A: mathematical and general, v. 18, n. 8, p. L419-L422, 1985.

39 GREENWOOD, G. W. Revisiting the complexity of finding globally minimum energy configurations in atomic clusters. Zeitschrift für Physikalische Chemie, v. 211, n. 1, p. 105114, 1999.

40 HARTKE, B. Global geometry optimization of clusters using genetic algorithms. Journal of Physical Chemistry, Washington, v. 97, n. 39, p. 9973-9976, 1993.

41 DAVEN, D.; TIT, N.; MORRIS, J.; HO, K. Structural optimization of Lennard-Jones clusters by a genetic algorithm. Chemical Physics Letters, Amsterdam, v. 256, n. 1-2, p. 195-200, 1996.

42 NIESSE, J. A.; MAYNE, H. R. Global geometry optimization of atomic clusters using a modified genetic algorithm in space-fixed coordinates. Journal of Chemical Physics, Woodbury, v. 105, n. 11, p. $4700,1996$.

43 JOHNSTON, R. L. Evolving better nanoparticles: genetic algorithms for optimising cluster geometries. Dalton Transactions, v. 32, n. 22, p. 4193-4207, 2003.

44 GARZÓN, I. L.; MICHAELIAN, K.; BELTRÁN, M. R.; POSADA-AMARILLAS, A.; ORDEJÓN, P.; ARTACHO, E.; SÁNCHEZ-PORTAL, D.; SOLER, J. M. Lowest energy structures of gold nanoclusters. Physical Review Letters, Woodbury, v. 81, n. 8, p. 1600-1603, 1998.

45 MICHAELIAN, K. A symbiotic algorithm for finding the lowest energy isomers of large clusters and molecules. Chemical Physics Letters, Amsterdam, v. 293, n. 3-4, p. 202-208, 1998. 
46 HARTKE, B. Size-dependent transition from all-surface to interior-molecule structures in pure neutral water clusters. Physical Chemistry Chemical Physics, v. 5, n. 2, p. 275-284, 2003.

47 ROSSI, G.; RAPALlO, A.; MOTTET, C.; FORTUNELLI, A.; BALETTO, F.; FERRANDO, R. Magic polyicosahedral core-shell clusters. Physical Review Letters, Woodbury, v. 93, n. 10, p. 105503, 2004.

48 DARBY, S.; MORTIMER-JONES, T. V.; JOHNSTON, R. L.; ROBERTS, C. Theoretical study of Cu-Au nanoalloy clusters using a genetic algorithm. Journal of Chemical Physics, Woodbury, v. 116, n. 4, p. 1536, 2002.

$49 \mathrm{LI}$, Z.; SCHERAGA, H. A. Monte Carlo-minimization approach to the multiple-minima problem in protein folding. Proceedings of the National Academy of Sciences of the United States of America, Washington, v. 84, n. 19, p. 6611-6615, 1987.

50 WALES, D. J.; DOYE, J. P. K. Global optimization by basin-hopping and the lowest energy structures of Lennard-Jones clusters containing up to 110 atoms. Journal of Physical Chemistry A, v. 101, n. 28, p. 5111-5116, 1997.

51 LEARY, R. H.; DOYE, J. P. K. Tetrahedral global minimum for the 98-atom LennardJones cluster. Physical Review E, v. 60, n. 6, p. R6320-R6322, 1999.

52 FLIKKEMA, E.; BROMLEY, S. T. Dedicated global optimization search for ground state silica nanoclusters: $\left(\mathrm{SiO}_{2}\right)_{N}(\mathrm{~N}=6-12)$. Journal of Physical Chemistry $B$, v. 108, n. 28, p. 9638-9645, 2004.

53 HAMAD, S.; CATLOW, C. R. A.; WOODLEY, S. M.; LAGO, S.; MEJÍAS, J. A. Structure and stability of small $\mathrm{TiO}_{2}$ nanoparticles. Journal of Physical Chemistry B, v. 109, n. 33, p. 15741-15748, 2005.

54 HARDING, D.; MACKENZIE, S. R.; WALSH, T. R. Structural isomers and reactivity for $\mathrm{Rh}_{6}$ and $\mathrm{Rh}_{6}^{+}$. Journal of Physical Chemistry B, v. 110, n. 37, p. 18272-18277, 2006.

55 WALSH, T. R. Relaxation dynamics and structural isomerism in $\mathrm{Nb}_{10}$ and $\mathrm{Nb}_{10}^{+}$. Journal of Chemical Physics, Woodbury, v. 124, n. 20, p. 204317, 2006.

56 AGUADO, A.; KOSTKO, O. First-principles determination of the structure of $\mathrm{Na}_{N}$ and $\mathrm{Na}_{N}^{-}$clusters with up to 80 atoms. Journal of Chemical Physics, Woodbury, v. 134, n. 16, p. 164304, 2011.

57 KIRAN, B.; BULUSU, S.; ZHAI, H.-J.; YOO, S.; ZENG, X. C.; WANG, L.-S. Planarto-tubular structural transition in boron clusters: $\mathrm{B}_{20}$ as the embryo of single-walled boron nanotubes. Proceedings of the National Academy of Sciences of the United States of America, Washington, v. 102, n. 4, p. 961-964, 2005. 
58 YOO, S.; ZENG, X. C. Motif transition in growth patterns of small to medium-sized silicon clusters. Angewandte Chemie International Edition, v. 44, n. 10, p. 1491-1494, 2005.

59 BULUSU, S.; ZENG, X. C. Structures and relative stability of neutral gold clusters: $A u_{n}$ $(\mathrm{n}=15-19)$. Journal of Chemical Physics, Woodbury, v. 125, n. 15, p. 154303, 2006.

60 GEHRKE, R.; REUTER, K. Assessing the efficiency of first-principles basin-hopping sampling. Physical Review B, v. 79, n. 8, p. 085412, 2009.

61 SHAO, N.; HUANG, W.; GAO, Y.; WANG, L.-M.; LI, X.; WANG, L.-S.; ZENG, X. C. Probing the structural evolution of medium-sized gold clusters: $\mathrm{Au}_{n}^{-}(\mathrm{n}=27-35)$. Journal of the American Chemical Society, Washington, v. 132, n. 18, p. 6596-6605, 2010.

62 BAI, J.; CUI, L.-F.; WANG, J.; YOO, S.; LI, X.; JELLINEK, J.; KOEHLER, C.; FRAUENHEIM, T.; WANG, L.-S.; ZENG, X. C. Structural evolution of anionic silicon clusters $\mathrm{Si}_{N}$ $(20 \leq \mathrm{N} \leq 45)$. Journal of Physical Chemistry A, v. 110, n. 3, p. 908-912, 2006.

63 DOLL, K.; SCHÖN, J. C.; JANSEN, M. Global exploration of the energy landscape of solids on the ab initio level. Physical Chemistry Chemical Physics, v. 9, n. 46, p. 6128-6133, 2007.

64 FERRANDO, R.; FORTUNELLI, A.; JOHNSTON, R. L. Searching for the optimum structures of alloy nanoclusters. Physical Chemistry Chemical Physics, v. 10, n. 5, p. 640649, 2008.

65 YOO, S.; ZENG, X. C. Search for global-minimum geometries of medium-sized germanium clusters. II. motif-based low-lying clusters $\mathrm{Ge}_{21}-\mathrm{Ge}_{29}$. Journal of Chemical Physics, Woodbury, v. 124, n. 18, p. 184309, 2006.

66 ROGAN, J.; GARCÍA, G.; LOYOLA, C.; ORELLANA, W.; RAMÍREZ, R.; KIWI, M. Alternative search strategy for minimal energy nanocluster structures: the case of rhodium, palladium, and silver. Journal of Chemical Physics, Woodbury, v. 125, n. 21, p. 214708, 2006.

67 YOO, S.; SHAO, N.; ZENG, X. Reexamine structures and relative stability of mediumsized silicon clusters: low-lying endohedral fullerene-like clusters $\mathrm{Si}_{30}-\mathrm{Si}_{38}$. Physics Letters $A$, Amsterdam, v. 373, n. 41, p. 3757-3760, 2009.

68 JIANG, D.-E.; WALTER, M.; DAI, S. Gold sulfide nanoclusters: a unique core-in-cage structure. Chemistry A European Journal, v. 16, n. 17, p. 4999-5003, 2010.

69 JIANG, D.; WALTER, M. Au un $_{40}$ : a large tetrahedral magic cluster. Physical Review B, v. 84, n. 19, p. 193402, 2011. 
70 COUTINHO, K. Modelo discreto de solvente. solvatocronismo no espectro de absorção molecular. 1997. 174 p. Tese (Doutorado em Física) - Instituto de Física, Universidade de São Paulo, São Paulo, 1997.

71 ALLEN, M. P.; TILDESLEY, D. J. Computer simulation of liquids. Oxford: Clarendon Press, 1989.

72 LENNARD-JONES, J. E. Cohesion. Proceedings of the Physical Society, v. 43, n. 5, p. 461-482, 1931.

73 FRENKEL, D.; SMIT, B. Understanding molecular simulation. 2nd. ed. San Diego, CA: Academic Press, 2002.

74 SUTTON, A. P.; CHEN, J. Long-range Finnis-Sinclair potentials. Philosophical Magazine Letters, v. 61, n. 3, p. 139-146, 1990.

75 ZHEN, S.; DAVIES, G. J. Calculation of the Lennard-Jones n-m potential energy parameters for metals. Physica Status Solidi A, Berlin, v. 78, n. 2, p. 595-605, 1983.

76 FREINDORF, M.; SHAO, Y. H.; FURLANI, T. R.; KONG, J. Lennard-Jones parameters for the combined QM/MM method using the B3LYP/6-31G*/AMBER potential. Journal of Computational Chemistry, v. 26, n. 12, p. 1270-1278, 2005.

77 LORENTZ, H. A. Über die Anwendung des Satzes vom Virial in der kinetischen Theorie der Gase. Annalen der Physik, v. 248, n. 1, p. 127-136, 1881.

78 BERTHELOT, D. Sur le mélange des gaz. Comptes Rendus Hebdomadaires des Séances de l'Académie des Sciences, v. 126, p. 1703-1706, 1898.

79 FINNIS, M. W.; SINCLAIR, J. E. A simple empirical n-body potential for transition metals. Philosophical Magazine A, London, v. 50, n. 1, p. 45-55, 1984.

80 BORN, M.; OPPENHEIMER, R. Zur Quantentheorie der Molekeln. Annalen der Physik, v. 389, n. 20 , p. $457-484,1927$.

81 HOHENBERG, P.; KOHN, W. Inhomogeneous electron gas. Physical Review, v. 136, n. 3B, p. B864-B871, 1964.

$82 \mathrm{KOHN}$, W.; SHAM, L. J. Self-consistent equations including exchange and correlation effects. Physical Review, v. 140, n. 4A, p. A1133-A1138, 1965.

83 PARR, R. G.; WEITAO, Y. Density-functional theory of atoms and molecules. Oxford: Oxford University Press, EUA, 1994. 
84 PERDEW, J. P.; WANG, Y. Accurate and simple analytic representation of the electrongas correlation energy. Physical Review B, v. 45, n. 23, p. 13244-13249, 1992.

85 PERDEW, J. P.; BURKE, K.; ERNZERHOF, M. Generalized gradient approximation made simple. Physical Review Letters, Woodbury, v. 77, n. 18, p. 3865-3868, 1996.

86 BLUM, V.; GEHRKE, R.; HANKE, F.; HAVU, P.; HAVU, V.; REN, X.; REUTER, K.; SCHEFFLER, M. Ab initio molecular simulations with numeric atom-centered orbitals. Computer Physics Communications, v. 180, n. 11, p. 2175-2196, 2009.

87 FHI-aims TEAM. Fritz Haber Institute ab initio molecular simulations: FHI-aims - Users' Guide. Berlin: Fritz-Haber-Institut der Max-Planck-Gesellschaft, 2013.

88 STILLINGER, F. H.; WEBER, T. A. Packing structures and transitions in liquids and solids. Science, Washington, v. 225, n. 4666, p. 983-989, 1984.

89 MURRELL, J. N.; LAIDLER, K. J. Symmetries of activated complexes. Transactions of the Faraday Society, v. 64, p. 371-377, 1968. doi: 10.1039/TF9686400371.

90 KUNZ, R. E.; BERRY, R. S. Statistical interpretation of topographies and dynamics of multidimensional potentials. Journal of Chemical Physics, Woodbury, v. 103, n. 5, p. 1904, 1995.

91 BERRY, R. S.; BREITENGRASER-KUNZ, R. Topography and dynamics of multidimensional interatomic potential surfaces. Physical Review Letters, Woodbury, v. 74, n. 20, p. 3951-3954, 1995.

92 BALL, K. D.; BERRY, R. S.; KUNZ, R. E.; LI, F.-Y.; PROYKOVA, A.; WALES, D. J. From topographies to dynamics on multidimensional potential energy surfaces of atomic clusters. Science, Washington, v. 271, n. 5251, p. 963-966, 1996.

93 BECKER, O. M.; KARPLUS, M. The topology of multidimensional potential energy surfaces: theory and application to peptide structure and kinetics. Journal of Chemical Physics, Woodbury, v. 106, n. 4, p. 1495, 1997.

94 DOYE, J. P. K.; MILLER, M. A.; WALES, D. J. The double-funnel energy landscape of the 38-atom Lennard-Jones cluster. Journal of Chemical Physics, Woodbury, v. 110, n. 14, p. 6896, 1999.

95 YURTSEVER, E.; CALVO, F.; WALES, D. J. Finite-size effects in the dynamics and thermodynamics of two-dimensional Coulomb clusters. Physical Review E, v. 72, n. 2, p. 026110, 2005. 
96 DE SOUZA, V. K.; WALES, D. J. Connectivity in the potential energy landscape for binary Lennard-Jones systems. Journal of Chemical Physics, Woodbury, v. 130, n. 19, p. 194508, 2009.

97 WALES, D. J. Energy landscapes: some new horizons. Current Opinion in Structural Biology, v. 20, n. 1, p. 3-10, 2010.

98 LEVINTHAL, C. How to fold graciously. In: DeBRUNNER, J. T. P.; MUNCK, E. (Ed.) Mössbauer spectroscopy in biological systems. Illinois: University of Illinois Press, 1969. p. 22-24.

99 DOYE, J. P. K.; WALES, D. J. On potential energy surfaces and relaxation to the global minimum. Journal of Chemical Physics, Woodbury, v. 105, n. 18, p. 8428, 1996.

100 LEVINTHAL, C. Are there pathways for protein folding? Journal de Chimie Physique et de Physico-Chimie Biologique, v. 65, n. 1, p. 44-45, 1968.

101 CAMACHO, C. J.; THIRUMALAI, D. Minimum energy compact structures of random sequences of heteropolymers. Physical Review Letters, Woodbury, v. 71, n. 15, p. 2505-2508, 1993.

102 ŠALI, A.; SHAKHNOVICH, E.; KARPLUS, M. How does a protein fold? Nature, London, v. 369, n. 6477, p. 248-251, 1994.

103 WALES, D. J.; DOYE, J. P. K.; MILLER, M. A.; MORTENSON, P. N.; WALSH, T. R. Energy landscapes: from clusters to biomolecules. In: PRIGOGINE, I.; RICE, S. A. (Ed.) Advances in Physical Chemistry. New York, NY, EUA: John Wiley and Sons, 2000. p. 1-113. (Advances in Chemical Physics, v. 115).

104 BRYNGELSON, J. D.; ONUCHIC, J. N.; SOCCI, N. D.; WOLYNES, P. G. Funnels, pathways, and the energy landscape of protein-folding - a synthesis. Proteins-Structure Function and Genetics, v. 21, n. 3, p. 167-195, 1995.

105 ZWANZIG, R.; SZABO, A.; BAGCHI, B. Levinthal's paradox. Proceedings of the National Academy of Sciences of the United States of America, Washington, v. 89, n. 1, p. 20-22, 1992.

106 ZWANZIG, R. Simple-model of protein-folding kinetics. Proceedings of the National Academy of Sciences of the United States of America, Washington, v. 92, n. 21, p. 98019804, 1995.

107 DOYE, J. P. K. A model metal potential exhibiting polytetrahedral clusters. Journal of Chemical Physics, Woodbury, v. 119, n. 2, p. 1136, 2003. 
108 YOO, S.; ZENG, X. C. Global geometry optimization of silicon clusters described by three empirical potentials. Journal of Chemical Physics, Woodbury, v. 119, n. 3, p. 1442, 2003.

109 KABREDE, H.; HENTSCHKE, R. Global minima of water clusters $\left(\mathrm{H}_{2} \mathrm{O}\right)_{N}, N \leq 25$, described by three empirical potentials. Journal of Physical Chemistry B, v. 107, p. 3914-3920, 2003.

110 LOCATELLI, M.; SCHOEN, F. Efficient algorithms for large scale global optimization: Lennard-Jones clusters. Computational Optimization and Applications, v. 26, n. 2, p. 173-190, 2003.

111 IWAMATSU, M.; OKABE, Y. Basin hopping with occasional jumping. Chemical Physics Letters, Amsterdam, v. 389, n. 4-6, p. 396-400, 2004.

112 KIM, H. G.; CHOI, S. K.; LEE, H. M. New algorithm in the basin hopping Monte Carlo to find the global minimum structure of unary and binary metallic nanoclusters. Journal of Chemical Physics, Woodbury, v. 128, n. 14, p. 144702, 2008.

113 APRÁ, E.; FERRANDO, R.; FORTUNELLI, A. Density-functional global optimization of gold nanoclusters. Physical Review B, v. 73, n. 20, p. 205414, 2006.

114 YOO, S.; ZHAO, J.; WANG, J.; ZENG, X. C. Endohedral silicon fullerenes $\operatorname{Si}_{N}(27 \leq$ $N \leq 39)$. Journal of the American Chemical Society, Washington, v. 126, n. 42, p. 1384513849, 2004.

115 DA SILVA, J. L. F.; KIM, H. G.; PIOTROWSKI, M. J.; PRIETO, M. J.; TREMILIOSIFILHO, G. Reconstruction of core and surface nanoparticles: the example of $\mathrm{Pt}_{55}$ and $\mathrm{Au}_{55}$. Physical Review B, v. 82, n. 20, p. 205424, 2010.

116 LAI, S. K.; HSU, P. J.; WU, K. L.; LIU, W. K.; IWAMATSU, M. Structures of metallic clusters: mono- and polyvalent metals. Journal of Chemical Physics, Woodbury, v. 117, n. 23 , p. $10715,2002$.

117 CAI, W.; FENG, Y.; SHAO, X.; PAN, Z. Optimization of Lennard-Jones atomic clusters. Journal of Molecular Structure: THEOCHEM, v. 579, n. 1-3, p. 229-234, 2002.

118 CORDERO, B.; GÓMEZ, V.; PLATERO-PRATS, A. E.; REVÉS, M.; ECHEVERRÍA, J.; CREMADES, E.; BARRAGÁN, F.; ALVAREZ, S. Covalent radii revisited. Dalton Transactions, v. 37, n. 21, p. 2832-2838, 2008.

119 SHEWCHUK, J. R. An introduction to the conjugate gradient methods without the agonizing pain. Pittsburgh, PA: Carnegie Mellon University, 1994. Relatório técnico CMU-CS94-125. 
120 NOCEDAL, J.; WRIGHT, S. J. Numerical optimization. New York, NY, EUA: Springer Verlag, 2006.

121 PRESS, W. H.; TEUKOLSKY, S. A.; VETTERLING, W. T.; FLANNERY, B. P. Numerical recipes: the art of scientific computing. 3rd. ed. Cambridge: Cambridge University Press, 2007.

122 DAI, Y.-H.; LIAO, L.-Z. New conjugacy conditions and related nonlinear conjugate gradient methods. Applied Mathematics and Optimization, v. 43, n. 1, p. 87-101, 2001.

123 ANDREI, N. Conjugate gradient algorithms for molecular formation under pairwise potential minimization. In: WORKSHOP MATHEMATICAL MODELING OF ENVIRONMENTAL AND LIFE SCIENCES PROBLEMS, 5., 2006, Constantza. Proceedings... Constantza: Editura Academiei Române, 2008. p. 7-26.

124 ROSSI, G.; FERRANDO, R. Searching for low-energy structures of nanoparticles: a comparison of different methods and algorithms. Journal of Physics: condensed matter, v. 21, n. 8, p. 084208, 2009.

125 BOCHICCHIO, D.; FERRANDO, R. Size-dependent transition to high-symmetry chiral structures in $\mathrm{AgCu}, \mathrm{AgCo}, \mathrm{AgNi}$, and AuNi nanoalloys. Nano Letters, v. 10, n. 10, p. 42114216, 2010.

$126 \mathrm{BOCHICCHIO,} \mathrm{D.;} \mathrm{FERRANDO,} \mathrm{R.} \mathrm{Structure} \mathrm{and} \mathrm{thermal} \mathrm{stability} \mathrm{of} \mathrm{AgCu} \mathrm{chiral}$ nanoparticles. European Physics Journal D, v. 66, n. 5, p. 115, 2012.

127 TAKEUCHI, H. Novel method for geometry optimization of molecular clusters: application to benzene cluster. Journal of Chemical Information and Modeling, v. 47, n. 1, p. 104-109, 2007.

128 ROBERTS, C.; JOHNSTON, R. L.; WILSON, N. T. A genetic algorithm for the structural optimization of Morse clusters. Theoretical Chemistry Accounts, v. 104, n. 2, p. 123-130, 2000.

129 GELMAN, A.; GILKS, W. R.; ROBERTS, G. O. Weak convergence and optimal scaling of random walk metropolis algorithms. Annals of Applied Probability, v. 7, n. 1, p. 110-120, 1997.

130 OPENMP ARCHITECTURE REVIEW BOARD. The OpenMP API specification for parallel programming. Disponível em <http://www.openmp.org $>$. Acesso em: 6 de out. 2013.

131 BOOCH, G.; MAKSIMCHUK, R. A.; ENGLE, M. W.; YOUNG, B. J.; CONALLEN, J.; HOUSTON, K. A. Object-oriented analysis and design with applications. Boston, MA: Addison-Wesley Professional, 2007. 
132 DURSTENFELD, R. Algorithm 235: random permutation. Communications of the ACM, v. 7, n. 7, p. $420,1964$.

133 GEHRKE, R.; GRUENE, P.; FIELICKE, A.; MEIJER, G.; REUTER, K. Nature of Ar bonding to small $\mathrm{Co}_{n}^{+}$clusters and its effect on the structure determination by far-infrared absorption spectroscopy. Journal of Chemical Physics, Woodbury, v. 130, n. 3, p. 034306, 2009.

134 HAZEL, P. PCRE - Perl Compatible Regular Expressions. Disponível em $<$ http://www.pcre.org>. Acesso em: 4 outubro 2013.

135 MACKAY, A. L. A dense non-crystallographic packing of equal spheres. Acta Crystallographica, v. 15, n. 9, p. 916-918, 1962.

136 MARKS, L. D. Surface structure and energetics of multiply twinned particles. Philosophical Magazine A, London, v. 49, n. 1, p. 81-93, 1984.

137 NORTHBY, J. A.; XIE, J.; FREEMAN, D. L.; DOLL, J. D. Binding energy of large icosahedral and cuboctahedral Lennard-Jones clusters. Zeitschrift für Physik D: atoms, molecules and clusters, v. 12, n. 1-4, p. 69-71, 1989.

138 XUE, G. Molecular conformation on the CM-5 by parallel two-level simulated annealing. Journal of Global Optimization, v. 4, n. 2, p. 187-208, 1994.

139 ROMERO, D.; BARRÓN, C.; GÓMEZ, S. The optimal geometry of Lennard-Jones clusters: 148-309. Computer Physics Communications, v. 123, n. 1-3, p. 87-96, 1999.

140 XIANG, Y.; JIANG, H.; CAI, W.; SHAO, X. An efficient method based on lattice construction and the genetic algorithm for optimization of large Lennard-Jones clusters. Journal of Physical Chemistry A, v. 108, n. 16, p. 3586-3592, 2004.

141 KRIVOV, S. V. Hierarchical global optimization of quasiseparable systems: application to Lennard-Jones clusters. Physical Review E, v. 66, n. 2, p. 025701, 2002.

142 GOEDECKER, S. Global optimization with the minima hopping method. In: OGANOV, A. R. (Ed.) Modern methods of crystal structure prediction. Weinheim, Alemanha: WILEYVCH Verlag GmbH \& Co. KGaA, 2011. p. 131-145.

143 LYNDEN-BELL, R. Migration of adatoms on the (100) surface of face-centred-cubic metals. Surface Science, v. 259, n. 1-2, p. 129-138, 1991.

144 TODD, B.; LYNDEN-BELL, R. Surface and bulk properties of metals modelled with Sutton-Chen potentials. Surface Science, v. 281, n. 1-2, p. 191-206, 1993. 
145 JOSWIG, J.-O.; SPRINGBORG, M. Genetic-algorithms search for global minima of aluminum clusters using a Sutton-Chen potential. Physical Review B, v. 68, p. 085408, 2003.

146 GRIGORYAN, V. G.; ALAMANOVA, D.; SPRINGBORG, M. Structure and energetics of $\mathrm{Cu}_{N}$ clusters with $2 \leq N \leq 150$ : an embedded-atom-method study. Physical Review B, v. 73 , n. 11, p. $115415,2006$.

147 MARQUES, J.; PEREIRA, F. An evolutionary algorithm for global minimum search of binary atomic clusters. Chemical Physics Letters, Amsterdam, v. 485, n. 1-3, p. 211-216, 2010.

148 AGUADO, A.; LÓPEZ, J. M. Structures and stabilities of $\mathrm{Al}_{n}^{+}, \mathrm{Al}_{n}$, and $\mathrm{Al}_{n}^{-}(n=13-34)$ clusters. Journal of Chemical Physics, Woodbury, v. 130, n. 6, p. 064704, 2009.

149 ASCHCROFT, N. W.; MERMIN, N. D. Solid state physics. Fort Worth: Saunders College Publishing, 1976.

150 DE HEER, W. A.; MILANI, P.; CHTELAIN, A. Nonjellium-to-jellium transition in aluminum cluster polarizabilities. Physical Review Letters, Woodbury, v. 63, n. 26, p. 2834-2836, 1989.

151 AKOLA, J.; HÄKKINEN, H.; MANNINEN, M. Ionization potential of aluminum clusters. Physical Review B, v. 58, n. 7, p. 3601-3604, 1998.

152 RAO, B. K.; JENA, P. Evolution of the electronic structure and properties of neutral and charged aluminum clusters: a comprehensive analysis. Journal of Chemical Physics, Woodbury, v. 111, n. 5 , p. $1890,1999$.

153 LLOYD, L. D.; JOHNSTON, R. L. Modelling aluminium clusters with an empirical many-body potential. Chemical Physics, v. 236, n. 1-3, p. 107-121, 1998.

154 CÂNDIDO, L.; RABELO, J. N. T.; DA SILVA, J. L. F.; HAI, G.-Q. Quantum Monte Carlo study of small aluminum clusters $\mathrm{Al}_{n}(n=2-13)$. Physical Review B, v. 85, n. 24, p. 245404, 2012.

155 KAXIRAS, E. Atomic and electronic structure of solids. Cambridge: Cambridge University Press, 2003.

156 KITTEL, C. Introduction to solid state physics. Hoboken, NJ: John Wiley \& Sons, Inc, 2005.

157 COX, D. M.; TREVOR, D. J.; WHETTEN, R. L.; ROHLFING, E. A.; KALDOR, A. Aluminum clusters: magnetic properties. Journal of Chemical Physics, Woodbury, v. 84, n. 8, p. 4651-4656, 1986. 
158 YANG, P.; GE, J.-H.; JIANG, Z.-Y. First principles study of the structures, electronic states and stabilities of $\mathrm{al}_{n} \mathrm{cu}(n=2-7)$ clusters. Journal of Molecular Structure: THEOCHEM, v. 755, n. $1-3$, p. $75-79,2005$.

159 ZOPE, R. R.; BARUAH, T. Conformers of $\mathrm{Al}_{13}, \mathrm{Al}_{12} \mathrm{M}$, and $\mathrm{Al}_{13} \mathrm{M}(\mathrm{M}=\mathrm{Cu}, \mathrm{Ag}$ and $\mathrm{Au}$ ) clusters and their energetics. Physical Review A, Woodbury, v. 64, n. 5, p. 053202, 2001.

160 KHANNA, S. N.; ASHMAN, C.; RAO, B. K.; JENA, P. Geometry, electronic structure, and energetics of copper-doped aluminum clusters. Journal of Chemical Physics, Woodbury, v. 114, n. 22 , p. $9792,2001$.

161 KUMAR, V.; KAWAZOE, Y. Hund's rule in metal clusters: prediction of high magnetic moment state of $\mathrm{Al}_{12} \mathrm{Cu}$ from first-principles calculations. Physical Review B, v. 64, n. 11, p. 115405, 2001.

162 THOMAS, O. C.; ZHENG, W.; BOWEN, K. H. Magic numbers in copper-doped aluminum cluster anions. Journal of Chemical Physics, Woodbury, v. 114, n. 13, p. 5514, 2001.

163 PAL, R.; CUI, L.-F.; BULUSU, S.; ZHAI, H.-J.; WANG, L.-S.; ZENG, X. C. Probing the electronic and structural properties of doped aluminum clusters: $\mathrm{Mal}_{12}^{-}(\mathrm{m}=\mathrm{li}, \mathrm{Cu}$, and au). Journal of Chemical Physics, Woodbury, v. 128, n. 2, p. 024305, 2008.

164 BEHM, J. M.; ARRINGTON, C. A.; LANGENBERG, J. D.; MORSE, M. D. Spectroscopic analysis of jet-cooled AICu. Journal of Chemical Physics, Woodbury, v. 99, n. 9, p. 6394, 1993.

165 OUYANG, Y.; WANG, J.; HOU, Y.; ZHONG, X.; DU, Y.; FENG, Y. First principle study of $\operatorname{AIX}(X=3 d, 4 d, 5 d$ elements and Lu) dimer. Journal of Chemical Physics, Woodbury, v. 128 , n. 7 , p. $074305,2008$.

166 RONDINA, G. G.; DA SILVA, J. L. F. Revised Basin-Hopping Monte Carlo algorithm for structure optimization of clusters and nanoparticles. Journal of Chemical Information and Modeling, v. 53, n. 9, p. 2282-2298, 2013.

167 DA SILVA, J. L. F. Effective coordination concept applied for phase change $(\mathrm{GeTe})_{m}\left(\mathrm{Sb}_{2} \mathrm{Te}_{3}\right)_{n}$ compounds. Journal of Applied Physics, Woodbury, v. 109, n. 2, p. 023502, 2011.

168 BROYDEN, C. G. The convergence of a class of double-rank minimization algorithms 1. general considerations. IMA Journal of Applied Mathematics, v. 6, n. 1, p. 76-90, 1970.

169 FLETCHER, R. A new approach to variable metric algorithms. The Computer Journal, v. 13, n. 3 , p. $317-322,1970$. 
170 GOLDFARB, D. A family of variable-metric methods derived by variational means. Mathematics of Computation, v. 24, n. 109, p. 23-26, 1970.

171 SHANNO, D. F. Conditioning of quasi-Newton methods for function minimization. Mathematics of Computation, v. 24, n. 111, p. 647-656, 1970.

172 SHERMAN, J.; MORRISON, W. J. Adjustment of an inverse matrix corresponding to a change in one element of a given matrix. Annals of Mathematical Statistics, v. 21, n. 1, p. 124-127, 1950. 


\section{APÊNDICE $A$ \\ Número de Coordenação Efetiva}

Neste apêndice é definido o conceito de número de coordenação efetiva média, empregado na análise de propriedades estruturais de clusters e nanopartículas ao longo do trabalho.

\section{A.1 Definição}

Tradicionalmente, o número de coordenação ( $\mathrm{CN}$ - coordination number) de um átomo em uma molécula, cluster, nanopartícula ou sólido é tomado como o número de vizinhos mais próximos a ele, de acordo com um parâmetro correspondente a uma distância de corte, $d_{\text {cut }}$. Na prática, o $\mathrm{CN}$ de um átomo $i$ é computado determinando o número de átomos $j$ que satisfazem a relação de vizinhança, $d_{i j}<d_{c u t}$, onde $d_{i j}$ é a distância entre o átomo $i$ e um átomo $j$. Assim, cada átomo $j$ que satisfaça o critério de distância contribui com uma unidade para o CN de $i$, independente da distância entre $i$ e $j$. Em outras palavras, todos os comprimentos de ligação possuem o mesmo peso na determinação do $\mathrm{CN}, w_{i j}=1.0$, i.e., peso unitário.

Um fator importante é a definição da distância de corte, $d_{c u t}$. No caso de sistemas metálicos, a definição dessa distância pode ser feita sem grandes dificuldades para estruturas simétricas, nas quais é possível identificar os vizinhos mais próximos de um átomo através de uma análise estrutural, e assim definir uma distância de corte adequada. Já no caso de estruturas distorcidas, ou de pouca simetria (caso comum em partículas), a tarefa se torna mais difícil, uma vez que os vizinhos de um átomo $i$ podem estar localizados a diferentes distâncias, mais curtas ou mais longas, e mesmo assim exercerem alguma influência em $i$. Caso essas distâncias variem devido alguma alteração estrutural no sistema, e.g., introdução de alguma outra espécie química, porém mantenham-se dentro da distância de corte, o CN se mantém inalterado e refletindo as variações nas propriedades do sistema. 
Uma alternativa é o emprego do número de coordenação efetiva (ECN - effective coordination number), no qual diferentes distâncias $d_{i j}$ recebem diferentes pesos na determinação do número de coordenação. Dessa maneira, mesmo pequenas variações nas distâncias dos vizinhos refletem-se em mudanças na coordenação efetiva. Os pesos $w_{i j}$ são calculados a partir do comprimento de ligação ponderado de cada átomo $i$, denotado por $d_{a v}^{i}$, e o ECN de um átomo $i\left(\mathrm{ECN}_{i}\right)$ é simplesmente a soma dos pesos $w_{i j}$, não sendo, portanto, necessariamente um valor inteiro. Quando $d_{i j}<d_{a v}^{i}$, então $w_{i j}>1.0$, diferindo mais da unidade quanto menor for $d_{i j}$, e indicando que o átomo $j$ dá uma contribuição mais significativa para $\mathrm{ECN}_{i}$. Por outro lado, se $d_{i j}>d_{a v}^{i}$, então $w_{i j}<1.0$, o que representa em uma contribuição menos significativa de $j$ para $\mathrm{ECN}_{i}$.

As análises feitas neste trabalho utilizando o ECN (capítulos 5 e 6) para partículas de $N$ átomos utilizam a seguinte definição (167)

$$
\operatorname{ECN}_{i}=\sum_{\substack{j=1 \\ j \neq i}}^{N} \exp \left[1-\left(\frac{d_{i j}}{d_{a v}^{i}}\right)^{6}\right]
$$

onde $d_{a v}^{i}$ deve ser obtido de maneira auto-consistente,

$$
d_{a v}^{i}=\frac{\sum_{\substack{j=1 \\ j \neq i}}^{N} d_{i j} \exp \left[1-\left(\frac{d_{i j}}{d_{a v}^{i}}\right)^{6}\right]}{\sum_{\substack{j=1 \\ j \neq i}}^{N} \exp \left[1-\left(\frac{d_{i j}}{d_{a v}^{i}}\right)^{6}\right]},
$$

onde o cálculo iterativo deve ser realizado até que um critério de convergência seja atingido. Neste trabalho o critério de convergência empregado foi $\mid d_{a v}^{i}($ novo $)-d_{a v}^{i}($ antigo $) \mid<10^{-4}$, e para o valor inicial de $d_{a v}^{i}$ foi usada a menor distância entre o átomo $i$ e qualquer outro átomo, $d_{\text {min. }}^{i}$. O número de coordenação efetiva médio é definido como

$$
\mathrm{ECN}=\frac{1}{N} \sum_{i=1}^{N} \mathrm{ECN}_{\mathrm{i}}
$$




\section{APÊNDICE $B$}

\section{Métodos de Otimização Local}

Neste apêndice são apresentados de maneira resumida os três métodos de minimização local empregados no trabalho, steepest descent adaptativo, gradientes conjugados, e BFGS. Maiores detalhes podem ser encontrados na literatura (119-121, 168-171).

\section{B.1 Método steepest descent adaptativo}

No método SDA, dada uma configuração inicial, $\mathbf{R}^{0}$, o método busca minimizar a energia do sistema iterativamente, determinando uma nova configuração cada iteração a partir da configuração da iteração anterior, até que em alguma das iterações o mínimo local seja atingido, de acordo com um critério para as forças que define o que é um mínimo local. Em uma iteração $n$, o processo de determinar $\mathbf{R}^{n+1}$ a partir da configuração $\mathbf{R}^{n}$ é chamado de um movimento sobre a SEP. A ideia básica por trás do método é fazer movimentos na direção em que a função de energia decresce mais rapidamente, isto é, na direção contrária ao gradiente da função $E(\mathbf{R})$. Isso equivale a dizer que em cada iteração os átomos são movidos na direção das forças que atuam sobre eles. O algoritmo do método SDA é mostrado na figura B.1.

O parâmetro $\gamma^{n}$ determina o comprimento do passo a ser dado na direção das forças, e pode variar durante a otimização. A atualização desse parâmetro ao longo do cálculo é realizada seguindo uma regra empírica, segundo a qual o parâmetro tem o seu valor aumentado em $5 \%$ para a iteração seguinte caso a iteração atual tenha obtido sucesso em minimizar energia com a nova configuração gerada, e em caso contrário, o parâmetro é reduzido para $60 \%$ do seu valor atual para a iteração seguinte. Esse esquema simples mostrou-se eficiente para os potenciais de LJ e SC.

Existem duas razões para o método ser denominado adaptativo. Uma delas é que o parâmetro $\gamma^{n}$ é modificado ao longo da otimização, e a cada iteração é adaptado (aumentado 
1. $n \Leftarrow 1, \gamma^{n} \Leftarrow 0.05$

2. $E^{n} \Leftarrow E\left(\mathbf{R}^{n}\right)$

3. Para cada átomo $i=1, \ldots, N$

(a) $\mathbf{F}_{i} \Leftarrow \mathbf{F}_{i}\left(\mathbf{R}^{n}\right)$

(b) $\hat{\mathbf{F}}_{i} \Leftarrow \frac{\mathbf{F}_{i}}{\left|\mathbf{F}_{i}\right|}$

(c) $\mathbf{R}_{i}^{n+1} \Leftarrow \mathbf{R}_{i}^{n}+\gamma^{n} \hat{\mathbf{F}}_{i}$

4. $E^{n+1} \Leftarrow E\left(\mathbf{R}^{n+1}\right)$

5. Se $E^{n+1}<E^{n}$ então

(a) $\gamma^{n+1} \Leftarrow 1.05 \gamma^{n}$

6. Senão

(a) $\gamma^{n+1} \Leftarrow 0.6 \gamma^{n}$

(b) $\mathbf{R}^{n+1} \Leftarrow \mathbf{R}^{n}$

7. $n \Leftarrow n+1$

8. Se $\max \left\{\left|F_{i, j}\right|\right\} \leq \epsilon(i=1, \ldots, N ; j=x, y, z)$ ou $n>n_{\max }$ então finaliza

9. Senão retorna ao passo 2

Figura B.1 - Algoritmo em pseudocódigo do método steepest descent adaptativo.

ou reduzido) de acordo com o sucesso ou insucesso em reduzir a energia do sistema. A outra razão é que como apenas as direções das forças são utilizadas nos deslocamentos, pode-se considerar que o algoritmo se adapta, mostrando bom desempenho e evitando que o sistema exploda mesmo em situações nas quais as forças tenham magnitude elevada.

\section{B.2 Método dos gradientes conjugados}

No método GC, em uma iteração $n$ a direção de busca na qual que o átomo $i$ é deslocado é dada por $\mathbf{G}_{i}^{n}$, definida como a direção conjugada ao gradiente da função,

$$
\mathbf{G}_{i}^{n}=\mathbf{F}_{i}^{n}+\beta^{n} \mathbf{G}_{i}^{n-1}
$$

onde $\mathbf{F}_{i}^{n}=\mathbf{F}_{i}\left(\mathbf{R}^{n}\right)$, e $\mathbf{G}_{i}^{0}=\mathbf{F}_{i}^{0}$. Portanto, apenas durante a primeira iteração é que o deslocamento se dá na direção das forças, sendo que nas iterações seguintes a direção dos deslocamentos leva em conta as direções tomadas no passo anterior, em particular a direção 
conjugada à força da iteração anterior. Diferente do que ocorre no método SDA, o método dos gradientes conjugados acumula informações de buscas de iterações passadas, modo que uma iteração não desfaz o progresso obtido em outas. O parâmetro $\beta^{n}$ presente na equação B.2.1 determina a maneira de considerar as direções conjugadas durante a busca, existindo diversas prescrições sobre como ele deve ser calculado. Neste trabalho a prescrição utilizada é aquela fornecida por Dai e Liao (122).

Uma vez definida a direção de busca, $\mathbf{G}_{i}^{n}$, o deslocamento dos átomos é dado por

$$
\mathbf{R}_{i}^{n+1}=\mathbf{R}_{i}^{n}+\gamma^{n} \mathbf{G}_{i}^{n}
$$

onde o parâmetro $\gamma^{n}$ deve ser tomado de modo a minimizar a função de energia na direção do deslocamento, isto é, uma minimização linear dada por

$$
\gamma^{n}=\min _{\gamma}\left\{E\left(\mathbf{R}_{i}^{n}+\gamma \mathbf{G}_{i}^{n}\right)\right\}
$$

Em comparação com o SDA, o método GC em geral converge para o mínimo local em um número menor de iterações, porém o custo de cada iteração é mais elevado, uma vez que é preciso realizar a minimização linear do parâmetro $\gamma^{n}$ durante cada iteração, e também exige que as forças, seus gradientes e respectivas direções conjugadas das iterações anteriores sejam armazenados.

\section{B.3 Método Broyden-Fletcher-Goldfarb-Shanno}

O método BFGS é um esquema quase-Newtoniano que utiliza informações sobre as derivadas segundas da função a ser minimizada. Para fins de descrição do método, é conveniente utilizar uma notação alternativa para as configurações atômicas. Ao invés de $\mathbf{R}$, é possível representar as coordenadas espaciais dos $3 N$ átomos do sistema pelo vetor $\mathbf{x}=$ $\left(x_{1}, x_{2}, x_{3}, \ldots, x_{3 N}\right)$, onde $\mathbf{R}_{1}=\left(x_{1}, x_{2}, x_{3}\right), \mathbf{R}_{2}=\left(x_{4}, x_{5}, x_{6}\right)$, e assim por diante. Assim, função de energia a ser minimizada pode ser escrita em função de $\mathbf{x}$, isto é, $E(\mathbf{x})$. O procedimento básico para a minimização local em métodos quase-Newtonianos é o mesmo dos métodos SDA e GC, isto é, partindo de um ponto inicial, determina-se uma direção de busca, atualiza-se o ponto deslocando-o nessa direção, e então procede iterativamente até que o mínimo local seja atingido. A diferença reside na maneira em que as direções de busca são calculadas ao longo da otimização.

No método de Newton, em uma iteração $n$ a direção de busca $\mathbf{G}^{n}$ é determinada através 
da solução da equação

$$
H^{n} \mathbf{G}^{n}=-\nabla E\left(\mathbf{x}^{n}\right)
$$

onde $H^{n}$ é a matriz hessiana da função $E$ no ponto $\mathbf{x}^{n}$. Uma vez determinado o vetor $\mathbf{G}^{n}$, as coordenadas são ajustadas da maneira usual, isto é,

$$
\mathbf{x}^{n+1}=\mathbf{x}^{n}+\gamma^{n} \mathbf{G}^{n}
$$

onde o passo $\gamma^{n}$ pode ser obtido através de uma minimização linear da função na direção de busca, de maneira análoga ao que acontece no método GC.

A determinação da matriz Hessiana utilizada na equação B.3.1 é custosa, uma vez que exige o cálculo de $9 N^{2}$ derivadas segundas para uma função de $3 N$ variáveis. Para evitar isso, os métodos quase-Newtonianos empregam uma aproximação para a matriz Hessiana. A determinação das direções de busca se dá, então, através da solução da equação

$$
B^{n} \mathbf{G}^{n}=-\nabla E\left(\mathbf{x}^{n}\right),
$$

onde $B^{n}$ é uma matriz que a próxima a matriz Hessiana em uma iteração $n$.

A distinção entre os diferentes métodos quase-Newtonianos disponíveis na literatura se dá na maneira em como a matriz $B$ é determinada. No método BFGS a matriz aproximada $B$ para uma iteração $n+1$ é calculada através da relação iterativa,

$$
B^{n+1}=B^{n}+\frac{\mathbf{y}^{n}\left(\mathbf{y}^{n}\right)^{T}}{\left(\mathbf{y}^{n}\right)^{T} \mathbf{s}^{n}}-\frac{B^{n} \mathbf{s}^{n}\left(\mathbf{s}^{n}\right)^{T} B^{n}}{\left(\mathbf{s}^{n}\right)^{T} B^{n} \mathbf{s}^{n}},
$$

onde os vetores $\mathbf{y}^{n}$ e $\mathbf{s}^{n}$ são definidos como

$$
\begin{gathered}
\mathbf{y}^{n}=\nabla E\left(\mathbf{x}^{n+1}\right)-\nabla E\left(\mathbf{x}^{n}\right), \\
\mathbf{s}^{n}=\gamma^{n} \mathbf{G}^{n} .
\end{gathered}
$$

Portanto, o cálculo da matriz $B$ utiliza apenas a função a ser minimizada e o seu gradiente gradiente, não havendo a necessidade de calcular suas derivadas segundas. A equação B.3.3 pode ser escrita como

$$
\mathbf{G}^{n}=-\left(B^{n}\right)^{-1} \nabla E\left(\mathbf{x}^{n}\right)
$$

onde a matriz $B^{n}$ pode ser invertida de forma eficiente através da aplicação da fórmula de Sherman-Morrison (172) à equação B.3.4.

Para que o método BFGS apresente convergência para um mínimo local é necessário que a matriz inicial $B^{1}$ seja uma matriz simétrica positiva definida, e uma prescrição comum é 
utilizar a matriz identidade, $B^{1}=I$. Durante a otimização, os gradientes nos pontos considerados são utilizados para melhorar a matriz Hessiana aproximada, com os elementos fora da diagonal tendo seus valores atribuídos com base nos elementos antigos e nos gradientes atuais. É possível demonstrar que o método BFGS apresenta boas propriedades de autocorreção, isto é, mesmo que a aproximação para a matriz Hessiana não seja uma boa estimativa da curvatura da função em uma determinada iteração, o método tende a se autocorrigir dentro de algumas iterações. O preço a pagar, nesse caso, é uma otimização mais lenta, porém ainda convergente. Além disso, devido a capacidade do método de se autocorrigir, a minimização linear do parâmetro $\gamma^{n}$ pode ser feita dentro de um intervalo mais largo de tolerância e não precisa ser ótima. O algoritmo do método BFGS é mostrado na figura B.2.

1. $B_{1} \Leftarrow I$

2. $n \Leftarrow 1$

3. Enquanto $\max \left\{\left|\partial E\left(\mathbf{x}^{n}\right) / \partial x_{i}\right|\right\}>\epsilon(i=1, \ldots, 3 N)$

(a) $\mathbf{G}^{n} \Leftarrow-\left(B^{n}\right)^{-1} \nabla E\left(\mathbf{x}^{n}\right)$

(b) $\gamma^{n} \Leftarrow \min _{\gamma}\left\{E\left(\mathbf{x}^{n}+\gamma \mathbf{G}^{n}\right)\right\}$

(c) $\mathbf{x}_{n+1} \Leftarrow \mathbf{x}^{n}+\gamma^{n} \mathbf{G}^{n}$

(d) $\mathbf{s}^{n} \Leftarrow \gamma^{n} \mathbf{G}^{n}$

(e) $\mathbf{y}^{n} \Leftarrow \nabla E\left(\mathbf{x}_{n+1}\right)-\nabla E\left(\mathbf{x}^{n}\right)$

(f) Calcula $\left(B^{n+1}\right)^{-1}$

(g) $n \Leftarrow n+1$

Figura B.2 - Algoritmo em pseudocódigo do método Broyden-Fletcher-Goldfarb-Shanno utilizando inicialização com matriz identidade. 
APÊNDICE $C$

\section{Clusters Binários de Lennard-Jones: Mínimos Globais}

Este apêndice contém todos os mínimos globais dos clusters $\mathrm{BLJ}_{N}(N=5-100)$ $\left(\sigma^{B B} / \sigma^{A A}=1.05,1.10,1.15,1.20,1.25,1.30\right)$ identificados com o método RBHMC. 
Tabela C.1 - $\quad$ Mínimos globais dos clusters $\operatorname{BLJ}_{N}(N=5-100)$ com $\sigma^{B B} / \sigma^{A A}=1.05$ encontrados com o método RBHMC para as composições indicadas. Energias totais e o grupos pontuais de simetria (GP) são mostrados.

\begin{tabular}{|c|c|c|c|c|c|c|c|}
\hline$N$ & $N_{A}$ & Energia $(\epsilon)$ & PG & $N$ & $N_{A}$ & Energia $(\epsilon)$ & PG \\
\hline 5 & 3 & -9.111507 & $D_{3 h}$ & 53 & 13 & -268.991573 & $C_{2 v}$ \\
\hline 6 & 2 & -12.712962 & $D_{4 h}$ & 54 & 13 & -276.058231 & $C_{5 v}$ \\
\hline 7 & 2 & -16.547241 & $D_{5 h}$ & 55 & 13 & -283.154531 & $I_{h}$ \\
\hline 8 & 3 & -19.887476 & $C_{1}$ & 56 & 16 & -287.691892 & $C_{3 v}$ \\
\hline 9 & 3 & -24.234145 & $C_{2 v}$ & 57 & 14 & -292.490914 & $C_{s}$ \\
\hline 10 & 4 & -28.641948 & $C_{3 v}$ & 58 & 13 & -298.295002 & $C_{3 v}$ \\
\hline 11 & 1 & -33.127634 & $C_{2 v}$ & 59 & 16 & -303.893779 & $C_{2}$ \\
\hline 12 & 1 & -38.629544 & $C_{5 v}$ & 60 & 16 & -310.001341 & $C_{s}$ \\
\hline 13 & 1 & -45.166580 & $I_{h}$ & 61 & 16 & -316.112220 & $C_{2}$ \\
\hline 14 & 1 & -48.678921 & $C_{3 v}$ & 62 & 18 & -321.789205 & $C_{s}$ \\
\hline 15 & 2 & -53.167589 & $C_{s}$ & 63 & 18 & -327.901806 & $C_{1}$ \\
\hline 16 & 2 & -57.758981 & $C_{s}$ & 64 & 18 & -334.013197 & $C_{s}$ \\
\hline 17 & 4 & -62.419138 & $C_{3 v}$ & 65 & 16 & -339.910437 & $C_{s}$ \\
\hline 18 & 2 & -68.022619 & $C_{5 v}$ & 66 & 18 & -346.360633 & $C_{1}$ \\
\hline 19 & 2 & -74.524048 & $D_{5 h}$ & 67 & 17 & -352.827543 & $C_{s}$ \\
\hline 20 & 4 & -79.067291 & $C_{2}$ & 68 & 19 & -359.272795 & $C_{1}$ \\
\hline 21 & 4 & -83.735808 & $C_{s}$ & 69 & 18 & -365.744424 & $C_{s}$ \\
\hline 22 & 3 & -89.272798 & $C_{s}$ & 70 & 19 & -372.669868 & $C_{5 v}$ \\
\hline 23 & 3 & -95.813706 & $D_{3 h}$ & 71 & 19 & -379.710375 & $C_{5 v}$ \\
\hline 24 & 4 & -100.407430 & $C_{s}$ & 72 & 22 & -385.168824 & $C_{1}$ \\
\hline 25 & 4 & -105.878653 & $C_{s}$ & 73 & 22 & -391.559518 & $C_{s}$ \\
\hline 26 & 4 & -112.438253 & $T_{d}$ & 74 & 22 & -397.664635 & $C_{s}$ \\
\hline 27 & 5 & -116.926080 & $C_{s}$ & 75 & 24 & -403.509173 & $C_{s}$ \\
\hline 28 & 5 & -122.322287 & $C_{s}$ & 76 & 23 & -409.836259 & $C_{1}$ \\
\hline 29 & 5 & -128.795218 & $D_{3 h}$ & 77 & 24 & -416.441050 & $C_{s}$ \\
\hline 30 & 5 & -133.409767 & $C_{2 v}$ & 78 & 25 & -422.800176 & $C_{1}$ \\
\hline 31 & 6 & -138.662748 & $C_{s}$ & 79 & 25 & -429.291308 & $C_{1}$ \\
\hline 32 & 6 & -145.044787 & $C_{2 v}$ & 80 & 26 & -436.214492 & $C_{s}$ \\
\hline 33 & 7 & -150.010109 & $C_{s}$ & 81 & 26 & -443.191273 & $C_{2 v}$ \\
\hline 34 & 7 & -156.228179 & $D_{5 h}$ & 82 & 26 & -448.772200 & $C_{2 v}$ \\
\hline 35 & 7 & -161.190333 & $C_{3 v}$ & 83 & 28 & -455.072951 & $C_{1}$ \\
\hline 36 & 8 & -166.111652 & $C_{1}$ & 84 & 26 & -461.542943 & $C_{s}$ \\
\hline 37 & 8 & -172.189967 & $C_{s}$ & 85 & 28 & -468.086930 & $C_{1}$ \\
\hline 38 & 8 & -177.260697 & $T_{d}$ & 86 & 31 & -474.634175 & $C_{s}$ \\
\hline 39 & 9 & -183.003251 & $C_{2 v}$ & 87 & 31 & -481.551013 & $C_{s}$ \\
\hline 40 & 9 & -188.146744 & $C_{s}$ & 88 & 31 & -488.468369 & $C_{3 v}$ \\
\hline 41 & 9 & -193.743072 & $C_{2}$ & 89 & 31 & -494.056891 & $C_{s}$ \\
\hline 42 & 10 & -199.257511 & $C_{s}$ & 90 & 31 & -500.236457 & $C_{1}$ \\
\hline 43 & 9 & -204.790489 & $C_{1}$ & 91 & 31 & -506.729133 & $C_{s}$ \\
\hline 44 & 8 & -210.978612 & $C_{s}$ & 92 & 32 & -513.205038 & $C_{1}$ \\
\hline 45 & 8 & -216.856331 & $C_{1}$ & 93 & 36 & -519.775813 & $C_{2}$ \\
\hline 46 & 10 & -223.210589 & $C_{s}$ & 94 & 34 & -526.614509 & $C_{s}$ \\
\hline 47 & 11 & -228.725544 & $C_{1}$ & 95 & 34 & -533.465067 & $C_{s}$ \\
\hline 48 & 12 & -235.079224 & $C_{1}$ & 96 & 34 & -539.063361 & $C_{s}$ \\
\hline 49 & 12 & -242.011604 & $C_{s}$ & 97 & 34 & -545.293382 & $C_{1}$ \\
\hline 50 & 13 & -247.882695 & $C_{s}$ & 98 & 34 & -551.683813 & $C_{1}$ \\
\hline 51 & 13 & -254.916947 & $C_{2 v}$ & 99 & 35 & -558.310074 & $C_{1}$ \\
\hline 52 & 13 & -261.953177 & $C_{3 v}$ & 100 & 37 & -564.909753 & $C_{1}$ \\
\hline
\end{tabular}


Tabela C.2 - Mínimos globais dos clusters $\mathrm{BLJ}_{N}(N=5-100)$ com $\sigma^{B B} / \sigma^{A A}=1.10$ encontrados com o método RBHMC para as composições indicadas. Energias totais e o grupos pontuais de simetria (GP) são mostrados.

\begin{tabular}{|c|c|c|c|c|c|c|c|}
\hline$N$ & $N_{A}$ & Energia $(\epsilon)$ & PG & $N$ & $N_{A}$ & Energia $(\epsilon)$ & PG \\
\hline 5 & 3 & -9.119302 & $D_{3 h}$ & 53 & 13 & -271.915714 & $C_{2}$ \\
\hline 6 & 2 & -12.715734 & $D_{4 h}$ & 54 & 12 & -278.194041 & $D_{3 h}$ \\
\hline 7 & 3 & -16.557098 & $C_{2 v}$ & 55 & 12 & -284.159496 & $C_{s}$ \\
\hline 8 & 2 & -19.948687 & $C_{2 v}$ & 56 & 14 & -290.398039 & $C_{2}$ \\
\hline 9 & 4 & -24.300649 & $C_{s}$ & 57 & 16 & -296.039531 & $T_{d}$ \\
\hline 10 & 1 & -28.771585 & $C_{3 v}$ & 58 & 16 & -302.562491 & $C_{3 v}$ \\
\hline 11 & 1 & -33.371304 & $C_{2 v}$ & 59 & 14 & -309.038480 & $C_{2 v}$ \\
\hline 12 & 1 & -38.954245 & $C_{5 v}$ & 60 & 12 & -315.474426 & $C_{3 v}$ \\
\hline 13 & 1 & -45.543272 & $I_{h}$ & 61 & 12 & -321.775834 & $T_{d}$ \\
\hline 14 & 1 & -49.049816 & $C_{3 v}$ & 62 & 13 & -326.823952 & $C_{s}$ \\
\hline 15 & 4 & -53.599281 & $C_{s}$ & 63 & 14 & -333.256699 & $C_{1}$ \\
\hline 16 & 4 & -58.279990 & $C_{s}$ & 64 & 14 & -339.520135 & $C_{1}$ \\
\hline 17 & 4 & -63.059172 & $C_{3 v}$ & 65 & 15 & -345.658505 & $C_{s}$ \\
\hline 18 & 2 & -68.792764 & $C_{5 v}$ & 66 & 14 & -352.051080 & $C_{s}$ \\
\hline 19 & 2 & -75.433396 & $D_{5 h}$ & 67 & 18 & -358.081907 & $C_{s}$ \\
\hline 20 & 4 & -80.143826 & $C_{2}$ & 68 & 18 & -364.666125 & $C_{s}$ \\
\hline 21 & 5 & -84.978975 & $C_{2 v}$ & 69 & 18 & -371.201139 & $C_{1}$ \\
\hline 22 & 4 & -90.682088 & $C_{1}$ & 70 & 18 & -377.921655 & $C_{3 v}$ \\
\hline 23 & 4 & -97.429591 & $C_{3 v}$ & 71 & 18 & -384.295723 & $C_{s}$ \\
\hline 24 & 4 & -102.241482 & $C_{s}$ & 72 & 18 & -390.588771 & $C_{s}$ \\
\hline 25 & 4 & -108.045220 & $C_{s}$ & 73 & 19 & -396.654201 & $C_{3 v}$ \\
\hline 26 & 4 & -114.892839 & $T_{d}$ & 74 & 19 & -402.397866 & $C_{s}$ \\
\hline 27 & 5 & -119.543605 & $C_{s}$ & 75 & 19 & -408.569903 & $C_{s}$ \\
\hline 28 & 5 & -125.296607 & $C_{s}$ & 76 & 21 & -414.563330 & $C_{1}$ \\
\hline 29 & 5 & -132.108090 & $D_{3 h}$ & 77 & 23 & -420.702588 & $C_{1}$ \\
\hline 30 & 7 & -136.742249 & $C_{2 v}$ & 78 & 22 & -427.333481 & $C_{1}$ \\
\hline 31 & 6 & -142.433255 & $C_{1}$ & 79 & 19 & -433.506938 & $C_{s}$ \\
\hline 32 & 6 & -149.212031 & $C_{2 v}$ & 80 & 18 & -440.098687 & $C_{2}$ \\
\hline 33 & 7 & -154.633546 & $C_{s}$ & 81 & 18 & -446.630646 & $C_{s}$ \\
\hline 34 & 7 & -161.360048 & $D_{5 h}$ & 82 & 18 & -453.113837 & $C_{3}$ \\
\hline 35 & 7 & -166.185706 & $C_{3 v}$ & 83 & 25 & -459.373833 & $C_{1}$ \\
\hline 36 & 8 & -171.524014 & $C_{s}$ & 84 & 25 & -466.108973 & $C_{1}$ \\
\hline 37 & 8 & -178.167061 & $C_{s}$ & 85 & 25 & -472.527416 & $C_{1}$ \\
\hline 38 & 9 & -183.371989 & $C_{s}$ & 86 & 25 & -479.182595 & $C_{1}$ \\
\hline 39 & 9 & -189.903875 & $C_{2 v}$ & 87 & 36 & -485.081933 & $C_{1}$ \\
\hline 40 & 9 & -195.024681 & $C_{s}$ & 88 & 36 & -492.189054 & $C_{1}$ \\
\hline 41 & 10 & -201.346753 & $C_{3 v}$ & 89 & 37 & -498.213051 & $C_{1}$ \\
\hline 42 & 10 & -207.024045 & $C_{s}$ & 90 & 36 & -504.977129 & $C_{s}$ \\
\hline 43 & 11 & -213.011525 & $C_{2 v}$ & 91 & 36 & -511.845979 & $C_{s}$ \\
\hline 44 & 12 & -218.600859 & $C_{5 v}$ & 92 & 37 & -518.431759 & $C_{1}$ \\
\hline 45 & 13 & -224.652192 & $I_{h}$ & 93 & 37 & -524.964281 & $C_{1}$ \\
\hline 46 & 12 & -229.387288 & $C_{1}$ & 94 & 37 & -531.583051 & $C_{s}$ \\
\hline 47 & 13 & -234.898732 & $C_{s}$ & 95 & 36 & -538.741277 & $C_{2 v}$ \\
\hline 48 & 14 & -240.845542 & $C_{3 v}$ & 96 & 40 & -544.671597 & $C_{1}$ \\
\hline 49 & 12 & -247.555272 & $C_{s}$ & 97 & 40 & -551.416081 & $C_{1}$ \\
\hline 50 & 12 & -254.363907 & $C_{s}$ & 98 & 40 & -558.264685 & $C_{1}$ \\
\hline 51 & 12 & -261.263002 & $D_{6 d}$ & 99 & 40 & -564.964519 & $C_{1}$ \\
\hline 52 & 13 & -266.585540 & $C_{s}$ & 100 & 43 & -571.812888 & $C_{1}$ \\
\hline
\end{tabular}


Tabela C.3 - Mínimos globais dos clusters $\operatorname{BLJ}_{N}(N=5-100)$ com $\sigma^{B B} / \sigma^{A A}=1.15$ encontrados com o método RBHMC para as composições indicadas. Energias totais e o grupos pontuais de simetria (GP) são mostrados.

\begin{tabular}{|c|c|c|c|c|c|c|c|}
\hline$N$ & $N_{A}$ & Energia $(\epsilon)$ & PG & $N$ & $N_{A}$ & Energia $(\epsilon)$ & PG \\
\hline 5 & 3 & -9.127219 & $D_{3 h}$ & 53 & 16 & -277.756061 & $C_{s}$ \\
\hline 6 & 2 & -12.720554 & $D_{4 h}$ & 54 & 17 & -283.532817 & $C_{s}$ \\
\hline 7 & 4 & -16.562111 & $C_{2 v}$ & 55 & 16 & -289.293185 & $C_{1}$ \\
\hline 8 & 2 & -20.102320 & $C_{2 v}$ & 56 & 17 & -296.263148 & $C_{2}$ \\
\hline 9 & 5 & -24.364017 & $C_{2 v}$ & 57 & 16 & -302.171252 & $C_{1}$ \\
\hline 10 & 2 & -28.863192 & $C_{s}$ & 58 & 16 & -309.171713 & $C_{s}$ \\
\hline 11 & 1 & -33.571031 & $C_{3 v}$ & 59 & 17 & -315.023963 & $C_{1}$ \\
\hline 12 & 3 & -39.016600 & $C_{s}$ & 60 & 17 & -321.988253 & $C_{2}$ \\
\hline 13 & 1 & -45.577215 & $I_{h}$ & 61 & 18 & -327.728804 & $C_{1}$ \\
\hline 14 & 4 & -49.252081 & $C_{3 v}$ & 62 & 18 & -334.662475 & $C_{s}$ \\
\hline 15 & 5 & -53.874698 & $C_{2}$ & 63 & 19 & -340.639075 & $C_{s}$ \\
\hline 16 & 5 & -58.561496 & $C_{1}$ & 64 & 19 & -347.239596 & $C_{2}$ \\
\hline 17 & 5 & -63.367529 & $C_{3 v}$ & 65 & 19 & -352.920771 & $C_{s}$ \\
\hline 18 & 7 & -69.162203 & $C_{5 v}$ & 66 & 20 & -359.749940 & $C_{s}$ \\
\hline 19 & 7 & -75.742422 & $D_{5 h}$ & 67 & 21 & -365.780253 & $C_{s}$ \\
\hline 20 & 7 & -80.606044 & $C_{2}$ & 68 & 21 & -371.819359 & $C_{s}$ \\
\hline 21 & 7 & -85.558493 & $C_{2 v}$ & 69 & 22 & -378.279505 & $C_{1}$ \\
\hline 22 & 7 & -91.377400 & $C_{s}$ & 70 & 22 & -385.326178 & $C_{s}$ \\
\hline 23 & 7 & -98.124846 & $C_{2 v}$ & 71 & 22 & -391.564061 & $C_{1}$ \\
\hline 24 & 7 & -103.094695 & $C_{s}$ & 72 & 21 & -397.654760 & $C_{1}$ \\
\hline 25 & 7 & -108.973915 & $C_{s}$ & 73 & 22 & -404.046888 & $C_{1}$ \\
\hline 26 & 4 & -115.856394 & $T_{d}$ & 74 & 24 & -410.534023 & $C_{1}$ \\
\hline 27 & 7 & -120.824602 & $C_{s}$ & 75 & 24 & -417.299214 & $C_{1}$ \\
\hline 28 & 5 & -126.686572 & $C_{s}$ & 76 & 25 & -423.812270 & $C_{1}$ \\
\hline 29 & 5 & -133.610721 & $D_{3 h}$ & 77 & 25 & -430.684586 & $C_{1}$ \\
\hline 30 & 7 & -138.632308 & $C_{2 v}$ & 78 & 25 & -436.990405 & $C_{1}$ \\
\hline 31 & 7 & -144.488697 & $C_{1}$ & 79 & 25 & -443.855667 & $C_{s}$ \\
\hline 32 & 7 & -151.384854 & $C_{2 v}$ & 80 & 25 & -450.392713 & $C_{1}$ \\
\hline 33 & 7 & -157.272375 & $C_{s}$ & 81 & 26 & -456.533750 & $C_{s}$ \\
\hline 34 & 7 & -164.222021 & $D_{5 h}$ & 82 & 26 & -463.282074 & $D_{2 h}$ \\
\hline 35 & 7 & -168.882563 & $C_{3 v}$ & 83 & 25 & -470.061091 & $C_{1}$ \\
\hline 36 & 8 & -174.798837 & $C_{s}$ & 84 & 26 & -476.669838 & $C_{1}$ \\
\hline 37 & 8 & -181.675233 & $C_{s}$ & 85 & 26 & -483.671543 & $C_{s}$ \\
\hline 38 & 9 & -187.367687 & $C_{1}$ & 86 & 26 & -490.630031 & $C_{1}$ \\
\hline 39 & 9 & -194.229977 & $C_{2 v}$ & 87 & 26 & -497.578761 & $C_{s}$ \\
\hline 40 & 10 & -199.703534 & $C_{s}$ & 88 & 26 & -503.728759 & $C_{s}$ \\
\hline 41 & 10 & -206.479560 & $C_{3 v}$ & 89 & 26 & -509.597767 & $C_{s}$ \\
\hline 42 & 13 & -212.864370 & $C_{3 v}$ & 90 & 27 & -516.704386 & $C_{s}$ \\
\hline 43 & 13 & -219.440909 & $C_{2 v}$ & 91 & 27 & -522.807019 & $C_{s}$ \\
\hline 44 & 13 & -226.066862 & $C_{5 v}$ & 92 & 30 & -529.175479 & $C_{2}$ \\
\hline 45 & 13 & -232.763363 & $I_{h}$ & 93 & 30 & -535.431187 & $C_{1}$ \\
\hline 46 & 13 & -237.126607 & $C_{2}$ & 94 & 30 & -542.094480 & $C_{1}$ \\
\hline 47 & 14 & -242.723641 & $C_{s}$ & 95 & 30 & -548.732770 & $C_{s}$ \\
\hline 48 & 14 & -249.375588 & $C_{3 v}$ & 96 & 28 & -555.027991 & $C_{1}$ \\
\hline 49 & 15 & -254.328385 & $C_{s}$ & 97 & 30 & -561.564627 & $C_{1}$ \\
\hline 50 & 15 & -260.903328 & $C_{2}$ & 98 & 30 & -568.603054 & $C_{2}$ \\
\hline 51 & 16 & -265.596260 & $C_{1}$ & 99 & 30 & -575.609709 & $C_{1}$ \\
\hline 52 & 16 & -272.093082 & $C_{s}$ & 100 & 30 & -582.701043 & $D_{3}$ \\
\hline
\end{tabular}


Tabela C.4 - Mínimos globais dos clusters $\mathrm{BLJ}_{N}(N=5-100)$ com $\sigma^{B B} / \sigma^{A A}=1.20$ encontrados com o método RBHMC para as composições indicadas. Energias totais e o grupos pontuais de simetria (GP) são mostrados.

\begin{tabular}{|c|c|c|c|c|c|c|c|}
\hline$N$ & $N_{A}$ & Energia $(\epsilon)$ & PG & $N$ & $N_{A}$ & Energia $(\epsilon)$ & PG \\
\hline 5 & 3 & -9.135241 & $D_{3 h}$ & 53 & 16 & -284.687258 & $C_{s}$ \\
\hline 6 & 2 & -12.727718 & $D_{4 h}$ & 54 & 17 & -291.129765 & $C_{s}$ \\
\hline 7 & 5 & -16.565375 & $C_{2 v}$ & 55 & 19 & -297.413420 & $C_{5 v}$ \\
\hline 8 & 2 & -20.233378 & $C_{2 v}$ & 56 & 19 & -304.064330 & $D_{5 h}$ \\
\hline 9 & 2 & -24.442494 & $C_{s}$ & 57 & 19 & -308.603733 & $C_{1}$ \\
\hline 10 & 3 & -28.963939 & $C_{s}$ & 58 & 20 & -314.892908 & $C_{2 v}$ \\
\hline 11 & 2 & -33.966602 & $C_{s}$ & 59 & 20 & -320.706313 & $C_{s}$ \\
\hline 12 & 4 & -39.055815 & $C_{s}$ & 60 & 21 & -326.165572 & $C_{1}$ \\
\hline 13 & 5 & -45.553927 & $C_{2 v}$ & 61 & 18 & -332.499319 & $C_{s}$ \\
\hline 14 & 4 & -49.327774 & $C_{3 v}$ & 62 & 18 & -339.016866 & $C_{2 v}$ \\
\hline 15 & 5 & -54.064278 & $C_{2}$ & 63 & 22 & -345.885361 & $C_{s}$ \\
\hline 16 & 6 & -58.855874 & $C_{s}$ & 64 & 22 & -352.164062 & $C_{1}$ \\
\hline 17 & 4 & -63.715344 & $C_{2}$ & 65 & 22 & -358.742585 & $C_{1}$ \\
\hline 18 & 7 & -69.601233 & $C_{5 v}$ & 66 & 22 & -365.735817 & $C_{s}$ \\
\hline 19 & 7 & -76.235787 & $D_{5 h}$ & 67 & 23 & -372.494895 & $C_{1}$ \\
\hline 20 & 8 & -81.049244 & $C_{s}$ & 68 & 23 & -378.825463 & $C_{s}$ \\
\hline 21 & 7 & -85.958319 & $C_{2}$ & 69 & 24 & -384.797658 & $C_{1}$ \\
\hline 22 & 9 & -91.867225 & $C_{s}$ & 70 & 25 & -391.125843 & $C_{1}$ \\
\hline 23 & 9 & -98.645805 & $C_{2 v}$ & 71 & 26 & -397.447900 & $C_{s}$ \\
\hline 24 & 7 & -103.594194 & $C_{1}$ & 72 & 26 & -404.239315 & $C_{1}$ \\
\hline 25 & 10 & -109.567066 & $C_{s}$ & 73 & 26 & -411.255891 & $C_{s}$ \\
\hline 26 & 10 & -116.459773 & $C_{3 v}$ & 74 & 26 & -418.261933 & $C_{1}$ \\
\hline 27 & 10 & -121.413505 & $C_{1}$ & 75 & 26 & -425.265743 & $C_{s}$ \\
\hline 28 & 10 & -127.341138 & $C_{s}$ & 76 & 26 & -431.192388 & $C_{s}$ \\
\hline 29 & 10 & -134.246055 & $C_{s}$ & 77 & 26 & -437.703081 & $C_{1}$ \\
\hline 30 & 10 & -139.296381 & $C_{1}$ & 78 & 27 & -444.864069 & $C_{s}$ \\
\hline 31 & 10 & -145.238298 & $C_{1}$ & 79 & 27 & -451.921407 & $C_{2 v}$ \\
\hline 32 & 10 & -152.149159 & $C_{1}$ & 80 & 28 & -457.933230 & $C_{s}$ \\
\hline 33 & 12 & -158.185112 & $C_{s}$ & 81 & 26 & -464.422970 & $C_{s}$ \\
\hline 34 & 12 & -165.168631 & $C_{5 v}$ & 82 & 26 & -471.263190 & $D_{2 h}$ \\
\hline 35 & 12 & -170.282025 & $C_{s}$ & 83 & 29 & -477.723147 & $C_{1}$ \\
\hline 36 & 12 & -176.347917 & $C_{s}$ & 84 & 30 & -484.538812 & $C_{s}$ \\
\hline 37 & 12 & -183.248506 & $C_{s}$ & 85 & 30 & -491.066290 & $C_{s}$ \\
\hline 38 & 12 & -189.280007 & $C_{1}$ & 86 & 30 & -497.823917 & $C_{1}$ \\
\hline 39 & 13 & -196.261792 & $C_{5 v}$ & 87 & 30 & -504.653742 & $C_{1}$ \\
\hline 40 & 13 & -203.169138 & $C_{s}$ & 88 & 30 & -511.213151 & $C_{1}$ \\
\hline 41 & 13 & -210.149549 & $C_{2 v}$ & 89 & 32 & -517.829589 & $C_{1}$ \\
\hline 42 & 13 & -217.116931 & $C_{3 v}$ & 90 & 31 & -524.617913 & $C_{1}$ \\
\hline 43 & 13 & -224.072028 & $C_{2 v}$ & 91 & 32 & -531.680233 & $C_{3 v}$ \\
\hline 44 & 13 & -231.099052 & $C_{5 v}$ & 92 & 33 & -538.316013 & $C_{s}$ \\
\hline 45 & 13 & -238.202225 & $I_{h}$ & 93 & 34 & -544.573272 & $C_{1}$ \\
\hline 46 & 13 & -242.531934 & $C_{2}$ & 94 & 35 & -550.756948 & $C_{1}$ \\
\hline 47 & 14 & -248.218022 & $C_{s}$ & 95 & 36 & -556.923409 & $C_{1}$ \\
\hline 48 & 14 & -255.212873 & $C_{3 v}$ & 96 & 37 & -563.417126 & $C_{1}$ \\
\hline 49 & 15 & -260.339254 & $C_{1}$ & 97 & 34 & -571.305006 & $C_{1}$ \\
\hline 50 & 15 & -267.329407 & $C_{2}$ & 98 & 34 & -577.816793 & $C_{1}$ \\
\hline 51 & 16 & -272.214736 & $C_{1}$ & 99 & 34 & -584.198593 & $C_{1}$ \\
\hline 52 & 16 & -279.115531 & $C_{s}$ & 100 & 34 & -590.500609 & $C_{1}$ \\
\hline
\end{tabular}


Tabela C.5 - $\quad$ Mínimos globais dos clusters $\mathrm{BLJ}_{N}(N=5-100)$ com $\sigma^{B B} / \sigma^{A A}=1.25$ encontrados com o método RBHMC para as composições indicadas. Energias totais e o grupos pontuais de simetria (GP) são mostrados.

\begin{tabular}{|c|c|c|c|c|c|c|c|}
\hline$N$ & $N_{A}$ & Energia $(\epsilon)$ & PG & $N$ & $N_{A}$ & Energia $(\epsilon)$ & PG \\
\hline 5 & 3 & -9.143350 & $D_{3 h}$ & 53 & 19 & -289.573568 & $C_{s}$ \\
\hline 6 & 2 & -12.737707 & $D_{4 h}$ & 54 & 19 & -296.605354 & $D_{5 h}$ \\
\hline 7 & 5 & -16.572175 & $C_{2 v}$ & 55 & 19 & -303.663061 & $C_{5 v}$ \\
\hline 8 & 2 & -20.333773 & $C_{2 v}$ & 56 & 19 & -310.691065 & $D_{5 h}$ \\
\hline 9 & 2 & -24.533074 & $C_{s}$ & 57 & 19 & -315.238733 & $C_{s}$ \\
\hline 10 & 1 & -29.502679 & $D_{3 h}$ & 58 & 20 & -321.914589 & $C_{2 v}$ \\
\hline 11 & 3 & -34.345763 & $C_{2}$ & 59 & 20 & -327.501569 & $C_{s}$ \\
\hline 12 & 5 & -39.087588 & $C_{s}$ & 60 & 21 & -333.705967 & $C_{1}$ \\
\hline 13 & 7 & -45.592206 & $C_{5 v}$ & 61 & 23 & -339.429084 & $C_{s}$ \\
\hline 14 & 6 & -49.361851 & $C_{1}$ & 62 & 23 & -346.177037 & $D_{3 h}$ \\
\hline 15 & 5 & -54.163210 & $C_{2}$ & 63 & 23 & -351.102761 & $C_{3 v}$ \\
\hline 16 & 6 & -59.067444 & $C_{s}$ & 64 & 23 & -358.040393 & $D_{3 h}$ \\
\hline 17 & 4 & -64.365365 & $C_{2}$ & 65 & 21 & -363.512662 & $C_{s}$ \\
\hline 18 & 7 & -69.915015 & $C_{5 v}$ & 66 & 21 & -370.103112 & $C_{s}$ \\
\hline 19 & 7 & -76.589260 & $D_{5 h}$ & 67 & 21 & -376.595389 & $C_{s}$ \\
\hline 20 & 8 & -81.465579 & $C_{s}$ & 68 & 22 & -383.006710 & $C_{s}$ \\
\hline 21 & 9 & -86.397935 & $C_{2}$ & 69 & 24 & -389.822930 & $C_{s}$ \\
\hline 22 & 9 & -92.368564 & $C_{s}$ & 70 & 24 & -396.944371 & $C_{s}$ \\
\hline 23 & 9 & -99.186042 & $C_{2 v}$ & 71 & 24 & -403.529486 & $C_{1}$ \\
\hline 24 & 9 & -104.215802 & $C_{s}$ & 72 & 24 & -410.107263 & $C_{s}$ \\
\hline 25 & 10 & -110.182559 & $C_{s}$ & 73 & 28 & -416.498169 & $C_{1}$ \\
\hline 26 & 10 & -117.119402 & $C_{3 v}$ & 74 & 28 & -423.659482 & $C_{1}$ \\
\hline 27 & 10 & -122.140725 & $C_{s}$ & 75 & 28 & -430.250717 & $C_{1}$ \\
\hline 28 & 11 & -128.036984 & $C_{s}$ & 76 & 29 & -436.447236 & $C_{1}$ \\
\hline 29 & 11 & -134.974912 & $C_{2 v}$ & 77 & 32 & -443.011860 & $C_{1}$ \\
\hline 30 & 11 & -139.997093 & $C_{1}$ & 78 & 32 & -450.147772 & $C_{2 v}$ \\
\hline 31 & 12 & -145.962936 & $C_{1}$ & 79 & 28 & -457.300970 & $C_{s}$ \\
\hline 32 & 12 & -152.905938 & $C_{s}$ & 80 & 28 & -464.399834 & $C_{s}$ \\
\hline 33 & 12 & -159.258976 & $C_{s}$ & 81 & 28 & -470.795038 & $C_{s}$ \\
\hline 34 & 12 & -166.318301 & $C_{5 v}$ & 82 & 30 & -477.447813 & $C_{s}$ \\
\hline 35 & 12 & -171.344302 & $C_{s}$ & 83 & 30 & -484.474951 & $C_{1}$ \\
\hline 36 & 12 & -177.367846 & $C_{s}$ & 84 & 30 & -491.591546 & $C_{s}$ \\
\hline 37 & 12 & -184.345543 & $C_{s}$ & 85 & 31 & -498.453301 & $C_{2 v}$ \\
\hline 38 & 13 & -190.778073 & $C_{1}$ & 86 & 31 & -504.842168 & $C_{s}$ \\
\hline 39 & 13 & -197.847765 & $C_{5 v}$ & 87 & 31 & -511.400044 & $C_{2 v}$ \\
\hline 40 & 13 & -204.897420 & $C_{s}$ & 88 & 33 & -518.256499 & $C_{s}$ \\
\hline 41 & 13 & -212.023029 & $C_{2 v}$ & 89 & 33 & -525.381891 & $C_{2 v}$ \\
\hline 42 & 13 & -219.151586 & $C_{3 v}$ & 90 & 34 & -531.763926 & $C_{s}$ \\
\hline 43 & 13 & -226.283209 & $C_{2 v}$ & 91 & 36 & -538.411196 & $C_{2 v}$ \\
\hline 44 & 13 & -233.490683 & $C_{5 v}$ & 92 & 34 & -544.507909 & $C_{1}$ \\
\hline 45 & 13 & -240.774604 & $I_{h}$ & 93 & 35 & -551.431854 & $C_{1}$ \\
\hline 46 & 13 & -245.105004 & $C_{2}$ & 94 & 35 & -558.070473 & $C_{1}$ \\
\hline 47 & 14 & -251.068364 & $C_{s}$ & 95 & 36 & -564.709518 & $C_{1}$ \\
\hline 48 & 14 & -258.051347 & $C_{3 v}$ & 96 & 37 & -571.183226 & $C_{s}$ \\
\hline 49 & 15 & -263.648530 & $C_{1}$ & 97 & 38 & -578.190853 & $C_{1}$ \\
\hline 50 & 15 & -270.658086 & $C_{2}$ & 98 & 40 & -584.556381 & $C_{1}$ \\
\hline 51 & 16 & -276.007398 & $C_{1}$ & 99 & 40 & -591.591133 & $C_{1}$ \\
\hline 52 & 16 & -282.974620 & $C_{s}$ & 100 & 40 & -598.135329 & $C_{1}$ \\
\hline
\end{tabular}


Tabela C.6 - Mínimos globais dos clusters $\mathrm{BLJ}_{N}(N=5-100)$ com $\sigma^{B B} / \sigma^{A A}=1.30$ encontrados com o método RBHMC para as composições indicadas. Energias totais e o grupos pontuais de simetria (GP) são mostrados.

\begin{tabular}{|c|c|c|c|c|c|c|c|}
\hline$N$ & $N_{A}$ & Energia $(\epsilon)$ & PG & $N$ & $N_{A}$ & Energia $(\epsilon)$ & PG \\
\hline 5 & 3 & -9.151532 & $D_{3 h}$ & 53 & 19 & -292.286192 & $C_{s}$ \\
\hline 6 & 2 & -12.751325 & $D_{4 h}$ & 54 & 19 & -299.477866 & $D_{5 h}$ \\
\hline 7 & 5 & -16.576776 & $C_{2 v}$ & 55 & 19 & -306.733764 & $C_{5 v}$ \\
\hline 8 & 2 & -20.400814 & $C_{2 v}$ & 56 & 19 & -313.981977 & $D_{5 h}$ \\
\hline 9 & 3 & -24.644760 & $C_{2 v}$ & 57 & 20 & -318.655257 & $C_{s}$ \\
\hline 10 & 1 & -29.896713 & $D_{3 h}$ & 58 & 20 & -325.589970 & $C_{2 v}$ \\
\hline 11 & 3 & -34.749685 & $D_{4 d}$ & 59 & 23 & -331.286991 & $C_{s}$ \\
\hline 12 & 4 & -39.203335 & $C_{1}$ & 60 & 23 & -338.396340 & $C_{2 v}$ \\
\hline 13 & 7 & -45.601094 & $C_{5 v}$ & 61 & 23 & -345.440684 & $C_{s}$ \\
\hline 14 & 7 & -49.421887 & $C_{s}$ & 62 & 23 & -352.541258 & $D_{3 h}$ \\
\hline 15 & 7 & -54.222875 & $C_{s}$ & 63 & 23 & -357.469508 & $C_{3 v}$ \\
\hline 16 & 4 & -59.470682 & $C_{2}$ & 64 & 24 & -363.997742 & $C_{s}$ \\
\hline 17 & 5 & -64.790023 & $C_{s}$ & 65 & 26 & -369.664027 & $C_{s}$ \\
\hline 18 & 7 & -70.151377 & $C_{5 v}$ & 66 & 26 & -376.666635 & $T_{d}$ \\
\hline 19 & 7 & -76.859376 & $D_{5 h}$ & 67 & 27 & -381.697668 & $C_{2}$ \\
\hline 20 & 8 & -81.777835 & $C_{s}$ & 68 & 28 & -387.094070 & $C_{s}$ \\
\hline 21 & 8 & -86.806107 & $C_{1}$ & 69 & 26 & -393.423819 & $C_{s}$ \\
\hline 22 & 9 & -92.720013 & $C_{s}$ & 70 & 24 & -400.540009 & $C_{s}$ \\
\hline 23 & 11 & -99.606519 & $D_{3 h}$ & 71 & 26 & -407.103445 & $C_{1}$ \\
\hline 24 & 9 & -104.674634 & $C_{s}$ & 72 & 26 & -414.312666 & $C_{s}$ \\
\hline 25 & 12 & -110.621882 & $C_{s}$ & 73 & 26 & -420.923993 & $C_{1}$ \\
\hline 26 & 10 & -117.480017 & $C_{3 v}$ & 74 & 32 & -427.714840 & $C_{2 v}$ \\
\hline 27 & 10 & -122.587527 & $C_{s}$ & 75 & 32 & -434.557994 & $C_{1}$ \\
\hline 28 & 12 & -128.415202 & $C_{s}$ & 76 & 32 & -441.662589 & $C_{2}$ \\
\hline 29 & 11 & -135.341699 & $C_{2 v}$ & 77 & 32 & -448.595192 & $C_{1}$ \\
\hline 30 & 12 & -140.458045 & $C_{s}$ & 78 & 32 & -455.747811 & $C_{2 v}$ \\
\hline 31 & 14 & -146.375980 & $C_{1}$ & 79 & 34 & -462.413785 & $C_{s}$ \\
\hline 32 & 14 & -153.348422 & $C_{2}$ & 80 & 34 & -469.652236 & $C_{2}$ \\
\hline 33 & 12 & -159.598157 & $C_{s}$ & 81 & 34 & -476.399256 & $C_{s}$ \\
\hline 34 & 12 & -166.653616 & $C_{5 v}$ & 82 & 35 & -483.437070 & $C_{s}$ \\
\hline 35 & 13 & -171.853006 & $C_{s}$ & 83 & 36 & -490.324955 & $C_{1}$ \\
\hline 36 & 14 & -177.844845 & $C_{s}$ & 84 & 36 & -497.524938 & $C_{s}$ \\
\hline 37 & 15 & -184.724505 & $C_{s}$ & 85 & 36 & -504.660242 & $C_{1}$ \\
\hline 38 & 13 & -191.184019 & $C_{1}$ & 86 & 36 & -511.844354 & $C_{2 v}$ \\
\hline 39 & 13 & -198.228135 & $C_{2 v}$ & 87 & 38 & -518.785356 & $C_{s}$ \\
\hline 40 & 14 & -204.963823 & $C_{s}$ & 88 & 38 & -525.996499 & $C_{6 h}$ \\
\hline 41 & 14 & -212.073757 & $C_{s}$ & 89 & 38 & -530.791989 & $C_{s}$ \\
\hline 42 & 14 & -219.163369 & $C_{3 v}$ & 90 & 38 & -536.557438 & $C_{2}$ \\
\hline 43 & 15 & -226.239574 & $C_{2 v}$ & 91 & 36 & -542.989912 & $C_{2 v}$ \\
\hline 44 & 13 & -233.385520 & $C_{5 v}$ & 92 & 37 & -549.757224 & $C_{1}$ \\
\hline 45 & 13 & -240.676356 & $I_{h}$ & 93 & 38 & -556.443498 & $C_{2}$ \\
\hline 46 & 15 & -245.364214 & $C_{1}$ & 94 & 39 & -562.752019 & $C_{1}$ \\
\hline 47 & 14 & -251.181462 & $C_{s}$ & 95 & 40 & -568.973141 & $C_{1}$ \\
\hline 48 & 14 & -258.057115 & $C_{3 v}$ & 96 & 41 & -576.517002 & $C_{s}$ \\
\hline 49 & 17 & -264.146588 & $C_{1}$ & 97 & 41 & -583.871531 & $C_{3 v}$ \\
\hline 50 & 18 & -271.250575 & $C_{s}$ & 98 & 42 & -589.019404 & $C_{1}$ \\
\hline 51 & 19 & -277.913411 & $C_{s}$ & 99 & 42 & -597.350577 & $C_{1}$ \\
\hline 52 & 19 & -285.100422 & $C_{s}$ & 100 & 42 & -604.233674 & $C_{s}$ \\
\hline
\end{tabular}

